\title{
Proposta de uma arquitetura de hardware em FPGA implementada para SLAM com multi-câmeras aplicada à robótica móvel
}

\author{
Vanderlei Bonato
}

Orientador: Prof. Dr. Eduardo Marques

Tese apresentada ao Instituto de Ciências Matemáticas e de Computação - ICMC-USP, como parte dos requisitos para obtenção do título de Doutor em Ciências Ciências de Computação e Matemática Computacional.

$$
\text { USP - São Carlos }
$$

Dezembro de 2007 

Para minha querida esposa Ivete Delai e meus queridos pais Gemma Maria Bonato e Tranqüilo Bonato (In Memoriam). 



\section{Agradecimentos}

Primeiramente, eu agradeço ao meu orientador e amigo Prof. Dr. Eduardo Marques pela sua solicitude e dedicação à elaboração deste trabalho.

Eu também gostaria de estender esse agradecimento ao Prof. Dr. George A. Constantinides pela sua intensa dedicação dada à minha orientação durante o período de 12 meses em que permaneci no Departamento de Engenharia Elétrica e Eletrônica do Imperial College London ${ }^{1}$.

Igualmente, eu agradeço a todas as pessoas que estiveram direta ou indiretamente ligadas à elaboração desta tese, e em especial a Carlos R.P. Almeida Jr. pelo seu apoio dado durante o período em que estive no exterior e a toda a equipe do serviço de pós-graduação, em especial a Elizabeth Luisa Moretti e Silva, pela sua prontidão nos atendimentos relativos aos assuntos acadêmicos.

Finalmente, eu agradeço a CAPES - Coordenação de Aperfeiçoamento de Pessoal de Nível Superior - pelo importante apoio financeiro concedido à elaboração da minha tese por meio de bolsas de estudos no país e no exterior.

\footnotetext{
${ }^{1}$ I am very grateful to Dr. George A. Constantinides for his important support and attention given to my research throughout the time I spent at the Department of Electrical end Electronic Engineering - Imperial College London.
} 

Podemos escolher o que semear, mas somos obrigados a colher aquilo que plantamos.

(Provérbio Chinês) 



\section{Resumo}

Este trabalho apresenta uma arquitetura de hardware, baseada em FPGA (Field-Programmable Gate Array) e com multi-câmeras, para o problema de localização e mapeamento simultâneos - SLAM (Simultaneous Localization And Mapping) aplicada a sistemas robóticos embarcados. A arquitetura é composta por módulos de hardware altamente especializados para a localização do robô e para geração do mapa do ambiente de navegação em tempo real com features extraídas de imagens obtidas diretamente de câmeras CMOS a uma velocidade de 30 frames por segundo. O sistema é totalmente embarcado em FPGA e apresenta desempenho superior em, pelo menos, uma ordem de magnitude em relação às implementações em software processadas por computadores pessoais de última geração. Esse desempenho deve-se à exploração do paralelismo em hardware junto com o processamento em pipeline e às otimizações realizadas nos algoritmos. As principais contribuições deste trabalho são as arquiteturas para o filtro de Kalman estendido - EKF (Extended Kalman Filter) e para a detecção de features baseada no algoritmo SIFT (Scale Invariant Feature Transform). A complexidade para a implementação deste trabalho pode ser considerada alta, uma vez que envolve uma grande quantidade de operações aritméticas e trigonométricas em ponto flutuante e ponto fixo, um intenso processamento de imagens para extração de features e verificação de sua estabilidade e o desenvolvimento de um sistema de aquisição de imagens para quatro câmeras CMOS em tempo real. Adicionalmente, foram criadas interfaces de comunicação para o software e o hardware embarcados no FPGA e para o controle e leitura dos sensores do robô móvel. Além dos detalhes e resultados da implementação, neste trabalho são apresentados os conceitos básicos de mapeamento e o estado da arte dos algoritmos SLAM com visão monocular e estéreo.

Palavras-chave: SLAM. FPGA. Arquitetura de Hardware Paralelo. Sistemas Embarcados. Visão Computacional. Robótica Móvel. 



\section{Abstract}

This work presents a hardware architecture for the Simultaneous Localization And Mapping (SLAM) problem applied to embedded robots. This architecture, which is based on FPGA and multi-cameras, is composed by highly specialized blocks for robot localization and feature-based map building in real time from images read directly from CMOS cameras at 30 frames per second. The system is completely embedded on an FPGA and its performance is at least one order of magnitude better than a high end PC-based implementation. This result is achieved by investigating the impact of several hardwareorientated optimizations on performance and by exploiting hardware parallelism along with pipeline processing. The main contributions of this work are the architectures for the Extended Kalman Filter (EKF) and for the feature detection system based on the SIFT (Scale Invariant Feature Transform). The complexity to implement this work can be considered high, as it involves a significant number of arithmetic and trigonometric operations in floating and fixed-point format, an intensive image processing for feature detection and stability checking, and the development of an image acquisition system from four CMOS cameras in real time. In addition, communication interfaces were created to integrate software and hardware embedded on FPGA and to control the mobile robot base and to read its sensors. Finally, besides the implementation details and the results, this work also presents basic concepts about mapping and state-of-the-art algorithms for SLAM with monocular and stereo vision.

Keywords: SLAM. FPGA. Parallel Hardware Architecture. Embedded Systems. Computer Vision. Mobile Robotics. 



\section{Lista de Figuras}

1.1 Relação entre o nível de autonomia e customização versus a estrutura do ambiente. . . . . . . . . . . . . . . . . 27

1.2 Sensores embarcados na base de num robô Pioneer 3DX. . . . . . . . . . . 30

2.1 Tipo de ambiente a ser explorado. . . . . . . . . . . . . . . 37

2.2 Tipos de navegação e de representação de mapas. . . . . . . . . . . . . . . 38

2.3 Landmark artificial. . . . . . . . . . . . . . . . . . . . . . . . . . . . . . 41

2.4 Landmarks naturais. . . . . . . . . . . . . . . . . . . . . . . . . 42

2.5 Alguns modos de representação de mapas. . . . . . . . . . . . . . . . . . 45

2.6 Erro acumulativo de localização de um robô decorrente de pequenos erros de odometria causados pelo escorregamento das rodas. . . . . . . . . . . . 46

2.7 Algoritmos base de mapeamento. . . . . . . . . . . . . . . . . . . 51

2.8 Classificação dos algoritmos estudados. . . . . . . . . . . . . . . . . . . . 61

2.9 Estrutura geral do KF. . . . . . . . . . . . . . . . . . . . . . . . . . . 62

2.10 Demonstração da integração de densidades probabilísticas no EKF. . . . . 64

2.11 Propagação da densidade condicional influenciada pelo controle $u$ e ruído $r$, onde $x$ representa a posição unidimensional do robô e $\sigma$ a sua dispersão. $\quad 66$

3.1 Estrutura geral do SLAM com visão . . . . . . . . . . . . . . . . . . . . 68

3.2 Um exemplo de associação de dado com imagem . . . . . . . . . . . . . . . 70

4.1 Arquitetura geral do sistema SLAM proposto embarcado em hardware reconfigurável. . . . . . . . . . . . . . . . . . . . . . 90 90

4.2 Sistema multi-câmeras implementado em FPGA e embarcado na plataforma do robô Pioneer 3DX. . . . . . . . . . . . . . . . . . . . . . 93

4.3 Arquitetura do sistema multi-câmeras para aquisição de imagens implementado em FPGA. . . . . . . . . . . . . . . . . . . . . . . . . 93 
4.4 Exemplos de imagens obtidas com o sistema de aquisição remoto, onde Camx informa o número da câmera e Tx a sequência temporal com que foram capturadas. . . . . . . . . . . . . . . . . . . . . . . . . . . . . . . 94

4.5 Aumento da precisão do EKF em função do número de sensores, onde (a) representa a leitura do sensor $z_{1}$; (b) a leitura de $z_{1}$ e $z_{2}$ e a estimação do resultado pelo EKF por meio de $\mu$; e (c) e (d) representam os dados semelhante a (b), porém com um número maior de sensores. . . . . . . . . 95

4.6 Um mapa baseado em features simulado num ambiente bidimensional. (a), (c) e (e) são mapas gerados com uma única câmera amostrados em três posições distintas de navegação do robô (R); (b), (d) e (f) representam a mesma informação, porém nesse caso com o uso de quatro câmeras. As elipses representam as incertezas da posição do robô e das features; " $\mathrm{x}$ " a posição real das features e as linhas traçadas e contínuas circulares representam a trajetória estimada e real do robô, respectivamente. . . . . . . . . 97

4.7 Modelo pinhole da câmera, onde $O_{c}$ é o centro ótico, $u_{i}$ e $v_{i}$ são as coordenadas de um feature no plano de imagem e $x_{i}, y_{i}$, e $z_{i}$ são as coordenadas de sua real localização no ambiente de aquisição da imagem. . . . . . . . . . 99

4.8 Da projeção no plano de imagem para a projeção na imagem digitalizada (pixel) . . . . . . . . . . . . . . . . . . . 100

4.9 Exemplos do conjunto de imagens usado na geração dos parâmetros da lente da câmera. . . . . . . . . . . . . . . . . . . . . . . . . 102

4.10 Exemplo de uma imagem distorcida (a) e a correspondente corrigida (b), onde o cruzamento da duas linhas retas pretas corresponde ao ponto central da lente $O_{c}$ e as outras linhas pretas curvadas representam os pixels que foram perdidos devido ao processo de arredondamento da correção. . . . 102

4.11 Elementos da triangulação para uma câmera em duas posições (p1,p2) em paralelo apontando para a mesma feature. . . . . . . . . . . . . . . 104

5.1 Representação de um robô num mapa bidimensional, onde as elipses representam as incertezas da co-variância e seus centros, as localizações estimadas do robô e das features, e $z$ a observação de uma feature através do sensor do robô. . . . . . . . . . . . . . . . . . . . . . . . . . . . . . 110

5.2 Arquitetura do EKF, onde MPEx são as memórias internas para reutilização de dados dos PEs, e b é o tamanho dessas memórias; e os demais símbolos são apresentados na Tabela 5.1. . . . . . . . . . . . . . . . . . . 114

5.3 Largura de banda de acesso à memória externa. . . . . . . . . . . . . . 117

5.4 Largura de banda da memória externa como uma função do tamanho do vetor de estado da feature usando quatro PEs $(j=8), 1,5 k$ features e $14 \mathrm{~Hz}$ de frequência de atualização. . . . . . . . . . . . . . . . 118 
5.5 Frequência de operação do pipeline PE requerida para o EKF em função do número de PEs. . . . . . . . . . . . . . . . . . . . . . . . . . . . . . 119

5.6 Número máximo de features e consumo de energia para os três dispositivos de processamento. . . . . . . . . . . . . . . . . . . . 122

6.1 Diagrama de blocos representando as principais operações usadas para detectar candidatos a features em uma octave usando um conjunto de seis imagens suavizadas pelo filtro Gaussiano. . . . . . . . . . . . . . . . . . . 127

6.2 Diagrama de blocos do sistema implementado composto por três blocos de hardware usados para extrair features das imagens e para pré-computar dados para os descritores, e um bloco de software para associar os descritores às features. . . . . . . . . . . . . . . . . . . . . . . . . . . 131

6.3 Análise da associação incorreta de features em relação à configuração do sistema, sendo 0 para a configuração desativada e 1 para ativada. . . . . . . 132

6.4 Uma arquitetura pipeline para uma versão otimizada do filtro Gaussiano. . 134

6.5 Faixa de valores para quinze imagens $D_{i} \ldots \ldots \ldots \ldots$. . . . . . . 136

6.6 Proporção de associação de features positiva falsa e de correta em função do sinal do pixel $D_{i} \ldots \ldots \ldots \ldots$. . . . . . . . . . . . . . . . . . . . . . . . .

6.7 Uma arquitetura pipeline que implementa a cascata de filtro Gaussiano e a função da diferença Gaussiana. . . . . . . . . . . . . . . . . . . . . . . 138

6.8 Arquitetura para computação da orientação e da magnitude do gradiente baseada no algoritmo CORDIC. . . . . . . . . . . . . . . . . . . . . . . 140

6.9 Arquitetura para detecção de keypoints com verificação de estabilidade. . . 143

6.10 Uma arquitetura baseada no NIOS II para associar descritores às features usando a informação da orientação e da magnitude do gradiente recebidos do bloco OriMag. . . . . . . . . . . . . . . . . . . . . . . . . . . . . . . . . 144

6.11 Organização das palavras nas FIFOs. . . . . . . . . . . . . . . . . . . 144

6.12 Exemplos de imagens reais obtidas diretamente do bloco de hardware DoG. 147

6.13 As linhas brancas correspondem às associações de pares de imagens lidas diretamente de uma câmera CMOS e processadas pelo sistema proposto. Os pares (a) e (b) demonstram associações de pares transformados entre si por escala e rotação, respectivamente; e o par (c) apresenta um exemplo de associação incorreta, a qual é representada pela linha mais inclinada. . . 148

6.14 Fluxo de desenvolvimento do projeto em FPGA. . . . . . . . . . . . . . . . 151 



\section{Lista de Tabelas}

2.1 Principais características dos algoritmos de mapeamento. . . . . . . . . . 62

3.1 Principais características dos trabalhos relacionados ao SLAM com visão monocular explorados neste capítulo. . . . . . . . . . . . . . . . . 81

3.2 Principais características dos trabalhos relacionados ao SLAM com visão estéreo explorados neste capítulo. . . . . . . . . . . . . . . . . . 82

5.1 A descrição e a dimensão dos símbolos do EKF. . . . . . . . . . . . . . . . 109

5.2 Número de operações de ponto flutuante (FLOP) para cada equação do EKF. . . . . . . . . . . . . . . . . . . . . 112

5.3 Operações do PE. . . . . . . . . . . . . . . . . . . . . 115

5.4 Recursos do FPGA para a implementação de um PE. . . . . . . . . . . . . 119

5.5 Recursos do FPGA para toda a arquitetura do EKF. . . . . . . . . . . . 120

5.6 Comparação entre o desempenho e a energia consumida entre o FPGA e os processadores Pentium M 1,6GHz e ARM920T 200MHz. . . . . . . . . . 122

6.1 Códigos da FIFO D para comunicar o hardware e o software. . . . . . . . . 145

6.2 Frequência operacional e resultados produzidos por ciclo de clock para cada bloco de hardware. . . . . . . . . . . . . . . . . . . . . . . . . . . . . . . . 149

6.3 Recursos de FPGA (Altera Stratix II EP2S60F672C3) necessários para cada bloco de hardware e para o sistema completo. . . . . . . . . . . . . . 151 



\section{Lista de Abreviaturas e Siglas}

$\begin{array}{ll}\text { ALUT } & \text { Adaptive Look-Up Table } \\ \text { ASIC } & \text { Aplication Specific Integrated Circuit } \\ \text { CML } & \text { Concurrent Mapping and Localization } \\ \text { CMOS } & \text { Complementary Metal Oxide Semiconductor } \\ \text { CORDIC } & \text { COordinate Rotation DIgital Computer } \\ \text { DBN } & \text { Dynamic Bayesian Network } \\ \text { DMA } & \text { Direct Memory Access } \\ \text { DMIPS } & \text { Dhrystone Million Instructions Per Second } \\ \text { DSP } & \text { Digital Signal Processing } \\ \text { EDA } & \text { Electronic Design Automation } \\ \text { EIF } & \text { Extended Information Form } \\ \text { EKF } & \text { Extended Kalman Filter } \\ \text { EM } & \text { Expectation Maximization } \\ \text { FOV } & \text { Field Of View } \\ \text { FPGA } & \text { Field-Programmable Gate Array } \\ \text { HSCI } & \text { High Speed Camera Interface } \\ \text { I C } & \text { Inter-Integrated Circuit } \\ \text { ICP } & \text { Iterative Closest Point } \\ \text { IFR } & \text { International Federation of Robotics } \\ \text { IP } & \text { Intellectual Property } \\ \text { KF } & \text { Kalman Filter } \\ \text { KPCA } & \text { Kernel Principal Component Analysis } \\ \text { PF } & \text { Particle Filter } \\ \text { PR } & \text { Personal Robot } \\ \text { RBPF } & \text { Rao-Blackwellised Particle Filter } \\ \text { RISC } & \text { Reduced Instruction Set Computer } \\ \text { SEIF } & \text { Sparse Extended Information Form } \\ \text { SIFT } & \text { Scale-Invariant Feature Transform } \\ \text { SLAM } & \text { Simultaneous Localization And Mapping } \\ \text { SoC } & \text { System-on-a-Chip } \\ \text { SoPC } & \text { System-on-a-Programmable-Chip } \\ \text { ULA } & \text { Arithmetic Logic Unit } \\ \text { UNECE } & \text { United Nations Economic Commission for Europe } \\ & \end{array}$





\section{Sumário}

1 Introdução $\quad 25$

1.1 Algoritmos para Robôs Móveis . . . . . . . . . . . . . . . . 26

1.1 .1 Localização . . . . . . . . . . . . . . . . . . . . 27

1.1.2 Mapeamento . . . . . . . . . . . . . . . . 27

1.1 .3 Navegação . . . . . . . . . . . . . . . . . . . . . . . . . . . . . . . . . . . . . . . . . . .

1.2 Algoritmo SLAM . . . . . . . . . . . . . . . . . . . . . . 28

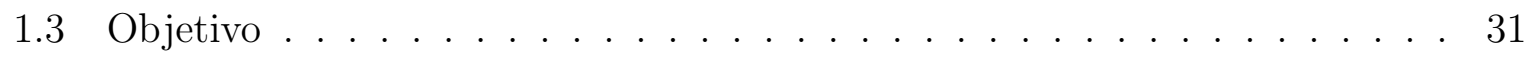

1.3.1 Objetivo Geral . . . . . . . . . . . . . . . . 31

1.3.2 Objetivos Específicos . . . . . . . . . . . . . . . 32

1.4 Justificativa . . . . . . . . . . . . . . . . . . . . . . . . 32

1.5 Organização do Documento . . . . . . . . . . . . . . . 33

2 Fundamentação Teórica $\quad 35$

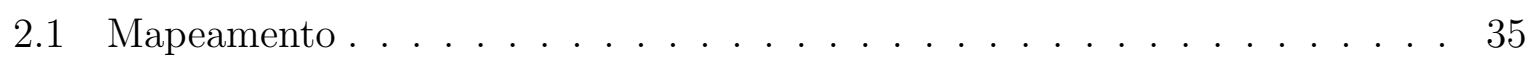

2.1.1 Landmarks para o Mapeamento . . . . . . . . . . . . . . . . . 39

2.1.2 Tipos de Mapeamento . . . . . . . . . . . . . . . . . . . . . 43

2.1.3 Considerações no Mapeamento . . . . . . . . . . . . . . . . . . . . . 44

2.1.4 Considerações na Localização . . . . . . . . . . . . . . . . . . . 48

2.2 Algoritmos de Mapeamento . . . . . . . . . . . . . . . . . . . . . . 49

2.2.1 Filtro de Kalman . . . . . . . . . . . . . . . . . . . . . . . 52

$2.2 .2 \quad$ Filtro de Partículas . . . . . . . . . . . . . . . . . 53

2.2 .3 FastSLAM . . . . . . . . . . . . . . . . 54

$2.2 .4 \mathrm{Lu} / \mathrm{Milios} \ldots \ldots \ldots \ldots \ldots \ldots . \ldots \ldots 5$

2.2.5 Expectation Maximization . . . . . . . . . . . . . . 56

2.2.6 Occupancy Grid . . . . . . . . . . . . . . . . . . . . . 57

2.2.7 Extended Information Form SLAM Algorithm . . . . . . . . . . . . 58

2.2 .8 Formato Geométrico . . . . . . . . . . . . . . . . . 59 
2.2.9 Análise dos Algoritmos de Mapeamento e Localização . . . . . . . . 60

2.3 Algoritmo do Filtro de Kalman . . . . . . . . . . . . . . . . . . . . . . . . 61

2.4 Considerações Finais . . . . . . . . . . . . . . . . . . 66

3 Estado da Arte do SLAM com Visão $\quad 67$

3.1 Estrutura Geral dos Algoritmos SLAM com Visão . . . . . . . . . . . . . . 67

3.1.1 Processamento de Imagem com Visão Monocular e Estéreo .... . 68

3.1 .2 Associação de Dados . . . . . . . . . . . . . . . . . 70

3.1.3 Gerenciamento de Mapa . . . . . . . . . . . . . . . . . . 71

3.2 SLAM com Visão Monocular e Estéreo . . . . . . . . . . . . . . . . . . . 71

3.2.1 Visão Monocular . . . . . . . . . . . . . . . . . . . . . . . . 72

3.2 .2 Visão Estéreo . . . . . . . . . . . . . . . . . . . . 76

3.2.3 Análise dos Trabalhos . . . . . . . . . . . . . . . . . 80

3.3 Implementações dos Algoritmos EKF e SIFT em FPGA . . . . . . . . . . . 83

$3.3 .1 \quad$ Algoritmo EKF . . . . . . . . . . . . . . . . . . 83

3.3.2 Algoritmo SIFT . . . . . . . . . . . . . . . . . . . . 84

3.4 Considerações Finais . . . . . . . . . . . . . . . . . . 86

4 A Arquitetura de Hardware Desenvolvida em FPGA para o SLAM 89

4.1 Integração do FPGA com o Controlador do Robô Móvel . . . . . . . . . . 91

4.2 Sistema de Aquisição de Imagens . . . . . . . . . . . . . . . . . . . . . . . 92

4.2.1 Vantagens do Uso de Multi-câmeras para o SLAM . . . . . . . . . . 94

4.3 Modelos para o EKF . . . . . . . . . . . . . . . 96

4.3.1 Modelo do Controle de Movimento do Robô . . . . . . . . . . . . . 98

4.3.2 Modelo da Câmera . . . . . . . . . . . . . . . . . . . . . . . . . . . 98

4.4 Considerações Finais . . . . . . . . . . . . . . . . . . . . . 105

5 A Arquitetura Desenvolvida para o Filtro de Kalman Estendido 107

5.1 Algoritmo do Filtro de Kalman Estendido . . . . . . . . . . . . . . . . . 107

5.1.1 Análise da Complexidade Computacional . . . . . . . . . . . . . . . 112

5.2 Arquitetura do Hardware . . . . . . . . . . . . . . . . . . . . . . . . . . . 113

5.2.1 Elementos de Processamento . . . . . . . . . . . . . . . . . . . . . . 115

5.2 .2 Configuração Alternativa do Sistema . . . . . . . . . . . . . . . 117

5.3 Resultados . . . . . . . . . . . . . . . . . . . . . 118

5.3.1 Análise do Desempenho e do Consumo de Energia . . . . . . . . . . 120

5.4 Considerações Finais . . . . . . . . . . . . . . . . . . . 123

6 A Arquitetura de Hardware Paralelo Criada para Detecção de Features Invariante à Escala e Rotação $\quad \mathbf{1 2 5}$

6.1 Algoritmo para Deteç̧ão de Features Invariante à Escala e à Rotação . . . 126 
6.1.1 Selecionando Features Candidatas . . . . . . . . . . . . . . . . . 126

6.1.2 Testando a Estabilidade da Feature . . . . . . . . . . . . . . . . . . 128

6.1 .3 Associando Descritor à Feature . . . . . . . . . . . . . . . . . . . . 129

6.2 Arquitetura Paralela Desenvolvida . . . . . . . . . . . . . . . . . 130

6.2.1 Configuração do Sistema . . . . . . . . . . . . . . . . . . . . . 131

6.2.2 Cascata de Filtros Gaussianos e a Diferença da Gaussiana .... 133

6.2.3 Computação da Orientação e da Magnitude do Gradiente . . . . . . 135

6.2.4 Detecção de Keypoints com Verificação da Estabilidade . . . . . . . . 141

6.2.5 Obtenção de Descritores para as Features . . . . . . . . . . . . . . . 142

6.3 Resultados . . . . . . . . . . . . . . . . . . . . . 145

6.3.1 Confiabilidade . . . . . . . . . . . . . . . . . . . 145

6.3.2 Plataforma de Desenvolvimento . . . . . . . . . . . . . . . . 150

6.4 Considerações Finais ． . . . . . . . . . . . . . . . . . . . . . . 152

7 Conclusão $\quad 153$

7.1 Aspectos Gerais . . . . . . . . . . . . . . . . . . 153

7.2 Contribuições . . . . . . . . . . . . . . . . . . . . . 154

7.3 Trabalhos Futuros . . . . . . . . . . . . . . . . 156

$\begin{array}{ll}\text { Referências Bibliográficas } & 158\end{array}$ 



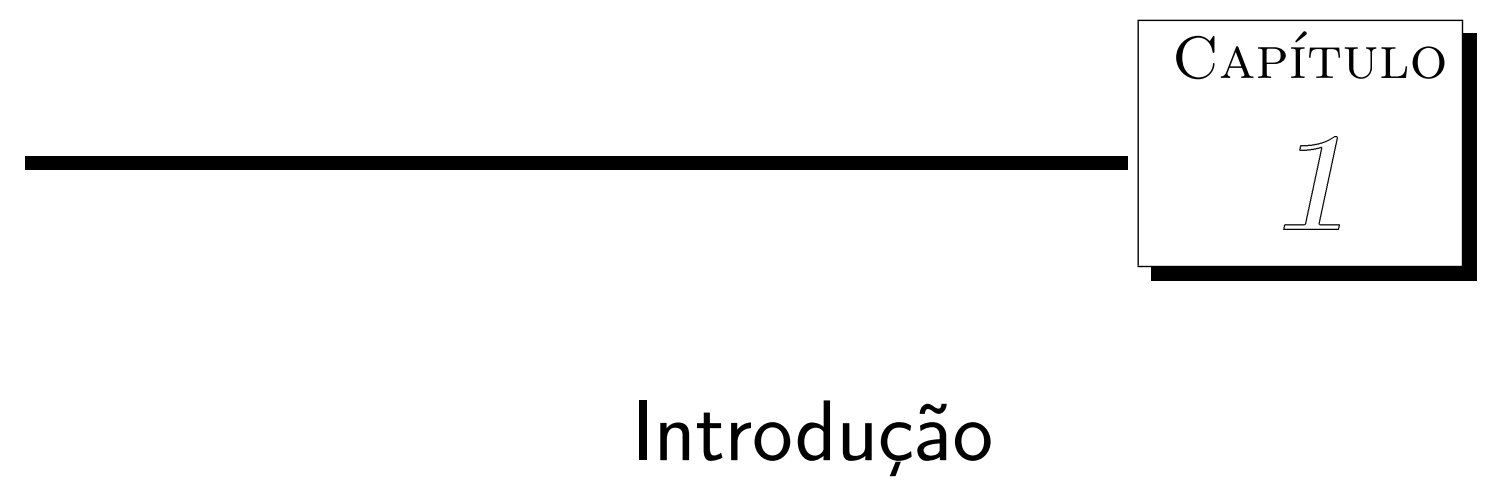

Há muitos anos o homem deseja criar máquinas inteligentes para servi-lo. Em 1920, o dramaturgo Karel Capec reproduziu esse desejo em uma peça teatral em que apresentava um autômato com forma humana capaz de fazer tudo no lugar do homem. Foi dessa peça que surgiu a palavra robô, originada do termo "robota" que significa trabalho forçado em tcheco e que hoje é usada para nomear certas máquinas que realizam funções automáticas. Apesar da grande vontade do homem de criar robôs para fins variados, a finalidade principal dos mesmos sempre foi a execução de serviços no meio industrial. Porém, hoje isso está mudando e uma nova geração de robôs de serviço para uso pessoal ou doméstico está surgindo, denominados de Personal Robot (PR) neste texto. Esse tipo de robô é produzido para um mercado de massa, usado principalmente no meio doméstico (household) e seu valor de venda é somente uma fração dos robôs usados no meio industrial.

Atualmente, já existe no mercado uma grande quantidade de robôs para aspirar pó, cortar grama e entreter. Além desses, outros modelos para vigilância, assistência a pessoas idosas e crianças já estão sendo introduzidos. Por exemplo, o robô aspirador de pó foi lançando no mercado no final do ano 2001 e já nos dois anos seguintes ao seu lançamento foram comercializadas aproximadamente 570.000 unidades (UNECE, 2004). 
Essa expansão ocorre mesmo com a existência de robôs com poucas funcionalidades autônomas ou inteligentes, como é o caso do robô aspirador de pó que usa navegação aleatória. Muito embora hoje já existam técnicas sofisticadas para implementar, por exemplo, um sistema de navegação mais eficiente, poucos PRs disponíveis para a comercialização no mercado usufruem dessas contribuições devido ao elevado custo para a implementação dessas técnicas. Assim, é necessária a investigação de soluções alternativas às já existentes a fim de viabilizar a sua implementação em robôs domésticos. A preocupação com a redução do custo existe, principalmente, porque a maior parte do mercado consumidor dessa nova geração de robôs, ao contrário do mercado de robôs industriais, é formado por pessoas físicas.

Nesse contexto, um dos grandes desafios atuais da robótica é conseguir preencher essa lacuna entre a tecnologia gerada pelos laboratórios de pesquisa e a tecnologia utilizada no desenvolvimento de robôs comerciais para fins domésticos ou pessoais. Em Pirjanian (2004) são citados os maiores desafios da nova geração de PRs que devem ser superados para que os robôs se tornem produtos viáveis comercialmente. Um dos desafios citados é o desenvolvimento de algoritmos eficientes com baixo custo de implementação para robôs móveis, a fim de "ensinar o robô a caminhar" (locomoção autônoma). Essa não é uma tarefa trivial, pois diferentemente dos robôs industriais, que são imóveis e possuem poucos recursos para interagir com o mundo em seu entorno, os PRs geralmente são móveis e interagem fortemente com o meio externo. Isso ocasiona a necessidade de maior autonomia e customização. A Figura 1.1 apresenta a relação entre o nível de autonomia e customização versus a estrutura do ambiente para alguns exemplos de robôs móveis.

\subsection{Algoritmos para Robôs Móveis}

A locomoção autônoma de um robô está relacionada aos algoritmos de localização, mapeamento e navegação. Esses algoritmos são utilizados como base para a construção de robôs capazes de executarem tarefas complexas, sendo a maioria deles baseados em teoria probabilística (Thrun, 2002). A probabilidade é usada para tornar os algoritmos mais robustos em relação às incertezas ou ruídos gerados pelos sensores e também para 


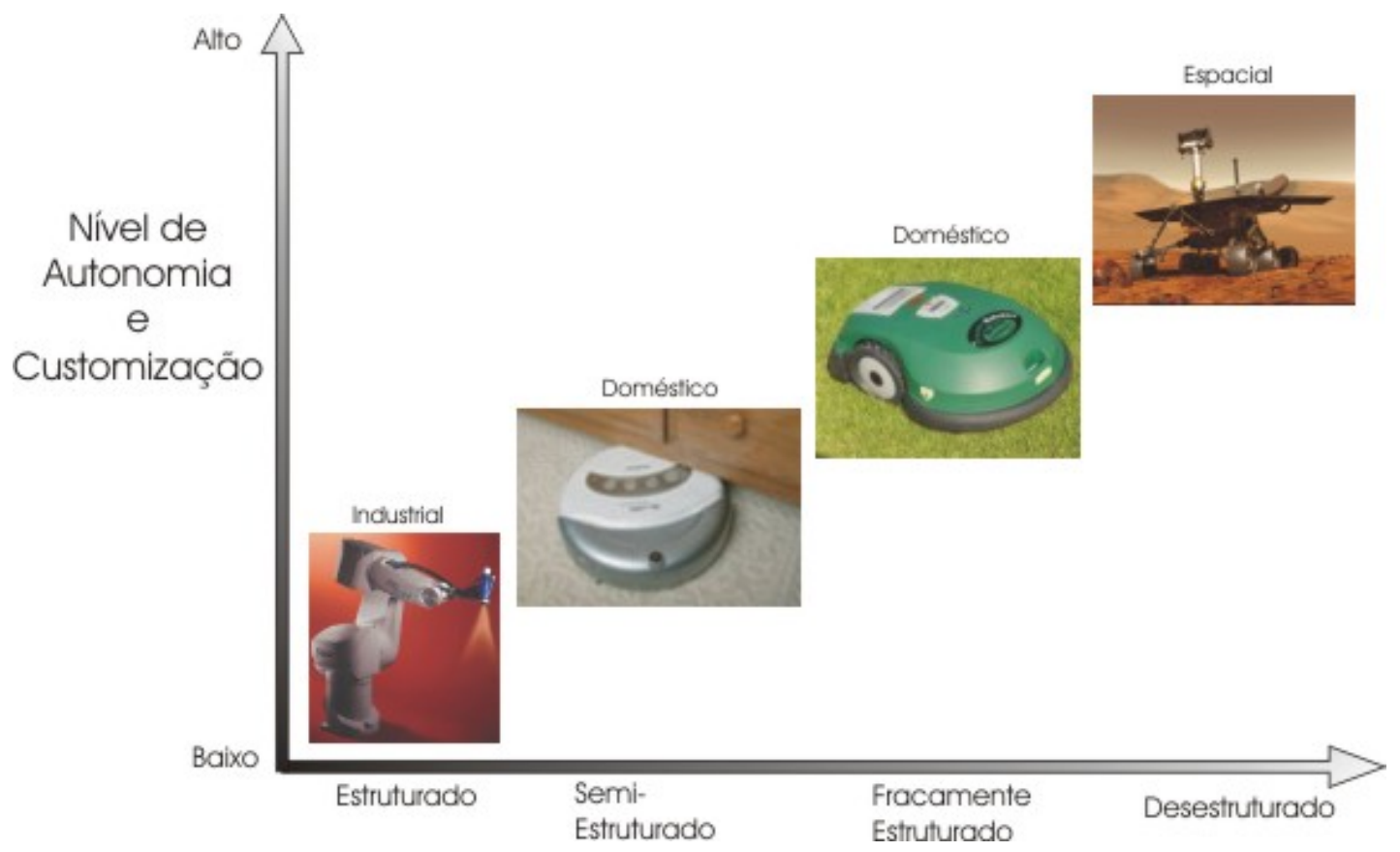

Figura 1.1: Relação entre o nível de autonomia e customização versus a estrutura do ambiente.

lidar com as incertezas presentes no ambiente.

\subsubsection{Localização}

A localização consiste em estimar a posição de um robô em seu ambiente, sendo essa uma capacidade necessária à execução de qualquer tarefa de maneira autônoma. No modo mais simples de localização, o mapa do ambiente já é conhecido a priori, sendo a localização estimada com base nas informações fornecidas pelos sensores. Os métodos frequentemente utilizados para essa função são os de Markov (Fox et. al., 1999) e de Monte-Carlo (Dellaert et. al., 1999).

\subsubsection{Mapeamento}

Os métodos de localização de Markov e Monte-Carlo partem do princípio que existe, a priori, um mapa do ambiente disponível. No entanto, isso nem sempre ocorre. Assim, a construção automática do mapa do ambiente também é considerada uma outra função fundamental para o desenvolvimento de robôs móveis autônomos. Os mapas são classificados em dois tipos: métricos e topológicos, sendo o primeiro tipo o prevalecente. Duas formas muito conhecidas de representação do ambiente com mapas métricos são: 
occupancy-grid (Moravec e Elfes, 1985) e landmarks (Borenstein et. al., 1996).

Um dos tópicos que tem recebido atenção da comunidade científica é a execução das tarefas de localização e mapeamento, simultaneamente. Tal técnica, é conhecida como SLAM (Simultaneous Localization and Mapping) ou CML (Concurrent Mapping and Localization) introduzido por Smith et. al. (1990). Muitos algoritmos de localização partem do princípio de que existe um mapa do ambiente onde o robô deve estimar sua posição e, muitos algoritmos de mapeamento assumem que o mesmo sabe com precisão sua posição no mapa. A tarefa do algoritmo SLAM consiste exatamente em criar o mapa do ambiente e estimar a posição do robô nesse mapa simultaneamente, sem informação a priori. Thrun (2002) enfatiza em seu trabalho que para a construção de robôs móveis verdadeiramente autônomos é necessário que o mapeamento e a localização sejam estimados automaticamente e simultaneamente. O trabalho proposto neste documento aborda exatamente esse tipo de algoritmo, o SLAM.

\subsubsection{Navegação}

A navegação se resume em planejamento e execução de caminhos para a locomoção do robô no ambiente. A partir da posição do robô no ambiente e do mapa do mesmo, os algoritmos de navegação são responsáveis por fazerem com que o robô planeje uma rota e atinja locais determinados para que outras tarefas sejam executadas naqueles locais. Dentre os algoritmos de navegação destacam-se os de campos potenciais (Koren e Borenstein, 1991) e o VFH (histograma de campos vetoriais) (Borenstein e Koren, 1991). Como pode ser notado, para uma navegação autônoma o robô precisa conhecer o mapa do ambiente e sua localização dentro dele.

\subsection{Algoritmo SLAM}

O SLAM é conhecido como um dos problemas mais difíceis da área da robótica e vem sendo estudado por, aproximadamente, duas décadas. Nesse período, diversos métodos foram propostos para diferentes tipos de ambientes, tendo como resultado métodos robus- 
tos para ambientes que são estáticos, estruturados e de tamanho limitado. No entanto, quando o ambiente é dinâmico, desestruturado e de larga escala, ainda há muitos problemas que não foram solucionados. Desse modo, atualmente, há diversas pesquisas que buscam resolver esses problemas, procurando tornar os robôs cada vez mais próximos do mundo real. Por exemplo, em Paz e Neira (2006) e em Guivant et. al. (2004) é abordado o problema de mapeamento em ambiente amplo e desestruturado. Já o trabalho de Thrun et. al. (2004b) apresenta um algoritmo de localização e mapeamento simultâneos (SLAM) com atualização do mapa em tempo constante, independente de seu tamanho ${ }^{1}$. Wang e Thorpe (2002), Wang et. al. (2003) e Wolf et. al. (2005) por sua vez focam o problema de mapeamento em ambiente dinâmico.

Apesar do avanço significativo dos algoritmos SLAM nos últimos anos, nem todos os segmentos de mercado da robótica conseguem aplicar esses algoritmos, uma vez que eles, geralmente, exigem o uso de sensores e plataformas de processamento sofisticadas e de valores elevados. Um tipo de sensor tipicamente usado é o laser range finder que custa aproximadamente US $\$ 5.000,00$, o que torna o seu uso proibitivo na construção de PRs, que em média tem o preço de venda em algumas centenas de dólares. Uma alternativa menos custosa adotada por muitos projetistas, ao invés desse laser, é a inclusão de anéis de sensores do tipo sonar (sonar rings) que custa em média US\$52,00 a unidade, sendo recomendado o uso de pelo menos 16. Apesar do valor desse tipo de sensor ser inferior ao laser, eles é mais sensível ao ruído, e sendo assim, considerado uma fonte de informação "pobre" 2. A Figura 1.2 apresenta a base de um robô móvel Pioneer 3DX equipada com os sensores laser range finder, sonar ring e câmera.

As implementações tradicionais do SLAM, em sua maioria, são processadas em plataformas de uso geral (Personal Computer - PC), o que dificilmente é permitido nas implementações do mundo real, onde a customização é fundamental para tornar os robôs competitivos comercialmente em seu segmento de mercado. Dentro deste contexto, ou-

\footnotetext{
${ }^{1}$ Para manter constante o tempo de atualização do mapa, a matriz tradicional de co-variância é substituída por uma matriz esparsa. Além disso, para atualizar o mapa, somente as informações de features localizadas na vizinhança próxima ao ponto de atualização são processadas, pois é mostrado que, quanto maior a distância do ponto de atualização, menor é a correlação.

${ }^{2}$ Os preços usados como base foram fornecidos pela empresa ActivMedia, sendo esses designados para instituições educacionais (ActivMedia Robotics, 2005).
} 


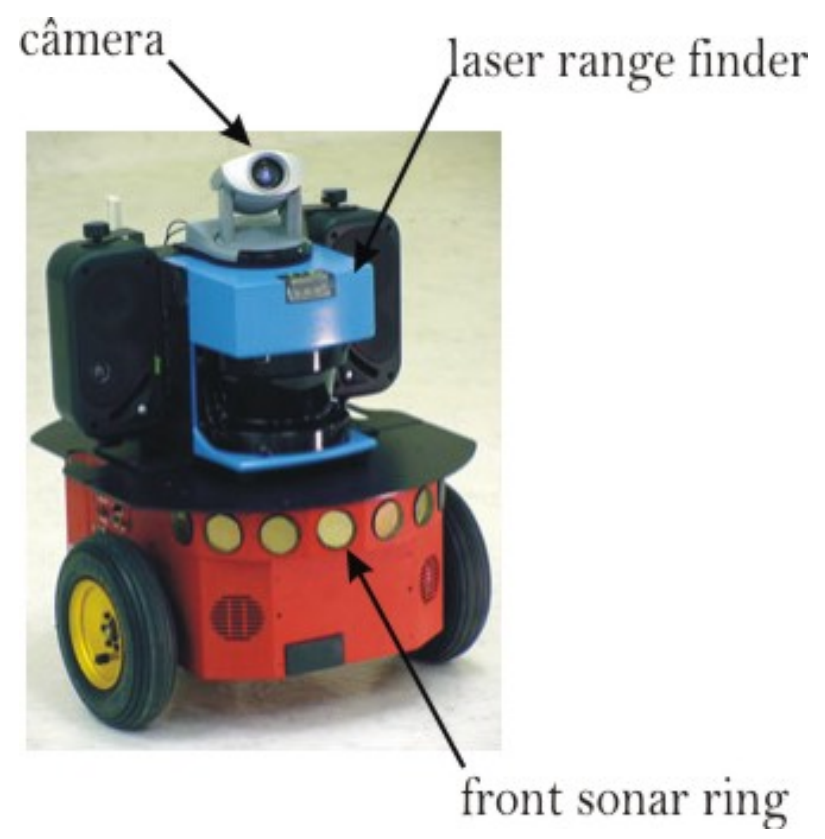

Figura 1.2: Sensores embarcados na base de num robô Pioneer 3DX.

tras soluções para a criação de algoritmos SLAM baseados em sensores de menor custo e processados numa plataforma de hardware customizado são desejadas. Uma solução menos custosa é o algoritmo SLAM baseado em visão, pois câmeras CMOS (Complementary Metal Oxide Semiconductor) de baixo custo (US\$56,95 cada unidade) ${ }^{3}$ podem ser utilizadas como sensores. O uso de câmera como sensor de entrada para o SLAM não é uma novidade. Porém, nos últimos dois ou três anos tem recebido maior atenção dos pesquisadores e das empresas devido a vários fatores:

1. Baixo custo dos sensores de imagem;

2. Alto poder de processamento das plataformas de hardware embarcado;

3. Surgimento eminente da nova geração de PRs;

4. Consideração da imagem como uma fonte "rica" de informação;

5. Multifuncionalidade da câmera que, além de fornecer dados para o SLAM, pode servir de fonte de informação para outras funções do robô, como por exemplo, na Interface Homem-Máquina (IHM) para identificar pessoas.

\footnotetext{
${ }^{3}$ Electronics123 Inc. (2005)
} 
Segundo Nistér et. al. (2004), com o avanço da tecnologia de processamento e de sensores e com o amadurecimento dos algoritmos de visão computacional, espera-se cada vez mais implementações de sistemas de navegação baseados em visão. Um exemplo dessa expansão pode ser notado num projeto de pesquisa da NASA (National Aeronautics and Space Administration), o qual tem como objetivo criar métodos computacionais eficientes para o SLAM baseado em imagens de uma ou mais câmeras embarcadas num robô móvel (Cheeseman et. al., 2005).

Apesar de existirem esses fatores positivos, interpretar as informações contidas nas imagens para o algoritmo SLAM é muito difícil, principalmente, devido ao grande volume de informações geradas e ao ruído causado pela variação de luminosidade do ambiente e da posição da câmera (escala, rotação, translação e oclusão). Esses são problemas complexos a serem resolvidos, os quais podem ser constatados através dos principais trabalhos publicados na área descritos no Capítulo 3. Outro aspecto notado nesses trabalhos é a falta de preocupação com a plataforma de processamento do algoritmo SLAM, onde a maioria o executa em PCs (desktops) e nem se quer menciona a possibilidade de plataforma embarcada.

\subsection{Objetivo}

\subsubsection{Objetivo Geral}

O objetivo deste trabalho de pesquisa é propor uma arquitetura de hardware otimizada e embarcada em FPGA (Field-Programmable Gate Array) para o processamento do SLAM com visão computacional e aplicada a robôs móveis na geração de mapas de ambiente de navegação baseado em features/landmarks. Essa arquitetura deverá implementar algoritmos que sejam considerados eficientes pela comunidade científica e que possam ser reutilizados como base para a exploração de novas técnicas na área do SLAM. 


\subsubsection{Objetivos Específicos}

1. Identificar através da revisão bibliográfica os algoritmos mais eficientes para o problema SLAM;

2. Identificar as arquiteturas propostas para os algoritmos identificados na revisão bibliográfica;

3. Integrar a plataforma de desenvolvimento em FPGA com o sistema de controle do robô;

4. Propor uma arquitetura de hardware otimizada para os algoritmos previamente escolhidos;

5. Validar todos os blocos do sistema proposto em dispositivos de FPGA.

\subsection{Justificativa}

Os robôs móveis e autônomos devem conhecer de algum modo o ambiente onde estão inseridos para que possam planejar sua navegação e localizar-se no ambiente. Essa representação do ambiente, que é armazenada no sistema de controle do robô, pode ser gerada manualmente pelo homem ou automaticamente pelo próprio robô. Atualmente, existem diversos algoritmos que geram o mapa automaticamente, alguns considerados offline por gerarem o mapa somente após a exploração completa do ambiente e outros, online por gerarem o mapa no mesmo instante em que o ambiente está sendo explorado. O processo de determinar a posição do robô relativa a seu ambiente e de construir um mapa do mesmo, simultaneamente, tem sido o tópico central da pesquisa na robótica móvel (Se et. al., 2002), com o seguinte paradigma: localização precisa é pré-requisito para construir um mapa consistente e ter um mapa consistente é essencial para obter a localização precisa. Portanto, localizar e mapear, simultaneamente (SLAM), é um fator crítico para o sucesso da navegação de robôs móveis e autônomos.

A maioria das implementações para o SLAM são propostas puramente em software para o processamento em computadores pessoais. A vantagem dessa opção é a facilidade 
e a velocidade do desenvolvimento, o que é extremamente importante principalmente na fase de criação de novas soluções. No entanto, a solução via software nem sempre alcança o desempenho desejado. Outro problema é referente à sua aplicação em soluções embarcadas onde muitas vezes há restrição de tamanho, consumo de energia e de custo. A arquitetura de hardware proposta otimizada para o problema SLAM, a qual procura estender as soluções já presentes em software para o hardware, busca justamente resolver esses problemas relacionados a aplicação em sistemas robóticos embarcados.

A visão computacional como principal fonte de informação para o sistema SLAM é uma opção que está ganhando cada vez mais atenção da comunidade de pesquisadores na área. Apesar do sensor mais comum para esse tipo de problema ser o laser range finder devido a sua alta precisão e confiabilidade, o mapeamento com imagem possibilita o uso de câmeras que, em comparação com o laser range finder, são mais compactas, consomem menos energia e podem ser encontradas a preços com duas ordens de magnitude mais baixos. Por outro lado, o processamento de imagem consome muito mais recursos computacionais do sistema, uma vez que a câmera gera um volume de informação superior, em pelo menos 100 vezes, ao do laser range finder e o seu processamento consome muito mais recursos computacionais do sistema como um todo. Adicionalmente, o uso de câmeras na robótica vem crescendo cada vez mais com as transmissões de vídeo em tempo real por vários tipos de robôs, usados tanto em aplicações na área de segurança como na de entretenimento.

\subsection{Organização do Documento}

Este trabalho, além dessa introdução, está dividido em seis capítulos. O Capítulo 2 aborda os conceitos básicos existentes na área de mapeamento da robótica móvel, juntamente com seus algoritmos clássicos. Ao final, o leitor terá as informações necessárias para avançar sua leitura para o capítulo seguinte, em que são descritos vários algoritmos de mapeamento com visão monocular e binocular e ainda são apresentadas algumas implementações em hardware dos algoritmos adotados para a implementação nesse projeto. Com essa descrição é possível identificar o estado da arte de trabalhos relacionados à proposta desta pesquisa. 
A arquitetura de hardware desenvolvida neste trabalho é introduzida no Capítulo 4, sendo descritos a integração da plataforma de FPGA com o sistema de controle do robô, o sistema multi-câmeras para aquisição de imagens e os modelos matemáticos das câmeras e do controlador de movimento do robô. Em seguida, os Capítulos 5 e 6 descrevem detalhadamente os dois blocos principais da arquitetura de hardware desenvolvida.

O último capítulo evidencia os principais resultados alcançados, apresenta as conclusões deste trabalho e por fim, sugere algumas aplicações e possibilidades de continuidade da pesquisa desenvolvida. 


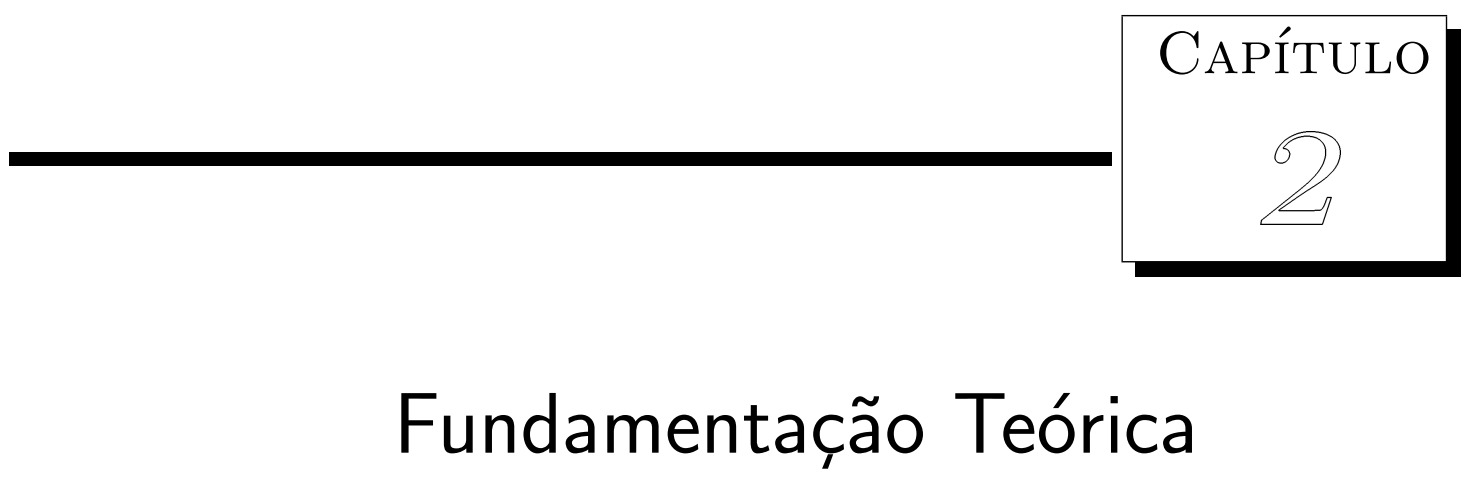

Este capítulo apresenta uma base teórica para o entendimento dos conceitos existentes na área de mapeamento da robótica móvel e da origem da maioria de seus algoritmos. Os algoritmos de navegação não são abordados, uma vez que não fazem parte do enfoque deste trabalho. Já os algoritmos de localização são vistos somente como parte integrante dos de mapeamento. Os principais tópicos abordados são: o que são e para que servem os landmarks e os mapas, e quais são os principais algoritmos base do mapeamento. Para cada algoritmo abordado é apresentada uma descrição da sua lógica de funcionamento e as suas principais vantagens e desvantagens. Por fim, um sumário do capítulo é apresentado nas considerações finais.

\subsection{Mapeamento}

Os algoritmos de mapeamento têm a função de gerar automaticamente uma representação do ambiente no sistema de controle do robô usada na navegação autônoma de robôs móveis não guiados por usuários. Segundo DeSouza e Kak (2002), a navegação autônoma pode ser classificada em três grupos: a baseada em mapas criados pelo usuário; 
a baseada em mapas criados pelo próprio robô; e as que não possuem mapa. A navegação com mapa proporciona maior poder de decisão durante a navegação, permitindo, por exemplo, localizar o robô no ambiente e planejar a sua rota de acordo com o mapa. Dentre os três tipos de navegação, os robôs que constroem o seu próprio mapa são considerados mais difíceis de serem desenvolvidos, porém são os que possuem maior nível de autonomia de navegação para lidar com os problemas do mundo real.

Os algoritmos que implementam essa tarefa de mapeamento dependem diretamente do tipo de ambiente que é mapeado, os quais podem ser: estático ou dinâmico, estruturado ou desestruturado e interno (indoor) ou externo (outdoor). A Figura 2.1 mostra essa estrutura de ambientes e aponta onde o trabalho desenvolvido está localizado. Um ambiente é dinâmico quando existem objetos móveis na cena e estático quando todos os objetos são fixos. Em aplicações do mundo real dificilmente são encontrados ambientes totalmente estáticos. Na prática, a maioria dos algoritmos consideram os objetos móveis como sendo ruídos do sistema. Portanto, quando o ambiente é altamente dinâmico, as implementações tradicionais não conseguem lidar de maneira eficiente com esse problema. Em Wang (2004) é apresentado um trabalho de SLAM que faz essa diferenciação entre objetos móveis e estáticos. Já a classificação entre ambiente estruturado e desestruturado depende das características geométricas dos objetos presentes na cena. A informação geométrica frequentemente extraída do ambiente é a reta. Logo, quando torna-se difícil a identificação na cena de formas geométricas conhecidas, o ambiente é classificado como desestruturado. Tanto no ambiente interno como no externo existem informações geométricas conhecidas. Porém, no ambiente interno a geometria é geralmente mais definida do que no externo. Por exemplo, janelas, portas e corredores são facilmente representados por retas. Assim, conhecer o ambiente é importante na implementação dos algoritmos de mapeamento, uma vez que isso influencia diretamente no tipo de informação que pode ser extraída dos sensores e no nível de ruído do sistema.

Nas subseções seguintes são apresentadas informações básicas para entender como os robôs navegam com mapas e como esses mapas são criados e organizados. A Figura 2.2 mostra o tipo de navegação e de mapa usados no trabalho desenvolvido. 

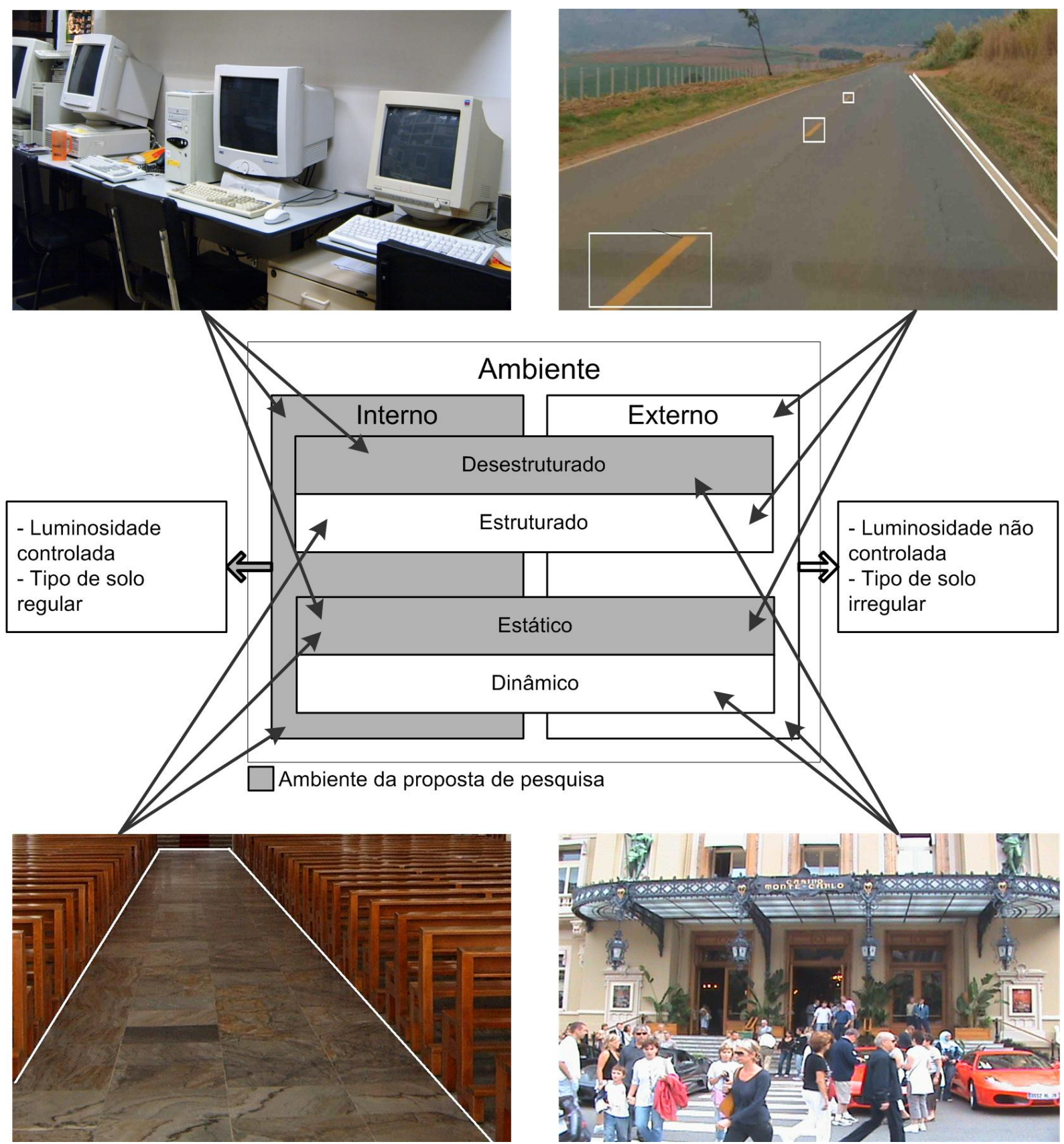

Figura 2.1: Tipo de ambiente a ser explorado. 


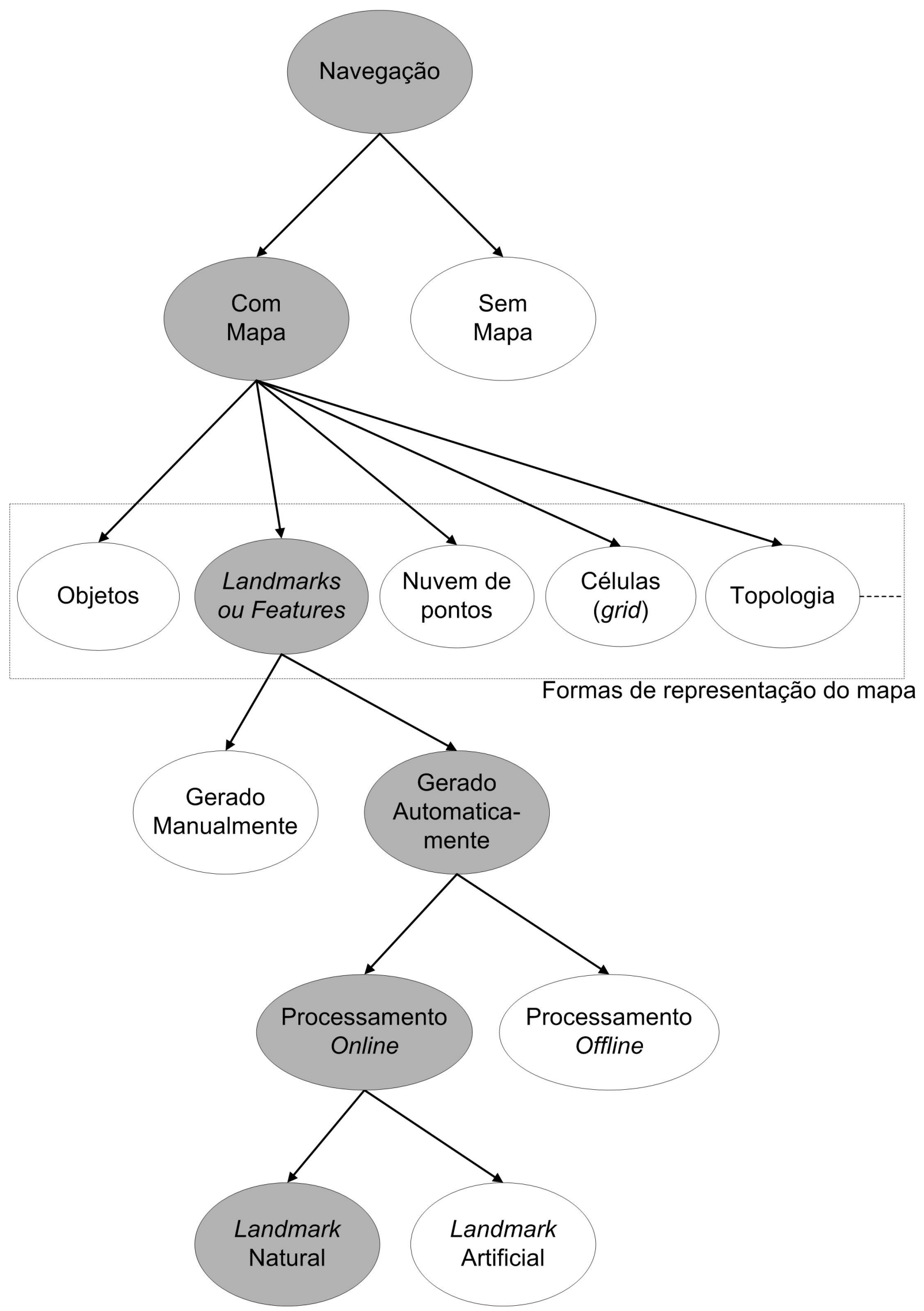

Características do trabalho desenvolvido

Figura 2.2: Tipos de navegação e de representação de mapas. 


\subsubsection{Landmarks para o Mapeamento}

Na robótica os landmarks são informações presentes no ambiente de navegação do robô que servem de referência para a construção do mapa desse ambiente no sistema de controle do robô, permitindo com isso a sua localização a partir dessas referências (Borenstein et. al., 1996). As informações presentes no ambiente que podem ser caracterizadas como landmarks dependem do tipo de sensor utilizado pelo robô para adquirir os dados e do algoritmo de pré-processamento adotado para interpretar esses dados. Os landmarks podem ser classificados em dois grupos: os naturais e os artificiais. Os naturais fazem parte do ambiente original, já os artificiais são propositalmente inseridos no ambiente. Independentemente do tipo de sensor, do algoritmo de pré-processamento e da informação a ser obtida do ambiente original ou modificado, os landmarks devem ser confiáveis. Em outras palavras, as características que os identificam devem permanecer estáveis enquanto servirem de referência ao robô.

\subsubsection{Detecção e Utilização de Landmarks}

O processo de detecção e de utilização de um landmark é composto basicamente pelas seguintes fases:

1. Captura dos dados do ambiente através do sensor;

2. Análise dos dados capturados a fim de identificar as informações que caracterizam um landmark;

3. Armazenamento das features que correspondem aos landmarks na memória do sistema controlador do robô para compor o mapa do ambiente. Essas features também são usadas para estimar a localização do robô através da relação entre o conjunto de features capturadas e o conjunto de features armazenadas previamente na memória.

Na literatura, landmark e feature são, na maioria dos casos, considerados sinônimos. Porém, alguns autores preferem usar landmark para referenciar o que está presente no 
ambiente e feature o que está armazenado na memória do sistema (Newman, 2005). Para este trabalho, essas palavras são consideradas sinônimas.

O tipo de sensor adotado na aquisição de dados depende basicamente do tipo de ambiente e do poder de processamento do robô. Conhecer as características do ambiente de navegação do robô é muito importante, pois os sensores possuem limitações e essas devem ser respeitadas para a implementação de um sistema robusto. Por exemplo, um sensor de imagem necessita de um nível mínimo de luminosidade do ambiente para poder capturar as imagens; e um sensor laser range finder não é capaz de capturar dados onde a luz emitida pelo mesmo é absorvida pelo ambiente ou não é refletida. A escolha do sensor também está relacionada ao poder de processamento do robô, dado que o volume de informações gerado pelo sensor e o processamento necessário para interpretar essas informações variam. Por exemplo, o sensor de imagem gera um volume de informações superior ao do laser range finder e o seu processamento consome muito mais recursos computacionais do sistema.

A identificação de um landmark a partir de um conjunto de informações capturadas pelo sensor é realizada por algum algoritmo que busca identificar um padrão ou uma característica dentro desse conjunto. O landmark pode ser, por exemplo, num ambiente interno, uma porta ou o marco de uma janela. Já num ambiente externo pode ser uma árvore ou a borda de uma calçada.

\subsubsection{Landmark Artificial e Natural}

O landmark é considerado artificial quando o mesmo é propositalmente inserido no ambiente de navegação do robô. Esse tipo de landmark é detectado facilmente pelo robô, pois suas características foram artificialmente criadas com o intuito de serem explícitas. Muitas vezes, o landmark artificial não somente serve de referência para a localização e navegação do robô, como também de fonte de informação utilizada para outro fim. Por exemplo, o landmark formado por um código de barras pode servir de referência e conter um código que representa um comando. A Figura 2.3 mostra um exemplo de landmark artificial composto por códigos. 


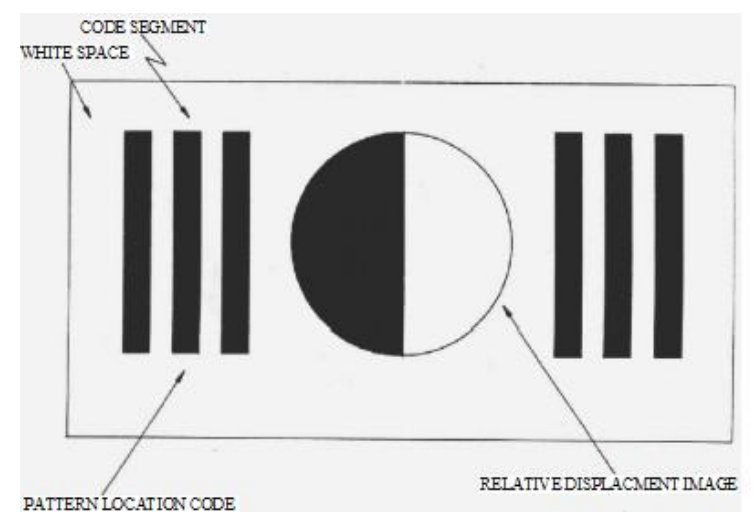

Figura 2.3: Landmark artificial usado em Kabuka e Arenas (1987).

A desvantagem de um sistema baseado em landmark artificial é a necessidade de adequação do ambiente para que o robô possa navegar; ou seja, criar um mundo artificial. O ideal é desenvolver sistemas que tenham a capacidade de identificar referências naturais do ambiente. Desse modo, sistemas cada vez mais eficientes para lidar com o mundo real são criados. A Figura 2.4 apresenta exemplos de landmarks naturais detectados com sensor de imagem. Conforme pode ser notado, os landmarks naturais podem basear-se na estrutura do ambiente como bordas e cantos de portas e janelas. Mas, também podem basear-se na variação da intensidade de luminosidade de um certa região de uma imagem.

\subsubsection{Considerações no Uso de Landmark}

É desejável que o landmark permaneça estável na imagem enquanto for utilizado pelo robô, mesmo com variação do ângulo de visão (viewpoint). Outra característica importante é a manutenção de uma quantidade de landmarks grande o suficiente para não comprometer o cálculo da localização do robô e nem a construção do mapa. O ideal é utilizar-se landmarks invariantes à translação, rotação, escala, luminosidade e oclusão. Porém, nem sempre todas essas restrições são atendidas, sendo muitas vezes necessário o desenvolvimento de algoritmos robustos para suportar essas deficiências. Em Davison e Murray (2002) é apresentado um algoritmo SLAM para a construção de mapa 3D a partir de landmarks detectados com o operador de saliência de Shi e Tomasi (1994). Segundo esses autores, utilizando-se janelas de $9 \times 9$ até $15 \times 15$ pixels é possível identificar landmarks estáveis na imagem; mesmo com grande variação do ângulo de visão. Ainda 


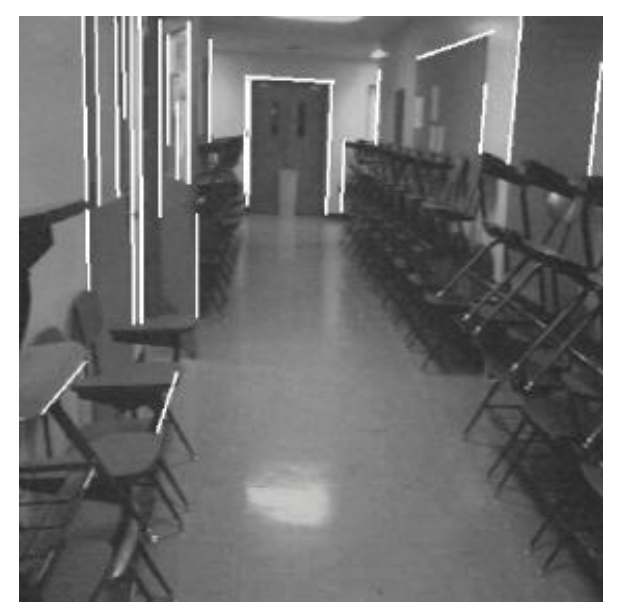

(a)

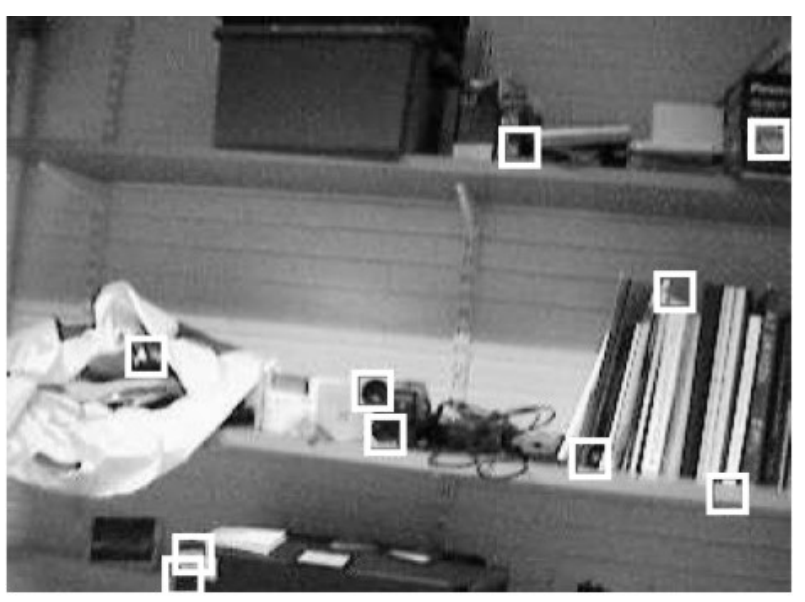

(b)

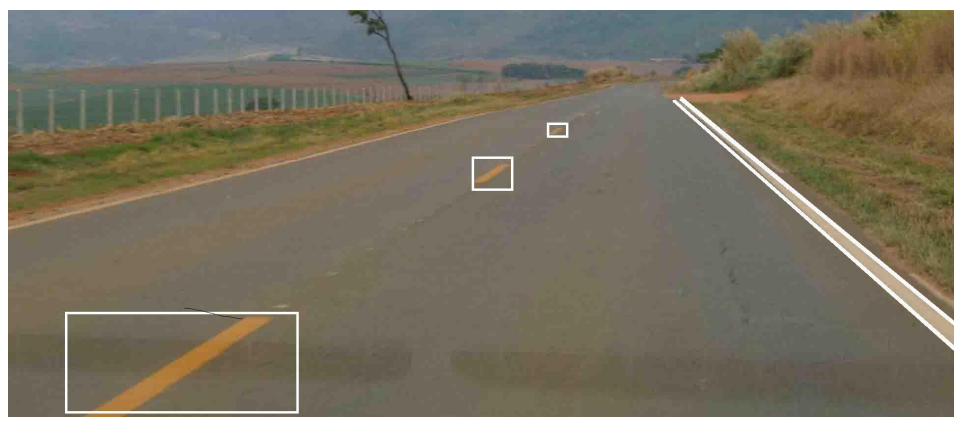

(c)

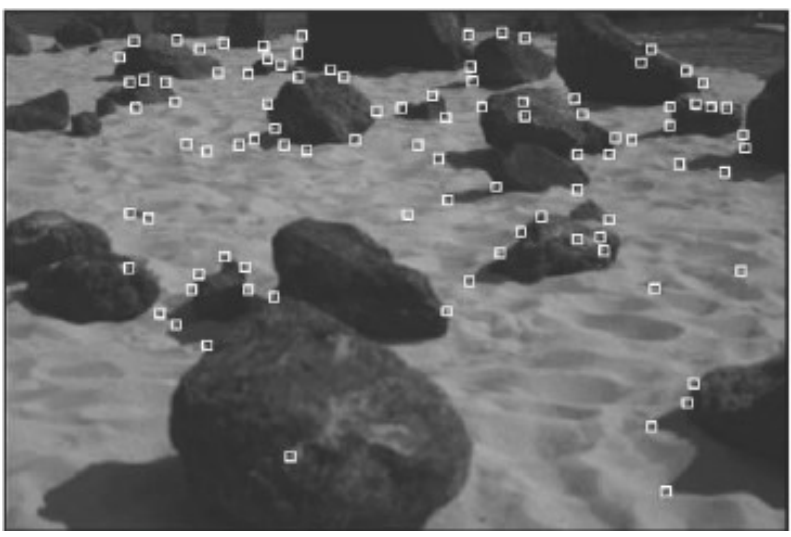

(d)

Figura 2.4: Landmarks naturais: (a)ambiente interno estruturado e (b)desestruturado; (c)ambiente externo estruturado e (d)desestruturado (Kosaka e Kak, 1992; Davison, 2003; Olson et. al., 2003). 
segundo esses autores, é desejável manter 12 landmarks dentro do ângulo de visão para que o algoritmo possa calcular com precisão a localização da câmera (robô).

Trabalhos recentes têm adotado algoritmos que detectam landmarks com alto nível de abstração (Se et. al., 2002; Davison e Murray, 2002). Esses algoritmos identificam regiões do ambiente sem se preocupar com a sua semântica. Por exemplo, se o sensor de captura de dados for uma câmera, um landmark pode ser gerado a partir da análise da intensidade dos pixels de uma região qualquer da imagem sem haver a necessidade de entender o seu significado. O importante, conforme já mencionado anteriormente, é detectar landmarks estáveis, invariantes à posição do robô e que sejam estáticos. Um estudo sobre algoritmos que implementam métodos baseados em landmarks pode ser visto em Fernandes (2003).

\subsubsection{Tipos de Mapeamento}

A pesquisa em mapeamento na robótica iniciou-se na década de 80. Durante essa década e no início da década de 90 o mapeamento era amplamente dividido em dois tipos: topológico e métrico. O mapa topológico representa o ambiente por meio de uma estrutura baseada em grafos, onde os nós representam os objetos significantes e os arcos as informações de relação entre os mesmos. Em Mataric (1990) é apresentado um exemplo de mapa topológico. Já o mapa métrico possui muito mais formas de representação, caracterizadas por apresentarem informações geométricas do ambiente, como por exemplo, as coordenadas cartesianas de regiões de interesse. O occupancy grid map, criado por (Moravec e Elfes, 1985), é uma representação clássica do mapa métrico. No entanto, segundo Thrun (2002), a distinção entre topológico e métrico não é clara, pois todo o mapa topológico virtualmente depende de informações geométricas, e que, na prática, o que os diferencia é a granularidade do mapa, sendo mais fina nos métricos.

Na Figura 2.5 são apresentados três modos de representação de mapas bidimensionais, sendo um topológico e dois métricos. O mapa (a) é topológico e representa um corredor de um ambiente interno. Os mapas (b) e (c) são métricos e representam corredores e uma sala, também de ambiente interno, respectivamente. A representação do mapa (a) é feita por meio de uma estrutura de grafos, do (b) por meio de uma grade de ocupação (occupancy 
grid) e do (c) por meio de landmarks. Como pode ser notado, o modo de representação está relacionado com o nível de detalhamento do mapa gerado e isso, influencia diretamente nos recursos computacionais necessários para o processamento e o armazenamento destes dados.

A partir do início da década de 90, o mapeamento passou a ser frequentemente denominado SLAM ou CML (Thrun, 2002). Essa mudança ocorreu a partir dos trabalhos de Smith et. al. $(1988,1990)$, que apresentaram um método probabilístico para resolver simultaneamente o problema de mapeamento e de localização. Neste trabalho, o mapa resultante é uma lista contendo as coordenadas de localização de landmarks e do robô. Todas essas informações são associadas à probabilidade de estarem corretas. Em sistemas onde a correlação entre esses elementos é mantida o mapa é referenciado como estocástico.

\subsubsection{Considerações no Mapeamento}

O objetivo do mapeamento é construir uma base de conhecimento que represente o ambiente na memória do sistema de controle do robô a partir das informações obtidas de sensores do tipo: câmera, sonar, laser range finder, infra-vermelho, radar, GPS, encoder, de toque, de colisão e etc. Além disso, as informações podem ser obtidas a partir de um único tipo de sensor ou da fusão entre eles, dependendo do tipo de ambiente a ser explorado, da capacidade de processamento do robô e do tipo de informação que o sensor tem capacidade de fornecer. No entanto, apesar dos sensores serem distintos em suas funções, todos eles estão sujeitos a erros causados por interferência do próprio ambiente ou gerados internamente pelo sensor. Além de lidar com os erros e limitações dos sensores, durante a exploração do ambiente erros de movimentação do robô também devem ser tratados, já que é necessário se conhecer a localização do robô para se construir o mapa simultaneamente.

O erro gerado pelos sensores, também conhecido como ruído, é um dos problemas mais complexos de ser tratado no mapeamento (Thrun, 2002). Esse ruído é difícil de ser filtrado, pois sua geração é estatisticamente dependente. Caso não fosse, leituras sucessivas poderiam cancelar o seu efeito por meio da média. Ao acumular esses erros, a 


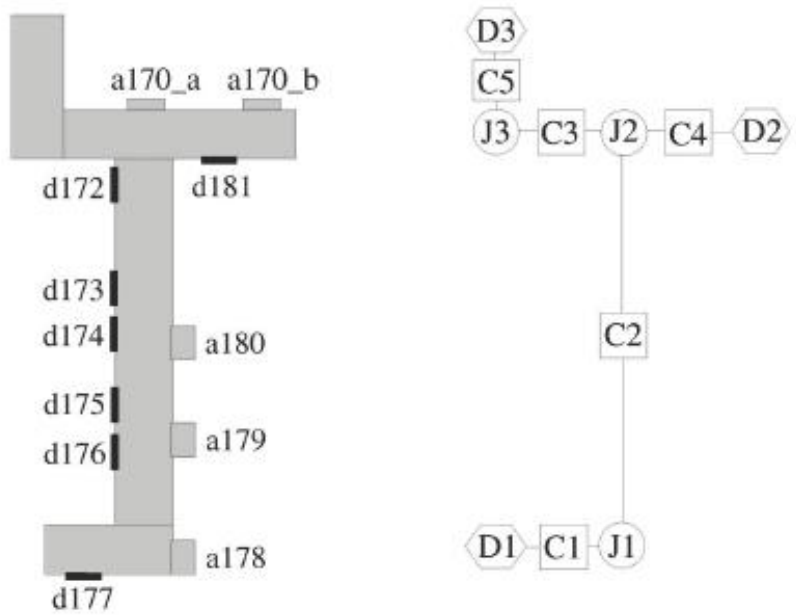

(a) Topológico

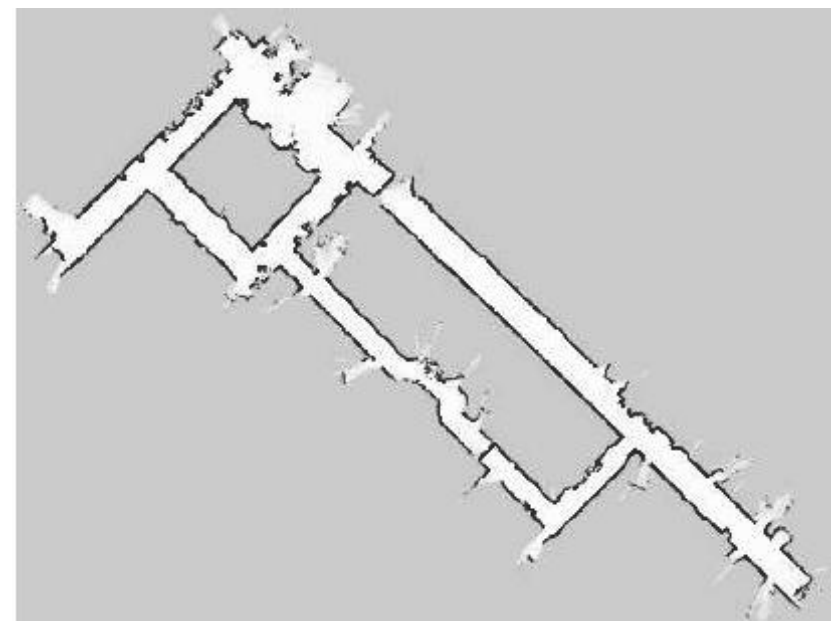

(b) Métrico

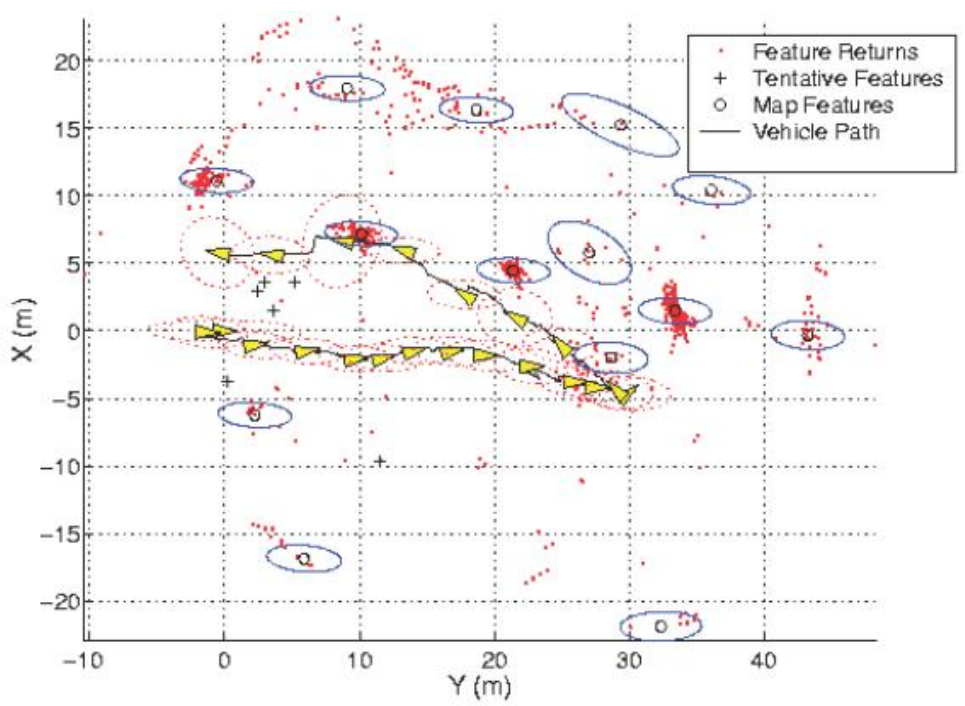

(c) Métrico

Figura 2.5: Alguns modos de representação de mapas (DeSouza e Kak, 2002; Thrun et. al., 2005). 
interpretação futura dos dados dos sensores pode ser afetada. Isso pode ser notado num exemplo apresentado na Figura 2.6, em que pequenos erros de odometria, causados pelo escorregamento das rodas, acumulam-se durante a movimentação do robô, ocasionando erro de vários metros na estimação da posição do robô.

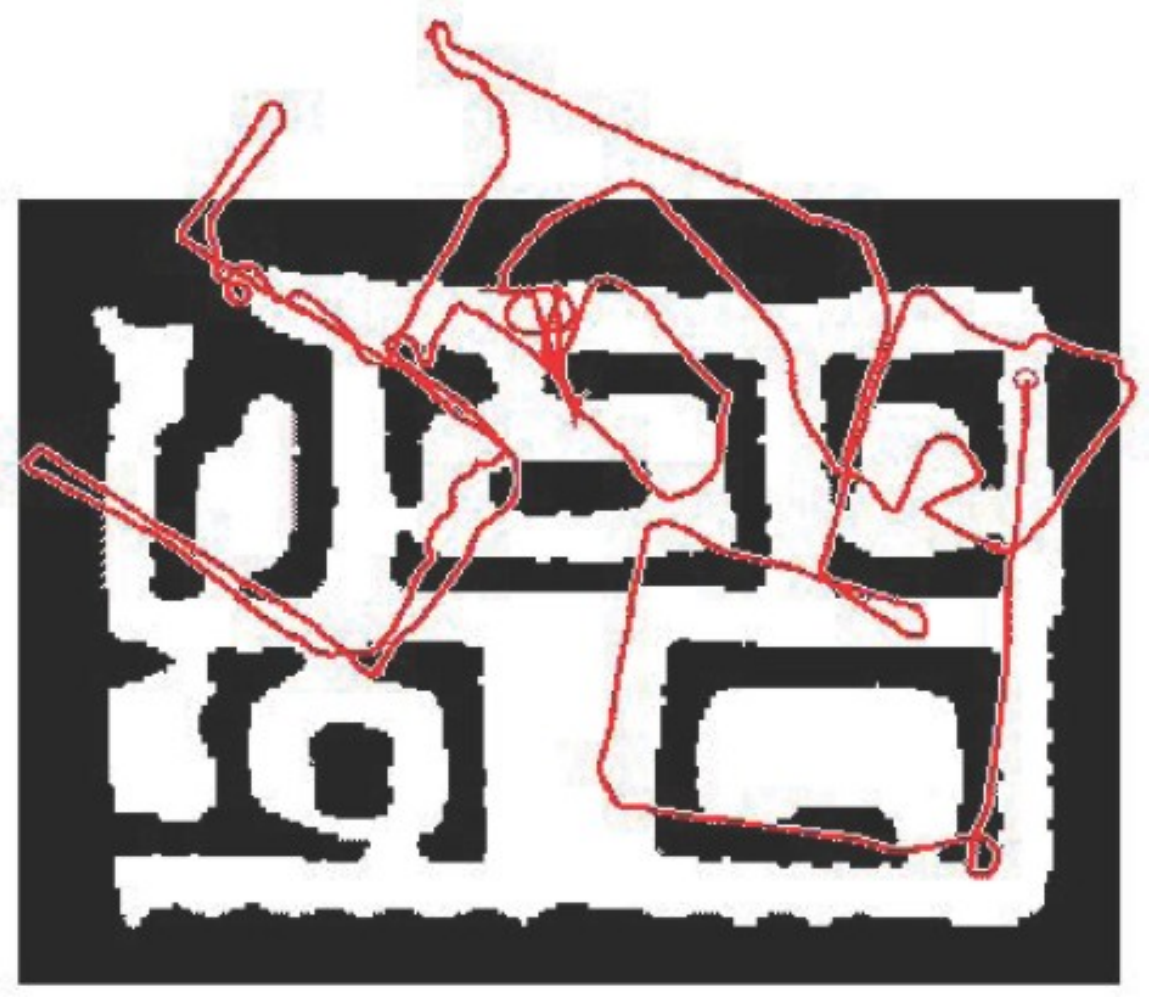

Figura 2.6: Erro acumulativo de localização de um robô decorrente de pequenos erros de odometria causados pelo escorregamento das rodas (Thrun, 2002).

Além dos ruídos, no mapeamento é necessário que se defina a forma de como lidar com a dimensionalidade das entidades que estão sendo mapeadas, com o problema da associação de dados, com a mudança do ambiente e com a estratégia de exploração.

Definir a dimensionalidade das entidades significa estabelecer quantos landmarks são necessários para descrever um ambiente. Por exemplo, para descrever uma casa através de um mapa topológico, onde a dimensão de um landmark pode ser um corredor, um quarto ou uma porta, apenas algumas dezenas de landmarks podem ser suficientes. Já numa representação bidimensional utilizando landmarks com alto nível de abstração, são necessários milhares de landmarks; e numa representação tridimensional o número de landmarks pode chegar a milhões. Como descrito, a dimensionalidade das entidades está 
diretamente relacionada com o nível de detalhamento do mapa do ambiente e com o formato das informações armazenadas no mesmo.

O problema da associação de dados é o problema de determinar se as medidas de um sensor obtidas em diferentes pontos correspondem ao mesmo objeto no ambiente. Esse tipo de problema pode ser evidente quando o robô finaliza o mapeamento num ambiente cíclico, em que o ponto inicial de mapeamento deve ser o mesmo que o ponto final. Ou seja, o robô deverá perceber, mesmo estando num ângulo de visão diferente, que ele retornou ao ponto inicial e que um trajeto deve ser fechado. Nesse exemplo, o problema de correspondência é difícil, pois o número de posições possíveis que o robô pode assumir cresce exponencialmente com o passar do tempo.

Em relação às mudanças no ambiente, os objetos existentes no ambiente podem ser estáticos ou dinâmicos (movimentar-se com o passar do tempo). No caso do dinâmico, esse dinamismo deve ser interpretado corretamente para que robôs aptos a trabalhar com o mundo real sejam construídos (Wang, 2004). A mudança pode ocorrer lentamente, tal como o crescimento de uma árvore; ou rapidamente, tal como a mudança do estado de uma porta de aberta para fechada. O dinamismo do ambiente é difícil de se tratar, pois muitas vezes é difícil definir o que é realmente dinâmico e o que é ruído gerado pelo sensor. Por exemplo, se um robô está em frente a uma porta fechada que estava aberta quando mapeada, isso pode causar inconsistência, visto que o robô pode assumir que a porta mudou de estado de aberta para fechada, ou ainda, que o robô pode não estar na posição em que ele realmente acredita estar. A maioria dos algoritmos de mapeamento não consideram o ambiente dinâmico, ou seja, o ambiente é estático e tudo que se move nele é considerado ruído do sensor. Consequentemente, a maioria das técnicas são aplicadas somente num pequeno intervalo de tempo, durante o período em que o ambiente permanece estático (Thrun, 2002).

Finalmente, além das fases descritas anteriormente, para construir o mapa o robô deve escolher o seu caminho durante a exploração do ambiente; tarefa comumente referenciada como robot exploration. A exploração de um ambiente totalmente modelado é relativamente fácil se comparada com ambientes parcialmente modelados, pois a exploração de 
áreas desconhecidas pode gerar surpresas. Para lidar com isso, os robôs são programados com base no conhecimento heurístico do programador. Durante a exploração, decidir qual caminho deve ser tomado é uma escolha que depende da estratégia de exploração e da expectativa sobre o que cada caminho pode fornecer. Por exemplo, a estratégia poderia ser visitar o maior número possível de áreas desconhecidas do ambiente no menor tempo possível, sem se preocupar com o consumo de energia e nem com o risco do robô se perder.

\subsubsection{Considerações na Localização}

A localização de robôs móveis, também conhecida como position estimation ou position tracking, tem a função de determinar a posição relativa ao mapa do ambiente. Conhecer a posição do robô é essencial tanto para a sua navegação como para a construção do mapa. A localização do robô geralmente não é obtida diretamente de um único sensor. Ela é inferida a partir da localização anterior do robô, dos comandos de movimentação do mesmo e dos dados dos sensores gerados na posição atual. Essa junção de informações é necessária, principalmente, para lidar com as ambiguidades do ambiente e com os ruídos dos sensores. O nível de dificuldade para calcular a localização do robô é variável. A dificuldade depende do tipo de conhecimento disponível no início e durante o cálculo, do ambiente ser estático ou dinâmico, da localização ser passiva ou ativa e do número de robôs envolvidos.

Quando a posição inicial do robô é conhecida, o cálculo de sua nova posição é mais fácil de ser determinada do que na ausência dessa informação, pois é possível determinar aproximadamente a sua nova posição a partir da sua localização anterior e das informações obtidas dos sensores de movimentação do robô. Esse tipo de localização é conhecido na literatura como incremental ou local. Já quando a posição inicial do robô não é conhecida, o cálculo torna-se mais difícil. Nesse caso, a posição do robô é calculada a partir da análise das informações capturadas pelos sensores e das informações armazenadas em sua memória, podendo ser um mapa do ambiente previamente conhecido ou landmarks distintos com posição conhecida no ambiente. Essa segunda abordagem é apresentada na literatura como localização absoluta ou global. A origem da diferença de dificuldade 
entre o cálculo da localização incremental e da absoluta está na modelagem dos ruídos dos sensores, dado que na incremental, geralmente, o ruído é modelado através de uma distribuição unimodal (distribuição Gaussiana) e na absoluta multimodal (filtro de partículas). Essa necessidade ocorre porque na localização global frequentemente existem situações de ambiguidade de informação, e para lidar com isso é mais adequado utilizar filtros que suportam múltiplas hipóteses (multi hypothesis).

Em ambiente estático, o cálculo da posição do robô é mais fácil de ser realizado do que em dinâmico, pois tudo no ambiente é considerado estático e a única movimentação que ocorre é a do robô. E se porventura algum objeto do ambiente se mover, esse é tratado como ruído gerado pelo sensor.

Na localização ativa o algoritmo de localização interfere na movimentação do robô e na passiva isso não ocorre. Interferir na movimentação do robô em muitos casos ajuda na sua localização. Isso ocorre quando o robô está num lugar com informações ambíguas, como por exemplo, num corredor onde há diversas portas semelhantes e o mesmo precisa deslocar-se para um outro lugar a fim de determinar a sua localização. Nesse caso, o algoritmo de localização poderia dirigir o robô diretamente para dentro de uma das salas através de uma das portas do corredor a fim de concluir onde realmente ele se encontra.

Utilizar informações de um único robô no cálculo da localização pode ser mais fácil do que o uso de vários robôs, pois não há problemas de comunicação de dados entre eles e o volume de informações processadas é menor. No entanto, com múltiplos robôs poderse-ia ter o cruzamento de informações e consequentemente ter o resultado do cálculo da localização mais preciso.

\subsection{Algoritmos de Mapeamento}

A maioria dos algoritmos de mapeamento estão relacionados com o filtro de Bayes originado da regra de Bayes (Thrun, 2002). Essa regra é um método probabilístico que utiliza evidências amostrais para calcular a probabilidade de eventos. Essa técnica muitas vezes é referenciada como posterior probability (Gnedenko, 1982), pois a probabilidade é calculada após (posterior) conhecer-se o dado amostral. A Equação 2.1 apresenta a 
fórmula discreta da regra de Bayes, sendo y o dado amostral utilizado para calcular a probabilidade posterior de $x_{i}$. O denominador da equação da regra de Bayes é o somatório da probabilidade da variável discreta $y$ em todas as combinações possíveis $(p(y))$, sendo o denominador frequentemente representado por uma variável de normalização, conforme a Equação 2.2.

$$
\begin{gathered}
p\left(x_{i} \mid y\right)=\frac{p\left(y \mid x_{i}\right) p\left(x_{i}\right)}{\sum_{j=1}^{n} p\left(y \mid x_{j}\right) p\left(x_{j}\right)} \\
p\left(x_{i} \mid y\right)=\eta p\left(y \mid x_{i}\right) p\left(x_{i}\right)
\end{gathered}
$$

O filtro de Bayes vai além do cálculo baseado em amostras, ele também integra dados temporais a fim de calcular a probabilidade recursivamente. Em outras palavras, para o cálculo da probabilidade posterior esse filtro considera o resultado obtido no passo anterior, conforme mostram as Equações 2.3 e 2.4. Como pode ser notado, a Equação 2.3 integra a probabilidade do passo anterior e seu resultado é utilizado na Equação 2.4 para determinar a probabilidade posterior. Nessas equações, o controle temporal é realizado pela variável $t$, onde somente o estado $t-1$ é considerado para a integração. Essa definição ocorre para tornar o algoritmo computável, assumindo que o sistema dinâmico é do tipo modelo Markov (Fox et. al., 2003). O modelo Markov assume que a informação amostral $y$ no instante $t$ depende somente da probabilidade de $x$ do mesmo instante; e que a probabilidade de $x$ no instante $t$ depende somente do instante $t-1$ (Markov apud Gnedenko (1982)).

$$
\begin{gathered}
p^{-}\left(x_{i}^{t}\right)=\int p\left(x_{i}^{t} \mid x_{i}^{t-1}\right) p\left(x_{i}^{t-1}\right) d x \\
p\left(x_{i}^{t} \mid y\right)=\eta p\left(y^{t} \mid x_{i}^{t}\right) p^{-}\left(x_{i}^{t}\right)
\end{gathered}
$$

Na prática, na fase de localização, a informação amostral y representa a leitura do sensor e $x$ representa um vetor contendo a localização do robô e as localizações dos land- 
marks no ambiente, sendo os elementos desse vetor referenciados através do $x_{i}$. Para que as equações do filtro de Bayes sejam aplicadas é necessário especificar o modelo de percepção (perceptual model) $p\left(y^{t} \mid x_{i}^{t}\right)$, o dinamismo do movimento (motion model) $p\left(x^{t} \mid x^{t-1}\right.$ ) e a representação da probabilidade posterior $p\left(x_{i}^{t} \mid y\right)$. A especificação pode ser realizada de várias formas, dependendo do tipo de sensor, da mecânica do robô e do tipo de ambiente. Essas diferentes formas de tratar os dados é a causa do grande número de algoritmos baseados no filtro de Bayes.

Nesta seção é apresentada uma visão geral dos principais algoritmos de mapeamento e localização existentes na área da robótica. A taxonomia adotada para apresentar esses algoritmos é vista na Figura 2.7, sendo essa organização criada com base nas informações obtidas diretamente dos trabalhos originais analisados e do survey específico sobre mapeamento apresentado em Thrun (2002). Conforme mencionado anteriormente, a maioria dos algoritmos de mapeamento estão de algum modo relacionados com a regra de Bayes e, consequentemente, com métodos probabilísticos. Esse destaque deve-se ao fato da probabilidade fornecer um meio eficiente de se lidar com as limitações e ruídos dos sensores, tendo como resultado robôs que podem recuperar-se de erros, manusear ambiguidades e integrar dados de sensores de maneira consistente.

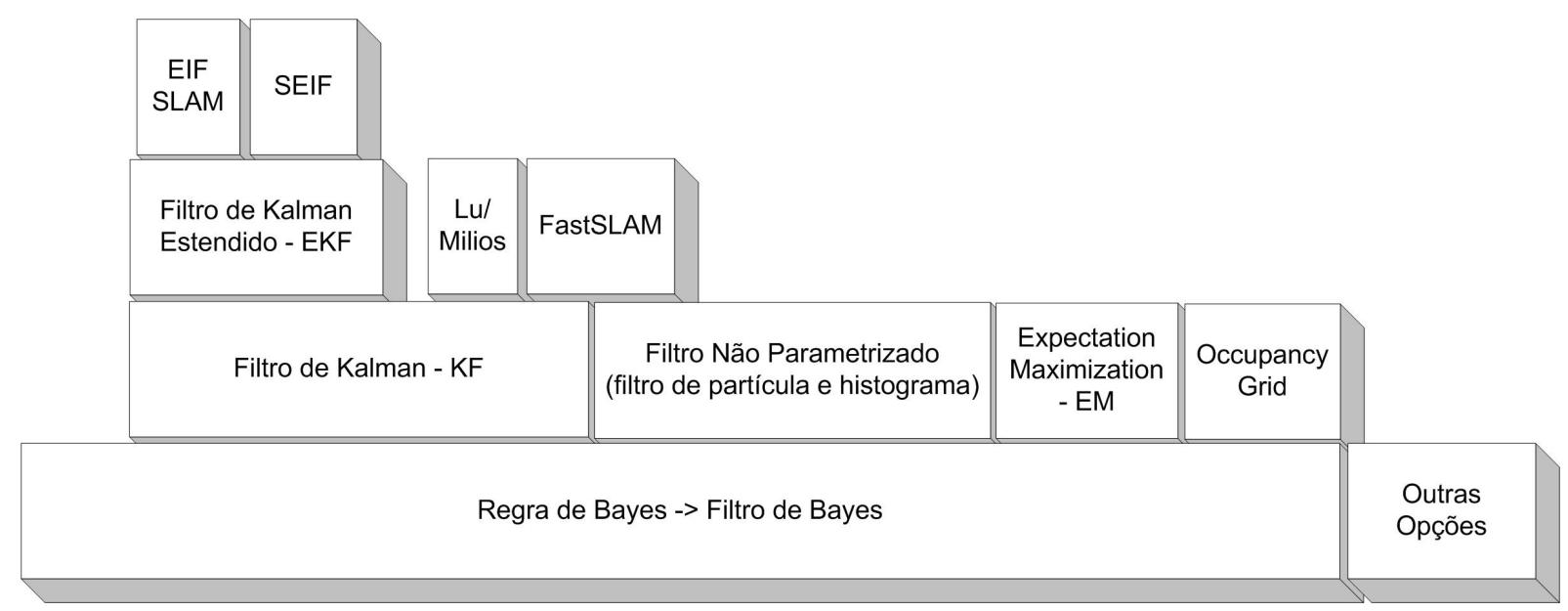

Figura 2.7: Algoritmos base de mapeamento. 


\subsubsection{Filtro de Kalman}

O Filtro de Kalman (KF) (Kalman, 1960) é um algoritmo de processamento de dados recursivo ótimo, sendo uma das variações mais usadas do filtro de Bayes (Fox et. al., 2003). Esse filtro é utilizado em sistemas dinâmicos normalmente perturbados por ruídos para estimar variáveis do sistema utilizando a distribuição Gaussiana (Maybeck, 1979). Seu uso para mapeamento na robótica foi introduzido por Smith et. al. (1990) para a construção de mapa contendo a estimativa de relacionamento espacial de objetos e suas incertezas. Além disso, forneceu a base teórica necessária para que outras extensões pudessem ser desenvolvidas.

O mapa do KF é composto por um conjunto de dados que representam a posição do robô $(x)$ e dos landmarks $\left(y_{i}\right)$. Considerando-se a posição do robô e dos landmarks num espaço unidimensional, é demonstrado nas Equações 2.5 e 2.6 a organização do mapa (M) juntamente com sua matriz de co-variância (C). Essa representação é composta pelos dois primeiros momentos de uma distribuição probabilística, ou seja, pela média $(\mu)$ e co-variância $(\Sigma)$, respectivamente. Desse modo, as informações presentes no mapa são estimativas $(\mu)$ com seus respectivos graus de incerteza $(\Sigma)$, que são atualizadas de acordo com os dados obtidos dos modelos que representam os sensores (perceptual model) e o controle do robô (motion model).

$$
\begin{gathered}
\mathbf{M}=\left[\begin{array}{c}
\hat{x} \\
\hat{y}_{1} \\
\hat{y}_{2} \\
\vdots
\end{array}\right] \\
\mathbf{C}(\mathbf{M})=\left[\begin{array}{cccc}
\sigma^{2} x & \sigma x y_{1} & \sigma x y_{2} & \ldots \\
\sigma x y_{1} & \sigma^{2} y_{1} & \sigma y_{1} y_{2} & \ldots \\
\sigma x y_{2} & \sigma y_{1} y_{2} & \sigma^{2} y_{2} & \ldots \\
\vdots & \vdots & \vdots & \ddots
\end{array}\right]
\end{gathered}
$$

Os modelos dos sensores e do controle do robô utilizados no KF são funções linea- 
res com a adição de ruído Gaussiano. No entanto, os dados gerados pelos sensores e o resultado dos comandos executados com os dados de controle do robô às vezes não se comportam linearmente, o que pode ocasionar erros no mapeamento. Para resolver essa limitação, foi introduzida uma extensão do KF, conhecida como EKF (Extended Kalman Filter), onde as funções lineares do KF passaram a se comportar de acordo com as condições que identificam o comportamento do robô e dos sensores. Com essa mudança os dados dos sensores e do controle são interpretados como localmente lineares com adição do ruído Gaussiano.

A demanda computacional para a execução do KF ou do EKF é $\Theta\left(n^{2}\right)$, onde $n$ representa o número de landmarks. Essa complexidade computacional quadrática permite que somente algumas centenas de landmarks possam ser utilizadas no mapeamento, enquanto que normalmente os mapas de ambientes naturais contém milhões de landmarks (Montemerlo et. al., 2002). Além dessa restrição, existem outras causadas pela deficiência que esse tipo de filtro tem para lidar com o problema da correspondência de dados, que é o problema de associar medidas do sensor com os landmarks no mapa. Nesse caso, poderão ocorrer problemas quando dois ou mais landmarks tiverem as mesmas medidas, pois tendo em vista que em uma distribuição unimodal, que é o caso da Gaussiana, não é possível representar essa ambiguidade de informação. A solução normalmente adotada identifica o landmark através de sua localização no mapa e ignora grande parte dos dados dos sensores. Como consequência, são gerados mapas que possuem poucos detalhes geométricos do ambiente. Essas limitações motivaram o desenvolvimento de várias outras técnicas de mapeamento, sendo algumas dessas apresentadas nas seções seguintes.

\subsubsection{Filtro de Partículas}

O Filtro de Partícula (PF) é frequentemente utilizado na funcionalidade de localização implementada nos algoritmos SLAM, pois é um poderoso algoritmo de inferência baseado em amostras para redes Bayesianas dinâmicas (DBN), conhecido em diversas áreas com o nome de Monte-Carlo, condensation e survival of the fittest (Doucet et. al., 2000). Esse filtro permite tratar qualquer tipo de distribuição de probabilidade, diferentemente do KF, 
em que a distribuição é Gaussiana, sendo esse um dos principais motivos de seu uso em técnicas de mapeamento na área da robótica. Apesar dessa vantagem, no mapeamento, o PF não é eficiente para lidar com a dimensionalidade dos mapas, já que o número de partículas necessárias para representar os estados no mapa cresce numa proporção que torna inviável o seu uso na maioria das situações reais de mapeamento. Para tornar o PF mais eficiente foi proposto o filtro de partículas Rao-Blackwellised (RBPF), que é uma extensão do PF tradicional capaz de explorar de forma mais eficiente a estrutura da DBN (Doucet et. al., 2000). Isso reflete no mapeamento como uma forma mais eficiente de lidar com o aumento da dimensionalidade do mapa, reduzindo a proporção entre o tamanho do mapa e o número de partículas necessárias para representar os estados posteriores (Sim et. al., 2005). Um exemplo prático do uso do RBPF no mapeamento é o algoritmo FastSLAM apresentado em Montemerlo et. al. (2002), no qual o estado posterior da localização do robô é estimado através de um conjunto de partículas.

\subsubsection{FastSLAM}

O FastSLAM é um algoritmo de mapeamento proposto por Montemerlo et. al. (2002) que tem como base o filtro de Kalman para estimar a posição dos landmarks no ambiente numa distribuição Gaussiana e o filtro de partículas estendido Rao-Blackwellized para projetar a posição do robô no ambiente através de partículas. Como resultado, é gerado um mapa composto por um conjunto de landmarks com suas posições estimadas numa distribuição Gaussiana.

Essa técnica pode ser considerada um avanço em relação à implementação puramente com o KF, que tem a complexidade computacional quadrática em relação ao número de landmarks. Nessa abordagem, o KF é utilizado somente para estimar a posição dos landmarks, sendo a posição do robô determinada pelo filtro de partículas. Com essa divisão, a complexidade computacional reduz para uma proporção logarítmica definida na ordem $\varnothing(M \log N)$, onde $M$ é o número de partículas e $N$ de landmarks. Os experimentos realizados pelos autores dessa técnica mostraram que aproximadamente 100 partículas é o suficiente para obter bons resultados, o que à torna uma técnica com complexidade com- 
putacional inferior às implementações que utilizam o filtro de Kalman nas duas operações: estimação da posição do robô e dos landmarks.

A técnica original utiliza landmarks para construir o mapa, o que pode ser considerado uma limitação em aplicações que desejam obter mapas com informações mais detalhadas da estrutura do ambiente. Em Hähnel et. al. (2003) é apresentado um aprimoramento do FastSLAM para a construção de mapa de ambiente amplo a partir de dados (raw data) obtidos diretamente do sensor laser range finder.

\subsubsection{Lu/Milios}

Em Lu e Milios (1997) é apresentada uma proposta de mapeamento em que o mapa é construído a partir de um conjunto de frames locais e de uma rede de relacionamento espacial entre eles. Cada frame local contém os dados obtidos de um sensor laser range finder a partir de uma determinada posição do robô no mapa, que em alto nível se assemelha a uma foto do ambiente naquela determinada posição. O relacionamento entre os frames na rede são modelados com variáveis aleatórias que são definidas a partir da comparação entre o conteúdo dos frames ou dos dados lidos com o sensor de odometria do robô.

Nessa abordagem, todo o frame contém informações associadas a ele para estimar, baseado numa modificação do filtro de Kalman, a sua posição geométrica de captura no mapa. Todos os frames capturados em locais diferentes são armazenados na memória do sistema controlador do robô, pois o mapa é formado pela integração desses diversos frames. Desse modo, é necessário que a posição de referência de cada frame seja precisa para que eles se "fundam" perfeitamente e gerem, por consequência, um mapa preciso. Para estimar a posição ótima de onde o frame foi capturado, o método de máxima probabilidade ou variância mínima (maximum likelihood) é adotado, o qual estima novamente a posição a partir das restrições (constraints) da rede de relacionamentos, corrigindo com isso possíveis erros de localização definidos na fase de captura do mesmo. Essa reestimativa da posição do frame local pode ser realizada toda vez que um novo frame for capturado pelo robô, ou somente após a captura de todos os frames necessários para 
concluir o mapeamento. A simulação apresentada em Lu e Milios (1997) mostrou que a segunda opção gera mapas mais precisos. Como resultado, obtém-se um mapa construído com dados obtidos diretamente do sensor ( raw data), sendo a resolução desse mapa definida pela resolução do sensor e pelo número de frames locais que são integrados, o que permite a construção de mapas com informações detalhadas da estrutura do ambiente. Característica esta que não é obtida quando o mapa é construído a partir de landmarks, conforme o algoritmo descrito na Seção 2.2.1. Apesar dessa vantagem, o algoritmo é deficiente para o mapeamento de ambientes amplos, pois o erro de posicionamento do robô (onde os frames são capturados) é acumulativo dificultando o fechamento do loop do mapeamento, ou seja, retorno ao ponto de origem. Esse algoritmo é considerado de grande potencialidade e tem motivado o desenvolvimento de outros trabalhos a partir dessa idéia original, como o de Thrun et. al. (2004a), em que um robô constrói o mapa detalhado de uma mina de carvão abandonada.

\subsubsection{Expectation Maximization}

Expectation Maximization (EM) é um algoritmo baseado no método probabilístico maximum likelihood, proposto por Dempster et. al. (1977), que busca estimar os parâmetros de maximização da probabilidade a partir de um conjunto incompleto de dados. Por exemplo, maximizar $g(y \mid \phi)$, onde $y$ é um conjunto incompleto de dados observado e $\phi$ o parâmetro que maximiza a função probabilística $g$. Um dos primeiros trabalhos a utilizar o EM, que também é conhecido como técnica de hill-climbing, na área de mapeamento foi o algoritmo apresentado em Thrun et. al. (1998) que tinha o objetivo de tornar a sua rotina de maximização de parâmetros computacionalmente viável. Segundo o autor desse trabalho, o EM é um algoritmo derivado do teorema de Bayes.

Para construir o mapa, o algoritmo EM inicialmente captura os dados do ambiente que deseja mapear. Nesse procedimento, além dos dados lidos pelos sensores, são armazenadas as localizações de onde o robô fez as aquisições. Em seguida, o algoritmo começa a executar alternadamente as fases Expectation e Maximization. Na primeira fase as localizações de aquisição dos dados são estimadas novamente e na segunda, um mapa é gerado baseado 
no resultado das localizações. A cada iteração um mapa com grau de confiança crescente é gerado.

O mapa gerado com o EM, geralmente, é representado como occupancy grid e exibe o ambiente real com alto grau de fidelidade (consistente), mesmo quando os dados coletados durante a exploração do ambiente possuem erros decorrentes dos sensores de controle (encoder) e de medida (laser). O algoritmo EM é considerado eficaz para o mapeamento de ambientes cíclicos de grande escala e para lidar com as ambiguidades do mesmo e com o problema de correspondência entre mapas. Porém, o seu processamento não ocorre em tempo real, uma vez que para gerar mapas com grau de consistência crescente, um grande volume de dados é processado múltiplas vezes. Além disso, essa não é uma técnica incremental, pois o mapa começa a ser gerado somente após a exploração de todo o ambiente que deseja mapear (Thrun, 2002).

\subsubsection{Occupancy Grid}

O algoritmo de mapeamento occupancy grid (Moravec e Elfes, 1985; Elfes, 1989), que é uma versão do filtro de Bayes, foi proposto na década de 80 e até os dias de hoje tem sido um ingrediente importante no desenvolvimento de vários outros algoritmos de mapeamento, pois é considerado robusto e simples para implementar. O occupancy grid gera mapas geométricos, em que o ambiente é dividido em pequenas células, as quais é associada uma probabilidade de estarem ou não ocupadas por objetos, e a união de todas essas células formam uma grade que corresponde ao mapa do ambiente.

Para mapear o ambiente o algoritmo parte do pressuposto de que a localização do robô é conhecida. A partir dessa referência, da probabilidade a priori da célula e das informações do ambiente medidas pelo sensor, é definida a probabilidade das células estarem ou não ocupadas. Para as células que estão entre a posição do robô e a posição de um determinado objeto detectado pelo sensor são atribuídas baixas probabilidades de estarem ocupadas; já as células onde o objeto está localizado são atribuídas altas probabilidades de estarem ocupadas. A probabilidade de cada célula é calculada recursivamente, pois cada vez que uma nova informação do sensor chega, a probabilidade de cada célula 
dentro da faixa de visualização do sensor é recalculada baseado no dado do sensor atual e, caso já exista, na probabilidade que foi associada anteriormente à célula. No final do processamento, cada célula do mapa possui um valor que pode variar entre $(0-0,5-1)$, sendo: menor do que 0,5 para indicar área livre, igual a 0,5 desconhecida e maior do que 0,5 ocupada. Quanto mais próximo dos limites inferior e superior, maior é a certeza do estado real da célula.

O algoritmo original occupancy grid lida eficientemente com o ruído do sensor; possibilita a geração de mapas detalhados do ambiente; e é simples para implementar em sistemas computacionais. Porém, apresenta algumas limitações. Primeiramente, o tamanho do mapa e a resolução do mesmo é limitida pela velocidade de processamento do robô; desse modo, mesmo com os recursos computacionais existentes atualmente, o mapeamento de ambientes amplos ou tridimensionais não é factível. Uma outra limitação é o fato da posição do robô não ser calculada automaticamente e nem possuir incerteza associada, o que prejudica em aplicações onde as tarefas de localização e de mapeamento, de preferência, devem ser realizadas automaticamente. Apesar dessas limitações, o modo de representar o ambiente é amplamente utilizado em outros algoritmos de mapeamento de mesma finalidade.

\subsubsection{Extended Information Form SLAM Algorithm}

Extended Information Form SLAM Algorithm (EIF SLAM) é um algoritmo de mapeamento baseado no Extended Information Filter (Maybeck apud Thrun et. al. (2004b)). O EIF SLAM é considerado um algoritmo offline, uma vez que constrói o mapa do ambiente somente após a sua exploração. Durante a exploração, as informações de controle e dos sensores são simplesmente armazenadas na memória do sistema controlador do robô. Esse tipo de algoritmo é indicado quando o conjunto de dados possui tamanho fixo e o sistema suporta todos esses dados na memória no momento em que o mapa está sendo construído. Os dados no mapa são representados pelos dois primeiros momentos da Gaussiana, semelhante ao EKF, conhecidos nessa abordagem por vetor e matriz de informação. Porém, o mecanismo de atualização dessas informações entre os dois algoritmos é diferente. A 
principal vantagem apontada para esse tipo de algoritmo é a capacidade de gerar mapas precisos e de grande dimensões.

Os dados utilizados na construção do mapa são compostos por um conjunto de medidas $z_{1: t}$ associadas à variáveis de correspondências que indicam a posição dos landmarks $c_{1: t}$ e por um conjunto de controle $u_{1: t}$. Baseado nesses dados, o algoritmo, primeiramente, inicializa um vetor contendo todas as posições que o robô esteve durante a coleta dos dados. Após isso, passos conhecidos como construção, redução e resolução são repetidos até que um limite desejado de precisão seja alcançado. Os detalhes referentes a cada um desses passos podem ser obtidos em Thrun et. al. (2005). O número de iterações depende do erro contido no vetor inicial de posições do robô. O mapa resultante é um vetor de médias $(\mu)$ que representa os relacionamentos espaciais dos landmarks e do caminho percorrido pelo robô.

Uma versão mais recente do EIF SLAM é o Sparse Extended Information Form Algorithm (SEIF) (Thrun et. al., 2004b). Nessa versão, o algoritmo realiza o mapeamento online, ou seja, durante a exploração do ambiente. O SEIF difere do EIF SLAM por manter uma matriz esparsa de informação. O principal motivo de manter uma matriz esparsa é computacional. Nesse caso, todas as equações de atualização do SEIF são executadas em tempo constante (Thrun et. al., 2004b).

\subsubsection{Formato Geométrico}

Além dos algoritmos descritos anteriormente, existem outros que se baseiam no formato geométrico básico de objetos presentes no ambiente, tais como: linhas, paredes, cantos, etc.. Essa idéia de representar o mapa por meio de formatos geométricos básicos, segundo Thrun (2002), foi introduzida no artigo apresentado em Chatila e Laumond (1985). Essa abordagem, também conhecida como mapeamento por objetos, apresenta várias vantagens em relação aos outros algoritmos, tais como: a representação do mapa é mais próxima da percepção humana; o mapa é mais compacto; e a detecção de objetos facilita o mapeamento de ambientes dinâmicos. Porém, o mapeamento por objetos é restrito a ambientes estruturados e é normalmente realizado em ambientes internos. Uma 
solução para essa restrição é parametrizar modelos de objetos com polígonos durante o mapeamento (Lui et. al., 2001).

Para lidar com as incertezas do sistema, a maioria desses algoritmos também usa métodos probabilísticos. Por exemplo, o sistema FINALE (Kosaka e Kak, 1992), que usa linhas para representar o mapa do ambiente num modelo CAD, lida com as incertezas de localização do robô e das linhas por meio do filtro de Kalman.

\subsubsection{Análise dos Algoritmos de Mapeamento e Localização}

Os algoritmos de mapeamento e de localização descritos anteriormente podem ser agrupados em algoritmos de mapeamento, de localização e de localização e mapeamento simultaneamente (SLAM), conforme apresentado na Figura 2.8. Na localização, o objetivo é associar os dados capturados por um sensor com os dados de um mapa previamente armazenado na memória do sistema controlador do robô. Já no mapeamento, o objetivo é gerar um mapa automaticamente, sendo a localização, nesse caso, informada manualmente. Por fim, o último grupo de algoritmos tem como objetivo gerar o mapa e localizar o robô simultaneamente. Esse último grupo é subdividido em dois: online e offline. No online encontram-se os algoritmos que geram o mapa durante a exploração do ambiente, já no offline os mapas são gerados somente após a coleta de todas as informações da região a ser mapeada. As técnicas offline são consideradas eficientes na resolução de ambiguidades, pois o processamento é realizado sobre todas as informações obtidas durante a fase de exploração do ambiente. Porém, consome uma grande quantidade de memória do sistema. Por outro lado, as técnicas online também são fortemente desejadas, dado que resolvem o mapeamento num modo incremental. Nesse sentido, o problema do SLAM continua recebendo atenção da comunidade científica, para que soluções cada vez menos restritas e mais robustas sejam criadas.

A Tabela 2.1 relaciona algumas características importantes dos algoritmos de mapeamento descritos nas subseções anteriores. Nessa tabela são identificados os seguintes aspectos: se o mapeamento é online, ou seja, se o mapa é criado durante a exploração do ambiente; como as informações são representadas no mapa, podendo ser landmarks 


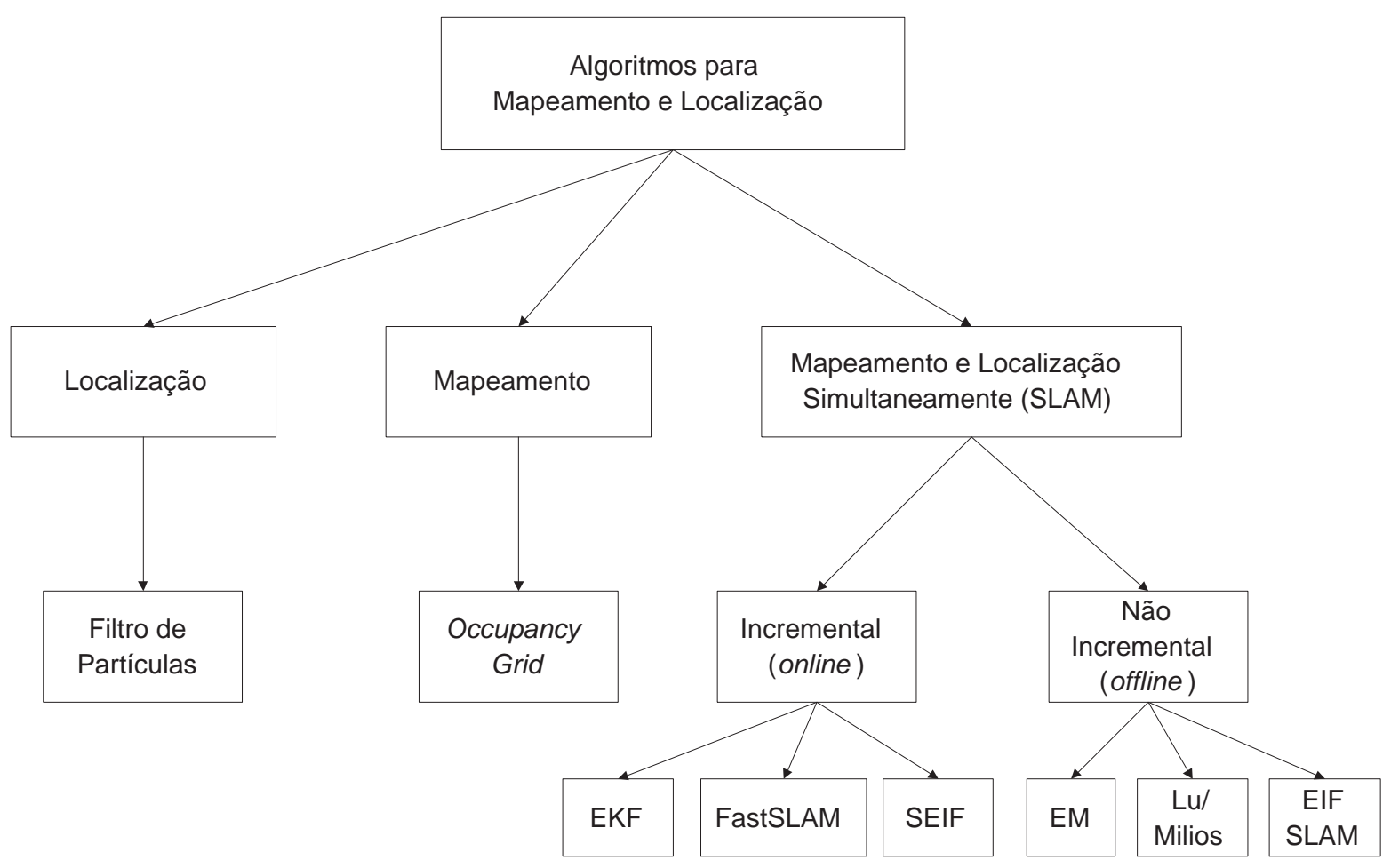

Figura 2.8: Classificação dos algoritmos estudados.

ou informações obtidas diretamente dos sensores (raw data); se a localização do sensor (leia-se robô) deve ser informada pelo usuário; qual é o custo computacional do algoritmo; e, finalmente, qual tipo de ruído dos sensores é esperado.

Como pode ser observado na Tabela 2.1, entre os métodos abordados, o FastSLAM demonstra ser um dos melhores para o mapeamento, pois é um algoritmo online e pode representar mapas com landmarks ou raw data. Uma das únicas desvantagens desta técnica está na definição do número de partículas necessárias para que o algoritmo funcione corretamente.

\subsection{Algoritmo do Filtro de Kalman}

O algoritmo do KF é dividido em duas fases: predição e atualização; também conhecidas na literatura como prediction e update, respectivamente. A predição serve para prever qual o valor as variáveis do vetor estado terão ao sofrer influência de um controle u. Enquanto a atualização tem a função de, a partir do dado lido de sensores $z_{n}$ e do novo valor do vetor estado (obtido na fase de predição), integrar essas informações e no- 
Tabela 2.1: Principais características dos algoritmos de mapeamento.

\begin{tabular}{|c|c|c|c|c|c|}
\hline Algoritmo & $\begin{array}{l}\text { Mapeamento } \\
\text { online }\end{array}$ & $\begin{array}{l}\text { Informações no } \\
\text { mapa }\end{array}$ & $\begin{array}{l}\text { Requer } \\
\text { localização do } \\
\text { sensor } \\
\text { informada pelo } \\
\text { usuário }\end{array}$ & $\begin{array}{l}\text { Complexidade } \\
\text { computacional } \\
\text { ( } n=\text { landmark e } \\
p=\text { partículas }\end{array}$ & Tipo de ruído \\
\hline KF e EKF & $\operatorname{sim}$ & landmark & não & $\phi\left(n^{2}\right)$ & Gaussiano \\
\hline PF e RBPF & $\operatorname{sim}$ & $\begin{array}{l}\text { (usado somente } \\
\text { para localizar o } \\
\text { sensor) }\end{array}$ & não & n.d. & qualquer \\
\hline FastSLAM & $\operatorname{sim}$ & $\begin{array}{l}\text { landmark ou } \\
\text { raw data }\end{array}$ & não & $\varnothing(p \log n)$ & $\begin{array}{lr}\text { Gaussiano } & \text { para } \\
\text { landmark } & \text { e } \\
\text { qualquer } & \text { para } \\
\text { posição } & \text { do } \\
\text { sensor } & \end{array}$ \\
\hline Lu/Milios & não & raw data & não & n.d. & Gaussiano \\
\hline EM & não & raw data & não & n.d. & qualquer \\
\hline $\begin{array}{l}\text { Occupancy } \\
\text { Grid }\end{array}$ & $\operatorname{sim}$ & raw data & sim & n.d. & qualquer \\
\hline EIF SLAM & não & landmark & não & n.d. & Gaussiano \\
\hline SEIF & $\operatorname{sim}$ & landmark & não & n.d. & Gaussiano \\
\hline
\end{tabular}

vamente atualizar as variáveis do vetor estado, sendo esse, o resultado final obtido após uma iteração do filtro, conforme pode ser visto na Figura 2.9.

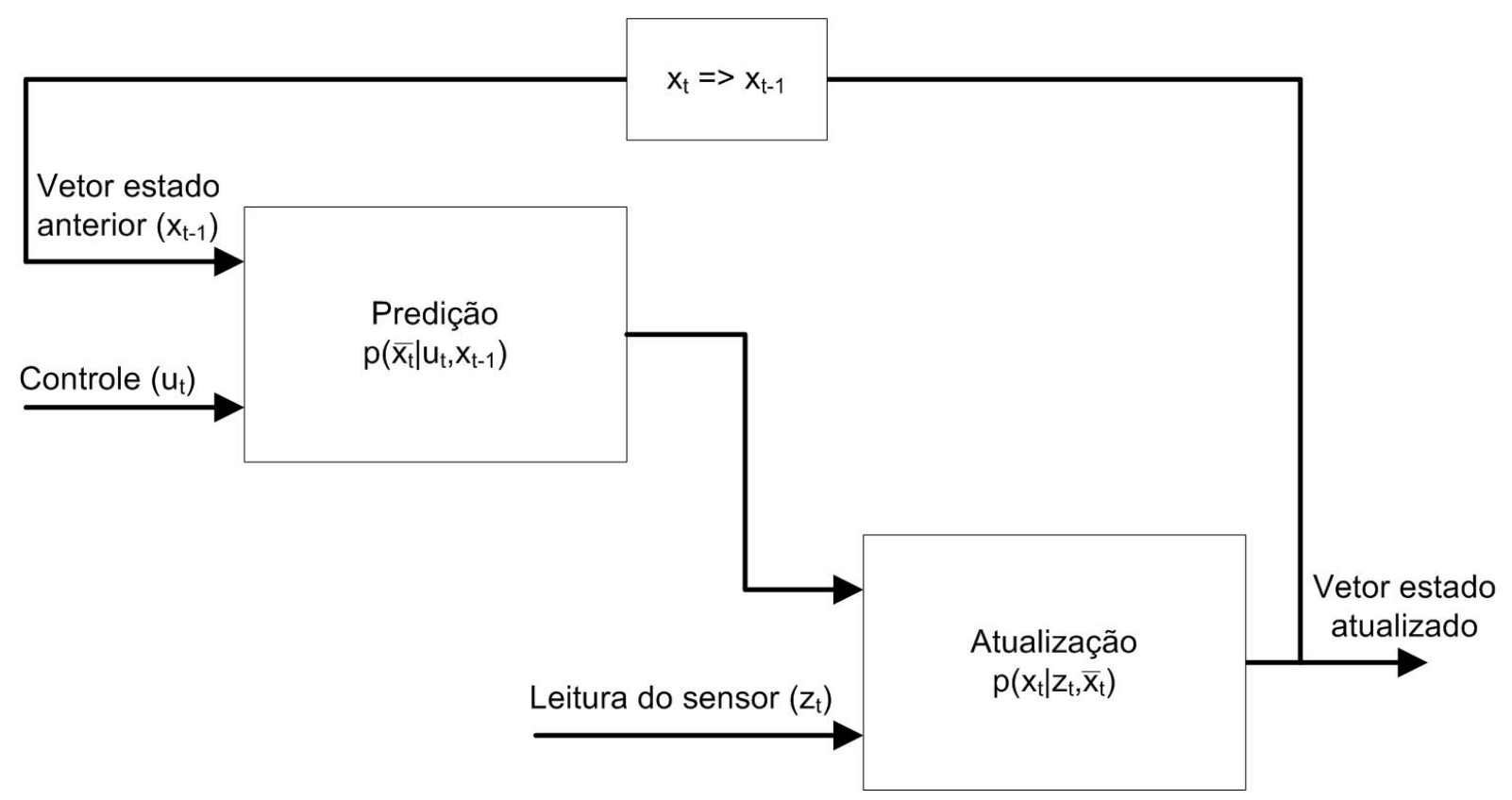

Figura 2.9: Estrutura geral do KF.

A fase de atualização do algoritmo do KF tem a função básica de integrar distribuições probabilísticas Gaussianas de estimativas independentes, a fim de obter como resultado uma nova distribuição probabilística, também Gaussiana, porém menos dispersa. Para isso, o filtro possui uma lógica que pondera os dados de entrada de acordo com a dispersão para que os mais precisos recebam maior peso e, consequentemente, influenciem com maior intensidade a resposta do filtro. Um exemplo simples usando uma distribuição de 
probabilidade unidimensional baseado em Maybeck (1979) é demonstrado na Figura 2.10. Note que a distribuição é representada no algoritmo do KF através dos dois primeiros momentos da Gaussiana, a média $(\mu)$ e a variância $\sigma^{2}$. Para entender esse exemplo, imagine que duas pessoas estejam num barco à noite perdidas no mar e usam como referência uma estrela para estimarem a sua posição, que para simplificar é considerada unidimensional. Uma das pessoas é um navegador experiente enquanto que a outra é um aprendiz. A parte (a) e (b) da Figura 2.10 representam as estimativas feitas pelos dois tripulantes, onde $z_{1}$ refere-se ao aprendiz e $z_{2}$ ao mais experiente. Como pode ser notado, $z_{1}$ é considerada menos precisa (maior dispersão) do que $z_{2}$ em função da menor experiência de navegação do aprendiz. Como resultado, a parte (c) da figura apresenta uma nova estimativa $(\mu)$, sendo essa mais precisa do que as outras duas e mais próxima da estimativa $z_{2}$. Isso ocorre graças à lógica de integração do KF que abstrai informações das estimativas feitas pelos dois tripulantes, porém dando mais peso para o navegador experiente.

As Equações 2.7 e 2.8 apresentam as fórmulas básicas que o KF usa para o cálculo da média e da variância de uma nova distribuição a partir de duas distribuições apresentadas ao filtro, sendo que na literatura essas equações geralmente são apresentadas num modo mais simplificado.

$$
\begin{gathered}
\mu=\left[\sigma_{z 2}^{2} /\left(\sigma_{z 1}^{2}+\sigma_{z 2}^{2}\right)\right] z_{1}+\left[\sigma_{z 1}^{2} /\left(\sigma_{z 1}^{2}+\sigma_{z 2}^{2}\right)\right] z_{2} \\
1 / \sigma^{2}=\left(1 / \sigma_{z 1}^{2}\right)+\left(1 / \sigma_{z 2}^{2}\right)
\end{gathered}
$$

O modo clássico usado para representar as Equações 2.7 e 2.8 é demonstrado nas Equações 2.11 e 2.12, respectivamente. Essas equações são obtidas a partir do desdobramento da Equação 2.9 e da substituição da parte que representa o peso pela variável $(\mathrm{K})$, conforme Equação 2.10.

$$
\mu=\left[\sigma_{z 2}^{2} /\left(\sigma_{z 1}^{2}+\sigma_{z 2}^{2}\right)\right] z_{1}+\left[\sigma_{z 1}^{2} /\left(\sigma_{z 1}^{2}+\sigma_{z 2}^{2}\right)\right] z_{2}=z_{1}+\left[\sigma_{z 1}^{2} /\left(\sigma_{z 1}^{2}+\sigma_{z 2}^{2}\right)\right]\left[z_{2}-z_{1}\right]
$$




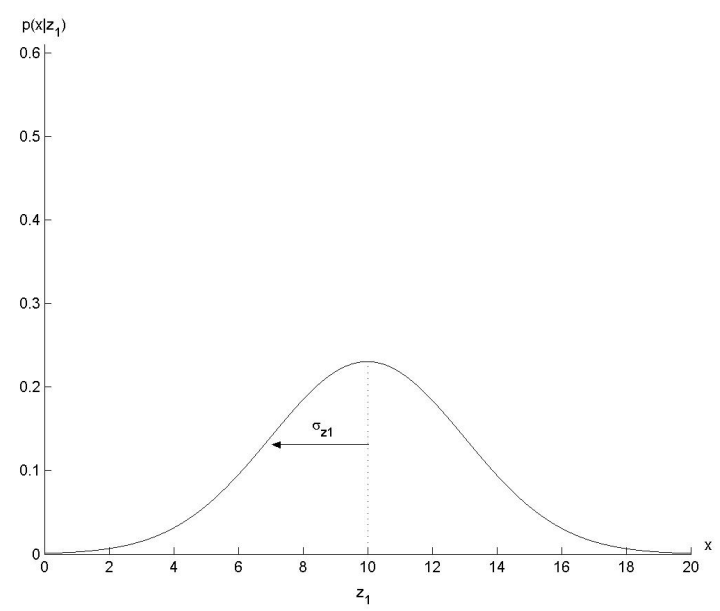

(a) Densidade condicional baseada na medida z1

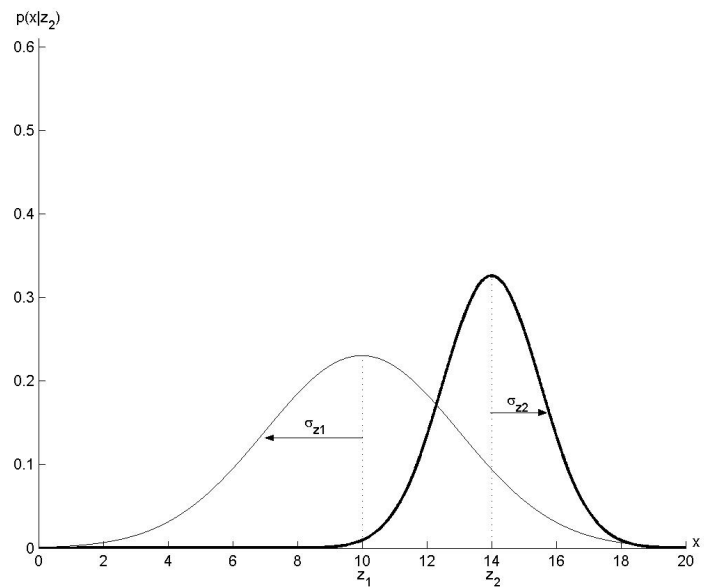

(b) Densidade condicional baseada na medida z2

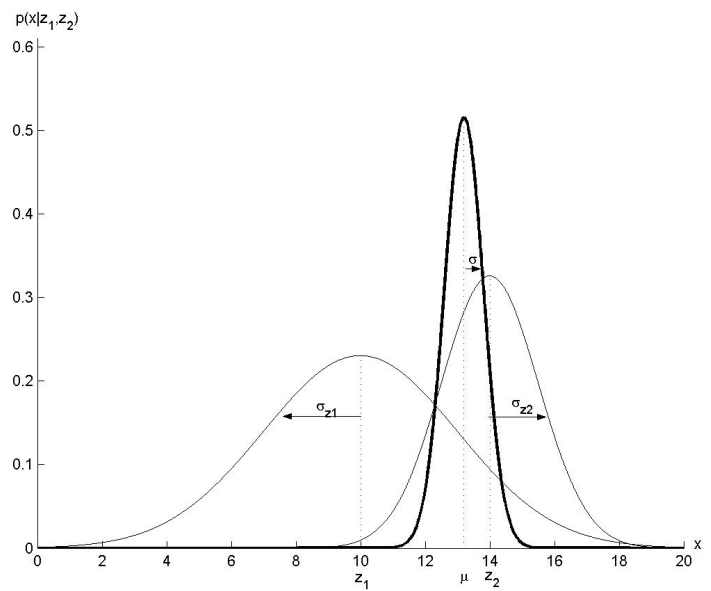

(c) Integração das densidades condicionais com o KF

Figura 2.10: Demonstração da integração de densidades probabilísticas no EKF. 


$$
\begin{gathered}
K=\sigma_{z 1}^{2} /\left(\sigma_{z 1}^{2}+\sigma_{z 2}^{2}\right) \\
\mu=z_{1}+K\left[z_{2}-z_{1}\right] \\
\sigma^{2}=\sigma_{z 1}^{2}-K \sigma_{z 1}^{2}
\end{gathered}
$$

O exemplo descrito anteriormente refere-se à fase de atualização do filtro, onde o resultado obtido é a resposta do filtro naquela dada iteração. A fase de predição usa essa resposta como realimentação de informação ao iniciar a próxima iteração, o que caracteriza a recursividade do KF. Baseado nessa informação e nos dados atuais de controle, as variáveis do vetor estado são novamente estimadas. Na robótica isso pode ser exemplificado quando o robô está numa posição estimada $x$ e executa um comando $u$ para mover-se até a posição y. A fase de predição busca maximizar a estimativa do valor da variável $y$ considerando não somente $x$ e $u$, mas também a perturbação do sistema causada pelo ruído $r$. A Figura 2.11 mostra a propagação de uma distribuição probabilística unidimensional influenciada pelo controle e pelo ruído, em que quanto maior o deslocamento do robô menor é a precisão da estimativa de sua posição. Nesse exemplo, $x_{t-1}$ e $\sigma_{t-1}$ podem corresponder à informação de realimentação do filtro vinda do estado anterior e $x$ e $\sigma$ a estimativa obtida considerando o controle e o ruído.

Para implementar o KF, além das fases descritas anteriormente, é necessário modelar para funções lineares o comportamento do sensor e do controle. Essa tarefa não é trivial, visto que na prática o comportamento do sensor e do controle geralmente não são lineares. Quando isso ocorre é necessário usar técnicas, como a série de Taylor com a matriz Jacobiana, para tornar as funções lineares. Nesse caso o KF passa a ser chamado de Filtro de Kalman Estendido (EKF). 


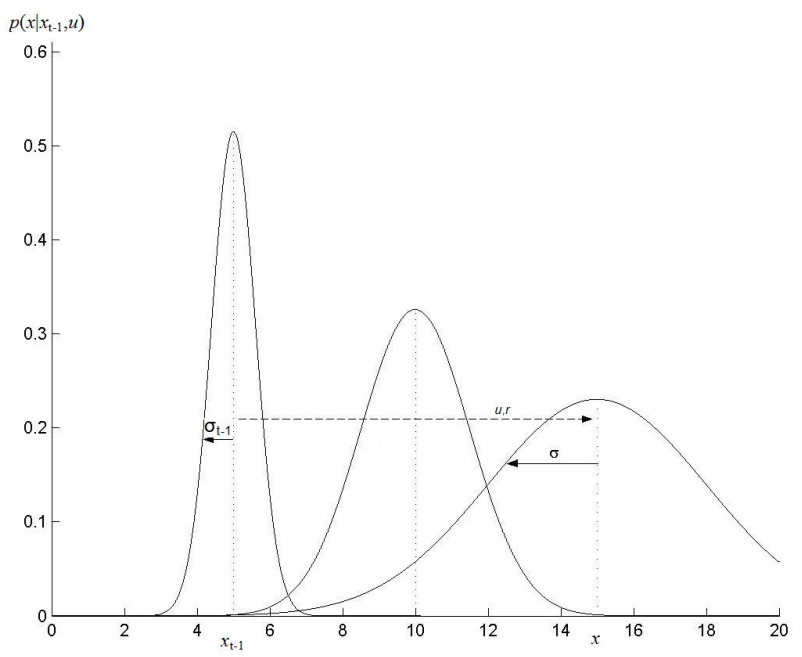

Figura 2.11: Propagação da densidade condicional influenciada pelo controle $u$ e ruído $r$, onde $x$ representa a posição unidimensional do robô e $\sigma$ a sua dispersão.

\subsection{Considerações Finais}

Neste capítulo, inicialmente, foram apresentados os conceitos de landmarks e mapas e em seguida uma revisão dos principais algoritmos base de desenvolvimento da maioria dos algoritmos de mapeamento de ambientes para a navegação de robôs móveis existentes na atualidade. Como pôde ser notado, o mapeamento implica na resolução de problemas difíceis, pois é necessário lidar com os ruídos dos sensores, tanto mecânicos como elétricos, e com as variações naturais do ambiente. Por isso, para tratar esses problemas a maioria dos algoritmos é baseada em técnicas probabilísticas que usam mapas estocásticos para armazenar as incertezas de estimação que são consideradas no procedimento de geração de mapas. Entretanto, existem algumas técnicas híbridas que buscam maximizar a expectativa sobre o mapa e a posição do robô sem armazenar as incertezas dos estados. Isso tem a vantagem de ser computacionalmente mais eficiente, mas a desvantagem de gerar mapas menos precisos. Os algoritmos de mapeamento descritos neste capítulo são voltados para sistemas que mapeiam com um único robô. No entanto, algumas extensões desses algoritmos também são aplicadas em mapeamentos com conjuntos de robôs que cooperam entre si. 


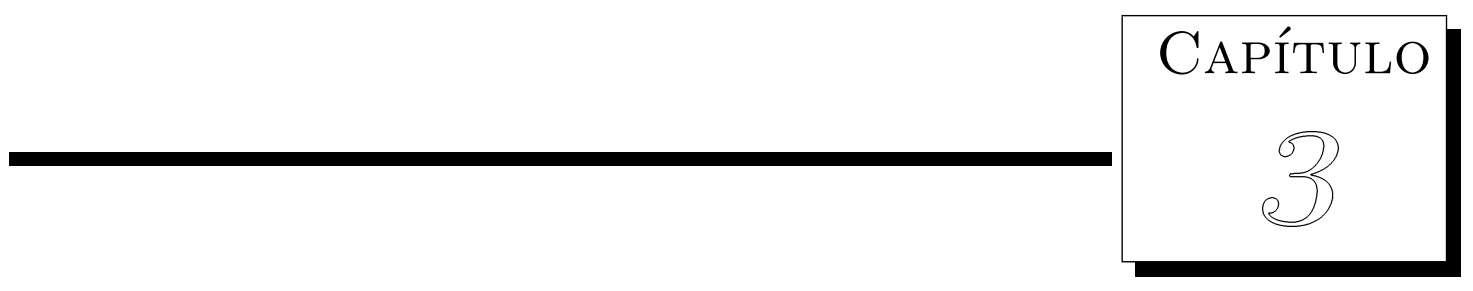

\section{Estado da Arte do SLAM com Visão}

O conteúdo apresentado neste capítulo tem como foco principal a exploração de algoritmos para a construção de mapas baseados em informações obtidas por sensores de imagem, que é a base da pesquisa desenvolvida. Inicialmente, são descritas as principais fases que compõem os algoritmos SLAM com visão. Em seguida, vários resumos de implementações atuais mostram o estado da arte do SLAM com visão monocular e visão binocular (estéreo), que são organizados em tabelas para facilitar sua análise comparativa. Finalmente, é apresentada uma revisão bibliográfica das implementações em hardware de dois algoritmos adotados para o desenvolvimento da arquitetura SLAM criada.

\subsection{Estrutura Geral dos Algoritmos SLAM com Visão}

A estrutura geral de um algoritmo para mapear e localizar simultaneamente com visão é formada pela integração das fases que realizam o processamento de imagem para a extração de características obtidas com visão monocular ou estéreo, que associam dados e que gerenciam mapas, conforme apresentadas na Figura 3.1. As principais diferenças entre as diversas abordagens do SLAM com visão existentes na literatura estão no tipo de 
algoritmo adotado para a implementação de cada uma dessas fases, as quais são descritas nas subseções seguintes.

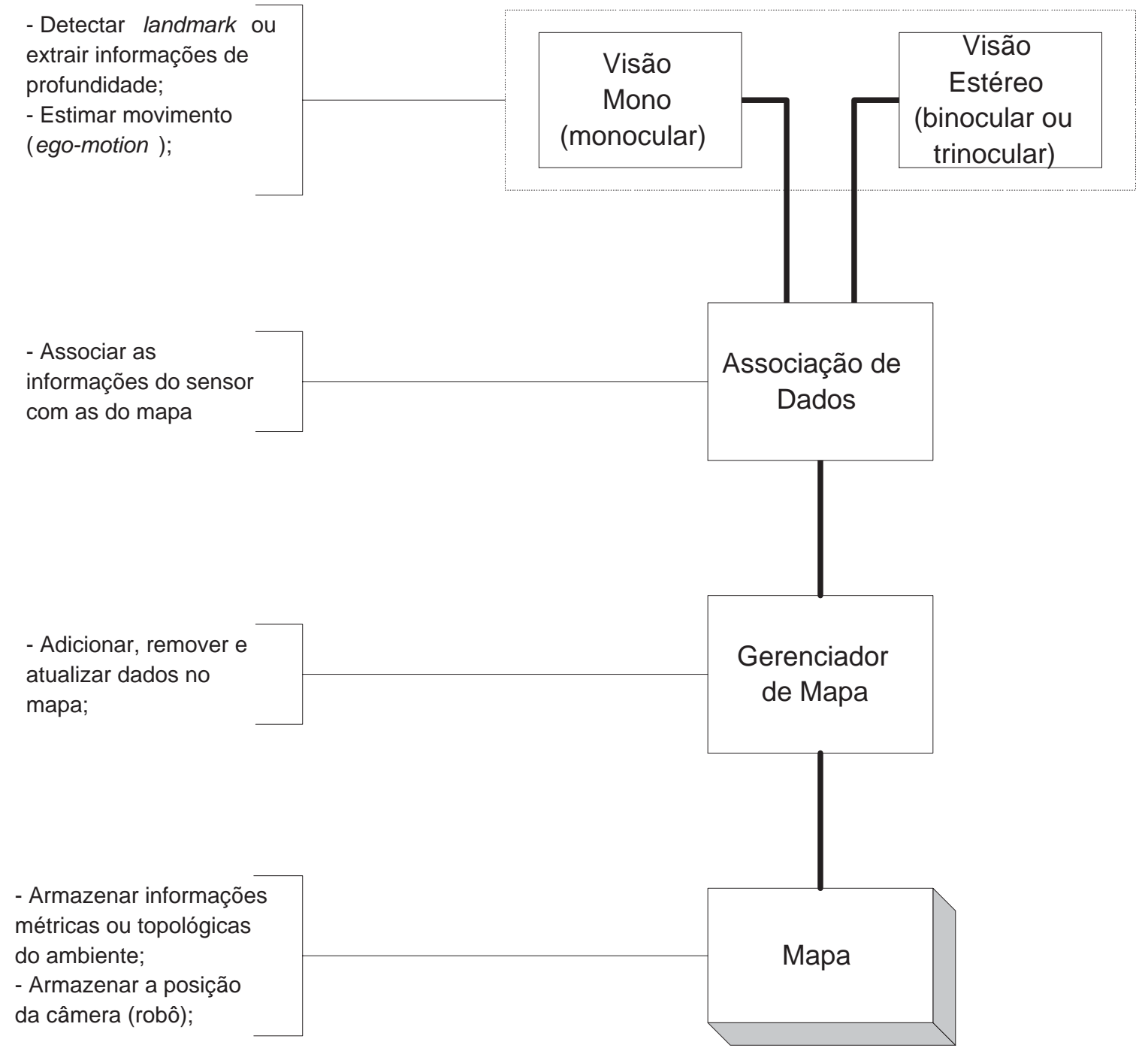

Figura 3.1: Estrutura geral do SLAM com visão

\subsubsection{Processamento de Imagem com Visão Monocular e Estéreo}

Os sensores utilizados para a aquisição das imagens nas implementações dos algoritmos SLAM baseados em visão nem sempre são especificados nos trabalhos publicados. No entanto, dentre as diversas tecnologias de sensores de imagem, as mais utilizadas atualmente são: CCD (Charged Coupled Device) e CMOS (Complementary Metal Oxide Semiconductor) (Company, 2003). Comparando CCD com CMOS, a tecnologia CCD fornece imagens de melhor qualidade e resolução, porém consome mais energia e seu preço 
é superior (Bonato, 2004). Apesar de, frequentemente, não ser justificada a escolha da tecnologia das câmeras adotadas nos projetos, a sua escolha é muito importante sempre que existir uma preocupação com a customização do sistema. Por exemplo, para os PRs, onde a relação custo, robustez, consumo de energia e tamanho são essenciais para o seu sucesso comercial.

Os trabalhos de SLAM com visão geralmente são desenvolvidos com visão monocular (uma câmera) ou estéreo (duas ou três câmeras), sendo o estéreo adotado com maior frequência. Essas câmeras também são, muitas vezes, usadas com espelhos a fim de aumentar o ângulo de visão. Esses sistemas são conhecidos como omnivision ou visão omnidirectional (Deccó, 2004). A grande diferença entre um sistema monocular e binocular está na maneira de extrair informação de profundidade do pixel da imagem. No estéreo, isso é realizado através da técnica de triangulação entre as imagens das câmeras, já na visão monocular, com a movimentação da câmera no espaço. Na visão estéreo, muitas vezes é utilizado um sistema trinocular com o objetivo de obter informações mais precisas de profundidade.

As informações extraídas das imagens, tanto na visão monocular como na estéreo, variam de acordo com o tipo de mapa a ser construído, com as características do ambiente e com os recursos de hardware disponíveis no sistema. Esses fatores motivam a exploração de diversos meios para buscar uma solução ao problema de mapeamento com visão. Por exemplo, em Diebel et. al. (2004) o mapa é construído com informações de profundidade dos pixels (raw data); em Folkesson et. al. (2005) com bordas (linhas) e lâmpadas acesas vistas de um teto; e em Davison (2003) com landmarks naturais extraídos do ambiente.

Apesar de existirem várias opções de como extrair dados de uma imagem para que sirvam de referência na construção de mapa e localização de robô, muitas dessas opções são exageradamente estritas a determinadas condições que dificilmente são mantidas em aplicações no mundo real. Isso pode ser notado no trabalho citado anteriormente, onde há uma implementação que utiliza como referência lâmpadas acessas. O ideal é utilizar como referência informações que não dependam de uma estrutura específica do ambiente, que sejam naturais e que permaneçam visíveis ao longo do tempo. 
Através das informações geradas pela visão também é possível estimar a movimentação do robô ou das câmeras no ambiente (ego-motion), conhecido na literatura como visual odometry ou visual motion estimation. Apesar de aumentar a complexidade dos algoritmos SLAM, essa técnica permite a exclusão de alguns sensores do rob, como por exemplo, o encoder.

\subsubsection{Associação de Dados}

O problema de associação de dados, em geral, consiste em comparar a leitura do ambiente por meio de sensores com o mapa armazenado na memória do sistema controlador do robô (Neira et. al., 1997). Em outras palavras, é o problema de determinar se dois landmarks observados de diferentes pontos no tempo correspondem ao mesmo landmark no mundo físico (Häehnel et. al., 2003). Um exemplo de associação de dado pode ser visto na Figura 3.2, onde dada uma imagem é necessário conhecer a sua relação com o mapa.

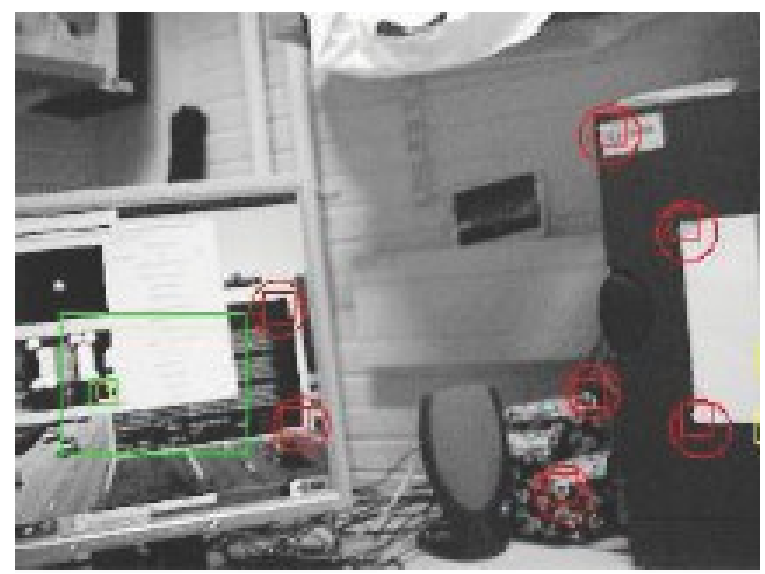

(a)

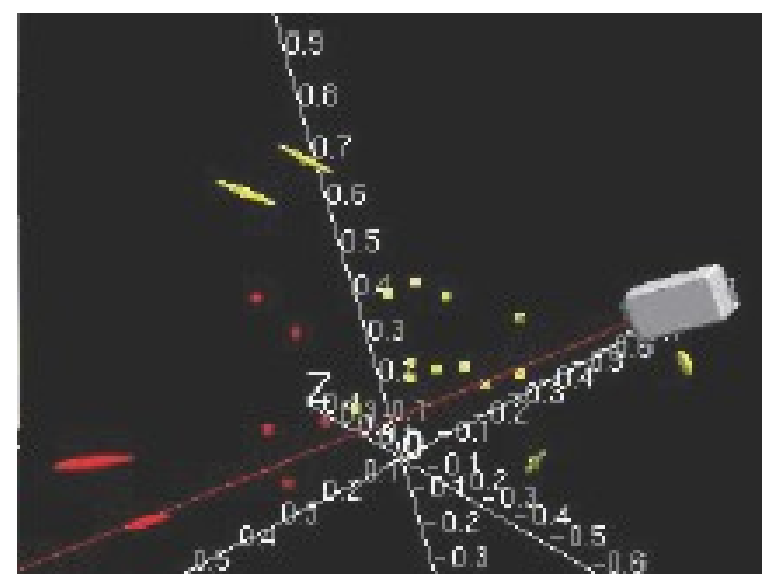

(b)

Figura 3.2: Um exemplo de associação de dado com imagem; (a) visão parcial do ambiente (b) modelo 3D do ambiente com landmarks das regiões já visitadas (Davison, 2003)

A associação de dados é abordada na literatura como um dos problemas mais complexos do SLAM. As dificuldades de associação ocorrem porque as condições do ambiente (ex. luminosidade) mudam com o passar do tempo, a posição do sensor (ex. escala, rotação e translação) varia entre leituras em tempos distintos e o número de possibilidades de associação cresce em relação ao número de elementos do mapa. Tudo isso ocasiona uma demanda maior de processamento computacional e um aumento da possibilidade de 
ocorrência de ambiguidade.

Segundo Häehnel et. al. (2003), a maioria das implementações de associação de dados geram todas as hipóteses no momento em que os dados dos sensores são lidos, sendo o maximum likelihood (ML) um exemplo clássico dessa estratégia. Soluções mais eficazes para esse problema no mapeamento de ambientes amplos e em situações em que ocorrem vários loops estão sendo investigadas, como a de Neira e Tardos (2001) que busca reduzir o número de associações incorretas; e a de Häehnel et. al. (2003) que busca revisar e reparar, quando necessário, associações de dados feitas anteriormente.

\subsubsection{Gerenciamento de Mapa}

Os mapas, que são uma representação virtual do ambiente na memória dos sistemas computacionais, geralmente, são estocásticos (Smith et. al., 1988) tendo seus dados representados pela média e matriz de co-variância (Thrun, 2002). Esses dados são atualizados, removidos ou adicionados durante a execução do algoritmo SLAM.

Na atualização, o objetivo é integrar informações obtidas de sensores de medida e de controle do robô para convergir num mapa mais preciso. Já o processo de remoção e adição de dados no mapa tem o objetivo de manter atualizada a representação do ambiente. Por exemplo, quando uma feature não for mais detectada numa região onde o sistema esperava detectá-la, ela pode ser removida e outra adicionada para substituí-la. A adição de feature também ocorre quando há necessidade de expansão do mapa para representar a exploração de novas regiões do ambiente.

\subsection{SLAM com Visão Monocular e Estéreo}

A seguir são apresentados diversos resumos de implementações atuais de algoritmos relacionados ao problema de simultaneamente mapear e localizar (SLAM) com a visão monocular ou binocular. Em cada resumo são exploradas, quando descritas nos artigos, as seguintes informações: o objetivo do trabalho, os algoritmos utilizados para a extração e associação de dados das imagens, o método probabilístico para lidar com os ruídos 
dos sensores, a estrutura do mapa, a forma de exploração do ambiente e os resultados alcançados nos experimentos. Os resumos são organizados em dois grupos, visão monocular e visão estéreo.

\subsubsection{Visão Monocular}

Neira et. al. (1997) descrevem um experimento para construir um mapa estocástico bidimensional de um ambiente interno baseado em bordas verticais e nas medidas de um encoder, tendo como propósito principal para esse mapa a localização do robô. As bordas são extraídas de esquinas verticais de corredores durante a exploração do ambiente, sendo as suas localizações e a do robô (2D) adicionadas ao mapa. O algoritmo de criação e atualização do mapa é baseado no EKF, sendo a ferramenta SPmodel utilizada para modelar a integração e a representação da incerteza. Os resultados apresentados não identificam precisamente o tipo de arquitetura utilizada no processamento e nem o tamanho do ambiente mapeado, tendo como foco principal a formulação matemática do algoritmo. Esse algoritmo mostrou que é possível resolver o problema do SLAM sem a informação de profundidade (distância da borda em relação a câmera). Porém, para que o mesmo funcione corretamente o ambiente deve ser estruturado para permitir a extração dessas bordas, o que se torna difícil de manter quando o ambiente, por exemplo, não for um corredor.

Pirjanian et. al. (2003) implementam um algoritmo SLAM, denominado vSLAM, de baixo custo para o uso em robôs pessoais ou domésticos. O vSLAM gera um mapa visual bidimensional que consiste de um conjunto de landmarks únicos. A publicação que descreve esse trabalho, provavelmente por ter finalidade comercial, não apresenta dados técnicos; simplesmente descreve que os landmarks são imagens capturadas durante o mapeamento do ambiente, não informando como são comparadas e associadas para compor o mapa. O algoritmo vSLAM usa como sensores uma câmera e um encoder. Como resultado experimental é apresentado o mapeamento de um ambiente interno de aproximadamente $1000 \times 700 \mathrm{~cm}$ com estimativa de erro de $10 \mathrm{~cm}$ nas coordenadas $\mathrm{x}, \mathrm{y}$ e de 5 graus no posicionamento da cabeça do robô. A plataforma de processamento 
utilizada não foi descrita; porém, está subentendido que não foi embarcada. Apesar de não haver dados técnicos, esse artigo mostra o potencial da visão para o algoritmo SLAM e enfatiza a redução de custo que pode ser alcançada com o uso da câmera em relação à implementação tradicional com sensor laser range finder e sonar.

Davison (2003) descreve um dos trabalhos mais bem sucedidos na área de mapeamento usando somente visão monocular. Em sua implementação é criado um mapa estocástico tridimensional do ambiente, contendo localizações de landmarks e da câmera, sendo todo o processamento executado em tempo real (30fps). Para construir o mapa, uma única câmera é transportada por uma pessoa no ambiente a fim de extrair features (landmarks) das imagens e inserí-las no mapa. As features são identificadas com o operador de saliência de Shi e Tomasi (1994) e o campo de visão (FOV) da câmera é de aproximadamente $100^{\circ}$, sendo em cada campo mantido aproximadamente 12 features. Ao detectar uma feature pela primeira vez a sua distância em relação à câmera (profundidade) é estimada a partir de um conjunto de partículas que são distribuídas uniformemente sobre uma linha semiinfinita 3D com origem na posição da câmera e que passa pelas possíveis localizações da feature. A distribuição dessas partículas são redefinidas frame após frame até que um determinado limiar de precisão seja alcançado e, consequentemente, a sua posição 3D seja definida. Nesse trabalho é apresentado o resultado para o mapeamento de um ambiente interno com desempenho em tempo real de 30 fps com imagem monocromática de $320 \times 240$ pixels, executando num desktop com processador Pentium IV 3GHz. Segundo o autor, esse desempenho pode ser mantido para mapas compostos de até 100 features, tendo em vista que a demanda computacional é de $\Theta\left(n^{2}\right)$, que é a mesma do KF, sendo $n$ o número de landmarks.

Meltzer et. al. (2004) propõem um algoritmo SLAM para criar um mapa tridimensional que consiste de uma base de dados composta por um conjunto de features e suas respectivas localizações. Para cada feature é associado um descritor a fim de incorporar as influências da variação de iluminação e do ângulo de visão durante o movimento da câmera no mapeamento. Esse descritor é usado para corrigir erros de ego-motion durante o processo de mapeamento, para localizar o robô quando ele retorna à uma posição já mapeada 
e para resolver o problema de kidnapped ${ }^{1}$. As features são selecionadas com o método de Shi e Tomasi, o descritor é gerado com o Kernel Principal Component Analysis (KPCA) e o ego-motion e o gerenciamento do mapa com o EKF. Esse sistema utiliza como sensor somente a visão monocular, sendo as features detectadas no espaço 2D e suas localizações no espaço 3D determinadas pelo EKF após a integração e várias medidas (tracking) no espaço 2D. Os experimentos foram realizados com imagens monocromáticas de $480 \times 640$ pixels e processados numa CPU Pentium IV 1,7GHz off-board. Para realizar o tracking de 200 features entre dois frames consecutivos foram necessários aproximadamente 300ms. Apesar da escassez de resultados, a idéia de associar um descritor a cada feature pode ser muito útil para aumentar a robustez das implementações dos algoritmos de SLAM com visão.

Karlsson et. al. (2005) apresentam, em alto nível de abstração, um algoritmo SLAM para gerar mapa bidimensional de ambiente interno baseado em landmarks naturais. Nesse trabalho o algoritmo é denominado vSLAM com o propósito semelhante ao descrito em Pirjanian et. al. (2003). Nessa proposta, os landmarks são detectados com o algoritmo SIFT (Scale-Invariant Feature Transform) (Lowe, 2004), que além de detectá-los, associa um código para torná-los únicos, simplificando com isso, o problema de associação de dados. Para estimar a movimentação do robô é usado um sensor encoder e as informações lidas com a câmera em sua posição atual. O algoritmo SLAM é implementado com o filtro de partículas para estimar as posições do robô e o EKF para estimar as posições dos landmarks. Um dos experimentos para validar o sistema ocorre numa sala de estar com área de $4000 \times 7000 \mathrm{~cm}$. As únicas informações descritas desse experimento são referentes ao erro de estimação dos elementos do mapa, que estão entre 20 e $25 \mathrm{~cm}$. O autor propõe uma extensão para essa implementação a fim de torná-la mais robusta em situações onde o ambiente possui poucos landmarks. Sua sugestão é adicionar uma câmera extra apontando para a traseira do robô para extrair mais informações do ambiente. Essa idéia de adicionar mais câmeras ao sistema a fim de torná-lo mais robusto, assemelha-se ao trabalho proposto neste documento.

\footnotetext{
${ }^{1}$ Localização definida sem informações a priori.
} 
Kim et. al. (2005) introduzem um novo método para implementar o algoritmo SLAM usando duas câmeras independentes. Uma nova formulação do filtro de Kalman e outra de gerenciamento de mapa são apresentadas. O mapa gerado é tridimensional, formado pela relação espacial de landmarks e das câmeras. O landmark é detectado usando o detector de cantos de Harris e Stephens (1988) e a sua localização espacial é obtida com um filtro de partículas. O movimento das câmeras é controlado pela mão e representado no algoritmo através dos parâmetros de velocidade angular e linear definidos pelo usuário. Nos experimentos foram usadas imagens com resolução de $640 \times 480$ pixels; uma câmera foi movida em círculos e a outra em uma linha diagonal de $0,9 \mathrm{~m}$. O principal resultado obtido com esse trabalho foi a redução da complexidade computacional do filtro de Kalman devido à aceleração de sua convergência. Com duas câmeras independentes a matriz de co-variância das câmeras e dos landmarks torna-se mais estável do que com uma única câmera, permitindo com isso fixar valores zero nos pontos considerados precisos.

Eade e Drummond (2006) propõem a integração do FastSLAM com a visão monocular para o mapeamento. Esse trabalho também introduz um novo método baseado no EKF para inicializar a estimação da distância de novos landmarks. Normalmente, com a visão monocular, na fase de inicialização de um landmark os dados referentes à sua localização são utilizados somente para melhorar a estimação de sua própria posição até o momento em que o mesmo for adicionado como um elemento do mapa. Com o novo método proposto, a informação na fase de atualização também passa a ser utilizada na estimação da posição da câmera. Isso se deve ao uso do inverso da distância para representar a posição do landmark na sua fase de inicialização. O sistema SLAM completo processado num Pentium IV 2,8GHz é capaz de gerar mapa tridimensional com 250 landmarks a uma taxa de atualização de 30 frames por segundo. Como o sistema é baseado no FastSLAM a taxa de atualização é praticamente linear em relação ao número de landmarks. Porém, segundo os autores, é difícil se determinar o número correto de partículas para mapeamento de ambientes grandes, sendo esse um dos problemas fundamentais do FastSLAM.

Montiel et. al. (2006) apresentam um método para estimar a distância dos landmarks similar ao proposto em Eade e Drummond (2006). Porém, nesse caso o cálculo da distância 
é embutido no próprio algoritmo de mapeamento, no caso o EKF. O landmark é adicionado ao mapa imediatamente após a sua detecção, ou seja, mesmo sem saber a sua real posição. Isso se tornou possível devido à codificação da distância através de seu inverso, possibilitando assim a formulação de um modelo linear para o EKF. As características do mapa produzido, o tipo de sensor e o algoritmo usado para detectar landmarks são semelhantes aos mencionados em Davison (2003), já que esse é uma extensão do mesmo. Porém, o tamanho do vetor de representação do landmark passou de três para seis. Assim, o desempenho do EKF é fortemente afetado, uma vez que a sua complexidade computacional é quadrática em relação ao número de elementos de sua matriz de co-variância. O artigo apresenta somente alguns resultados experimentais obtidos da ferramenta Matlab. Em Civera et. al. (2007) é apresentada uma evolução desse mesmo trabalho, onde é formulada uma técnica para converter de seis para três o número de variáveis que representam o landmark. Como resultado essa última versão processada num Pentium M $1,8 \mathrm{GHz}$ teve desempenho de 30 frames por segundo para mapas com aproximadamente 100 landmarks. A principal diferença entre o trabalho apresentado em Davison (2003) e Civera et. al. (2007) está na robustez do sistema para suportar melhor os movimentos da câmera.

\subsubsection{Visão Estéreo}

Sim et. al. (2005) propõem um algoritmo SLAM para construir, a partir de landmarks naturais, um mapa métrico tridimensional denso de um ambiente interno. Nessa abordagem o movimento do robô é estimado através da comparação da imagem capturada na posição origem e destino (visual odometry) e projetada por um conjunto de partículas do filtro Rao-Blaskwellised (RBPF). Cada landmark detectado é distinguido por um dado associado a ele através do algoritmo SIFT (Lowe, 2004), que segundo o autor, é robusto por ser invariante à escala, rotação, translação e parcialmente à iluminação. Para testar, foi coletado com um robô guiado manualmente 4000 frames num percurso de aproximadamente $68 \mathrm{~m}$ e em seguida, os dados foram processados numa CPU Pentium IV 2,6GHz. Apesar do mapa ser preciso, o tempo médio de processamento para cada frame foi de 
11,9s, inviabilizando seu uso em aplicações de tempo real, pois o tempo total de processamento para gerar o mapa foi de 13,2hs. Os pontos de gargalo do sistema foram identificados e possíveis soluções foram apontadas pelo autor.

Diebel et. al. (2004) apresentam um algoritmo SLAM para criar um mapa tridimensional globalmente consistente de ambiente cíclico a partir de um conjunto de frames, onde cada frame é composto por dados que representam a profundidade do ambiente ( raw data), sendo essa técnica semelhante à apresentada na Subseção 2.2.5. Para compor o mapa, cada frame capturado é alinhado com o seu antecessor e no final da exploração do ambiente todos os frames são novamente alinhados a fim de eliminar os erros do alinhamento local, fechando-se assim, o ciclo do mapa. O objetivo principal desse trabalho é estender o algoritmo ICP (Iterative Closest Point) (Chen et. al., 1994) usado no alinhamento local dos frames para lidar com os desafios do alinhamento de dados capturados em distâncias longas (long-range). Nesse trabalho é apresentado um teste de mapeamento de ambiente interno de $8 \times 8$ metros, onde a cada polegada de deslocamento um frame é capturado. O sistema é composto por duas câmeras para obter visão estéreo; um encoder para informar o deslocamento do robô; e um projetor para projetar padrões no ambiente. Apesar da proposta do algoritmo ser a construção de mapas globalmente consistentes, o mapa gerado não fechou o ciclo; e desse modo o autor propõe modificações na técnica para obter melhores resultados. O tempo de processamento para realizar esse experimento não é descrito no artigo.

Garcia e Solanas (2004) descrevem uma técnica para determinar a trajetória do robô e ao mesmo tempo para criar um modelo volumétrico tridimensional de seu ambiente (SLAM). Esse modelo volumétrico, que tem o formato semelhante a um mapa métrico tridimensional, é composto por um conjunto de landmarks capturados pela visão estéreo com o detector de Harris e Stephens e arranjados para representar o ambiente. A proposta desse trabalho é criar esse modelo volumétrico e localizar o robô somente com a visão estéreo, empregando técnicas de ego-motion para estimar o movimento do robô, evitando o uso de modelos matemáticos que as implementações tradicionais requerem para modelar o comportamento de encoder mecânico. Nesse trabalho foram apresentados dois 
experimentos de mapeamento: um para ambiente interno e outro externo; sendo os dois executados numa CPU Pentium III $850 \mathrm{MHz}$ embarcada no robô com imagem colorida de $320 \times 240$ pixels. Nos dois experimentos foram modelados apenas alguns metros do ambiente com o robô guiado manualmente em que o tempo de processamento foi elevado, sendo acima de 12 segundos para o ambiente interno e acima de 160 segundos para o ambiente externo.

Sáez e Escolano (2004) apresenta um algoritmo para criar um mapa bidimensional com a agregação de vários conjuntos de pontos tridimensionais extraídos da visão estéreo. O processo de criação é executado em duas fases: a primeira extrai features (pontos) da imagem estéreo e estima o movimento do robô (ego-motion) a partir do matching entre pontos de frames consecutivos; e a segunda cria o mapa com as informações geradas após a exploração de todo o ambiente. Em outras palavras, após a conclusão da primeira fase que corresponde a todas as posições em que o robô capturou frames. Na primeira e na segunda fases são aplicados refinamentos locais e globais, respectivamente, para reduzir as inconsistências do mapa. No local, o refinamento ocorre com funções criadas pelo próprio autor e no global com uma versão do algoritmo ICP. Como validação do sistema foram apresentados dois experimentos de mapeamento para ambiente interno utilizando imagens de $320 \times 240$ pixels; um processador Pentium IV 4,5GHz; e um robô guiado manualmente para capturar as imagens. O tempo de processamento nos dois experimentos foi de $0,3 \mathrm{~ms}$ para cada frame processado na primeira fase e de 2,5 s para cada iteração de minimização de erros do mapa; onde o número de iterações aplicadas foi de até 100 no primeiro e 200 no segundo experimento.

Jung e Lacroix (2003) descrevem um algoritmo SLAM para a construção de um mapa de elevação digital tridimensional de alta resolução de um terreno usando um balão dirigível (zepelim). A partir de landmarks naturais extraídos de imagens com o detector de Harris adaptável à mudança de escala, um algoritmo, através da associação de dados entre imagens capturadas sequencialmente, constrói o mapa do ambiente e localiza a câmera. O processamento é baseado somente em imagens e o ruído é tratado com o EKF. A sintonia do filtro é ajustada automaticamente por meio de técnicas de identificação de erros, tanto 
para os erros das posições dos landmarks como para a posição do robô. O mapa do terreno é construído sobre uma grade cartesiana regular com resolução 0,1 $m$. Para cada célula da grade é computado a elevação através da média das elevações dos pontos 3D verticalmente projetados sobre a célula, sendo o alinhamento desses pontos baseado nos landmarks. O sistema foi testado no mapeamento de uma área com aproximadamente $3500 \mathrm{~m}^{2}$, tendo sido coletados para isso 100 pares de imagens com $1024 \times 768$ pixels e detectados 320 landmarks. Apesar de criar um mapa detalhado somente com a visão, o processamento não foi embarcado no balão e a distância entre as câmeras para obter a profundidade da imagem é de 2,2 $m$ metros, o que pode ser incômodo em várias aplicações. O tempo de processamento off-board não foi especificado no artigo.

Se et. al. (2002) apresentam um algoritmo SLAM para gerar um mapa bidimensional composto por landmarks naturais detectados com o SIFT. O deslocamento da câmera (ego-motion) é calculado com os dados gerados pelo sensor de odometria (encoder) e através da minimização de erros usando o procedimento dos mínimos quadrados LeastSquares Minimization. Nesse artigo foram apresentadas duas implementações: a primeira sem considerar os erros do sistema e a segunda considerando os erros e utilizando o KF. Os experimentos foram realizados num ambiente interno com um robô guiado manualmente para explorar o ambiente e construir o mapa a partir de landmarks extraídos de imagens monocromáticas com resolução de $320 \times 240$ pixels. O desempenho do sistema foi cerca de $2 \mathrm{~Hz}$ para as duas implementações processadas num Pentium III 700 MHz embarcado no robô.

Murray e Jennings (1997) descrevem um algoritmo para construir um mapa occupancy grid bidimensional de um ambiente interno e estratégias de navegação para a exploração do ambiente utilizando técnicas de campos potenciais. As informações para preencher as células do mapa são obtidas de imagens de profundidade geradas pela visão estéreo. A localização do robô é determinada diretamente pela odometria (encoder). A arquitetura do sistema é dividida em duas partes: a primeira é embarcada no robô e é composta por DSPs e Transputers; e a segunda é uma estação de trabalho Sun Ultra Sparc 1. A função da primeira parte é informar a posição e orientação do robô com base no encoder e além 
disso, fornecer a linha de profundidade computada a partir de imagens com resolução de $128 \times 120$ pixels, as quais são obtidas diretamente das câmeras. Já a função da segunda parte é executar o algoritmo que gera o mapa e explora o ambiente. O desempenho do sistema foi de $2 \mathrm{~Hz}$ e pode explorar o ambiente a uma velocidade de $0,5 \mathrm{~m} / \mathrm{s}$.

\subsubsection{Análise dos Trabalhos}

De acordo com o estado da arte dos algoritmos SLAM com visão descritos anteriormente, pode-se observar que:

1. A maioria não executa em tempo real;

2. Tem elevado nível de restrição em relação ao ambiente;

3. São processados em plataformas não embarcadas;

4. A exploração do ambiente é manual;

5. A maioria das implementações usam métodos probabilísticos para lidar com as incertezas intrínsecas do mapeamento.

Essas e outras informações importantes referentes aos resumos são classificadas nas Tabelas 3.1 e 3.2. A Tabela 3.1 apresenta os dados para as abordagens com visão monocular e a Tabela 3.2 com visão estéreo. As colunas das tabelas apresentam as seguintes informações: a autoria dos trabalhos, os objetivos, os algoritmos base usados, o tipo de ambiente e seu modo de exploração, os tipos de sensores usados e, finalmente, as informações referentes ao processamento.

Como pode ser constatado nas Tabelas 3.1 e 3.2, os algoritmos SLAM com visão monocular e estéreo são a maioria aplicados em ambientes internos, usam o filtro de Kalman como base, não são embarcados, utilizam como referência landmarks naturais e não processam em tempo real. Isso mostra que os algoritmos SLAM baseados em visão precisam, principalmente, aumentar o desempenho. O aumento do desempenho, também reflete na dimensionalidade do mapa, que hoje ainda está limitada a apenas alguns metros. Outro dado importante é o tipo de arquitetura usada no processamento. 
Tabela 3.1: Principais características dos trabalhos relacionados ao SLAM com visão monocular explorados neste capítulo.

\begin{tabular}{|c|c|c|c|c|c|}
\hline Referências & Objetivos & $\begin{array}{l}\text { Algoritmos } \\
\text { base }\end{array}$ & $\begin{array}{l}\text { Ambientes e } \\
\text { explorações }\end{array}$ & $\begin{array}{l}\text { Sensores } \\
\text { auxiliares }\end{array}$ & Processamento \\
\hline $\begin{array}{l}\text { Neira et. al. } \\
(1997)\end{array}$ & $\begin{array}{l}\text { Apresentar uma formulação } \\
\text { matemática para construir um } \\
\text { mapa estocástico } 2 \mathrm{D} \text { baseado } \\
\text { em bordas verticais }\end{array}$ & EKF & Interno & Encoder & \\
\hline $\begin{array}{l}\text { Pirjanian et. } \\
\text { al. (2003) }\end{array}$ & $\begin{array}{l}\text { Mostrar uma implementação } \\
\text { de baixo custo para o uso em } \\
\text { robôs pessoais ou domésticos } \\
\text { de um algoritmo SLAM, deno- } \\
\text { minado pelo autor de vSLAM, } \\
\text { que gera um mapa visual bidi- } \\
\text { mensional com um conjunto de } \\
\text { landmarks únicos }\end{array}$ & - & Interno & Encoder & Não é embarcado \\
\hline $\begin{array}{l}\text { Davison } \\
(2003)\end{array}$ & $\begin{array}{l}\text { Criar um mapa probabilístico } \\
\text { 3D com landmarks naturais }\end{array}$ & $\begin{array}{l}\text { EKF } \\
\text { Operador de } \\
\text { Shi e Tomasi }\end{array}$ & $\begin{array}{l}\text { Interno } \\
\text { Manual }\end{array}$ & & $\begin{array}{l}\text { Não é embarcado } \\
\text { Pentium } 3 \mathrm{GHz} \\
320 \times 240(\mathrm{M}) \\
\text { Tempo real }\end{array}$ \\
\hline $\begin{array}{l}\text { Meltzer et. } \\
\text { al. }(2004)\end{array}$ & $\begin{array}{l}\text { Propor um algoritmo para } \\
\text { criar um mapa 3D com fea- } \\
\text { tures associadas a um descri- } \\
\text { tor que incorpora as influências } \\
\text { da variação de iluminação e do } \\
\text { ângulo de visão durante o mo- } \\
\text { vimento da câmera no processo } \\
\text { de mapeamento }\end{array}$ & $\begin{array}{l}\text { EKF } \\
\text { KPCA } \\
\text { Operador de } \\
\text { Shi e Tomasi }\end{array}$ & Interno & & $\begin{array}{l}\text { Não é embarcado } \\
\text { Pentium IV } \\
1,7 \mathrm{GHz} \\
640 \times 480(\mathrm{M}) \\
\text { Não é tempo real }\end{array}$ \\
\hline $\begin{array}{l}\text { Karlsson et. } \\
\text { al. (2005) }\end{array}$ & $\begin{array}{l}\text { Apresentar em alto nível de } \\
\text { abstração um algoritmo SLAM } \\
\text { para gerar mapa 2D de ambi- } \\
\text { ente interno baseado em land- } \\
\text { marks naturais }\end{array}$ & $\begin{array}{l}\text { FastSLAM } \\
\text { SIFT }\end{array}$ & Interno & Encoder & Tempo real \\
\hline $\begin{array}{l}\text { Kim et. al. } \\
(2005)\end{array}$ & $\begin{array}{l}\text { Propor um novo método } \\
\text { para implementar o algoritmo } \\
\text { SLAM com duas câmeras } \\
\text { independentes para gerar } \\
\text { um mapa 3D baseado em } \\
\text { landmarks naturais }\end{array}$ & $\begin{array}{l}\text { EKF } \\
\text { Harris- } \\
\text { Stephens }\end{array}$ & Interno & & Não é tempo real \\
\hline $\begin{array}{l}\text { Eade e } \\
\text { Drummond } \\
(2006)\end{array}$ & $\begin{array}{l}\text { Integrar o FastSLAM com a } \\
\text { visão monocular e introduzir } \\
\text { um novo método baseado no } \\
\text { EKF para inicializar a es- } \\
\text { timação da distância de novos } \\
\text { landmarks }\end{array}$ & $\begin{array}{l}\text { FastSLAM } \\
\text { EKF }\end{array}$ & Interno & & $\begin{array}{l}\text { Tempo real } \\
\text { Pentium } \\
2,8 \mathrm{GHz}\end{array}$ \\
\hline $\begin{array}{l}\text { Civera et. } \\
\text { al. (2007); } \\
\text { Montiel et. } \\
\text { al. }(2006)\end{array}$ & $\begin{array}{l}\text { Propor um método para o } \\
\text { cálculo da distância embutido } \\
\text { no próprio algoritmo de ma- } \\
\text { peamento (EKF) e formular } \\
\text { uma técnica para converter a } \\
\text { representação do inverso da } \\
\text { distância ( } 6 \text { variáveis) para um } \\
\text { sistema de coordenadas 3D ( } 3 \\
\text { variáveis) }\end{array}$ & $\begin{array}{l}\text { EKF } \\
\text { Operador de } \\
\text { Shi e Tomasi }\end{array}$ & $\begin{array}{l}\text { Interno e ex- } \\
\text { terno }\end{array}$ & & $\begin{array}{ll}\text { Tempo real } & \\
\text { Pentium } & \mathrm{M} \\
1,8 \mathrm{GHz} & \end{array}$ \\
\hline
\end{tabular}


Tabela 3.2: Principais características dos trabalhos relacionados ao SLAM com visão estéreo explorados neste capítulo.

\begin{tabular}{|c|c|c|c|c|c|}
\hline Referências & Objetivos & $\begin{array}{l}\text { Algoritmos } \\
\text { base }\end{array}$ & $\begin{array}{l}\text { Ambientes e } \\
\text { exploracõos }\end{array}$ & $\begin{array}{l}\text { Sensores } \\
\text { auxiliares }\end{array}$ & Processamento \\
\hline $\begin{array}{l}\text { Sim et. al. } \\
(2005)\end{array}$ & $\begin{array}{l}\text { Construir a partir de land- } \\
\text { marks naturais um mapa } \\
\text { métrico 3D denso de um } \\
\text { ambiente interno }\end{array}$ & RBPF & $\begin{array}{l}\text { Interno } \\
\text { Manual }\end{array}$ & & $\begin{array}{l}\text { Não é embarcado } \\
\text { Pentium IV } \\
2,6 \mathrm{GHz} \\
\text { Não é tempo real }\end{array}$ \\
\hline $\begin{array}{l}\text { Diebel et. al. } \\
(2004)\end{array}$ & $\begin{array}{l}\text { Estender o algoritmo ICP (Ite- } \\
\text { rative Closest Point) usado em } \\
\text { alinhamento local de frames a } \\
\text { fim de criar um mapa 3D glo- } \\
\text { balmente consistente com a in- } \\
\text { formação de profundidade da } \\
\text { imagem (raw data) }\end{array}$ & $\begin{array}{l}\text { EM } \\
\text { ICP }\end{array}$ & Interno & Encoder & \\
\hline $\begin{array}{l}\text { Garcia e So- } \\
\text { lanas (2004) }\end{array}$ & $\begin{array}{l}\text { Gerar um modelo volumétrico } \\
\text { 3D baseado em landmarks na- } \\
\text { turais }\end{array}$ & $\begin{array}{l}\text { Detector de } \\
\text { Harris }\end{array}$ & $\begin{array}{l}\text { Interno e Ex- } \\
\text { terno } \\
\text { Manual }\end{array}$ & & $\begin{array}{l}\text { Embarcado } \\
\text { Pentium III } \\
0,8 \mathrm{MHz} \\
320 \times 240(\mathrm{C}) \\
\text { Não é tempo real }\end{array}$ \\
\hline $\begin{array}{l}\text { Sáez e Esco- } \\
\text { lano (2004) }\end{array}$ & $\begin{array}{l}\text { Criar um mapa bidimensio- } \\
\text { nal agregando vários conjuntos } \\
\text { de pontos tridimensionais ex- } \\
\text { traídos da visão estéreo }\end{array}$ & $\mathrm{ICP}$ & $\begin{array}{l}\text { Interno } \\
\text { Manual }\end{array}$ & & $\begin{array}{l}\text { Não é embarcado } \\
\text { Pentium IV } \\
4,5 \mathrm{GHz} \\
320 \times 240 \\
\text { Não é tempo real }\end{array}$ \\
\hline $\begin{array}{l}\text { Jung e La- } \\
\text { croix (2003) }\end{array}$ & $\begin{array}{l}\text { Gerar um mapa de elevação di- } \\
\text { gital 3D de alta resolução de } \\
\text { um terreno usando landmarks } \\
\text { naturais e informação de pro- } \\
\text { fundidade da imagem }\end{array}$ & $\begin{array}{l}\text { EKF } \\
\text { Detector de } \\
\text { Harris }\end{array}$ & Externo & & $\begin{array}{l}\text { Não é embarcado } \\
1024 \times 768(\mathrm{M})\end{array}$ \\
\hline $\begin{array}{l}\text { Se et. al. } \\
(2002)\end{array}$ & $\begin{array}{l}\text { Apresentar um algoritmo } \\
\text { SLAM que gera uma mapa } \\
\text { bidimensional composto por } \\
\text { landmarks naturais invariantes } \\
\text { à escala, rotação, translação e } \\
\text { parcialmente à iluminação }\end{array}$ & $\begin{array}{l}\text { KF } \\
\text { SIFT } \\
\text { Least-Squares } \\
\text { Minimization }\end{array}$ & $\begin{array}{l}\text { Interno } \\
\text { Manual }\end{array}$ & Encoder & $\begin{array}{l}\text { Embarcado } \\
\text { Pentium III } \\
700 \mathrm{MHz} \\
320 \times 240(\mathrm{M}) \\
\text { Não é Tempo real }\end{array}$ \\
\hline $\begin{array}{l}\text { Murray } \quad \text { e } \\
\text { Jennings } \\
(1997)\end{array}$ & $\begin{array}{l}\text { Gerar um mapa occupancy grid } \\
\text { bidimensional de um ambi- } \\
\text { ente interno e apresentar es- } \\
\text { tratégias de navegação para a } \\
\text { exploração do ambiente utili- } \\
\text { zando técnicas de campos po- } \\
\text { tenciais }\end{array}$ & & $\begin{array}{l}\text { Interno } \\
\text { Automática }\end{array}$ & Encoder & $\begin{array}{l}\text { Parcialmente em- } \\
\text { barcado } \\
\text { Sun Ultra Sparc } 1 \\
128 \times 120(\mathrm{M}) \\
\text { Não é Tempo real }\end{array}$ \\
\hline
\end{tabular}


Como pode ser observado, a maioria não é embarcada no robô. Desse modo, grande parte dos trabalhos apresentados processam os dados offline, ou seja, o mapa é gerado somente após a exploração do ambiente.

\subsection{Implementações dos Algoritmos EKF e SIFT em FPGA}

Esta seção apresenta uma revisão bibliográfica das implementações dos algoritmos EKF e SIFT, enfatizando as implementações em hardware. Os mesmos foram escolhidos por serem amplamente utilizados no desenvolvimento de sistemas SLAM com visão, conforme pode ser notado nos trabalhos revisados nas seções anteriores. O EKF apesar de ter um custo computacional elevado é considerado uma das soluções atuais mais robustas para a geração de mapas. Já o SIFT, foi escolhido por ser uma das únicas soluções que detecta features invariante à escala e rotação; característica que é muito importante para o problema SLAM. O EKF e o SIFT também foram adotados como base para o desenvolvimento da arquitetura SLAM proposta neste trabalho.

\subsubsection{Algoritmo EKF}

Em Lee e Salcic (1997) é apresentada uma das primeiras implementações do KF em FPGA (as versões do EKF e KF possuem o mesmo núcleo de processamento, a principal diferença são os modelos, pois o EKF é somente uma extensão do KF para lidar com problemas não lineares). O trabalho propõe um co-processador para seguir alvos em sistemas de radares, que atingiu desempenho de 1,8 4 s para iteração do filtro. Esse trabalho mostra um ganho de desempenho de três a quatro vezes em relação às implementações disponíveis naquela época. Porém, o trabalho não informa o número máximo de alvos que podem ser seguidos a essa velocidade.

A partir desse período várias outras implementações em FPGA foram propostas em Liu et. al. (2007), Zhangxing e Xinhua (2002) e Salcic e Lee (2001). No entanto, nenhuma delas é específica para o problema do SLAM. Embora o núcleo do EKF seja basicamente igual entre as aplicações, a complexidade computacional depende de como as informações 
dos estados internos são representadas, atualizadas e expandidas. A principal diferença entre o EKF para SLAM e as implementações existentes em hardware é que a arquitetura para o SLAM precisa atualizar para cada iteração do filtro toda a matriz de co-variância para cada elemento sendo estimado pelo filtro, pois no SLAM os elementos/features e a posição do robô/sensores são estimados simultaneamente. Consequentemente, qualquer informação adicionada ao filtro precisa ser propagada através de todos os elementos, independente do mesmo ser ou não detectado no momento pelo sensor. Assim, a arquitetura proposta na Seção 5 para o EKF está concentrada, além de uma eficiente implementação do núcleo, em reduzir o gargalo de acesso à memória externa através da exploração do reúso de dados on-chip e da distribuição dos dados entre quatro bancos de memória externa.

Nos últimos anos, também houve um interesse significativo na redução da complexidade computacional para o SLAM em implementações baseadas em sofware por meio da redução do esforço computacional necessário para atualizar a matriz de co-variância do filtro. Uma abordagem comum é a divisão do mapa global em conjuntos de mapas locais e a atualização localmente (Paz e Neira, 2006; Estrada et. al., 2005). Outro método adotado é também parar a atualização dos elementos do mapa que possuem baixa variância (Kim et. al., 2005). Algumas pesquisas também estão concentradas na otimização de memória necessária para o EKF (Guivant e Nebot, 2003).

Embora tenham ocorridos avanços significativos do EKF para o SLAM em software, pouca atenção parece ter sido dada em relação às arquiteturas de hardware. Porém, é possível aumentar o desempenho do sistema por meio da criação de hardware especializado para o EKF aplicado ao SLAM. Além disso, hardware dedicado tende a consumir menos energia que as plataformas de processamento genéricas, o que é considerado muito importante para os robôs móveis alimentados por baterias.

\subsubsection{Algoritmo SIFT}

Um dos primeiros algoritmos usados na detecção de pontos de interesse de imagens e aplicado ao problema de associação (matching) de imagens foi proposto por Harris e 
Stephens (1988), sendo esse uma extensão do algoritmo detector de cantos (corner) proposto por Moravec (1980), que extrai pontos de interesse de bordas e de regiões entorno de cantos baseado na informação da magnitude do gradiente. Embora o algoritmo de Harris e Stephens seja sensível à mudança de escala da imagem (Lowe, 2004), ele tem sido amplamente usado como base em problemas de tracking e na associação de imagens em sistemas estéreo. Shi e Tomasi também propuseram um sistema para detectar features por meio da análise do comportamento da intensidade dos pixels dentro de uma determinada região entorno da feature durante a operação de tracking (Shi e Tomasi, 1994). Esse método para monitorar o comportamento é eficiente para rejeitar pontos que desaparecem em diferentes viewpoints e é robusto para transformações de affine. Porém, como ele é baseado na variação da intensidade dos pixels, o mesmo é sensível a mudanças de iluminação.

A partir dessas contribuições importantes tem havido um esforço contínuo para desenvolver algoritmos robustos para detectar features invariante a transformações de rotação, escala, affine e mudança de iluminação (Shokoufandeh et. al., 1999; Mikolajczyk e Schmid, 2004). Entre todas essas propostas, Lowe (2004) apresenta uma das soluções mais completas e robustas da atualidade, que é referencia como SIFT.

Quando completamente implementado, o SIFT tem alto custo computacional, o que tem levado a propostas otimizadas do mesmo (Ke e Sukthankar, 2004; Grabner et. al., 2006). Para uma configuração típica, um computador pessoal com um processador Intel Core 2 1.66GHz demora aproximadamente um segundo para processar uma imagem de $320 \times 240$ pixels. Em Se et. al. (2004) é demonstrada uma versão modificada do SIFT implementada em FPGA empregado num sistema de visão estéreo para navegação de robôs, que apresenta desempenho 10 vezes melhor do que um Pentium III 700MHz (de 600ms para $60 \mathrm{~ms}$ para imagens de $640 \times 480$ pixels). No entanto, esse trabalho não exibe detalhes da arquitetura e nem discute como foram implementados em hardware as verificações de estabilidade existentes no SIFT.

Em Pettersson e Petersson (2005) uma implementação parcial do algoritmo SIFT em FPGA para calibração de um sistema estéreo é demonstrada. O trabalho apresenta 
uma arquitetura para detectar pixels candidatos a features a uma taxa de 60 frames por segundo. Porém, não há informação referente à resolução da imagem e nem aos recursos de hardware do FPGA necessários. Outro sistema baseado em FPGA para o SIFT está presente em Chati et. al. (2007), onde são necessários 0, $8 m s$ para processar uma imagem de $320 \times 240$ pixels. Entretanto, novamente, pouca informação sobre o hardware é fornecida.

\subsection{Considerações Finais}

O problema da implementação de algoritmos SLAM está muito bem difundido na área da robótica móvel, tendo convergido para implementações que têm como base sensores de distância (range sensors) para capturar dados do ambiente, sendo o laser range finder o principal. Atualmente, essa vertente já apresenta soluções para problemas reais do SLAM na robótica móvel, como por exemplo, o apresentado em Thrun et. al. (2004a). No entanto, existe uma outra vertente promissora para o SLAM que é a baseada em sensor de imagem. A imagem é uma fonte rica de informações. Porém, é facilmente afetada por interferências externas, como a variação de luminosidade, e produz uma grande quantidade de dados, exigindo recursos avançados para o seu processamento em tempo real.

De acordo com o estado da arte das implementações de algoritmos SLAM baseados em visão, o grande desafio está em romper a barreira do desempenho mantendo a robustez, para atingir o processamento em tempo real em arquiteturas embarcadas nos robôs. Um dos poucos trabalhos que conseguiram romper essa barreira foram os de Civera et. al. (2007) e Davison (2003), conforme descritos anteriormente. No entanto, o seu uso na robótica ainda possui algumas restrições: o espaço de mapeamento é limitado a algumas centenas de landmarks e o movimento da câmera é restringido.

As propostas de SLAM mais recentes com visão apresentam uma tendência para o uso da visão monocular ao invés da estéreo (Sola et. al., 2007). Apesar da visão estéreo ser mais fácil de se utilizar, a visão monocular apresenta algumas vantagens importantes, como a possibilidade de representar landmarks em qualquer posição, inclusive no infinito. Assim, um landmark pode ser adicionado ao mapa do ambiente a partir de sua primeira 
visualização (primeiro frame) na imagem, mesmo não sabendo a sua distância real em relação à câmera. Esse tipo de informação é útil, principalmente, para a estimação da orientação da câmera (Civera et. al., 2007).

Fazendo uma análise dos trabalhos apresentados nesse capítulo é possível constatar que o SLAM com visão tem sido explorado com maior frequência nos últimos anos, mas poucas soluções podem ser aplicadas em problemas práticos da robótica móvel, pois são geralmente implementadas em plataformas de hardware de propósito geral (desktop) não embarcadas nos robôs, e o processamento não é em tempo real. Embora a análise das implementações em hardware para os algoritmos EKF e SIFT apontem alguns trabalhos já realizados nesse sentido, ainda há uma necessidade de investigação nessa área para que soluções completas, totalmente embarcadas e de tempo real sejam construídas. 



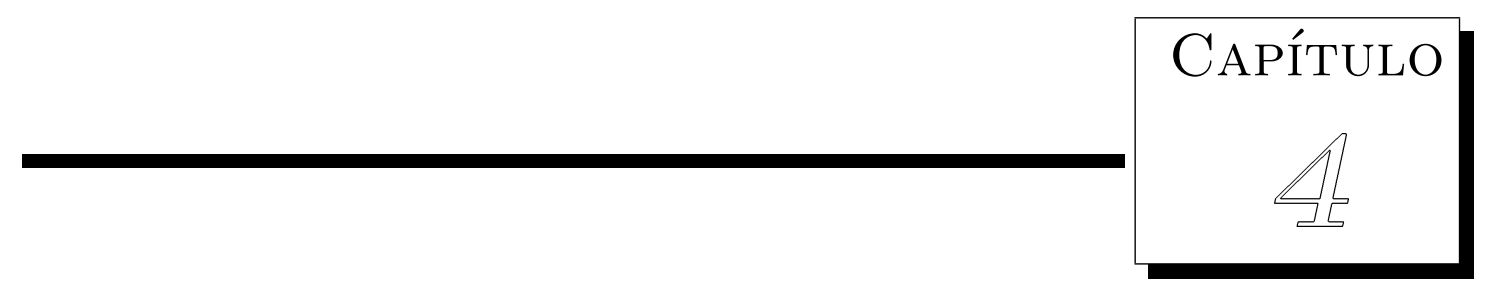

\title{
A Arquitetura de Hardware Desenvolvida em
}

\author{
FPGA para o SLAM
}

Este capítulo introduz a arquitetura para o SLAM embarcada num dispositivo de FPGA desenvolvida nesta pesquisa. Esta arquitetura dispõe de recursos de hardware e software para as seguintes funcionalidades: integração do robô com a plataforma de desenvolvimento em FPGA (Wolf et. al., 2006, 2007); aquisição de imagens de até quatro câmeras em tempo real (Bonato et. al., 2006a,b); processamento do filtro de Kalman estendido (EKF) para o mapeamento e a localização (Bonato et. al., 2007a,b, 2008a) e extração de features de imagens baseado no algoritmo SIFT (Bonato et. al., 2008c,b). Além disso, são apresentados modelos matemáticos do controlador de movimentos do robô e dos sensores de imagem e um método básico para a estimação da posição das features em relação à câmera usando visão monocular. A Figura 4.1 exibe, em alto nível de abstração, um diagrama de blocos com os módulos da arquitetura desenvolvida em FPGA. Todos esses módulos foram implementados e validados nas plataformas de desenvolvimento NIOS II da Altera (Altera, 2007b) e RC250 da Celoxica (Celoxica, 2005b), sendo a primeira equipada com um FPGA Stratix II 2S60 e a segunda Stratix II 2S90. 

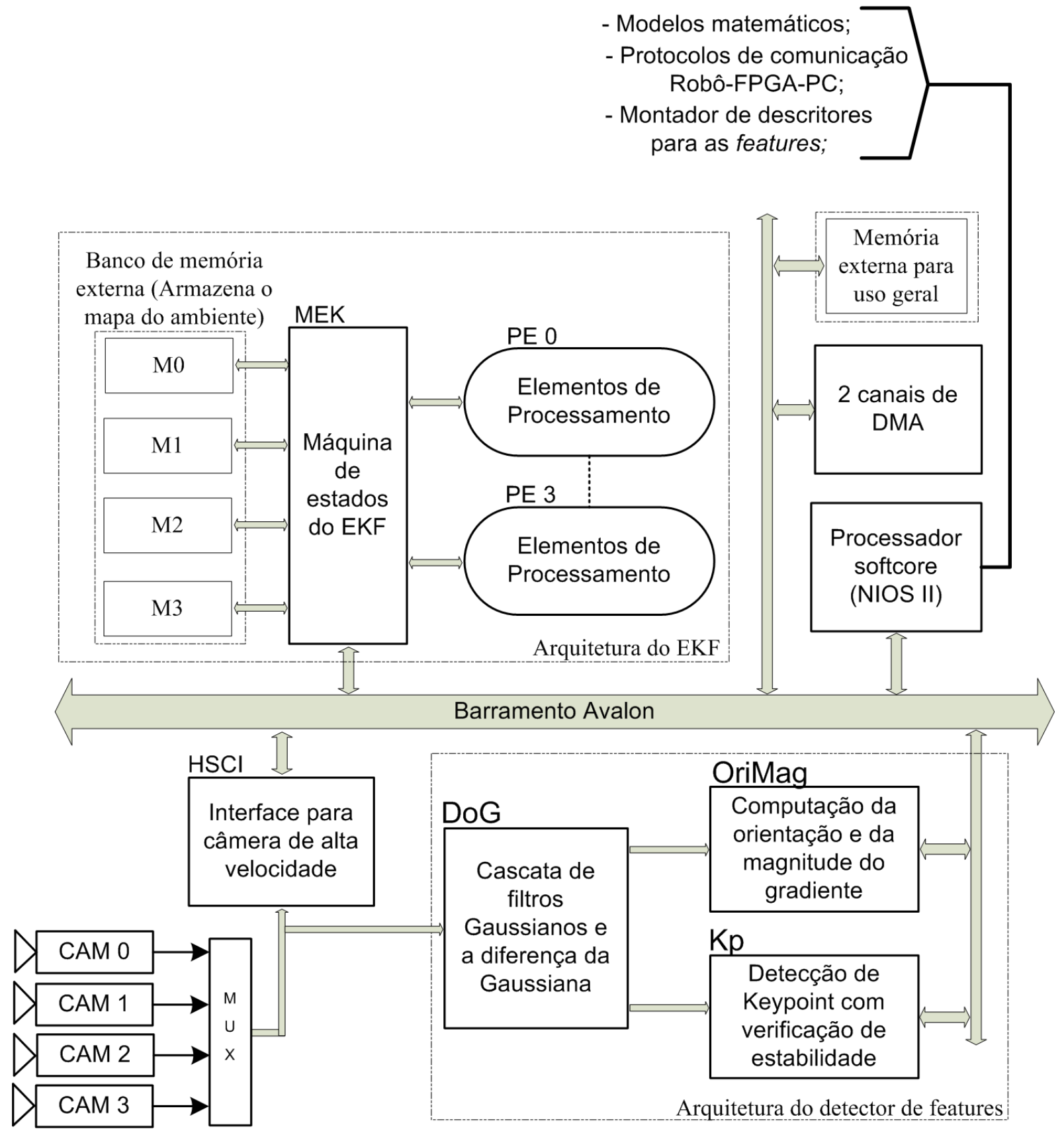

Figura 4.1: Arquitetura geral do sistema SLAM proposto embarcado em hardware reconfigurável, onde basicamente há três blocos de hardware: um para o processamento do EKF, um para a detecção de features e outro para a configuração e a leitura de pixels em alta velocidade das câmeras. Além disso, há um processador softcore usado para o processamento dos modelos matemáticos do EKF, para a montagem dos descritores das features e para a comunicação via Ethernet entre FPGA-Robô-PC. 
Os módulos principais e de maior complexidade dessa arquitetura SLAM são os do EKF e da extração de features, pois ambos envolvem implementações de hardware sofisticadas com alto nível de paralelismo e de otimização. Desse modo, esses módulos são apresentados separadamente nos Capítulos 5 e 6 , onde o primeiro descreve a arquitetura do EKF e o segundo a arquitetura do sistema de extração de features. Porém, as outras funcionalidades da arquitetura SLAM e os modelos matemáticos são descritos neste Capítulo. A Seção 4.1 descreve a integração da plataforma de desenvolvimento em FPGA com o sistema de controle do robô. Em seguida, a Seção 4.2 apresenta o sistema de aquisição de imagens. Por fim, a Seção 4.3 exibe os modelos matemáticos e a Seção 4.4 descreve as considerações finais.

\subsection{Integração do FPGA com o Controlador do Robô Móvel}

A integração do hardware do robô com a plataforma de desenvolvimento em FPGA é feita por meio de uma interface Ethernet. Por outro lado, a integração do software é feita por meio de uma interface baseada no sistema Player (Gerkey et. al., 2001), que é um modelo cliente-servidor amplamente utilizado pela comunidade científica para a comunicação e o controle dos dispositivos existentes nos robôs móveis, tais como o controle da velocidade dos motores e a leitura de encoders. O robô móvel utilizado é o Pioneer 3-DX (ActivMedia Robotics, 2006) e o FPGA é o Stratix II da Altera (Altera, 2007b).

O player utiliza o modelo cliente-servidor baseado em sockets. O cliente é executado na aplicação, que nesse caso está no processador NIOS II configurado no FPGA, e o servidor é executado num processador Pentium $M$ instalado na base do robô. Assim, qualquer requisição de dados ou envio de comandos entre o robô e o FPGA é realizado por meio de pacotes trocados entre o servidor e o cliente Player. Como no FPGA o cliente Player é executado no processador NIOS II, foi necessário portar a versão original do Player utilizada em PCs para o processador embarcado NIOS II, onde basicamente foram feitas adaptações nos componentes envolvidos na comunicação via socket.

A escolha do Player está relacionada às seguintes características: a operação é remota e transparente pela rede; a comunicação baseada em sockets é simples; os clientes 
podem ser implementados em C; é uma interface que suporta grande quantidade de plataformas robóticas e sensores comerciais; e é um software livre. Além disso, o cliente (aplicação) pode conectar-se a múltiplos servidores (robôs) e os servidores aceitam conexões de múltiplos clientes (aplicação). Finalmente, esse ambiente é compatível com simuladores, o que permite a realização de experimentos com robôs virtuais, reduzindo-se com isso a probabilidade de danificar o robô real enquanto o algoritmo encontra-se em fase de desenvolvimento e teste.

\subsection{Sistema de Aquisição de Imagens}

A plataforma de desenvolvimento em FPGA está equipada com quatro câmeras CMOS que permitem uma visão de praticamente todo o entorno do robô. A Figura 4.2 apresenta essa plataforma embarcada na base do robô Pioneer 3DX. As câmeras podem ser configuradas e lidas via software no processador NIOS II através do componente de hardware HSCI (High Speed Camera Interface) desenvolvido especificamente para essa função, o qual está conectado ao barramento Avalon da arquitetura SLAM. A configuração é realizada por meio de uma interface $I^{2} C$ (Inter-Integrated Circuit), também implementada nesse componente, onde o usuário pode definir, por exemplo, a taxa de frames por segundo, os modos de controle de brilho e a resolução das imagens. Por outro lado, a parte do componente que realiza a leitura em alta velocidade dos pixels das câmeras, além de servir de interface com o sensor de imagem, ele controla, por meio de um canal de DMA, o fluxo de dados entre a câmera e a memória principal do processador NIOS II implementado. Esse sistema de aquisição de imagens, visto na Figura 4.3, suporta uma taxa de transferência de até 30 frames por segundo para imagens com resolução de $320 \times 240$ pixels.

O sistema de aquisição de imagens pode ser utilizado localmente no processador NIOS II ou ainda remotamente através de um conexão via socket com um PC. O uso remoto é importante para a criação de base de dados offline, geralmente utilizada para validar os algoritmos em fase de desenvolvimento. Para isso, desenvolveu-se um software para PC capaz de controlar remotamente a velocidade e direção do robô e de visualizar e salvar em 

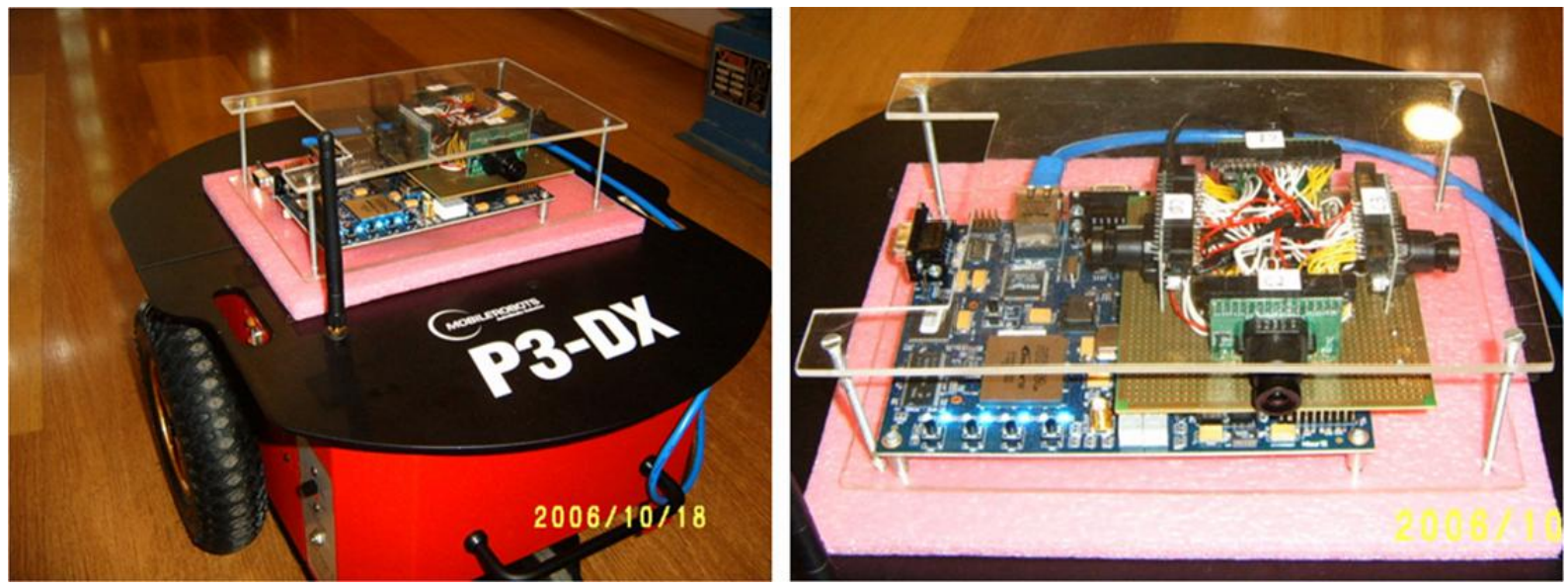

Figura 4.2: Sistema multi-câmeras implementado em FPGA e embarcado na plataforma do robô Pioneer 3DX.

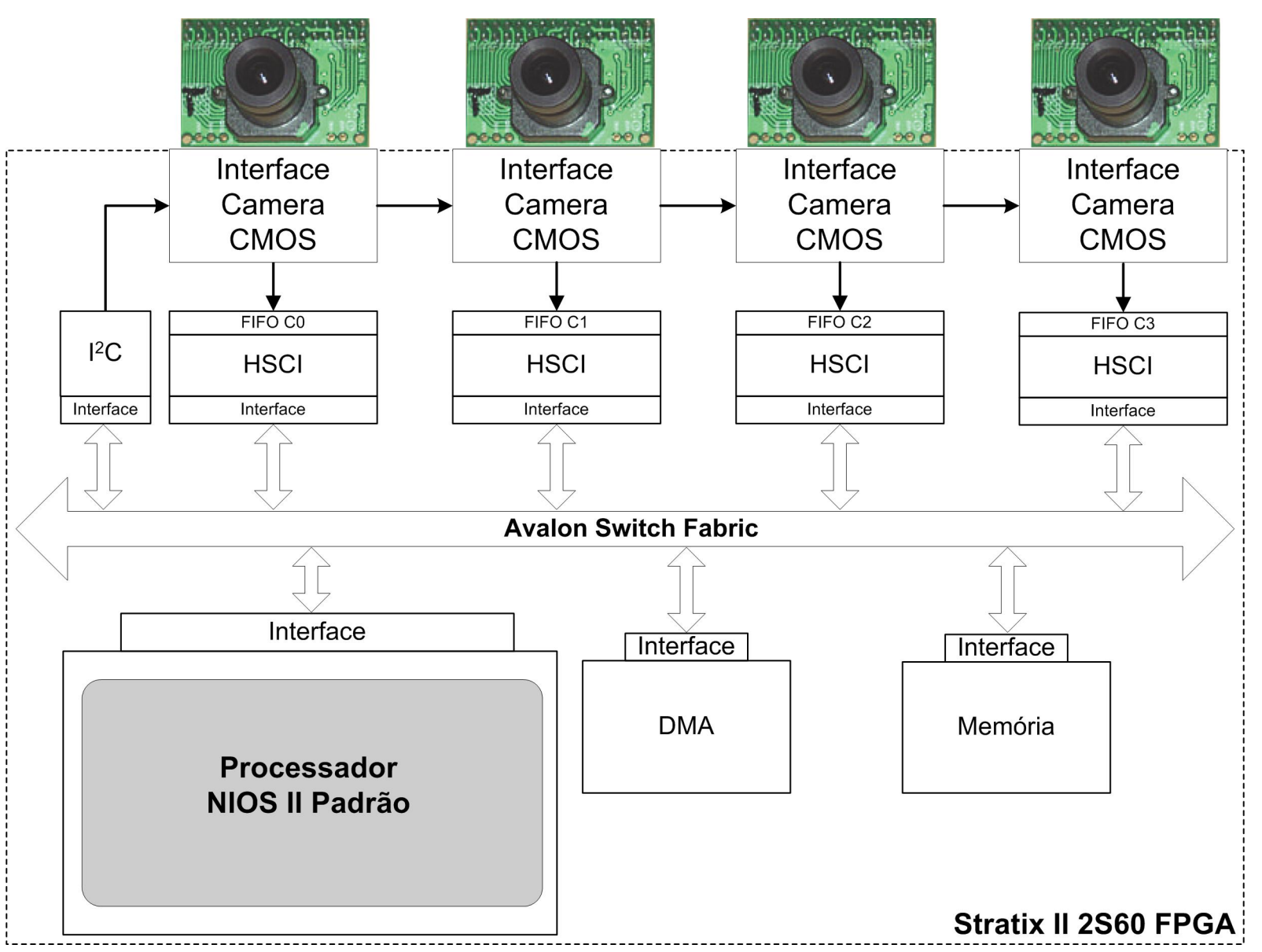

Figura 4.3: Arquitetura do sistema multi-câmeras para aquisição de imagens implementado em FPGA. 
tempo real as imagens capturadas. Assim, para a aquisição de dados do robô, o software no PC trabalha como cliente do NIOS II e o software no NIOS II como cliente do robô.

A Figura 4.4 mostra algumas das imagens obtidas com esse sistema de aquisição remoto, onde "Cam" representa as câmeras e "Seq" a sequência com que foram obtidas. Cada uma dessas imagens possui associada a posição odométrica do robô de onde elas foram capturadas. Com esse banco de dados, vários experimentos relacionados aos algoritmos SLAM puderam ser realizados offline. Um vídeo demonstrando o robô em funcionamento durante a aquisição dessas imagens pode ser visto em: http://www.icmc.usp.br/ vbonato/movies/MOV01949.MPG (tamanho 15MB).

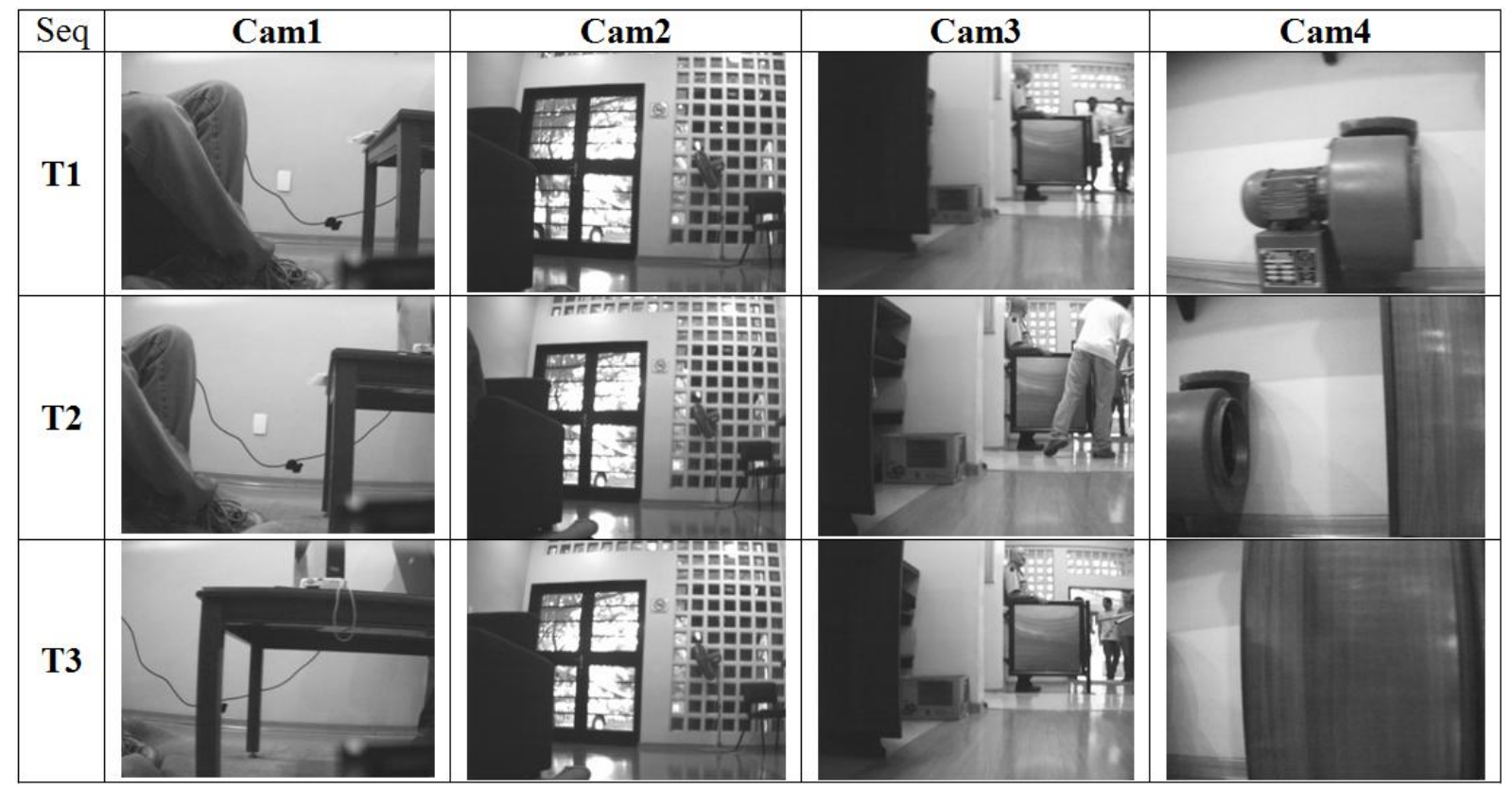

Figura 4.4: Exemplos de imagens obtidas com o sistema de aquisição remoto, onde Camx informa o número da câmera e Tx a sequência temporal com que foram capturadas.

\subsubsection{Vantagens do Uso de Multi-câmeras para o SLAM}

O propósito do uso de múltiplas câmeras no problema do SLAM são três: 1) melhorar a robustez em situações em que o ambiente possui pouca informação que possa ser usada como feature; 2) aumentar a velocidade de convergência do EKF; e 3) melhorar a precisão do mapa gerado. A Figura 4.5 ilustra, através de um gráfico unidimensional, como o EKF pode aumentar a sua precisão a partir de dados gerados por sensores independentes (as câmeras). Nessa demonstração é usada a função de densidade de probabilidade (pdf) 
Gaussiana para representar as incertezas. O eixo horizontal dos gráficos representa a leitura dos sensores através de $z_{1}, z_{2}, z_{3}$ e $z_{4}$, juntamente com suas dispersões/incertezas, e o eixo vertical mostra a probabilidade dessas leituras estarem corretas. No eixo horizontal também está representado por meio da média $\mu$ o resultado gerado pelo filtro. Como pode ser notado, quanto maior o número de sensores maior é a precisão final gerada. Também é interessante notar que o ganho do EKF depende do desvio padrão associado ao dado do sensor, ou seja, quanto mais preciso for o dado maior será o seu peso ou contribuição no resultado final (Bonato e Marques, 2006).

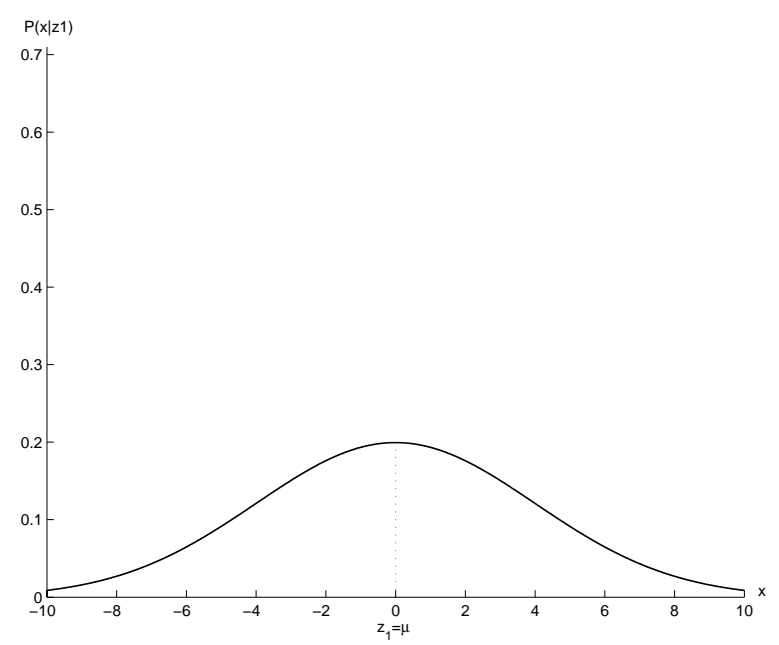

(a)

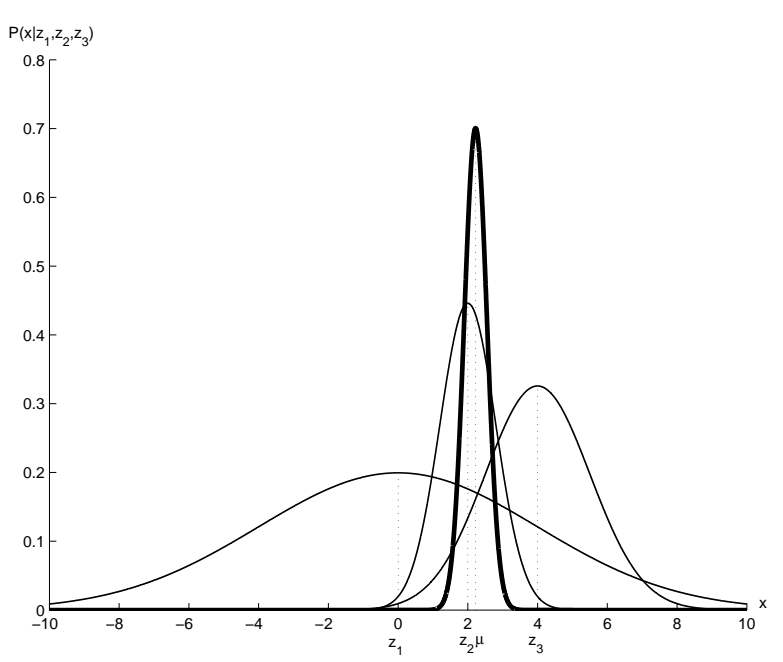

(c)

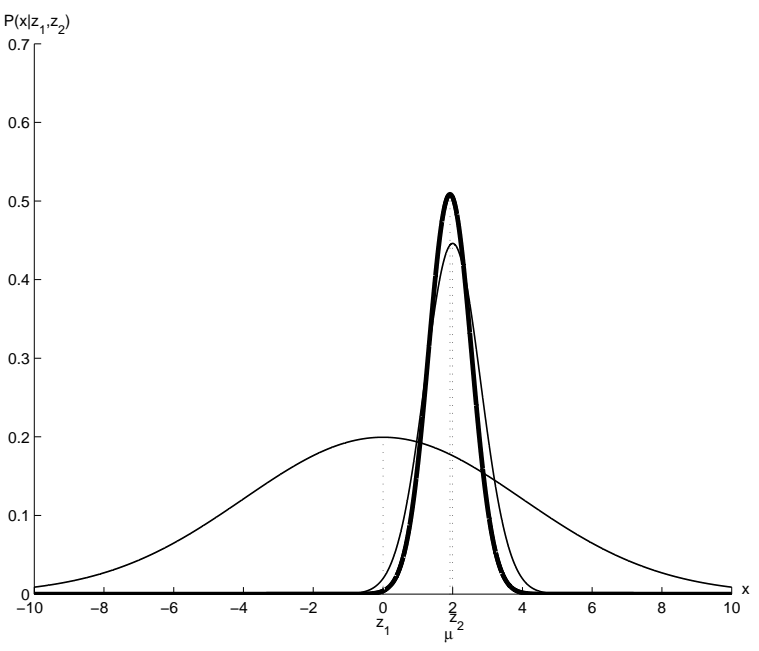

(b)

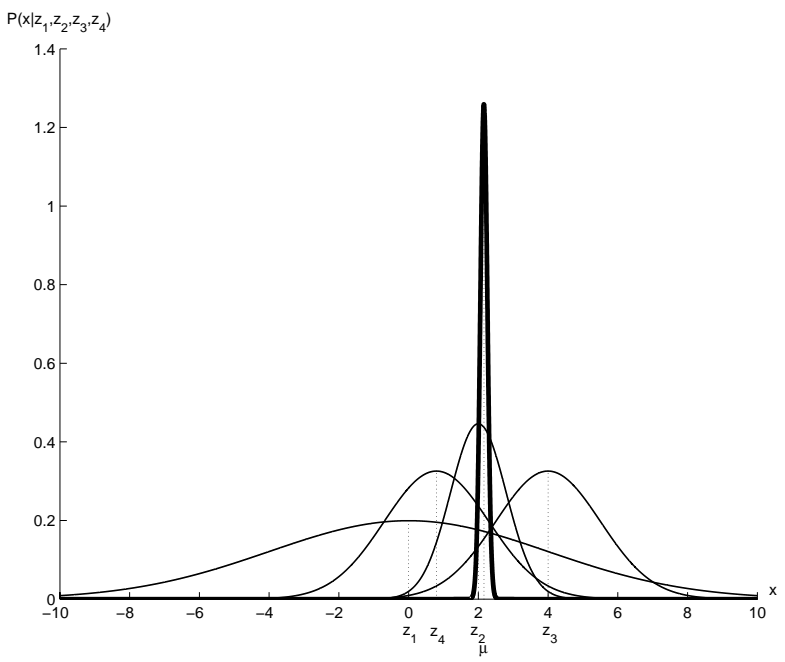

(d)

Figura 4.5: Aumento da precisão do EKF em função do número de sensores, onde (a) representa a leitura do sensor $z_{1}$; (b) a leitura de $z_{1}$ e $z_{2}$ e a estimação do resultado pelo EKF por meio de $\mu$; e (c) e (d) representam os dados semelhante a (b), porém com um número maior de sensores. 
Devido ao fato das quatro câmeras usadas no sistema proposto apontarem para quatro direções distintas, praticamente, toda a área do entorno do robô pode ser vista e, consequentemente, uma grande quantidade de informações podem ser lidas do ambiente sem ter a necessidade de locomover o robô. A Figura 4.6 ilustra uma simulação de como o uso de quatro câmeras influencia a precisão e a velocidade de convergência do EKF na geração de uma mapa bidimensional. Essas informações podem ser verificadas através da análise do tamanho das elipses, que representam as incertezas associadas a cada estimação presente no mapa.

A diferença básica entre se usar uma única câmera ou mais de uma está no aumento da precisão da localização do robô/sensor. Toda vez que uma câmera é lida e, principalmente, se ela estiver na direção em que há maior incerteza da localização do sensor, definido pelo formato da elipse, a posição da câmera é recalculada e a precisão melhorada. Esse ganho é propagado no mapa sempre que uma feature for redetectada ou uma nova adiciona-

da. É interessante notar que no EKF qualquer nova informação vinda de um sensor é mantida no mapa, ou seja, as elipses, com exceção da posição do robô, nunca aumentam o tamanho. Essas elipses das features são criadas no momento em que elas são detectadas pelo sensor, sendo que seu tamanho e orientação são definidos de acordo com a incerteza da posição do sensor/robô e em função da distância em que ela se encontra do sensor. Em contraste, a do robô aumenta toda vez que ele se locomover, o que é definido pelo modelo de controle de movimento executado na fase de predição do EKF.

\subsection{Modelos para o EKF}

No algoritmo EKF os modelos representam as entidades que realizam o controle de movimento do robô e os sensores usados no sistema. Esses dois modelos são implementados em software no processador NIOS II, basicamente, por dois motivos: a complexidade computacional associada a esses modelos é geralmente pequena (menos de $1 k$ FLOPs; independente do tamanho do mapa) e eles podem ser facilmente modificados de acordo com o tipo de sensor e de robô utilizados. 


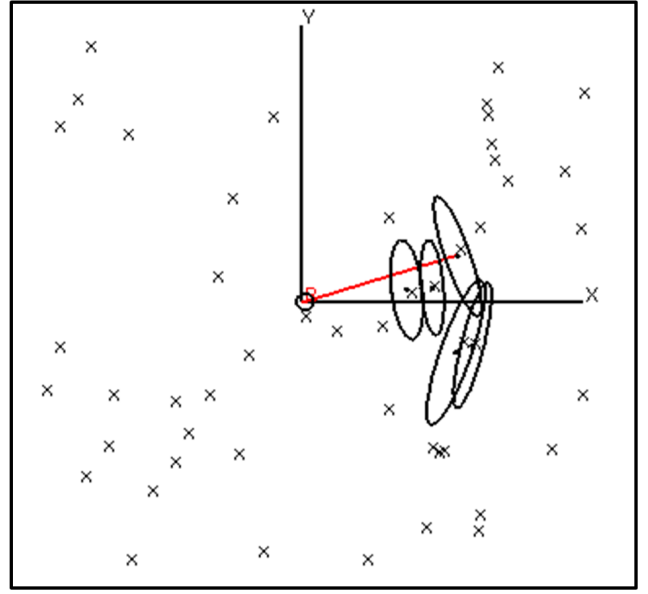

(a)

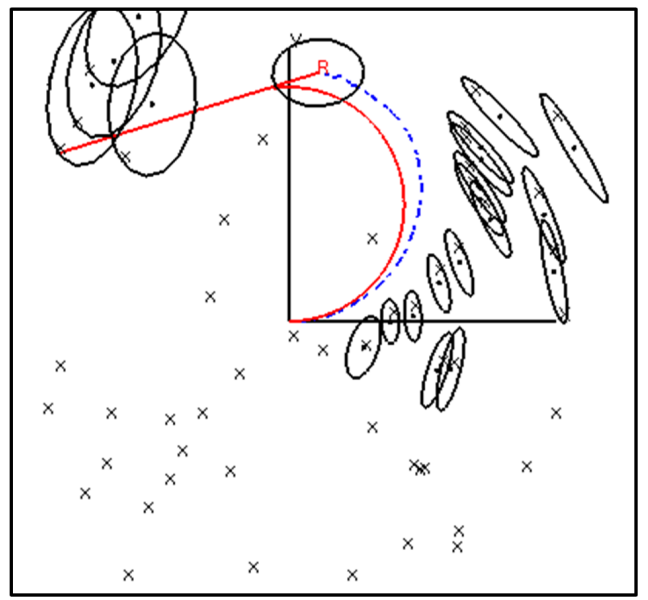

(c)

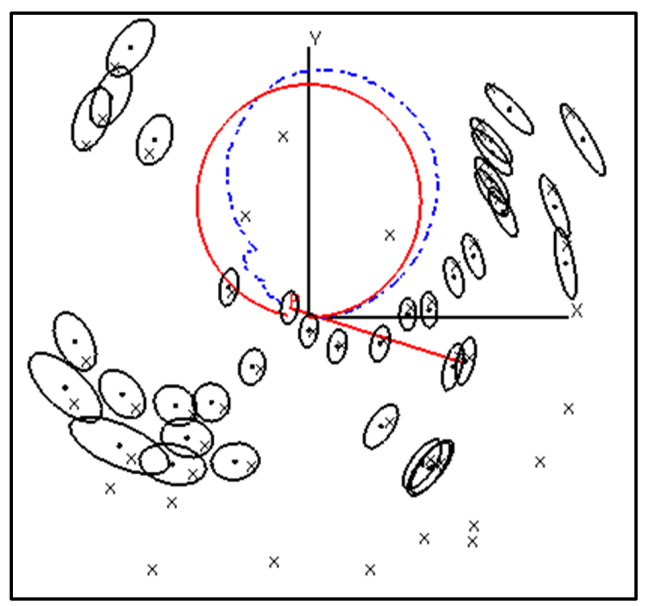

(e)

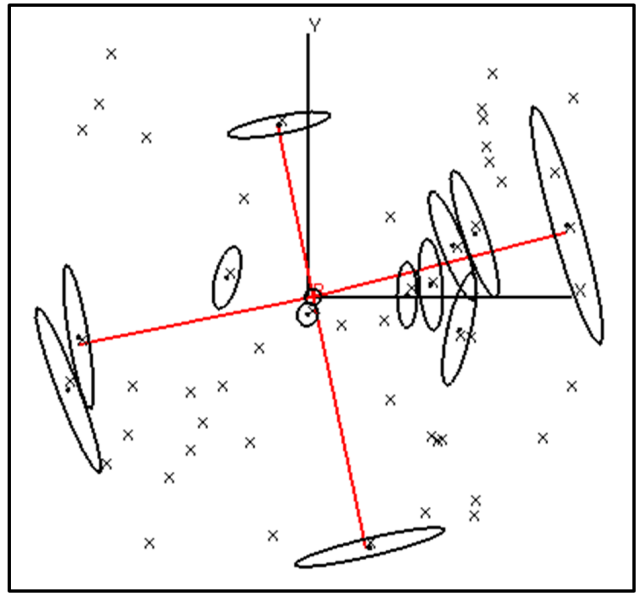

(b)

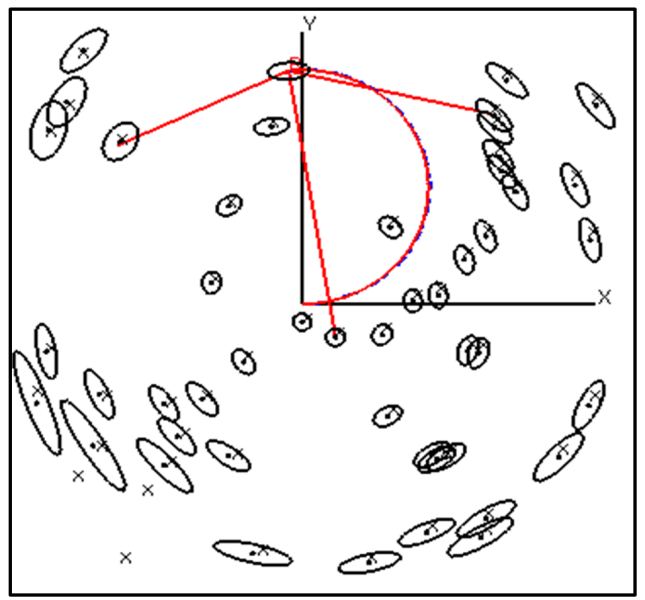

(d)

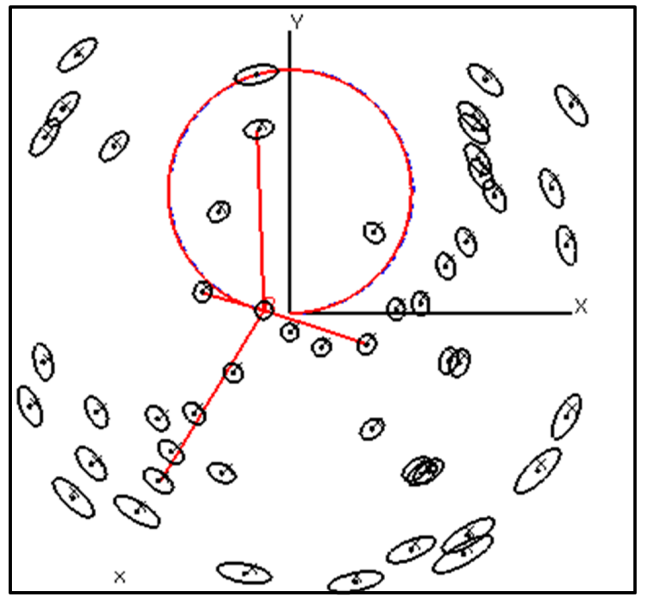

(f)

Figura 4.6: Um mapa baseado em features simulado num ambiente bidimensional. (a), (c) e (e) são mapas gerados com uma única câmera amostrados em três posições distintas de navegação do robô (R); (b), (d) e (f) representam a mesma informação, porém nesse caso com o uso de quatro câmeras. As elipses representam as incertezas da posição do robô e das features; " $\mathrm{x}$ " a posição real das features e as linhas traçadas e contínuas circulares representam a trajetória estimada e real do robô, respectivamente. 


\subsubsection{Modelo do Controle de Movimento do Robô}

O modelo para o movimento do robô numa superfície planar (2D) é definido através da Equação (4.1), onde $\mu_{v}^{(t-1)}=\left[x_{v}^{(t-1)}, y_{v}^{(t-1)}, \theta_{v}^{(t-1)}\right]^{T}$ representa a posição do robô estimada na iteração anterior e $u^{(t)}=\left[x_{u}^{(t)}, y_{u}^{(t)}, \theta_{u}^{(t)}\right]^{T}$ o comando (controle) atual para mover o robô. Como resultado, obtém-se a predição da nova posição do robô $\mu_{v}^{(t)}$.

$$
\mu_{v}^{(t)}=\left[\begin{array}{c}
x_{v}^{(t-1)}+x_{u}^{(t)} \cos \theta_{v}^{(t-1)}-y_{u}^{(t)} \sin \theta_{v}^{(t-1)} \\
y_{v}^{(t-1)}+x_{u}^{(t)} \sin \theta_{v}^{(t-1)}+y_{u}^{(t)} \cos \theta_{v}^{(t-1)} \\
\theta_{v}^{(t-1)}+\theta_{u}^{(t)}
\end{array}\right]
$$

Para utilizar esse modelo no EKF também é necessário calcular as derivadas Jacobianas em relação à posição e ao controle do robô para que o ruído dos modelos sejam adequadamente inseridos na estimação do EKF. O resultado da derivação em relação à posição do veículo $\mu_{v}^{(t-1)}$ é apresentado na Equação 4.2 e em relação ao controle $u^{(t)}$ na Equação 4.3, onde F e G são matrizes Jacobianas com dimensões definidas pelo número de variáveis que representam a posição do robô e o controle.

$$
\begin{gathered}
F^{(t)}=\frac{\partial \alpha}{\partial v}=\left[\begin{array}{cccc}
1 & 0 & -x_{u}^{(t)} \sin \theta_{v}^{(t-1)}-y_{u}^{(t)} \cos \theta_{v}^{(t-1)} \\
0 & 1 & -x_{u}^{(t)} \cos \theta_{v}^{(t-1)}-y_{u}^{(t)} \sin \theta_{v}^{(t-1)} \\
0 & 0 & 1 &
\end{array}\right] \\
G^{(t)}=\frac{\partial \alpha}{\partial u}=\left[\begin{array}{ccc}
\cos \theta_{v}^{(t-1)} & -\sin \theta_{v}^{(t-1)} & 0 \\
\sin \theta_{v}^{(t-1)} & \cos \theta_{v}^{(t-1)} & 0 \\
0 & 0 & 1
\end{array}\right]
\end{gathered}
$$

\subsubsection{Modelo da Câmera}

Neste projeto as imagens são adquiridas com a câmera digital C3188A (Electronics, 2007), representada por meio do modelo pinhole (Hartley e Zisserman, 2004), conforme visto na Figura 4.7, sendo o plano de imagem representado em frente ao centro ótico $O_{c}$ para facilitar a visualização do modelo. Essas transformações entre o ambiente onde as 
features estão localizadas (mundo) e a sua equivalente projeção na imagem digitalizada ( pixel) precisam ser definidas para a representação da câmera no modelo de leitura EKF.

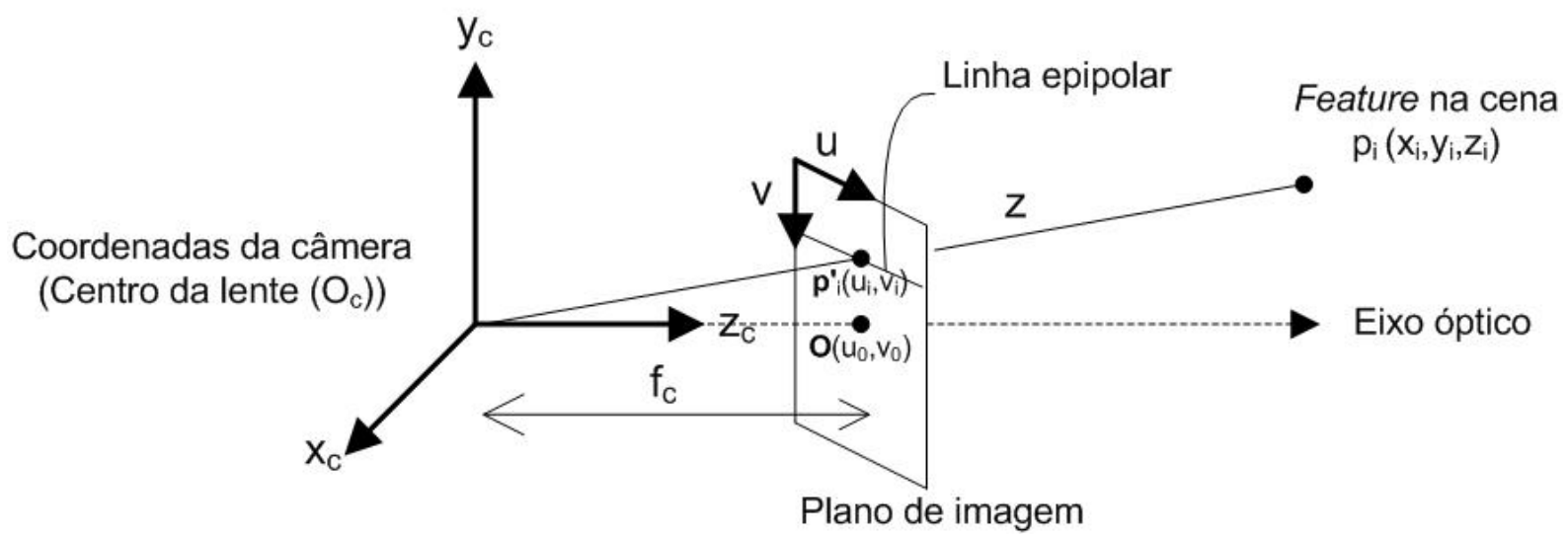

Figura 4.7: Modelo pinhole da câmera, onde $O_{c}$ é o centro ótico, $u_{i}$ e $v_{i}$ são as coordenadas de um feature no plano de imagem e $x_{i}, y_{i}$, e $z_{i}$ são as coordenadas de sua real localização no ambiente de aquisição da imagem.

Um ponto tridimensional $p_{i}\left(x_{i}, y_{i}, z_{i}\right)$ na cena é projetado onde o vetor $z$ cruza o plano de imagem no ponto $p_{i}^{\prime}\left(u_{i}, v_{i}\right)$. Essa posição é calculada na Equação 4.4 usando como parâmetro a distância focal da lente $f_{c}$ e a localização do ponto na cena $p_{i}$.

$$
p_{i}^{\prime}=\left[\begin{array}{c}
u_{i} \\
v_{i}
\end{array}\right]=\frac{f_{c}}{z_{i}}\left[\begin{array}{l}
x_{i} \\
y_{i}
\end{array}\right]
$$

Isso em coordenadas homogêneas corresponde:

$$
p_{i}^{\prime}=\left[\begin{array}{c}
u_{i} \\
v_{i} \\
1
\end{array}\right]=\frac{1}{z_{i}}\left[\begin{array}{c}
f_{c} x_{i} \\
f_{c} y_{i} \\
z_{i}
\end{array}\right]
$$

Conhecendo a localização do ponto no plano de imagem, a coordenada do pixel correspondente numa imagem digitalizada $y_{i}^{d}\left(x_{i}^{d}, y_{i}^{d}\right)$ é dada pela Equação 4.6. Essa transformação considera o tamanho da janela de imagem do sensor e também a sua resolução, os quais são representados através de fatores para colunas $k_{u}$ e linhas $k_{v}$. A Figura 4.8 apresenta essa transformação. 


$$
y_{i}^{d}=\left[\begin{array}{c}
x_{i}^{d} \\
y_{i}^{d} \\
1
\end{array}\right]=\left[\begin{array}{ccc}
-k_{u} & 0 & u_{0} \\
0 & -k_{v} & v_{0} \\
0 & 0 & 1
\end{array}\right]\left[\begin{array}{c}
\frac{f_{c} x_{i}}{z_{i}} \\
\frac{f_{c} y_{i}}{z_{i}} \\
1
\end{array}\right]=\left[\begin{array}{ccc}
-f_{c} k_{u} & 0 & u_{0} \\
0 & -f_{c} k_{v} & v_{0} \\
0 & 0 & 1
\end{array}\right]\left[\begin{array}{c}
\frac{x_{i}}{z_{i}} \\
\frac{y_{i}}{z_{i}} \\
1
\end{array}\right]
$$

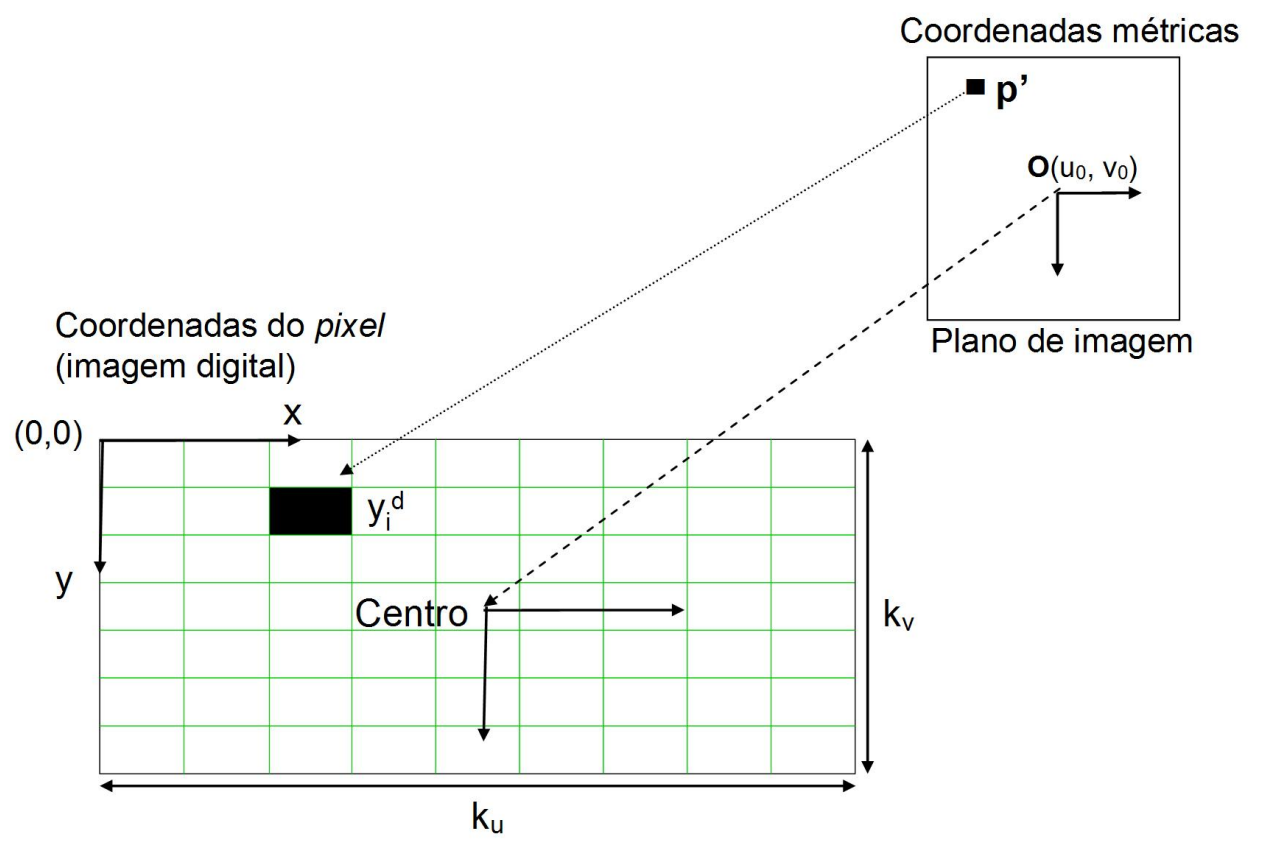

Figura 4.8: Da projeção no plano de imagem para a projeção na imagem digitalizada (pixel).

\subsubsection{Método para Distorcer Imagens}

As imagens capturadas com a câmera são deformadas pelas lentes ópticas, efeito conhecido como barrel, onde a intensidade dessa deformação depende das características das lentes utilizadas. Neste projeto as lentes possuem as seguintes especificações: distância focal $f_{c} 6,0 \mathrm{~mm}$; abertura $\mathrm{F} 1,6$; e campo de visão FOV $43^{0} \times 33^{0}$.

A correção da deformação contribui para uma estimação mais precisa das posições das features no mapa. Neste projeto, a correção da distorção é realizada via software através da Equação 4.7, onde $O_{c}$ é o centro óptico, $k_{1}$ a distância focal, $r_{d}$ a distorção radial, $y_{i}^{d}$ o pixel numa imagem distorcida e $y_{i}^{u}$ o pixel numa imagem corrigida. Os parâmetros $k_{1}$ e $O_{c}$ são fornecidos pelo manual de especificação da lente da câmera. Porém, como a lente adotada é de baixa qualidade, consequentemente, as especificações são imprecisas 
e comprometem o processo de correção. Assim, para conhecer os reais parâmetros das lentes utilizou-se uma toolbox do Matlab, desenvolvida por Strobl et. al. (2006), que gera as especificações da lente baseada num conjunto de imagens capturadas pela própria câmera a ser calibrada. As imagens são obtidas de variações de um padrão de quadrados alinhados e impressos sobre um fundo branco, conforme mostrado na Figura 4.9.

Para cada pixel numa imagem distorcida $y_{i}^{d}$ a Equação 4.7 calcula a sua posição correspondente numa imagem corrigida $y_{i}^{u}$. O processo inverso também pode ser realizado por meio da Equação 4.8.

$$
\begin{aligned}
& y_{i}^{u}=O+\frac{y_{i}^{d}-O}{1-k_{1} r_{d}^{2}} \\
& y_{i}^{d}=O+\frac{y_{i}^{u}-O}{1+k_{1} r_{u}^{2}}
\end{aligned}
$$

onde:

$$
\begin{aligned}
& r_{d}=\left\|y_{i}^{d}-O\right\| \\
& r_{u}=\left\|y_{i}^{u}-O\right\|
\end{aligned}
$$

A imagem (a) da Figura 4.10 mostra um exemplo de imagem deformada pela ação da lente da câmera, onde as caixas pretas, que são quadradas no mundo real, apresentamse curvadas e com intensidade da deformação amplificada em função da sua distância em relação ao ponto central da lente $O_{c}$. A imagem (b) apresenta o resultado após a aplicação do método de correção da Equação 4.7. Nesse caso, o ponto central da lente encontra-se na intersecção entre as duas linhas pretas retas; e as outras linhas pretas curvadas representam os pixels que foram perdidos devido ao arredondamento no processo de correção. Esses espaços vazios podem ser preenchidos usando-se interpolação com os pixels vizinhos. Porém, nesse projeto, como a correção é implementada somente localmente, onde a feature está localizada, a interpolação não é necessária. 


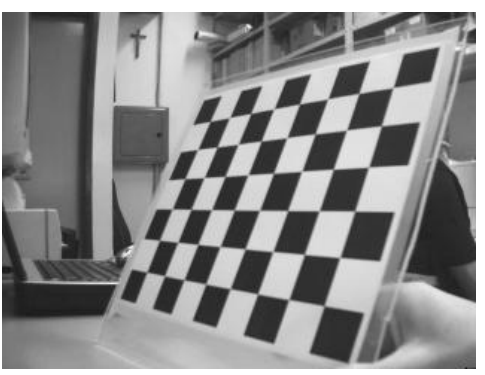

(a)

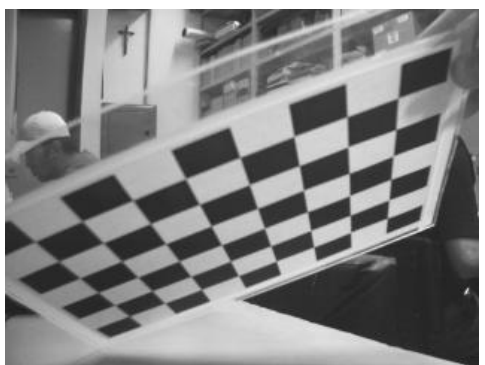

(d)

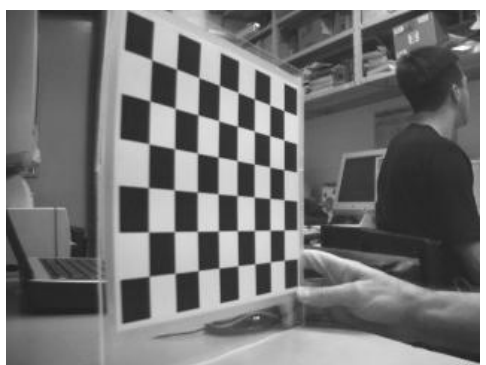

(b)

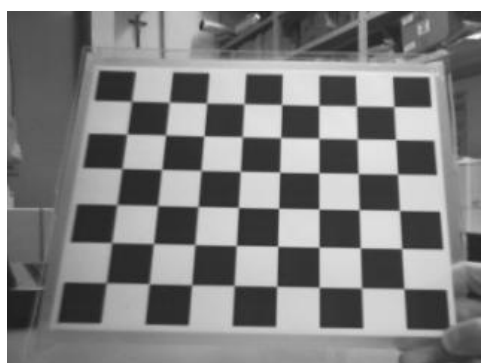

(e)

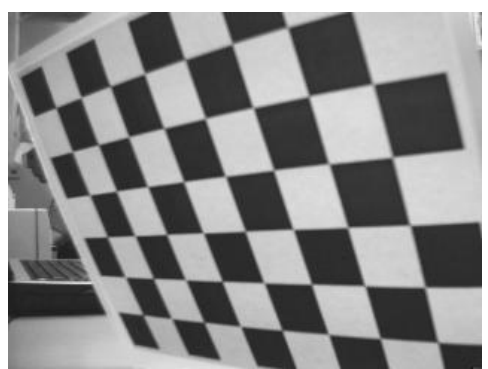

(c)

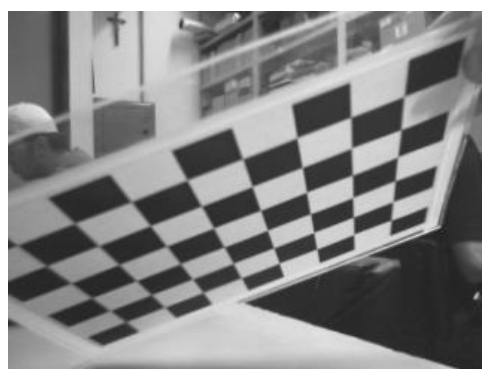

(f)

Figura 4.9: Exemplos do conjunto de imagens usado na geração dos parâmetros da lente da câmera.

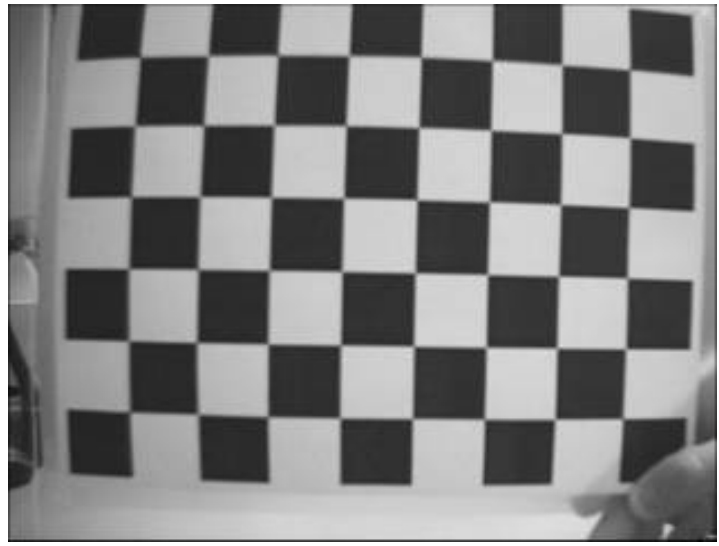

(a)

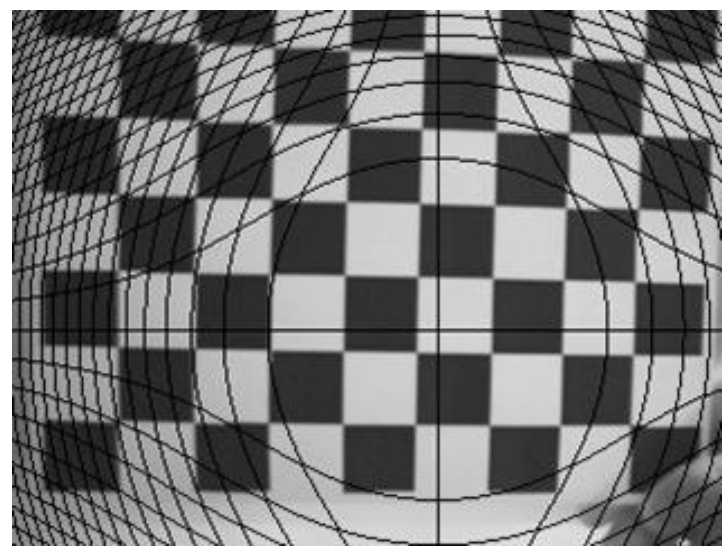

(b)

Figura 4.10: Exemplo de uma imagem distorcida (a) e a correspondente corrigida (b), onde o cruzamento da duas linhas retas pretas corresponde ao ponto central da lente $O_{c}$ e as outras linhas pretas curvadas representam os pixels que foram perdidos devido ao processo de arredondamento da correção. 


\subsubsection{Obtendo a Localização Espacial das Features com Visão Monocular}

Após ter definido os modelos de distorção de imagem e de transformações existentes entre a câmera e a imagem digitalizada, é necessário também que se defina um método para estimar a localização espacial das features. Com a visão monocular, a localização da feature não pode ser obtida diretamente a partir de uma única imagem/frame, pois não há informação de profundidade disponível. Para se obter essa informação, pelo menos duas imagens precisam ser capturadas com ângulo parallax $\alpha$ (ângulo do vértice do plano epipolar onde se encontra a feature (ver Figura 4.11)) maior do que zero, onde quanto maior for o ângulo parallax maior será a disparidade entre as imagens e, consequentemente, melhor será a estimativa da distância ${ }^{1}$ (Hartley e Zisserman, 2004). Para isso, considera-se que a feature apareça nas duas imagens em posições distintas e que as imagens foram obtidas com a câmera em posições paralelamente alinhadas. A precisão do resultado também depende da resolução do sensor de imagem e da distância em que a feature encontra-se em relação à câmera. Assim, havendo essa disparidade entre as imagens, a distância da feature pode ser facilmente obtida com a bem conhecida técnica de triangulação por meio da Equação 4.11. Onde $B$ é a distância entre as câmeras (base line), $f_{c}$ a distância focal, $p_{u}^{\prime(l)}$ a projeção no plano de imagem da câmera esquerda e $p_{u}^{\prime(r)}$ a projeção no plano da direita. As outras coordenadas $x_{i}$ e $y_{i}$ são obtidas diretamente aplicando-se $z_{i}$ nas Equações 4.12 e 4.13.

$$
\begin{array}{r}
z_{i}=f_{c} \frac{B}{p_{u}^{\prime(l)}-p_{u}^{\prime(r)}} \\
x_{i}=p_{u}^{\prime} \frac{z_{i}}{f_{c}} \\
y_{i}=p_{v}^{\prime} \frac{z_{i}}{f_{c}}
\end{array}
$$

No entanto, considerando-se que o robô está num espaço 2D planar e que, em princípio, pode mover-se para qualquer coordenada e orientação, as imagens para a triangulação

\footnotetext{
${ }^{1} \mathrm{Na}$ literatura, essas transformações entre um ponto no espaço e a sua representação numa imagem digitalizada, e a posição e orientação relativa entre duas câmeras são referenciados como parâmetros intrínsecos e extrínsecos, respectivamente.
} 


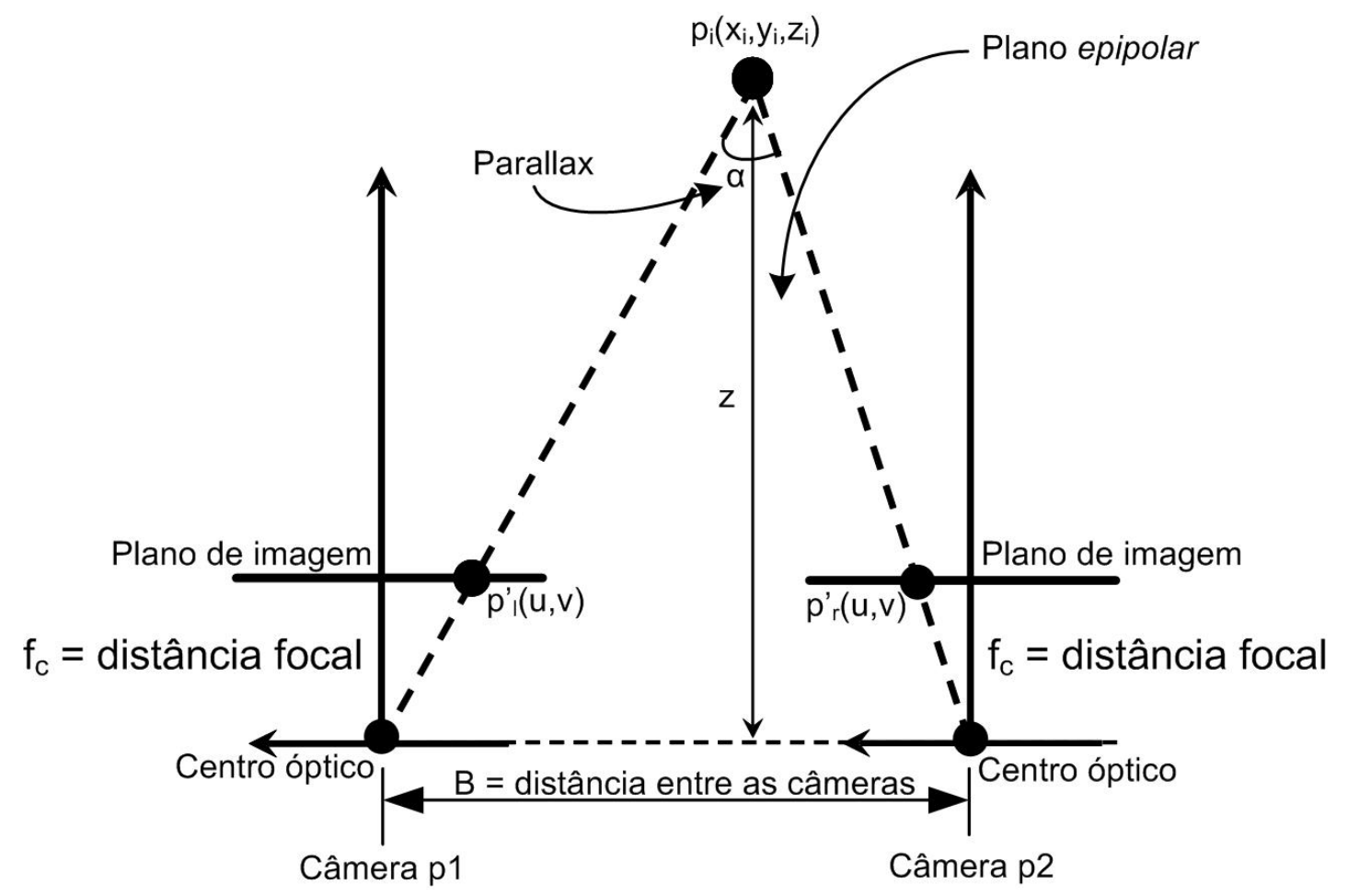

Figura 4.11: Elementos da triangulação para uma câmera em duas posições (p1,p2) em paralelo apontando para a mesma feature.

dificilmente são obtidas de posições de câmeras fisicamente alinhadas em paralelo. Desse modo, uma operação de rotação é necessária para satisfazer esse requisito, sendo o ângulo dessa rotação fornecido pelo modelo de controle do robô.

Esse método tradicional de triangulação foi utilizado para validar o funcionamento dos módulos da arquitetura SLAM, pois é uma técnica bem difundida e simples de ser implementada. Porém, ela não é considerada a mais eficiente para o SLAM, visto que o erro da estimação da posição de uma feature no espaço não é linear, sendo a linearidade requisito fundamental para o bom funcionamento do EKF. Recentemente, uma nova técnica baseada no inverso da disparidade foi proposta, na qual a distância/profundidade da feature é estimada de modo linear independente da sua distância em relação à câmera (Montiel et. al., 2006). Essa nova abordagem também possibilita representar uma feature no infinito e usar a informação de orientação da feature na estimação da posição da câmera, e isso, pode ser realizado desde a sua detecção no primeiro frame. Em Sola et. al. (2007) também são discutidas as vantagens e desvantagens dessas técnicas na visão monocular e estéreo para o problema SLAM. 


\subsection{Considerações Finais}

A integração do robô com o FPGA baseada no sistema Player permite que seja reutilizada para qualquer tipo de robô suportado por este ambiente. Além disso, possibilita o uso de simuladores de robôs virtuais, tal como, por exemplo, o simulador Stage (Gerkey et. al., 2001), durante o desenvolvimento dos algoritmos executados no FPGA evitandose, assim, danificar o equipamento na fase de teste. Apesar dessa integração com o Player também permitir a leitura de sensores de imagem, as quatro câmeras CMOS utilizadas neste projeto estão diretamente conectadas aos pinos do FPGA. Desse modo, as imagens são enviadas a 30 frames por segundo, via DMA, diretamente para a memória do processador NIOS II, sem comprometer a conexão Ethernet entre o FPGA e o Robô.

O número de câmeras que pode ser utilizado no projeto é variável de um até quatro. Porém, conforme ilustrado na Figura 4.6, essa quantidade influencia significativamente a precisão da localização do robô e a velocidade de convergência e precisão do mapa gerado.

Os modelos matemáticos referentes ao controle do robô e ao da câmera serviram de base para a realização de experimentos e validação dos módulos de hardware da arquitetura SLAM criada. Finalmente, a aplicação do módulo de correção da distorção das imagens e a estimação dos parâmetros reais das lentes com a toolbox do Matlab aumentaram, significativamente, a precisão das estimações de localização das features no espaço.

Os outros módulos dessa arquitetura SLAM, que são responsáveis pelo processamento do algoritmo EKF e pela detecção das features, são apresentados nos Capítulos 5 e 6 . Todos os módulos da arquitetura desenvolvida foram validados no FPGA por meio de duas plataformas de desenvolvimento. Para o EKF utilizou-se a plataforma da (Celoxica, 2005b), a qual possui quatro bancos de memória externa com acesso independente e um chip FPGA EP2S90F1020C4. Já os demais módulos foram validados na plataforma de desenvolvimento NIOS II da Altera (2007b), equipada com o FPGA Stratix II 2S60. 



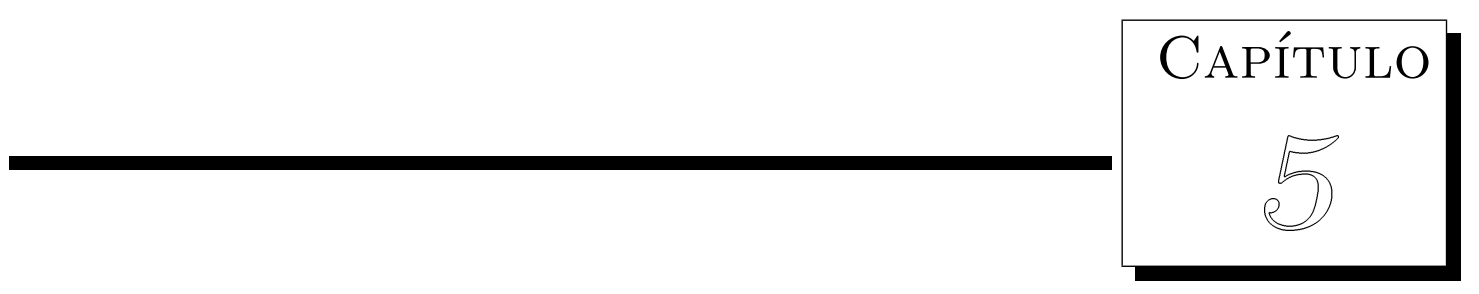

A Arquitetura Desenvolvida para o Filtro de

\section{Kalman Estendido}

Este capítulo apresenta uma arquitetura baseada em FPGA para o algoritmo do EKF aplicada ao problema SLAM. Inicialmente, a Seção 5.1 descreve o algoritmo do EKF e apresenta uma análise da sua complexidade computacional. Em seguida, são mostrados a arquitetura do hardware e alguns resultados experimentais nas Seções 5.2 e 5.3, respectivamente. Finalmente, a Seção 5.4 descreve as considerações finais.

\subsection{Algoritmo do Filtro de Kalman Estendido}

Esta seção descreve o algoritmo EKF, cuja descrição completa pode ser encontrada em Thrun et. al. (2005), juntamente com uma análise da complexidade relacionada ao número de operações de ponto flutuante. O EKF é composto por duas fases: predição e atualização. No contexto do SLAM, a fase de predição estima a posição do robô $\mu_{v}^{(t)}$ no tempo $t$ baseado na crença da sua posição anterior $\mu_{v}^{(t-1)}$ e no controle do seu movimento $u^{(t)}$, enquanto que a fase de atualização integra as medidas dos sensores $z^{(t)}$ com o objetivo 
de atualizar o mapa do ambiente do robô e estimar novamente a sua posição. Esses dois passos são repetidos para cada iteração do EKF, onde os dados estimados numa iteração são usados como entrada para a próxima.

Nessa implementação, a posição do robô é representada num espaço de coordenadas bidimensional $(x, y)$ e pela sua orientação angular $\theta$. O mapa consiste de um conjunto de posições de features $\left(\mu_{f_{1}}^{(t)}, \mu_{f_{2}}^{(t)}, \ldots, \mu_{f_{n}}^{(t)}\right)$ detectadas do ambiente de navegação do robô através de um sensor, onde cada feature, para generalização do problema, é representada do mesmo modo pelas suas coordenadas $(x, y)$. Esses parâmetros são representados neste trabalho por $r$ e $s$, respectivamente. Como esses estados do robô e das features são estimados, eles têm uma matriz de co-variância associada para representar as suas incertezas, a qual é representada por $\Sigma^{(t)}$ no tempo $t$. No algoritmo EKF esses dados são organizados como na Equação 5.1, onde $\mu^{(t)}$ é composto pela posição estimada do robô e por um conjunto de features no tempo $t$. A Figura 5.1 também mostra uma representação gráfica desses dados num ambiente simulado.

$$
\mu^{(t)}=\left[\begin{array}{c}
\mu_{v}^{(t)} \\
\mu_{f_{1}}^{(t)} \\
\mu_{f_{2}}^{(t)} \\
\vdots \\
\mu_{f_{n}}^{(t)}
\end{array}\right], \Sigma^{(t)}=\left[\begin{array}{cccc}
\Sigma_{v v}^{(t)} & \Sigma_{v f_{1}}^{(t)} & \ldots & \Sigma_{v f_{n}}^{(t)} \\
\Sigma_{f_{1} v}^{(t)} & \Sigma_{f_{1} f_{1}}^{(t)} & \ldots & \Sigma_{f_{1} f_{n}}^{(t)} \\
\Sigma_{f_{2} v}^{(t)} & \Sigma_{f_{2} f_{1}}^{(t)} & \ldots & \Sigma_{f_{2} f_{n}}^{(t)} \\
\vdots & \vdots & \ddots & \\
\Sigma_{f_{n} v}^{(t)} & \Sigma_{f_{n} f_{1}}^{(t)} & \ldots & \Sigma_{f_{n} f_{n}}^{(t)}
\end{array}\right]
$$

A Tabela 5.1 descreve as variáveis usadas nas equações de predição e atualização do EKF, juntamente com as suas dimensões. As Equações 5.2 e 5.3 são usadas para estimar a nova posição do robô, dado o vetor de crenças $\mu_{v}^{(t-1)}$ e a matriz de co-variância que corresponde à posição do robô $\Sigma_{v v}^{(t-1)}$ e ao atual controle de movimento $u^{(t)} \cdot F^{(t)}$ e $G^{(t)}$ são matrizes Jacobianas que contém derivadas da função de predição $\alpha$ em relação às variáveis de comando de movimento no tempo $t$. A Equação 5.4 estima a co-variância entre a posição do robô e a da feature $\Sigma_{v f}$, dada a co-variância correspondente no tempo $(t-1)$ e a matriz $F^{(t)}$.

Após computar as equações de predição, a fase de atualização inicializa predizendo a 
Tabela 5.1: A descrição e a dimensão dos símbolos (Sym) do EKF, onde $s$ e $r$ representam o tamanho do vetor de estados do robô e da feature; $v$ e $f$ a posição do robô e da feature; $i$ o número da feature; e $n$ a quantidade total de features.

\begin{tabular}{c||c|l}
\hline Sym & Dimensão & Descrição \\
\hline \hline$\mu$ & $(r+s n) \times 1$ & Posições do robô e das features \\
$\mu_{v}$ & $r \times 1$ & Elementos de $\mu$ relacionados à posição do robô \\
$\mu_{f}$ & $s n \times 1$ & Elementos de $\mu$ relacionados à posição da feature \\
$\Sigma_{v v}$ & $r \times r$ & Co-variância da posição do robô \\
$\Sigma_{v f}$ & $r \times(s n)$ & Co-variância cruzada robô-feature \\
$\Sigma_{f f}$ & $(s n) \times(s n)$ & Co-variância cruzada feature-feature \\
$\Sigma$ & $(r+s n) \times$ & Co-variância cruzada robô-feature \\
& $(r+s n)$ & e feature-feature \\
$\alpha$ & - & Função de predição \\
$\gamma$ & - & Função de medida \\
$u$ & $r \times 1$ & Comando de movimento do robô \\
$F$ & $r \times r$ & Jacobiano do movimento do robô \\
$G$ & $r \times r$ & Jacobiano do ruído do movimento do robô \\
$Q$ & $r \times r$ & Ruído permanente do movimento \\
$H_{v}$ & $s \times r$ & Jacobiano da função de medida em relação a $v$ \\
$H_{f i}$ & $s \times s$ & Jacobiano da função de medida em relação a fi \\
$H$ & $s \times(r+s n)$ & Jacobiano da função de medida composta \\
$R$ & $s \times s$ & Ruído da medida permanente \\
$W$ & $(r+s n) \times s$ & Ganho do filtro \\
$\nu$ & $s \times 1$ & Média da inovação \\
$z$ & $s \times 1$ & Medida do sensor \\
$z_{p r e d}$ & $s \times 1$ & Predição da medida do sensor \\
$S$ & $s \times s$ & Inovação da co-variância \\
$Z_{1}$ & $s \times(s(i-1))$ & Matriz de zeros \\
$Z_{2}$ & $s \times(n-i))$ & Matriz de zeros \\
\hline \hline
\end{tabular}




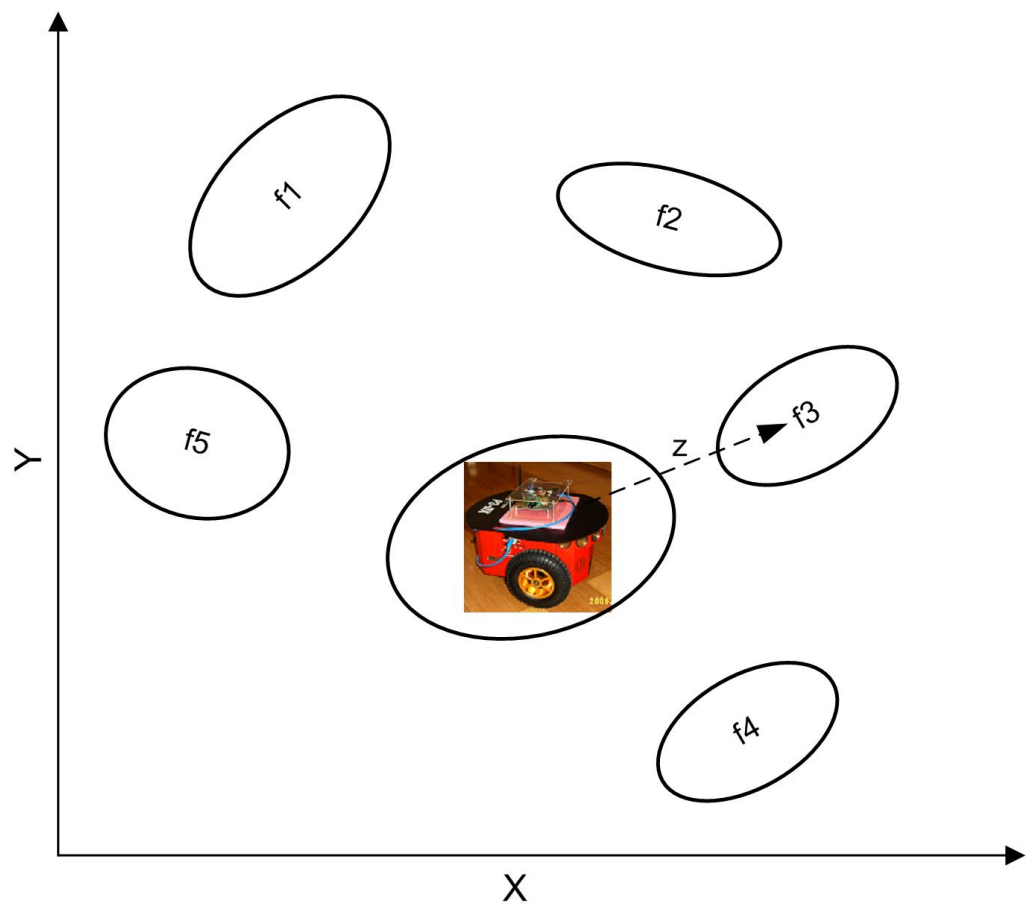

Figura 5.1: Representação de um robô num mapa bidimensional, onde as elipses representam as incertezas da co-variância e seus centros, as localizações estimadas do robô e das features, e $z$ a observação de uma feature através do sensor do robô.

leitura do sensor através da Equação 5.9, usando-se a posição do robô estimada $\mu_{v}^{(t)}$ e a feature detectada $\mu_{f i}^{(t-1)}$. As Equações 5.10 e 5.11 calculam as inovações relacionadas à medida $\nu^{(t)}$ e à co-variância $S^{(t)}$, respectivamente. $\nu^{(t)}$ é a diferença entre a medida real e a estimada do sensor, e $S^{(t)}$ é a nova informação adicionada à co-variância do sistema dada a matriz atual $H^{(t)}$ e a co-variância da fase de predição anterior. $H^{(t)}$ é uma matriz composta por duas matrizes Jacobianas $H_{v}^{(t)}$ e $H_{f i}^{(t)}$ da Equação 5.8, que são derivadas da função de predição $\gamma$ em relação à posição estimada do robô e da feature detectada no tempo t. A Equação 5.12 computa o ganho do filtro. Finalmente, as Equações 5.5 e 5.6 atualizam todos os dados que correspondem ao mapa estimado.

\section{Predição:}

$$
\begin{array}{r}
\mu_{v}^{(t)}=\alpha\left(\mu_{v}^{(t-1)}, u^{(t)}\right) \\
\Sigma_{v v}^{(t)}=F^{(t)} \Sigma_{v v}^{(t-1)} F^{(t) T}+G^{(t)} Q G^{(t) T} \\
\Sigma_{v f}^{(t)}=F^{(t)} \Sigma_{v f}^{(t-1)}
\end{array}
$$


Atualização:

$$
\begin{aligned}
& \mu^{(\mathbf{t})}=\bar{\mu}^{(t)}+W^{(t)} \nu^{(t)} \\
& \Sigma^{(t)}=\bar{\Sigma}^{(t)}-W^{(t)} S^{(t)} W^{(t) T}
\end{aligned}
$$

onde:

$$
\begin{aligned}
& \bar{\mu}^{(t)}=\left[\begin{array}{c}
\mu_{v}^{(t)} \\
\mu_{f}^{(t-1)}
\end{array}\right], \bar{\Sigma}^{(t)}=\left[\begin{array}{cc}
\Sigma_{v v}^{(t)} & \Sigma_{v f}^{(t)} \\
\Sigma_{v f}^{(t) T} & \Sigma_{f f}^{(t-1)}
\end{array}\right] \\
& H^{(t)}=\left[\begin{array}{llll}
H_{v}^{(t)} & Z_{1} & H_{f i}^{(t)} & Z_{2}
\end{array}\right] \\
& z_{\text {pred }}^{(t)}=\gamma\left(\mu_{v}^{(t)}, \mu_{f i}^{(t-1)}\right) \\
& \nu^{(t)}=z^{(t)}-z_{\text {pred }}^{(t)} \\
& S^{(t)}=H^{(t)} \bar{\Sigma}^{(t)} H^{(t) T}+R \\
& W^{(t)}=\bar{\Sigma}^{(t)} H^{(t) T} S^{(t)^{-1}} \\
& \mathbf{F}=\frac{\partial f}{\partial x_{v}}=\left[\begin{array}{ccc}
\frac{\partial f_{1}}{\partial x_{1}} & \cdots & \frac{\partial f_{1}}{\partial x_{m}} \\
\vdots & & \vdots \\
\frac{\partial f_{n}}{\partial x_{1}} & \cdots & \frac{\partial f_{n}}{\partial x_{m}}
\end{array}\right] \\
& \mathbf{G}=\frac{\partial f}{\partial u}=\left[\begin{array}{ccc}
\frac{\partial f_{1}}{\partial u_{1}} & \ldots & \frac{\partial f_{1}}{\partial u_{m}} \\
\vdots & & \vdots \\
\frac{\partial f_{n}}{\partial u_{1}} & \cdots & \frac{\partial f_{n}}{\partial u_{m}}
\end{array}\right] \\
& \mathbf{H}_{\mathbf{v}}=\frac{\partial h}{\partial x_{v}}=\left[\begin{array}{ccc}
\frac{\partial h_{1}}{\partial x_{1}} & \cdots & \frac{\partial h_{1}}{\partial x_{m}} \\
\vdots & & \vdots \\
\frac{\partial h_{n}}{\partial x_{1}} & \cdots & \frac{\partial h_{n}}{\partial x_{m}}
\end{array}\right] \\
& \mathbf{H}_{\mathbf{f}}=\frac{\partial h}{\partial x_{f}}=\left[\begin{array}{ccc}
\frac{\partial h_{1}}{\partial x_{1}} & \cdots & \frac{\partial h_{1}}{\partial x_{m}} \\
\vdots & & \vdots \\
\frac{\partial h_{n}}{\partial x_{1}} & \cdots & \frac{\partial h_{n}}{\partial x_{m}}
\end{array}\right]
\end{aligned}
$$




\subsubsection{Análise da Complexidade Computacional}

É amplamente conhecido que a complexidade computacional do algoritmo EKF para o SLAM é $\Theta\left(n^{2}\right)$, onde $n$ representa o número de features (Thrun et. al., 2005). Porém, para melhor entender como essa complexidade computacional está distribuída entre as equações, é apresentada na Tabela 5.2 uma análise do número de operações de ponto flutuante para cada equação do EKF usada na arquitetura proposta. Como pode ser notado, a maior complexidade está localizada na Equação 5.6, onde todos os elementos da matriz de co-variância, a qual tem dimensão definida por $(r+s n) \times(r+s n)$, devem ser computados e atualizados em cada iteração. Consequentemente, essa equação, em particular, tem não somente um grande número de operações em ponto flutuante, mas também requer uma larga banda de acesso à memória onde a matriz de co-variância encontra-se armazenada. Portanto, ambos aspectos devem ser considerados para desenvolver um sistema de alto desempenho. Outra consideração importante está relacionada à matriz $H^{(t)}$ de dimensão $s \times(r+s n)$, a qual é usada para multiplicar a matriz de co-variância, que apresenta dimensão $(r+s n) \times(r+s n)$. De acordo com a Equação $5.8, H^{(t)}$ é uma matriz esparsa e estruturada. Considerando-se essa estrutura, a complexidade total do EKF pode ser reduzida de $48 n^{2}+202 n+255$ para $16 n^{2}+170 n+465$, como visto na Tabela 5.2.

Tabela 5.2: Número de operações de ponto flutuante para cada equação do EKF, onde $r=3$ e $s=2$, para $n$ features .

\begin{tabular}{c|l}
\hline Equação & FLOP \\
\hline \hline$(5.2)$ & 9 \\
$(5.3)$ & 189 \\
$(5.4)$ & $30 n$ \\
$(5.10)$ & 2 \\
$(5.11)$ & $36 n+97$ \\
$(5.12)$ & $36 n+93$ \\
$(5.5)$ & $8 n+21$ \\
$(5.6)$ & $16 n^{2}+60 n+54$ \\
\hline Total & $16 n^{2}+170 n+465$ \\
\hline \hline
\end{tabular}




\subsection{Arquitetura do Hardware}

Esta seção apresenta a arquitetura de hardware especialmente desenvolvida para computar as fases de predição e atualização do algoritmo EKF aplicado ao problema do SLAM. Essa arquitetura foi desenvolvida para ser integrada com um processador simples embarcado para computar os modelos de predição e de medida das Equações 5.2 e 5.10, juntamente com as suas matrizes Jacobianas. Essa partição hardware/software permite que os modelos sejam facilmente atualizados de acordo com o tipo de sensor usado para detectar as features. Assim, o hardware proposto pode ser reutilizado para qualquer tipo de modelo de sensor, desde que o tamanho do vetor de estados do robô e da feature sejam mantidos com dimensões compatíveis com o hardware. Além disso, a complexidade computacional associada a estes modelos é geralmente pequena (menos de $1 k$ FLOPs), e independente do número de features. Para cada iteração do EKF, o hardware recebe $\mu_{v}^{(t)}$, $\nu^{(t)}, F^{(t)}, G^{(t)}$ e $H^{(t)}$ (do software) e retorna $v^{(t-1)}$ e $\mu_{f i}^{(t-1)}$. De acordo com a Tabela 5.1, a quantidade de dados envolvidos nessa comunicação é pequena e, consequentemente, não compromete a latência geral do sistema.

Como pôde ser notado na Seção 5.1, as principais características desse algoritmo são: muitas operações de multiplicação, adição e subtração de matrizes; e, particularmente, na Equação 5.6, há uma grande quantidade de dados lidos e atualizados na matriz de covariância. Guiado por essas características dominantes, e também pelo desempenho desejado do sistema, uma arquitetura baseada em FPGA é proposta, conforme demonstrada na Figura 5.2, a qual é composta por quatro bancos de memória externa, um conjunto de memórias internas, uma máquina de estados e quatro Elementos de Processamento (PEs).

Para definir o desempenho desejado para essa arquitetura, considera-se sua aplicação num sistema SLAM, onde os dados do ambiente de navegação do robô são obtidos por meio de visão monocular utilizando-se câmeras como sensor exteroceptivo, que é o caso do projeto onde essa arquitetura é aplicada (Bonato et. al., 2006b). Nesse sistema SLAM, a distância das features em relação ao robô é obtida usando-se a técnica de triangulação 


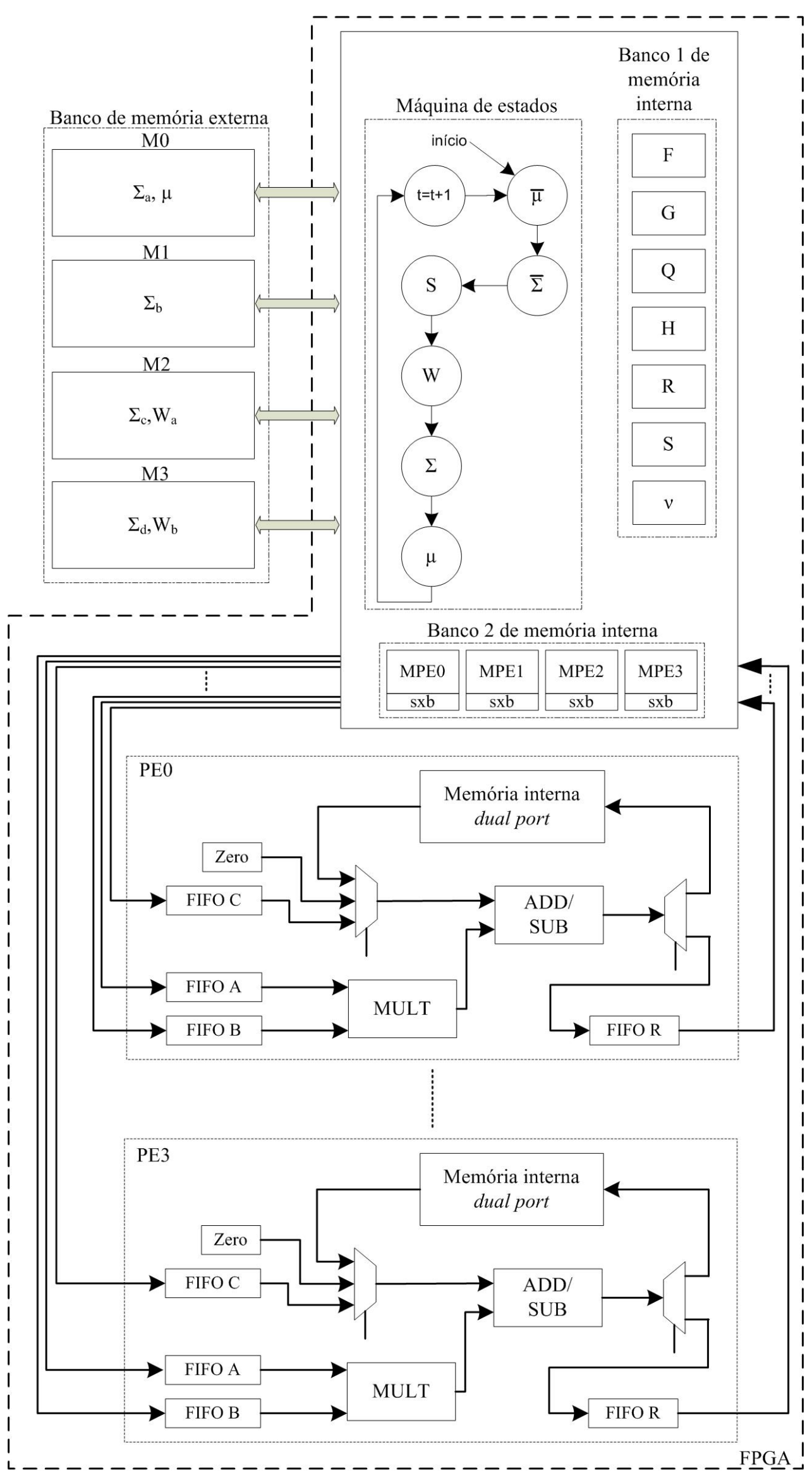

Figura 5.2: Arquitetura do EKF, onde MPEx são as memórias internas para reutilização de dados dos PEs, e b é o tamanho dessas memórias; e os demais símbolos são apresentados na Tabela 5.1. 
apresentada por Hartley e Zisserman (2004). Portanto, as câmeras, que estão fixas na base do robô, devem ser movidas para capturar imagens de posições diferentes. Considerandose que o robô navega em uma linha reta com velocidade máxima de $1 \mathrm{~m} / \mathrm{s}$ e que a triangulação trabalha com imagens capturadas a cada $70 \mathrm{~mm}$, a frequência de iteração do EKF é definida por $1000 / 70=14,28 \mathrm{~Hz}$. Assim, o desempenho requerido pode ser estimado por meio da combinação dessa informação com o número desejado de 1,5k features a ser processado pelo EKF em tempo real.

Para 1,5k features e $r$ e $s$ iguais a 3 e 2, respectivamente, a dimensão da matriz de co-variância $\Sigma^{(t)}$ é $3003 \times 3003$ e do vetor da média $\mu^{(t)}$ é $3003 \times 1$. Nessa implementação, os dados são representados em ponto flutuante com precisão simples (32bits) tendo, assim, essa matriz a capacidade de armazenar o total de 36MB. Esses dados são armazenados em memória externa e devem ser lidos e escritos a uma frequência de $14 \mathrm{~Hz}$. Como resultado, a largura de banda da memória é de $1 \mathrm{~GB} / \mathrm{s}$. Com o objetivo de reduzir esse gargalo, a arquitetura proposta distribui os dados entre quatro memórias externas. O controle de acesso para essas memórias é implementado por uma máquina de estados e cada memória é acessada em paralelo. Essa máquina de estados também controla o fluxo de dados entre as memórias internas e os PEs; explora a reutilização de dados dentro do FPGA usando os bancos de memórias internas (MPEs); computa a inversão da matriz $S$; e controla a iteração entre as equações do EKF.

\subsubsection{Elementos de Processamento}

O propósito dos PEs na arquitetura do EKF é computar as três operações mais comuns do algoritmo EKF, apresentadas na Tabela 5.3, explorando-se a reutilização de dados no código, que reduz o gargalo de acesso à memória externa, e o paralelismo no FPGA.

Tabela 5.3: Operações do PE, onde $A, B, C$ e $R$ são blocos de partições de matrizes.

\begin{tabular}{c|l}
\hline Código & Operação \\
\hline \hline 00 & $R=A B$ \\
01 & indefinido \\
10 & $R=C+A B$ \\
11 & $R=C-A B$ \\
\hline \hline
\end{tabular}


Nessa arquitetura, as matrizes de tamanho $N \times M$ são divididas em blocos. Considere três matrizes A, B e C onde A multiplica B e o resultado é adicionado com C. Assim, cada bloco é composto de $1 \times M$ elementos da matriz A, $N \times 8$ elementos da matriz B e $1 \times 8$ elementos da matriz C. A constante 8 corresponde ao número de palavras que pode ser armazenado na memória interna de cada PE para reutilização de dados. A Figura 5.3 apresenta como os dados reutilizados internamente nos PEs influenciam a largura de banda de acesso à memória externa. Esse gráfico mostra a influência na largura de banda de todos os elementos da Equação 5.6 para um conjunto variado de número de features computado de acordo com a Equação 5.17, onde $\omega$ é a largura de banda da memória externa em MB/s, $u$ a frequência de atualização, $m$ a dimensão da matriz, $j$ o tamanho do buffer do PE, e $s$ o tamanho do vetor de estados da feature. Como pode ser notado nessa equação, quanto maior for $j$, mais dominante se torna o termo $2 m^{2}$, o qual corresponde às operações de escrita e leitura de toda a matriz de co-variância na memória externa. Nos PEs propostos, o tamanho 8 foi escolhido por resultar num bom balanço para a plataforma de desenvolvimento adotada entre a quantidade de memória interna e a largura de banda da memória externa requeridos. Na arquitetura proposta, cada bloco da matriz é processado por um simples PE podendo, assim, quatro blocos serem concorrentemente computados.

$$
\omega=u\left(m^{2} s / j+m s+2 m^{2}\right) 4
$$

$\mathrm{Na}$ arquitetura PE, o dado da matriz A é reutilizado 8 vezes. Porém, sempre que a matriz B tiver menos que 8 colunas, a computação é reordernada para otimizar o uso do tamanho do pipeline. A reordenação, que é facilmente realizada na máquina de estados através da mudança da ordem dos dados enviados pelos PEs às FIFOs, é definida para as três operações do PE (ver Tabela 5.3) do seguinte modo: $R=\left(B^{T} A^{T}\right)^{T}$, $R=\left(C^{T}+B^{T} A^{T}\right)^{T}$ e $R=\left(C^{T}-B^{T} A^{T}\right)^{T}$. No algoritmo EKF, essa reordenação é utilizada para calcular o ganho do filtro $W$. Finalmente, na situação onde a matriz A tem menos que 8 linhas e a matriz B menos que 8 colunas, é necessário preencher esse espaço 


\section{MBytes/s}

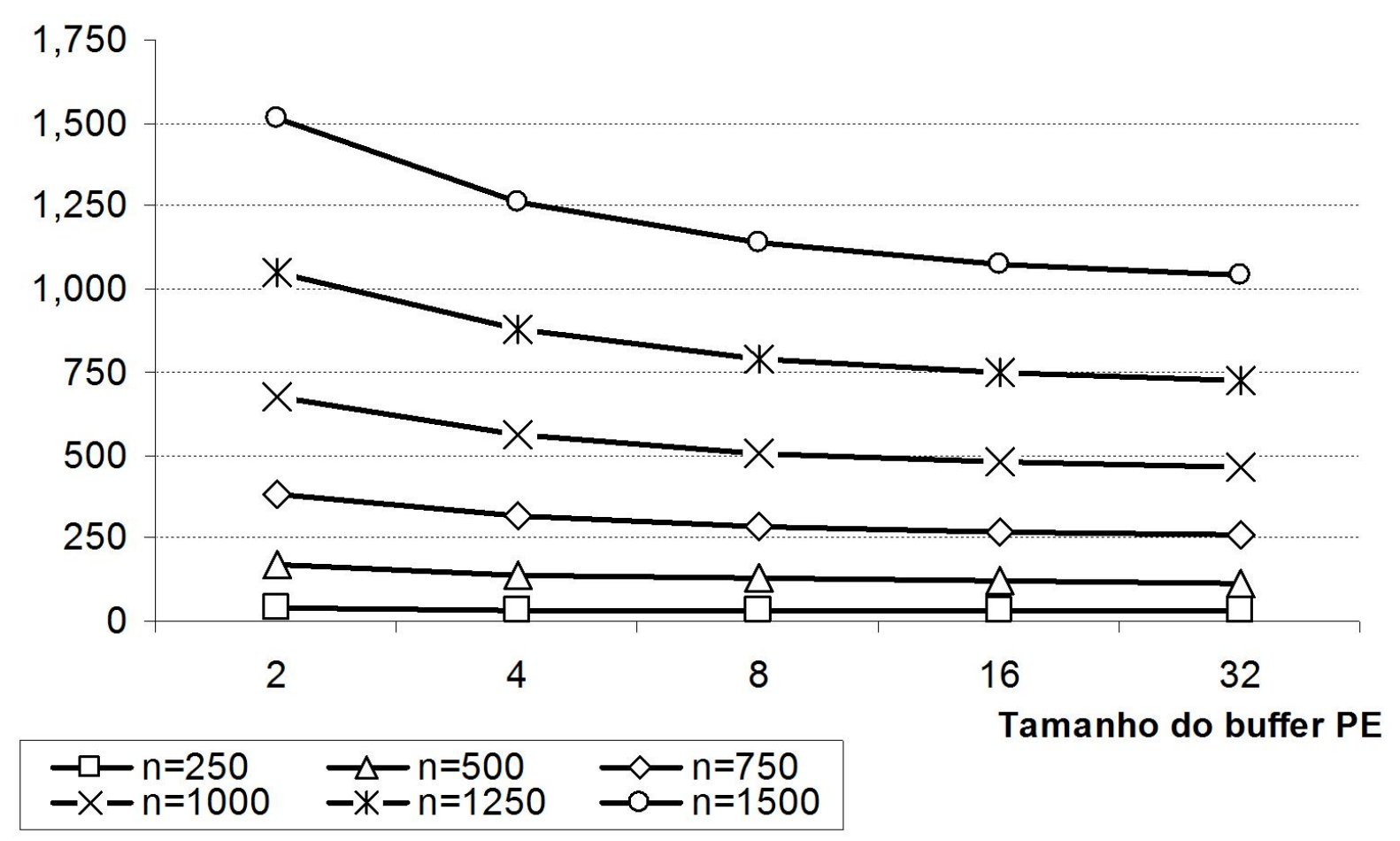

Figura 5.3: Largura de banda de acesso à memória externa.

com dados quaisquer e em seguida rejeitar os resultados correspondentes. No algoritmo EKF isso ocorre somente na Equação 5.3.

\subsubsection{Configuração Alternativa do Sistema}

Após apresentar a arquitetura do PE e a metodologia adotada para implementar as operações com as matrizes, esta subseção demonstra o impacto na largura de banda da memória externa e na frequência de operação do PE para configurações alternativas do sistema alterando o tamanho do vetor de estado da feature e a quantidade de PEs. Essas projeções são realizadas usando 1,5k features e uma frequência de atualização de $14 \mathrm{~Hz}$. A Figura 5.4 demonstra o impacto na largura de banda da memória externa quando altera-se o tamanho do vetor de estado da feature e mantém-se os quatro PEs $(j=8)$. Considere que cada PE tem uma memória externa dedicada e que cada memória é capaz de transferir até $400 \mathrm{MB} / \mathrm{s}$. Assim, o sistema proposto pode suportar features com a dimensão de até quatro elementos sem reduzir o número de $1,5 k$ features e nem a frequência de atualização. 
Porém, para atingir esse desempenho é necessário ajustar a frequência de operação do PE de acordo com a demanda de processamento.

\section{Mbytes/s}

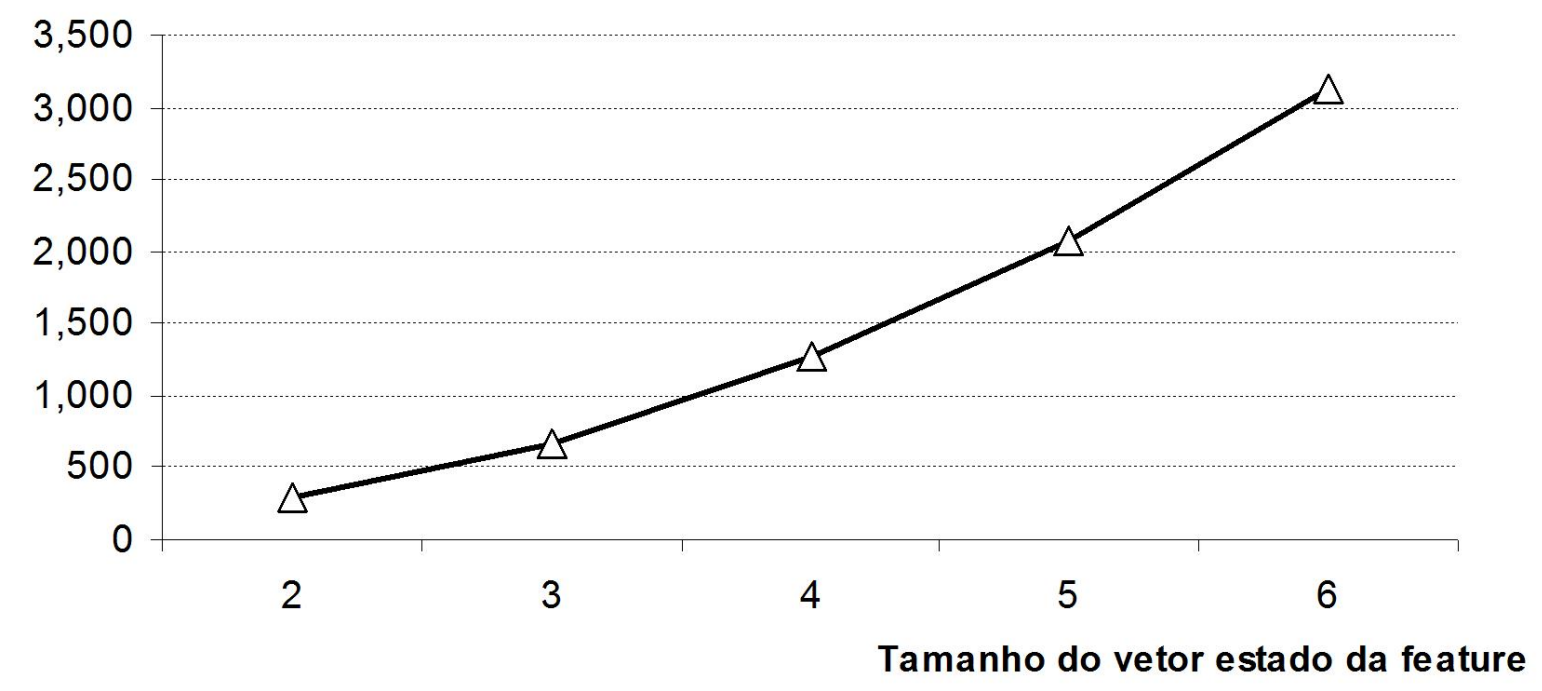

Figura 5.4: Largura de banda da memória externa como uma função do tamanho do vetor de estado da feature usando quatro $\mathrm{PEs}(j=8), 1,5 k$ features e $14 \mathrm{~Hz}$ de frequência de atualização.

A Figura 5.5 exibe a frequência requerida de operação do pipeline para o EKF em relação ao número de PEs, o qual é obtido baseado na complexidade computacional do EKF (FLOPs), considerando-se que o tamanho do vetor de estado da feature é igual a dois e que cada PE realiza duas operações de ponto-flutuante por ciclo de clock. De acordo com esse gráfico, com quatro PE's a frequência requerida é de aproximadamente $50 \mathrm{MHz}$, demonstrando que é possível melhorar o desempenho do sistema para uma dimensão maior do vetor de estado da feature, uma vez que é factível para FPGAs ter PEs operando a uma frequência superior à 100MHz.

\subsection{Resultados}

Esta seção apresenta alguns resultados experimentais relacionados à arquitetura descrita neste trabalho, em particular, os recursos de hardware empregados, seu desempenho e consumo de energia. A arquitetura foi programada com a linguagem Handel-C (Celoxica, 2005a) e validado na plataforma de desenvolvimento RC250 da Celoxica (Celoxica, 


\section{Frequência do pipeline PE (MHz)}

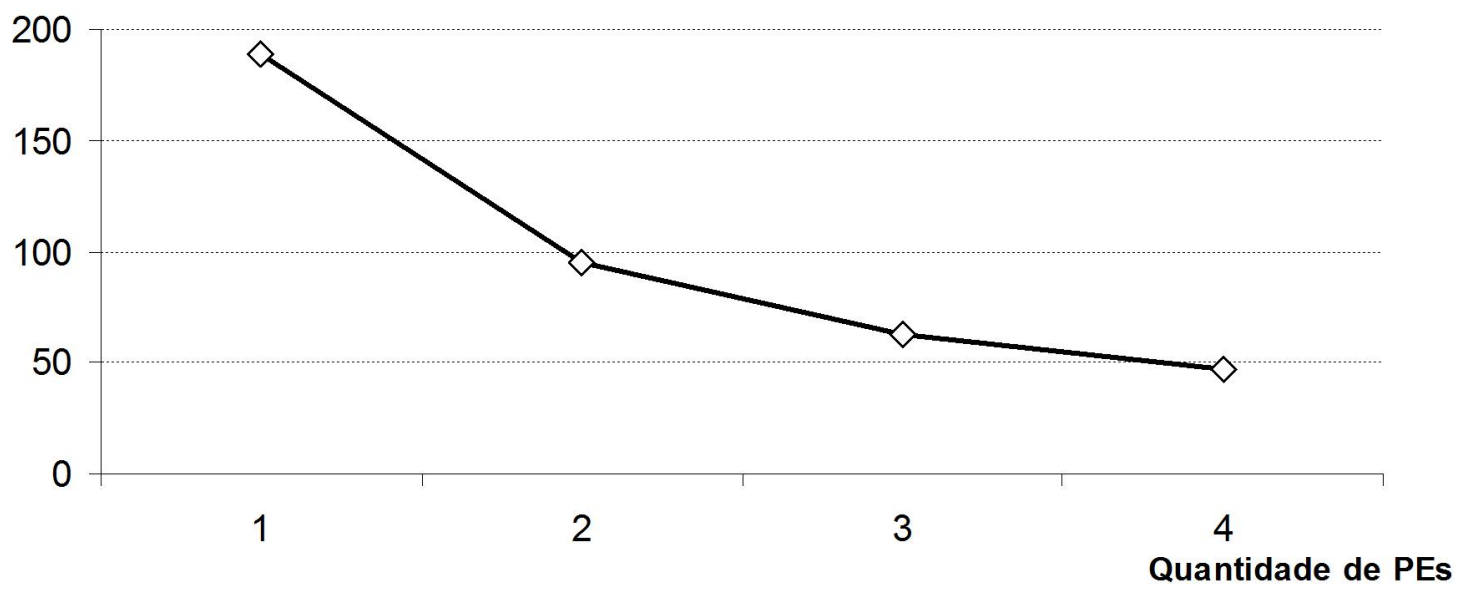

Figura 5.5: Frequência de operação do pipeline PE requerida para o EKF em função do número de PEs, sendo que o tamanho do vetor de estado da feature é igual a dois e que cada PE processa dois FLOP por ciclo de clock.

2005b), o qual possui quatro bancos de memória externa com acesso independente e um FPGA EP2S90F1020C4.

Os recursos utilizados e a frequência máxima do clock de um único PE são mostrados na Tabela 5.4. Como pode ser notado, 70\% dos recursos de um PE são usados nas unidades de ponto flutuante (MULT, ADD) e os 30\% restantes na lógica de controle. Essas unidades de ponto flutuante são obtidas da biblioteca fornecida pela Celoxica, que são baseadas no padrão IEEE754 no formato de precisão simples. Embora a unidade MULT tenha uma frequência de operação superior ao da unidade ADD, a frequência de operação do PE é limitada pela do ADD, uma vez que esse hardware opera com um único clock. A latência mínima do PE é de quatro clocks e a máxima depende da operação nele executada e do tamanho das matrizes a serem processadas.

Tabela 5.4: Recursos do FPGA para a implementação de um PE.

\begin{tabular}{l||c|c|c}
\hline EP2S90F1020C4 & MULT & ADD/SUB & PE completo \\
\hline \hline Clock $(\mathrm{MHz})$ & 156 & 97 & 94 \\
\hline Latência (em clocks) & 3 & 3 & 4 (mínimo) \\
\hline ALUTs & 599 & 1078 & 2368 \\
\hline Registradores & 517 & 546 & 1492 \\
\hline Blocos de DSP (9bit) & 8 & 0 & 8 \\
\hline \hline
\end{tabular}


A Tabela 5.5 apresenta os recursos de hardware necessários para a implementação de toda a arquitetura, incluindo os controladores de acesso das memórias externas, a máquina de estado do EKF, as memórias internas e os quatro PEs. Grande parte dos recursos na coluna $S M+E M C$ são utilizados para implementar a máquina de estado do EKF. O custo de hardware dessa implementação é relativamente alto, uma vez que é necessário o controle do particionamento de cada matriz entre os PEs e da combinação no final da operação para concatenar novamente os resultados/blocos. Além disso, esse hardware contém uma divisão em ponto flutuante necessária para calcular o inverso da matriz $S$. Embora o PE tenha maior frequência de operação que a máquina de estado, nessa arquitetura a frequência de clock de todo o sistema está limitada à frequência da máquina de estado pelo fato dela controlar todo o fluxo dos dados enviados e lidos das FIFOs presentes nos PEs.

Tabela 5.5: Recursos do FPGA para toda a arquitetura do EKF; sendo SM a máquina de estado do EKF e EMC o controlador de acesso à memória externa.

\begin{tabular}{l||c|c|c}
\hline EP2S90F1020C4 & 4 PEs & SM+EMC & Total \\
\hline \hline Clock $(\mathrm{MHz})$ & 90 & 70 & 70 \\
\hline ALUTs & 9252 & 8868 & $18120(25 \%)$ \\
\hline Registradores & 5332 & 2985 & 8317 \\
\hline Blocos de DSP (9bit) & 32 & 0 & $32(8 \%)$ \\
\hline Memória bits & 9216 & 3392 & $12608(1 \%)$ \\
\hline \hline
\end{tabular}

\subsubsection{Análise do Desempenho e do Consumo de Energia}

A análise do desempenho do sistema é realizada com base na frequência de operação obtida de $70 \mathrm{MHz}$, na frequência de iteração do EKF de $14 \mathrm{~Hz}$, e na complexidade computacional apresentada na Tabela 5.2, onde $n$ representa o número de features. Nessa implementação, cada PE processa duas operações de ponto flutuante (MULT and ADD) por ciclo de clock, tendo-se um pico de desempenho do sistema de 560MFLOPs, uma vez que o mesmo possui 4 PEs. Porém, a média de desempenho é ligeiramente inferior a esse número devido às seguintes razões: as FIFOs são esvaziadas sempre que existir transição de uma operação de matriz para outra; e em alguns ciclos de clock a máquina de estados 
não envia dados para as FIFOs devido ao controle interno de ciclos de execução (loops). O primeiro overhead é constante e quanto maior forem as matrizes menor será a influência no desempenho médio do sistema. Porém, o segundo overhead é um valor proporcional que reduz a média de desempenho em aproximadamente 3\%. Assim, o número máximo de features que podem ser processadas em tempo real $(14 \mathrm{~Hz})$ é de aproximadamente $1,8 k$. A energia consumida pelo sistema do EKF estimada com o PowerPlay Power Analyzer da ferramenta Quartus II e usando-se métodos probabilísticos para ativar as suas entradas é de 1,3W. Cabe ressaltar, que estimar o consumo de energia em FPGA é uma tarefa difícil, mas nesse caso, a sua complexidade foi reduzida pelo fato do sistema EKF não utilizar processador sofcore (Holanda et. al., 2007).

Para comparar esses resultados com outras tecnologias considerou-se os processadores Pentium M 1,6GHz e o ARM920T 200MHz (Logic, 2005), pois o primeiro é encontrado normalmente em placas embarcadas em robôs móveis, como na plataforma Pioneer 3DX (ActivMedia Robotics, 2006); e o segundo é amplamente usado em sistemas embarcados de baixo consumo de energia. O desempenho alcançado em tempo real $(14 \mathrm{~Hz})$ nesses dispositivos, executando-se o EKF implementado em C, foi de 572 features para o Pentium e de 131 para o ARM920T.

De acordo com o manual desses processadores, o Pentium $\mathrm{M}$ consome $31,1 \mathrm{~W}$ e o ARM920T 750mW quando em frequência máxima. A Tabela 5.6 e a Figura 5.6 resumem e ilustram a comparação entre essas três opções. Como pode ser visto, apesar do processador ARM920T ter o menor consumo de energia, o FPGA processa mais features em tempo real consumindo menos energia por feature que ambos os processadores. Também é importante considerar que a complexidade computacional do EKF é $\Theta\left(n^{2}\right)$, onde $n$ representa o número de features. Assim, para alcançar o mesmo desempenho do FPGA, o Pentium M precisa incrementar seu atual processamento em aproximadamente 9,9 vezes e o ARM920T em 189 vezes. 
Tabela 5.6: Comparação entre o desempenho e a energia consumida entre o FPGA e os processadores Pentium M 1,6GHz e ARM920T 200MHz.

\begin{tabular}{l||c|c|c}
\hline & FPGA & Pentium M & ARM920T \\
\hline \hline Energia $(\mathrm{W})$ & 1,3 & 31,1 & 0,75 \\
\hline Max. número de features em tempo real $(\mathrm{k})$ & 1,8 & 0,57 & 0,13 \\
\hline Energia por feature $(\mathrm{mW})$ & 0,7 & 54 & 5,7 \\
\hline \hline
\end{tabular}

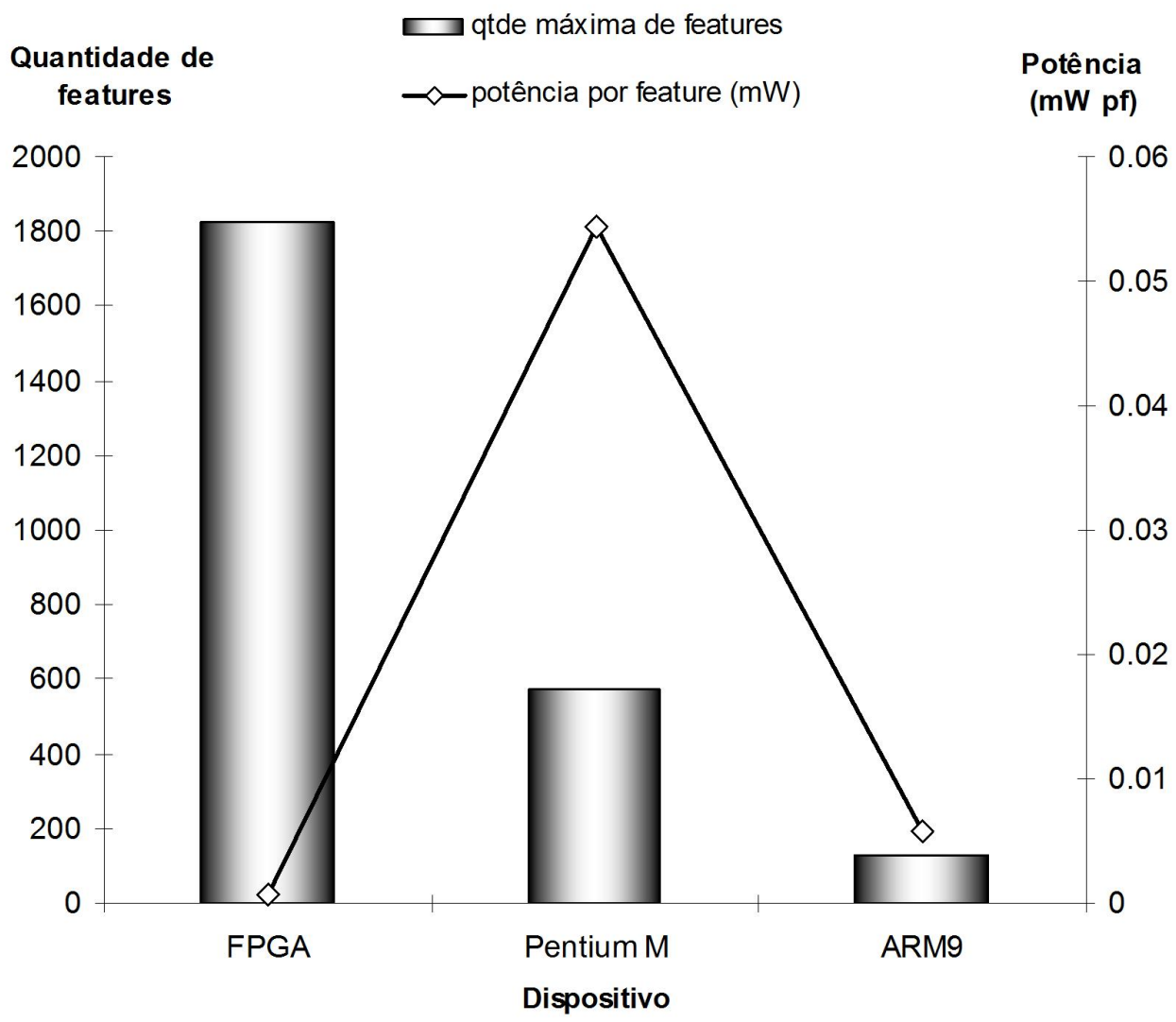

Figura 5.6: Número máximo de features e consumo de energia para os três dispositivos de processamento. 


\subsection{Considerações Finais}

Neste capítulo foram apresentadas uma análise computacional e uma arquitetura baseada em FPGA para o algoritmo do EKF aplicado ao problema do SLAM. A análise demonstrou que para uma implementação em hardware é necessário ter tanto um eficiente método para multiplicação de matrizes (com dados em ponto flutuante), quanto uma banda larga para acesso à memória externa. Na plataforma de desenvolvimento RC250 da Celoxica foi possível demonstrar que a tecnologia FPGA é adequada para resolver o problema, uma vez que a multiplicação de matrizes pode ser acelerada fazendo-se uso do paralelismo, enquanto que a banda de acesso à memória externa pode ser melhorada por meio do acesso paralelo dos bancos de memória externa. Como resultado, a arquitetura implementada no FPGA apresentou desempenho e consumo de energia significantemente melhores que os processadores Pentium M 1,6GHz e ARM920T 200MHz. Embora o FPGA adotado pudesse suportar mais do que quatro PEs, o desempenho do sistema atual de $1,8 \mathrm{k}$ features a $14 \mathrm{~Hz}$ é adequado para a maioria das aplicações em ambientes internos e está limitado devido à largura de banda de acesso à memória externa. 

CAPÍtulo

\section{A Arquitetura de Hardware Paralelo Criada}

\section{para Detecção de Features Invariante à Escala \\ e Rotação}

Este capítulo apresenta uma arquitetura de hardware paralela para detecção de features invariante à escala e rotação, baseado no algoritmo SIFT (Lowe, 2004) e aplicado no problema SLAM (Thrun et. al., 2005). A arquitetura proposta é stand-alone e totalmente embarcada em FPGA; processa até 30 frames por segundo lidos diretamente de uma câmera CMOS e fornece as features detectadas com seus descritores associados.

Este capítulo está assim organizado: na Seção 6.1 é apresentado o algoritmo SIFT e em seguida, na Seção 6.2, é descrito detalhadamente a arquitetura orientada a hardware proposta para o algoritmo; na Seção 6.3 são descritos os resultados experimentais, com o objetivo de verificar o desempenho do sistema e os recursos de FPGA utilizados; e por fim, a Seção 6.4 apresenta as considerações finais. 


\subsection{Algoritmo para Detecção de Features Invariante à Escala e à Rotação}

Esta seção descreve o algoritmo SIFT (Lowe, 2004), no qual o sistema proposto de detecção de features é baseado. O algoritmo está dividido em três estágios principais: o primeiro identifica os pixels candidatos a feature, o seguinte aplica um conjunto de testes para verificar se os candidatos são estáveis em relação a transformações de imagens onde o mesmo pode ser rejeitado ou aceito. Por fim, após detectar as features estáveis, o estágio final gera um descritor/assinatura para ser associado com a feature.

\subsubsection{Selecionando Features Candidatas}

Uma feature candidata (keypoint) é um pixel localizado numa escala de frequência específica que possui o mínimo ou o máximo valor em relação à sua vizinhança (extremo), que é definida por uma janela de $3 \times 3$ localizada no mesmo espaço de escala e nas escalas adjacentes acima e abaixo (total 26 pixels). A banda de frequência para cada escala é obtida por meio da operação de diferença da Gaussiana (DoG), obtida através da subtração de duas imagens idênticas geradas a partir da convolução de dois kernels Gaussianos distintos. As Equações 6.1 e 6.2 definem a operação de convolução (*) para a primeira e as outras subsequentes escalas, respectivamente, e a Equação 6.3 define a operação de diferença, onde $I$ é a imagem de entrada, $K$ o kernel Gaussiano, $G$ a imagem filtrada e $D$ a imagem resultante numa escala específica de frequência definida pelos valores do kernel.

$$
G_{0}(x, y)=K_{0}(x, y) * I(x, y)
$$

$$
G_{s+1}(x, y)=K_{s+1}(x, y) * G_{s}(x, y)
$$




$$
D_{i}(x, y)=G_{s+1}(x, y)-G_{s}(x, y)
$$

A Figura 6.1 ilustra essas operações mostrando um exemplo com cinco bandas de frequência computadas a partir de seis operações de convoluções Gaussianas. Nesse caso, como o keypoint é determinado por meio da análise da escala a qual ele pertence e das duas escalas adjacentes, é possível a existência de keypoints pertencendo até três escalas diferentes. Nessa figura, o símbolo "x" corresponde a um keypoint.

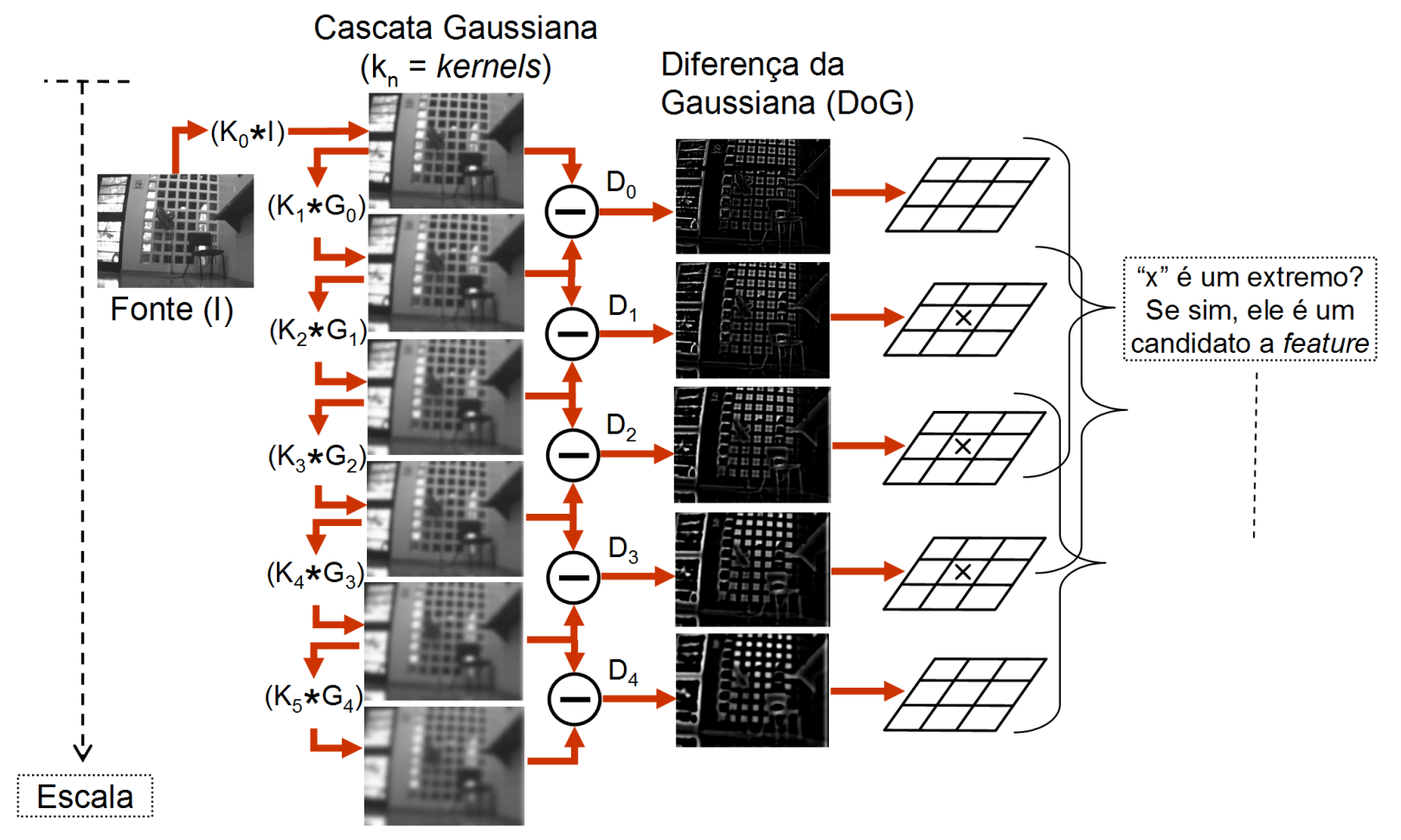

Figura 6.1: Diagrama de blocos representando as principais operações usadas para detectar candidatos a features em uma octave usando um conjunto de seis imagens suavizadas pelo filtro Gaussiano.

O número de escalas é um parâmetro definido de acordo com a aplicação. Além do número de escalas, o algoritmo é também parametrizado com um número de octave, onde cada octave corresponde a um conjunto de imagens processadas a uma determinada resolução. Neste trabalho foram utilizada três octaves, sendo o primeiro conjunto com resolução de $320 x \times 240$, o segundo $160 \times 120$ e o terceiro $80 \times 60$. A justificativa para o uso de três octaves está presente na subseção6.2.1. 


\subsubsection{Testando a Estabilidade da Feature}

O estágio de verificação da estabilidade da feature tem o objetivo de rejeitar ou aceitar um keypoint como uma feature e é realizado por meio de três funções: refinamento de localização; verificação de contraste; e verificação de borda. O refinamento de localização é realizado pela Equação 6.4 em que $\omega$ é o valor da correção da localização para as coordenadas $\langle x, y\rangle$ e a escala $s, D$ é a função DoG e $l$ o vetor de localização do pixel $(x, y, s)$ (Brown e Lowe, 2002). Essa equação realiza uma operação de interpolação com os pixels localizados dentro da vizinhança do keypoint (26 pixels), onde $\omega$ é adicionado à posição atual do keypoint para produzir sua nova posição. Nessa implementação, o refinamento pára quando: os valores de correção $\langle x, y, s\rangle$ forem menores do que 0,5 pixel; a nova localização encontra-se na borda da imagem; ou ainda mais do que três correções consecutivas ocorreram. Nos últimos dois casos o keypoint é rejeitado e no primeiro ele é mantido para as próximas fases de verificação de estabilidade.

$$
\omega=-\left(\frac{\partial^{2} D}{\partial l^{2}}\right)^{-1} \frac{\partial D}{\partial l}
$$

O valor de correção $\omega$ é também usado na Equação 6.5 para computar o contraste do keypoint. Se o resultado for menor do que um determinado limiar, então o keypoint é rejeitado, caso contrário, o teste final de estabilidade é realizado.

$$
\xi=D+\frac{1}{2}\left(\frac{\partial D}{\partial l}\right)^{T} \omega
$$

Finalmente, uma análise de curvatura principal é realizada para rejeitar keypoints que estão localizados em bordas mal definidas, os quais, consequentemente, são altamente instáveis. Isso é particularmente importante para a função DoG, uma vez que a maioria dos keypoints são localizados nas bordas. Quanto maior for a curvatura principal, menor será a qualidade da borda. Assim, a Equação 6.6 calcula a principal curvatura e a rejeita se o resultado estiver acima de um determinado limiar. 


$$
\frac{\left(\frac{\partial D}{\partial x^{2}}+\frac{\partial D}{\partial y^{2}}\right)^{2}}{\operatorname{Det}(H)}<\text { Threshold }
$$

onde:

$$
H=\left[\begin{array}{cc}
\frac{\partial D}{\partial x^{2}} & \frac{\partial D}{\partial x \partial y} \\
\frac{\partial D}{\partial y \partial x} & \frac{\partial D}{\partial y^{2}}
\end{array}\right]
$$

Uma vez que o keypoint passou pelas fases anteriores, ele é finalmente classificado como uma feature sendo, a partir desse ponto, identificado pelas suas coordenadas $\langle x, y\rangle \mathrm{e}$ escala $s$.

\subsubsection{Associando Descritor à Feature}

Nesse estágio, a feature recebe um rótulo representado por um vetor de 128 bytes. A partir desse momento, a imagem obtida após a operação DoG não é mais utilizada e todas as informações necessárias para gerar o descritor são obtidas da cascata de imagens Gaussianas (ver Figura 6.1).

Após detectar uma feature, o primeiro passo calcula a sua orientação dominante. Para ter essa informação, uma imagem da cascata de filtros Gaussianos é escolhida de acordo com a escala da feature. Após selecionar a imagem apropriada, a orientação e a magnitude de cada pixel, numa janela de $16 \times 16$ pixels centrada nas coordenadas $\langle x, y\rangle$ da feature, são computadas através das Equações 6.8 e 6.9, respectivamente. A partir desses dados é gerado um histograma de orientações composto por 36 elementos/direções em que cada elemento é ponderado em função da magnitude do gradiente e de sua distância em relação ao centro da janela. Como resultado, o pico mais alto do histograma representa a orientação dominante da feature. Porém, para melhorar a estabilidade, o resultado final é obtido através da interpolação entre os três picos mais altos.

$$
\theta(x, y)=\operatorname{atan} 2(G(x, y+1)-G(x, y-1), \quad G(x+1, y)-G(x-1, y))
$$




$$
m(x, y)=\left((G(x+1, y)-G(x-1, y))^{2}+(G(x, y+1)-G(x, y-1))^{2}\right)^{\frac{1}{2}}
$$

A orientação e a magnitude do gradiente computados anteriormente a partir de uma região de $16 \times 16$ pixels, no entorno da feature, são também usados para gerar o descritor dessa feature. Porém, nesse caso, inicialmente a região é rotacionada relativamente à orientação dominante da feature. Em seguida, um histograma de 8 elementos é gerado para cada $4 \times 4$ sub-região. Essa rotação relativa é necessária para que os descritores sejam invariantes à rotação da imagem. Finalmente, um descritor composto por um vetor de 128 bytes é formado a partir do valor da magnitude de cada elemento dos histogramas.

\subsection{Arquitetura Paralela Desenvolvida}

O algoritmo apresentado na Seção 6.1 é considerado uma solução eficiente para detectar features. Porém, ele tem um alto custo computacional causado principalmente pela cascata de filtro Gaussiano e pela verificação da estabilidade do keypoint. Um sistema configurado com 3 octaves e 6 escalas por octave, e baseado totalmente em software, utiliza 1,1s para extrair 514 features de uma imagem de $320 \times 240$ pixels com um processador Intel Core 2 de 1,66GHz; o que é considerado insatisfatório para aplicações de tempo real. Desse modo, por software o sistema detecta 514 features a 0,9 frames por segundo. Nesta seção, é apresentado um System-on-a-Programmable-Chip (SOPC) para detectar features a 30 frames por segundo de imagens com a mesma resolução.

A Figura 6.2 mostra o diagrama de blocos da arquitetura proposta composto por três blocos de hardware e um de software. Os blocos de hardware detectam as features e calculam a orientação e a magnitude do gradiente para cada pixel de uma imagem por octave. Assim, baseado nesses dados, o bloco de software gera os descritores para as features. As subseções seguintes, inicialmente, justificam a configuração do sistema adotada e, posteriormente, descrevem cada bloco de hardware e software desenvolvidos. 


\section{Hardware}

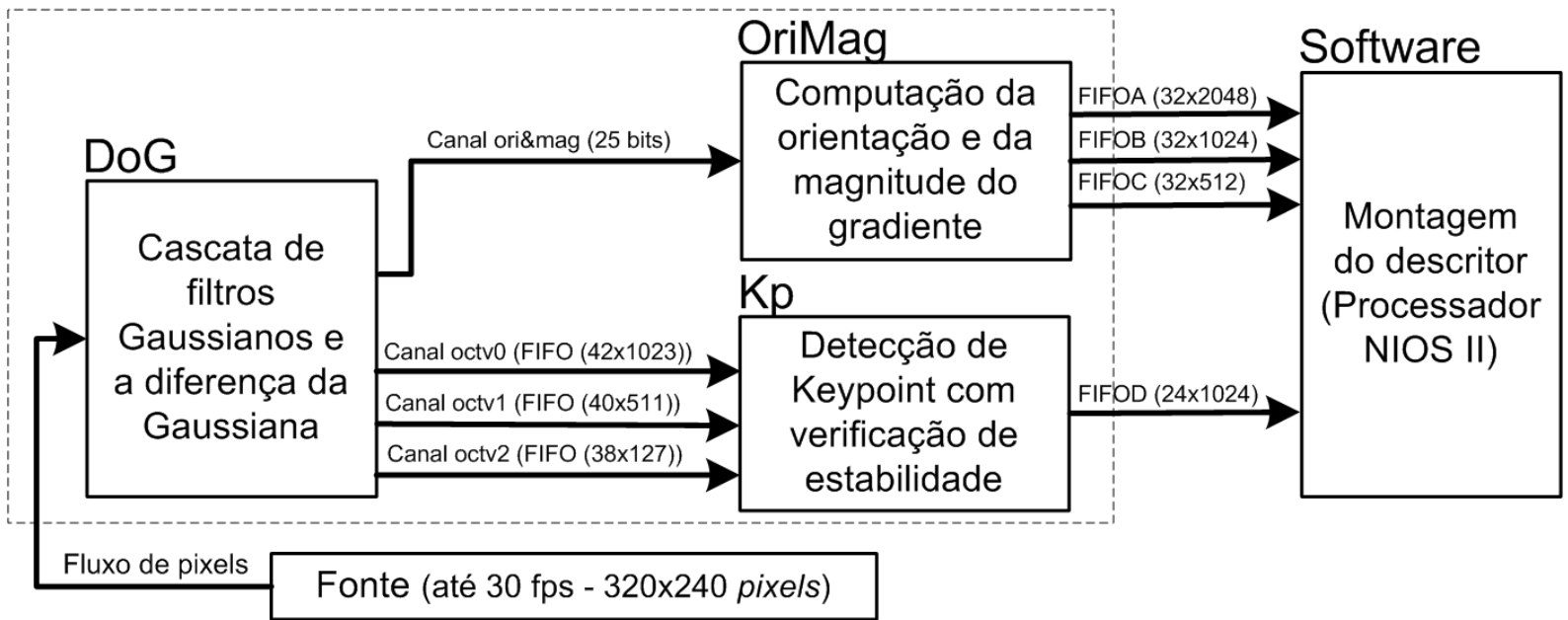

Figura 6.2: Diagrama de blocos do sistema implementado composto por três blocos de hardware usados para extrair features das imagens e para pré-computar dados para os descritores, e um bloco de software para associar os descritores às features. Os blocos são conectados usando canais dedicados que, com exceção do canal entre DoG e OriMag, tem FIFOs internas usadas como buffer enquanto o bloco receptor estiver temporariamente indisponível.

\subsubsection{Configuração do Sistema}

O algoritmo apresentado na Seção 6.1 tem parâmetros e funcionalidades que diretamente afetam a complexidade e o desempenho da arquitetura de hardware. Para identificar uma configuração adequada para a implementação em hardware, a Figura 6.3 apresenta 16 configurações e a suas influências no resultado de associação (matching) de features. O primeiro parâmetro determina se a orientação e a magnitude do gradiente são computados a partir de uma imagem escolhida, conforme a escala da feature, ou de uma escala prédeterminada. O segundo parâmetro apresenta a opção de duplicar o tamanho da imagem de entrada na octave 0 ou de manter o tamanho original. Os outros dois parâmetros estão relacionados à verificação da estabilidade da feature: o primeiro ativa a localização do keypoint e o segundo verifica o contraste e a qualidade da borda.

As features usadas nesses testes foram geradas a partir de dois conjuntos de dez imagens cada, onde o segundo conjunto é uma transformação do primeiro em relação à escala, rotação e ponto de observação (viewpoint). Como visto na Figura 6.3, as opções de configuração de 12 até 16 produzem uma taxa de associação incorreta muito parecidas (positivo falso). Com base nessas informações, a arquitetura é proposta usando-se a opção 12, uma 
vez que essa configuração permite que a orientação e a magnitude do gradiente sejam calculadas em paralelo, enquanto que o keypoint está sendo detectado, e também reduz o uso de memória interna do chip através do processamento da imagem de entrada em seu tamanho original. Outro motivo é o fato de que a maior parte da computação envolvida nas funções de contraste e de verificação da qualidade da borda são reutilizadas na função de localização de keypoints.

O sistema está configurado para três octaves com cinco escalas em cada uma. Esse número de octaves é suficiente para imagens de $320 \times 240$ pixels, uma vez que uma quarta octave produziria imagens pequenas e com pouca nitidez, reduzindo significantemente as chances de detecção de features. O número de escalas foi escolhido baseado em Lowe (2004), onde é demonstrado que esse número tem a maior taxa de repetibilidade de features.

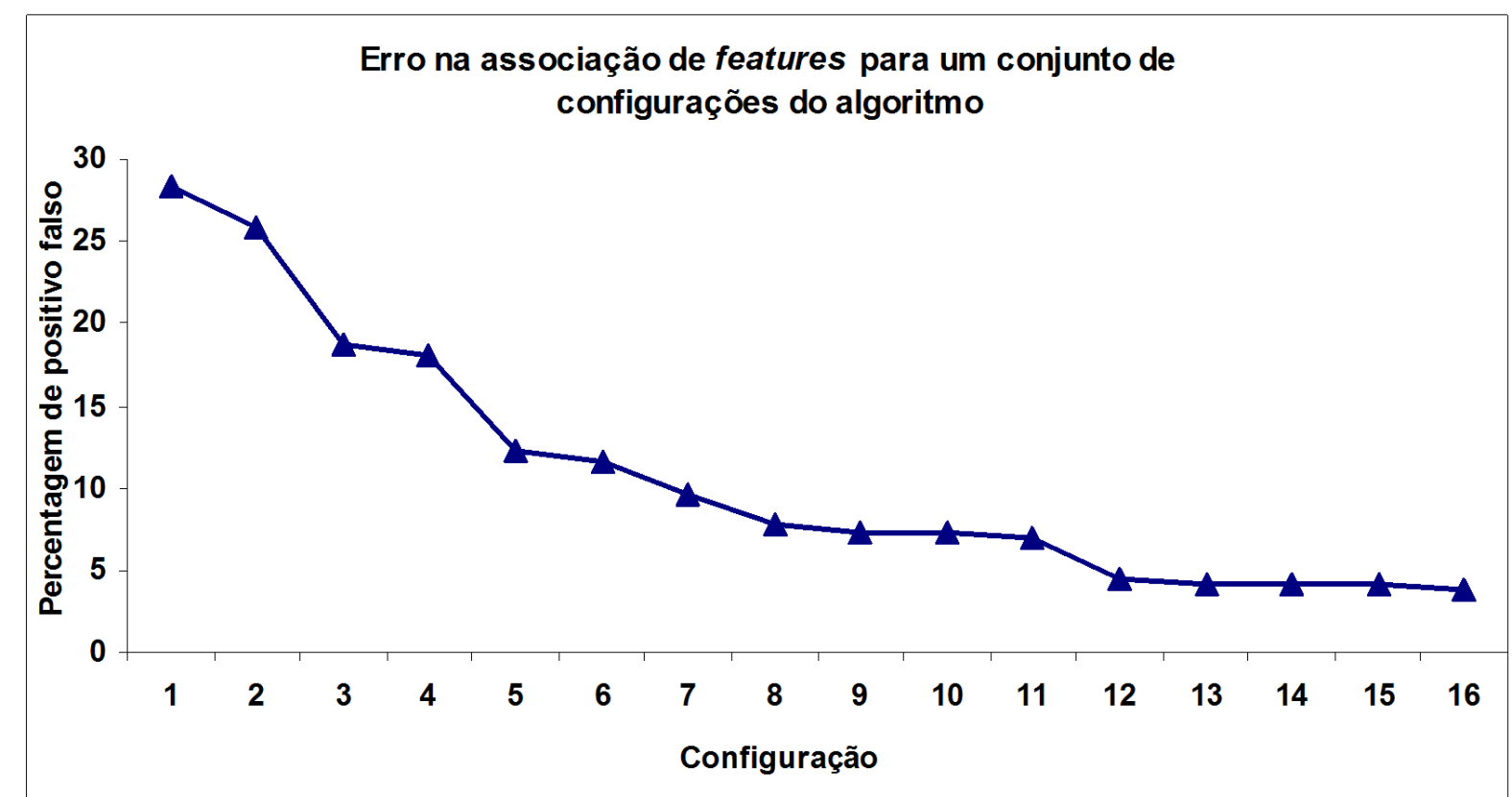

\begin{tabular}{|l|c|c|c|c|c|c|c|c|c|c|c|c|c|c|c|c|}
\hline Configuração & $\mathbf{1}$ & $\mathbf{2}$ & $\mathbf{3}$ & $\mathbf{4}$ & $\mathbf{5}$ & $\mathbf{6}$ & $\mathbf{7}$ & $\mathbf{8}$ & $\mathbf{9}$ & $\mathbf{1 0}$ & $\mathbf{1 1}$ & $\mathbf{1 2}$ & $\mathbf{1 3}$ & $\mathbf{1 4}$ & $\mathbf{1 5}$ & $\mathbf{1 6}$ \\
\hline $\begin{array}{l}\text { ori e mag baseados na } \\
\text { escala da feature }\end{array}$ & 0 & 1 & 1 & 0 & 1 & 0 & 1 & 0 & 1 & 0 & 0 & 0 & 0 & 1 & 1 & 1 \\
\hline imagem duplicada & 1 & 1 & 1 & 1 & 0 & 0 & 1 & 0 & 0 & 1 & 0 & 0 & 1 & 1 & 0 & 0 \\
\hline localização & 0 & 0 & 1 & 1 & 0 & 0 & 0 & 1 & 1 & 0 & 0 & 1 & 1 & 1 & 1 & 0 \\
\hline $\begin{array}{l}\text { limiar do contraste e } \\
\text { qualidade da borda }\end{array}$ & 0 & 0 & 0 & 0 & 0 & 0 & 1 & 0 & 0 & 1 & 1 & 1 & 1 & 1 & 1 & 1 \\
\hline
\end{tabular}

Figura 6.3: Análise da associação incorreta de features em relação à configuração do sistema, sendo 0 para a configuração desativada e 1 para ativada. 


\subsubsection{Cascata de Filtros Gaussianos e a Diferença da Gaussiana}

Uma simples abordagem para implementar o filtro Gaussiano é através da convolução de um kernel Gaussiano bidimensional com a imagem, conforme visto na Equação 6.1. Porém, esse método é computacionalmente ineficiente, pois a complexidade para filtrar uma imagem é dada por $\Theta\left(n^{2} m^{2}\right)$, sendo $n$ e $m$ as dimensões do kenel e da imagem, respectivamente. Considerando-se que o kernel $K$ é separável, por exemplo $K=k k^{t}$ para um vetor $k$ representando uma distribuição Gaussiana unidimensional, o filtro pode ser implementado de uma maneira otimizada por meio da convolução da imagem de entrada $I$, na ordem de linha, com o vetor $k$ e a convolução do resultado $H$, na ordem de coluna, novamente com o vetor $k$, conforme apresentadas pelas Equações 6.10 e 6.11. Nesse caso, o custo computacional é reduzido para $\Theta\left(n m^{2}\right)$.

$$
\begin{gathered}
H(x, y)=k(x) * I(x, y) \\
G(x, y)=k^{T}(x) * H(x, y)
\end{gathered}
$$

A Figura 6.4 apresenta uma arquitetura pipeline para o filtro Gaussiano usando um kernel de $7 \times 7$. O lado esquerdo demonstra a convolução na ordem de linha e o direito a de coluna. A implementação proposta também explora a característica de simetria do vetor $k$ e, desse modo, dois multiplicadores no lado esquerdo são poupados por meio do reúso de dados oriundos dos resultados da multiplicação na posição $k_{1}$ e $k_{2}$. No lado direito o mesmo número de multiplicadores poderiam ser poupados. No entanto, nesse caso, como a convolução é realizada na ordem de coluna, seria necessário ter um buffer do tamanho $6 \times w$ para armazenar os dados a serem reutilizados, onde $w$ corresponde ao número de colunas da imagem. Essa arquitetura é novamente otimizada para economizar mais quatro multiplicadores quando se assume que o vetor do kernel tem sempre os valores zero ou um 
nas posições 1 e 7 e, consequentemente, não precisa da operação de multiplicação nesses pontos. Para manter esse padrão com qualquer valor de $\sigma$, o vetor do kernel, quando necessário, deve ser multiplicado por uma constante. Como o sistema proposto tem 18 filtros Gaussianos trabalhando em paralelo, essas otimizações reduzem significantemente os recursos de hardware necessários para a implementação. Outra otimização é também obtida através da conexão do filtros Gaussianos em cascata a fim de reduzir a dimensão do kernel necessária para filtrar imagens de alta escala.

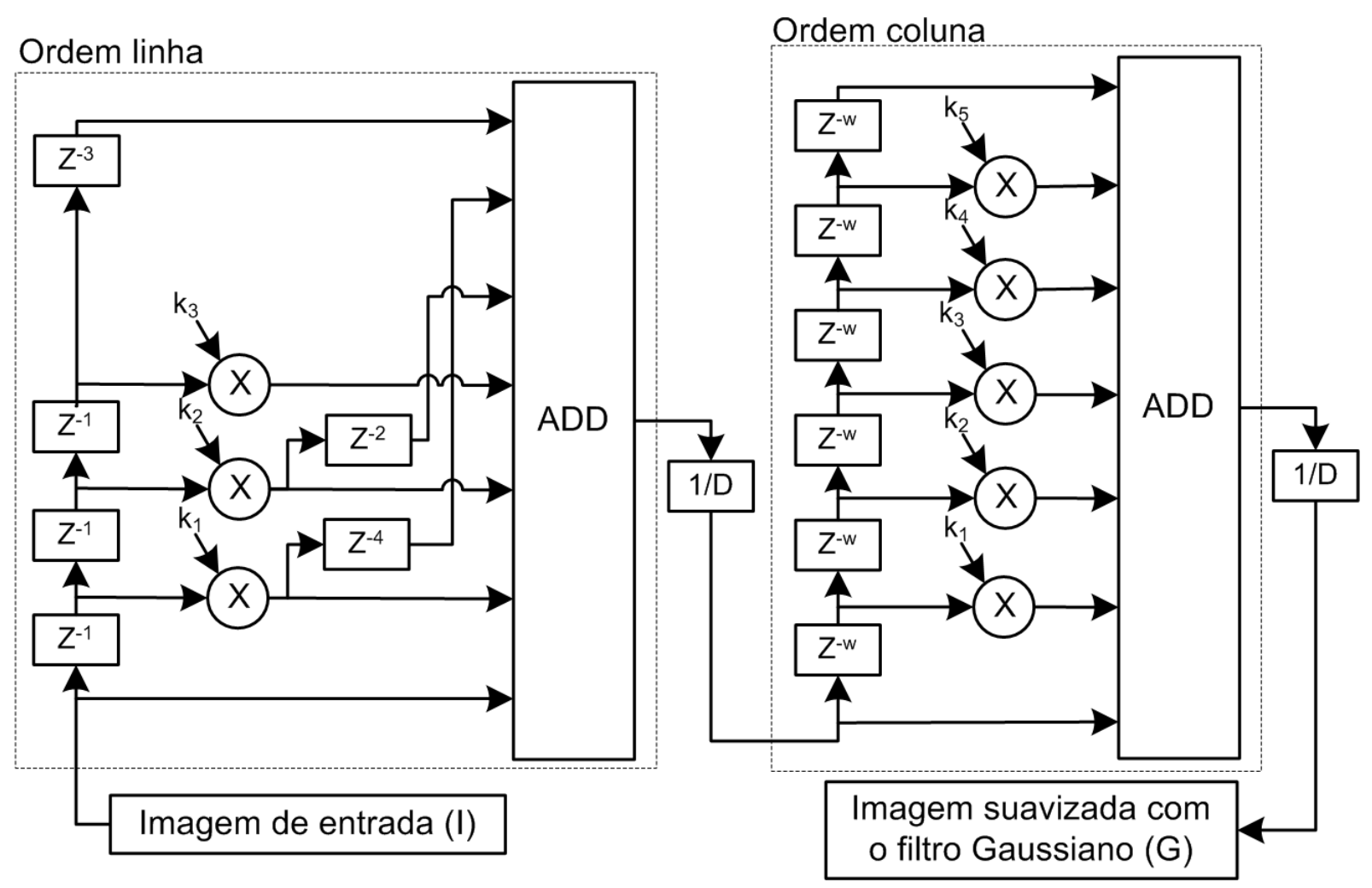

Figura 6.4: Uma arquitetura pipeline para uma versão otimizada do filtro Gaussiano.

A próxima operação computa a diferença da Gaussiana $D_{i}$ por meio da subtração de pares de imagens $\left(G_{i}, G_{i+1}\right)$ filtradas com diferentes $\sigma$ e sincronizadas através de buffers internos $Z$. Cada octave produz cinco $D_{i}$ em paralelo, totalizando-se quinze para as três octaves que são enviadas para o bloco de hardware $K p$ (veja Figura 6.2). A Figura 6.5 apresenta três gráficos gerados a partir de 50 imagens $D_{i}$ que demonstraram que a maioria dos valores dos pixels $D_{i}$ estão localizados na faixa de -15 a +15 . Esses três gráficos também demonstram que as faixas das octaves mais altas estão ligeiramente mais largas, sendo isso ocasionado pela filtragem acumulada da cascata de filtros Gaussianos. 
Como uma imagem $G_{s}$ usa 8 bits para representar um pixel, 9 bits seria o suficiente para armazenar os pixels de $D_{i}$ com o sinal. Porém, se considerada a distribuição dos valores dos pixels de $D_{i}$, demonstrado na Figura 6.5, é possível reduzir significantemente a quantidade de recursos necessários para a implementação do sistema em FPGA. No sistema proposto foram utilizados somente cinco bits (sem o sinal), pois conforme a distribuição apresentada nessa figura, é altamente improvável que a intensidade dos pixels de $D_{i}$ seja maior do que $2^{5}$.

A Figura 6.6 apresenta a influência do sinal do pixel $D_{i}$ na proporção de associações positivas falsas e de corretas, a qual foi obtida do mesmo conjunto de imagens anteriormente usado para determinar a configuração do sistema. Como pode ser verificado, existe pouca influência do uso do sinal do pixel $D_{i}$ na proporção de positivas falsas e corretas; porém, um significante impacto no número de features detectadas. Esse número de feature detectadas é reduzido aproximadamente pela metade, pois, nesse caso, o keypoint é considerado uma feature somente se ele apresentar o valor máximo em relação aos seus vizinhos, desconsiderando-se, assim, o teste do valor mínimo.

Finalmente, a Figura 6.7 exibe a arquitetura proposta para todo o bloco de hardware DoG (ver Figura 6.2). Além das funções anteriormente descritas, essa arquitetura também realiza a redução do tamanho da imagem $G_{3}$ usada como entrada na octave subsequente e gera as coordenadas dos pixels usadas em outros blocos de hardware do sistema.

\subsubsection{Computação da Orientação e da Magnitude do Gradiente}

A arquitetura proposta realiza o pré-processamento da orientação e da magnitude do gradiente para cada pixel de uma imagem por octave, independentemente deste localizarse ou não dentro da região de vizinhança de um keypoint. Essas imagens são obtidas da escala zero de cada octave, após terem sido suavizadas pelo filtro Gaussiano, o que é diferente do algoritmo original onde as imagens são escolhidas de acordo com a escala do keypoint. Porém, a solução proposta reduz significantemente a complexidade do hardware enquanto que a robustez do sistema é mantida, como pode ser visto na Seção 6.3. O propósito de computar com antecedência a orientação e a magnitude do gradiente é reduzir 


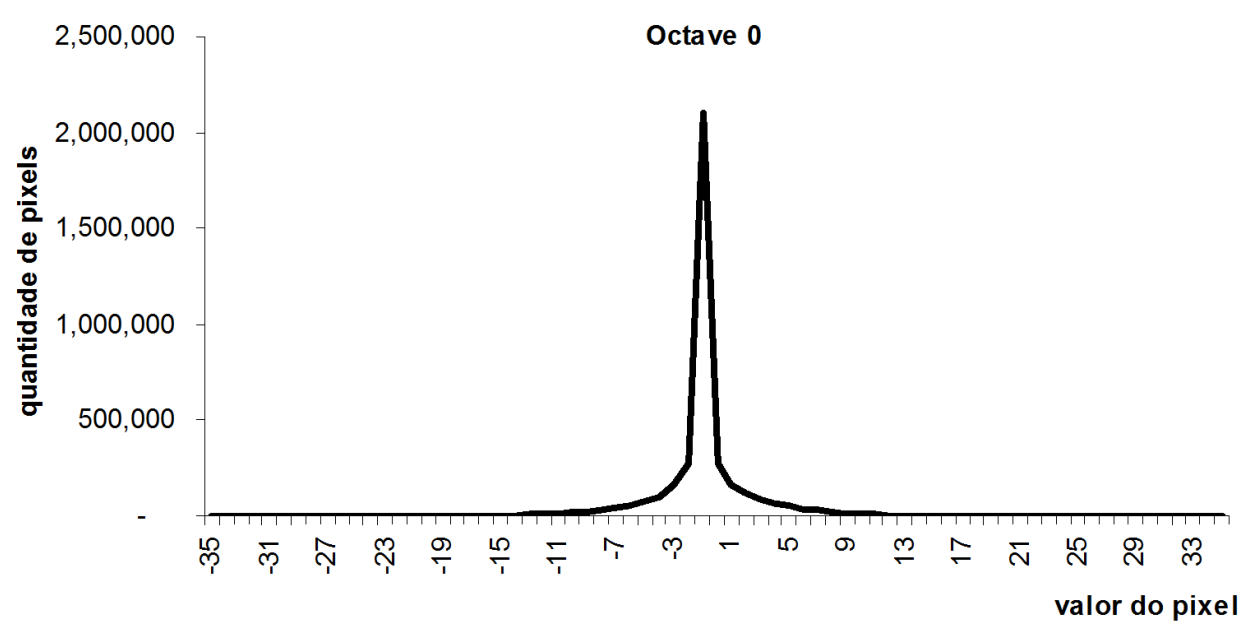

(a)

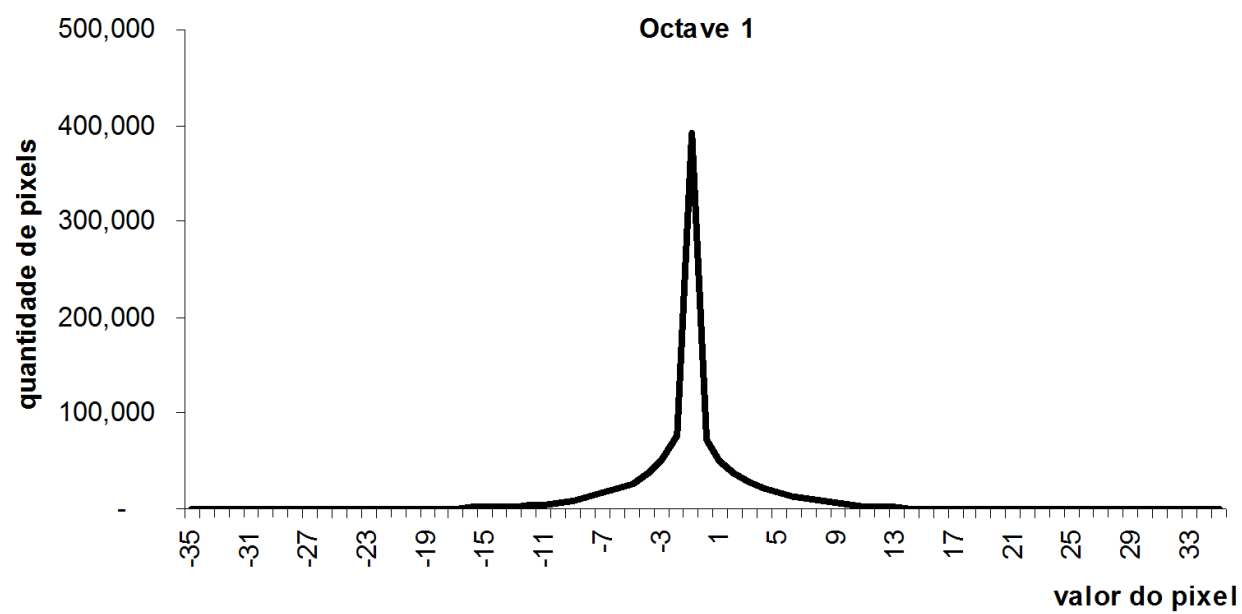

(b)

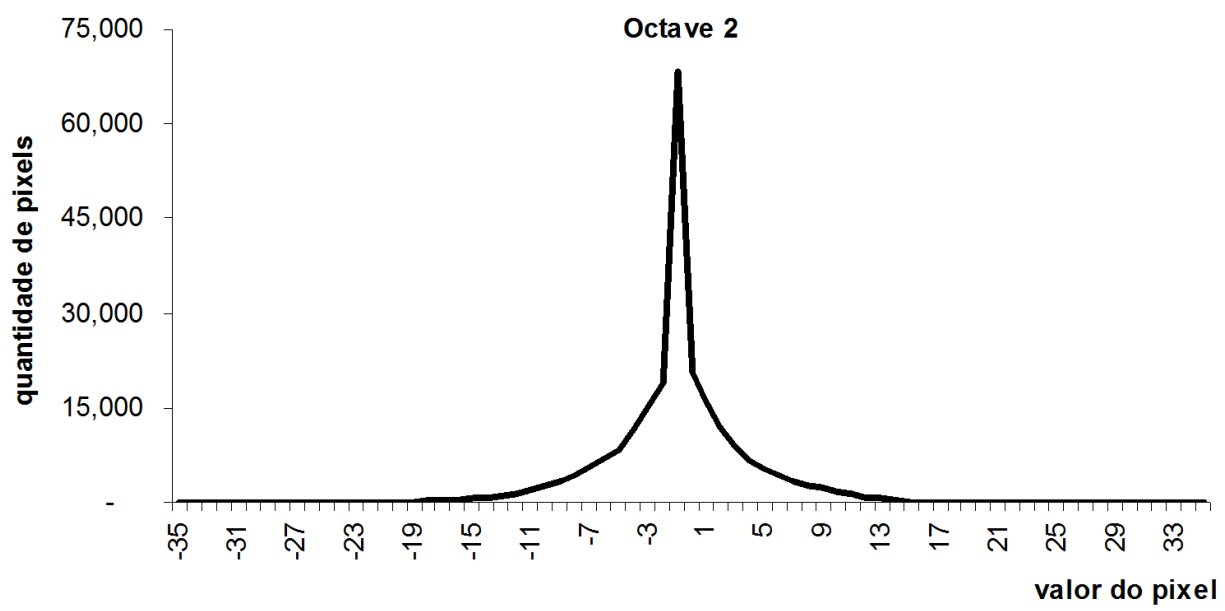

(c)

Figura 6.5: Faixa de valores para quinze imagens $D_{i}$, onde a resolução da imagem de (a) é $320 \times 240$, (b) $160 \times 120$ e (c) $80 \times 60$. 


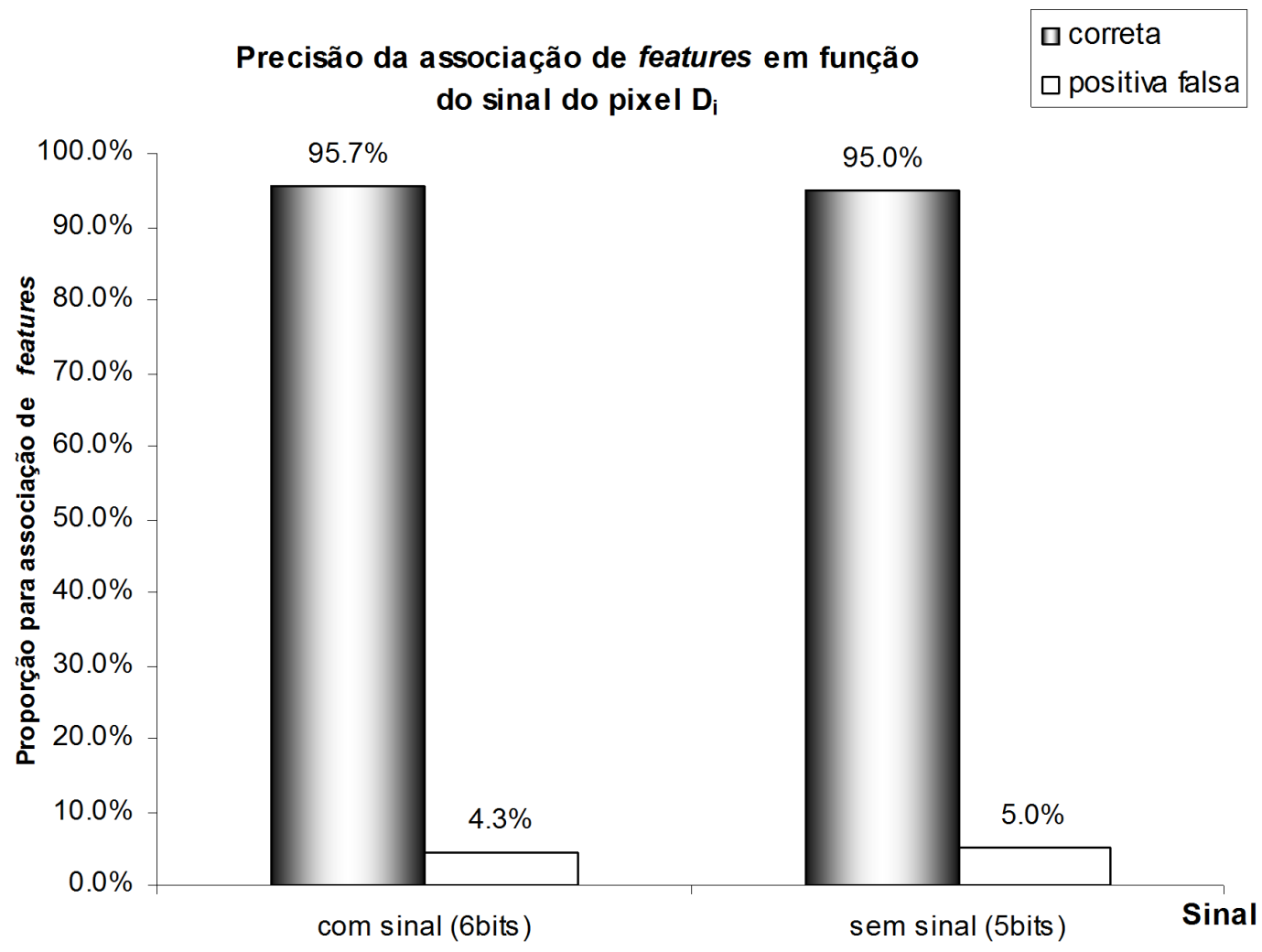

Figura 6.6: Proporção de associação de features positiva falsa e de correta em função do sinal do pixel $D_{i}$.

o tempo de processamento necessário para a geração dos descritores das features em software (processador NIOS II), um vez que essa operação pode ser realizada em paralelo enquanto as features estão sendo detectadas nas imagens.

A operação trigonométrica atan2 e a raíz quadrada são realizadas em hardware usando uma versão adaptada do algoritmo CORDIC (COordinate Rotation DIgital Computer) no modo vetor (Andraka, 1998). Uma função padrão do algoritmo CORDIC é a computação atan, onde cada iteração do algoritmo é realizada de acordo com as Equações 6.12, 6.13 e 6.14. Dadas as coordenadas de um pixel $\left\langle x_{0}, y_{0}\right\rangle$, as regras para a transição entre as iterações, e a rotação inicial $z_{0}$ igual a zero, os valores das Equações 6.12 e 6.14 na iteração $n$ correspondem à raíz quadrada e ao atan, respectivamente. 


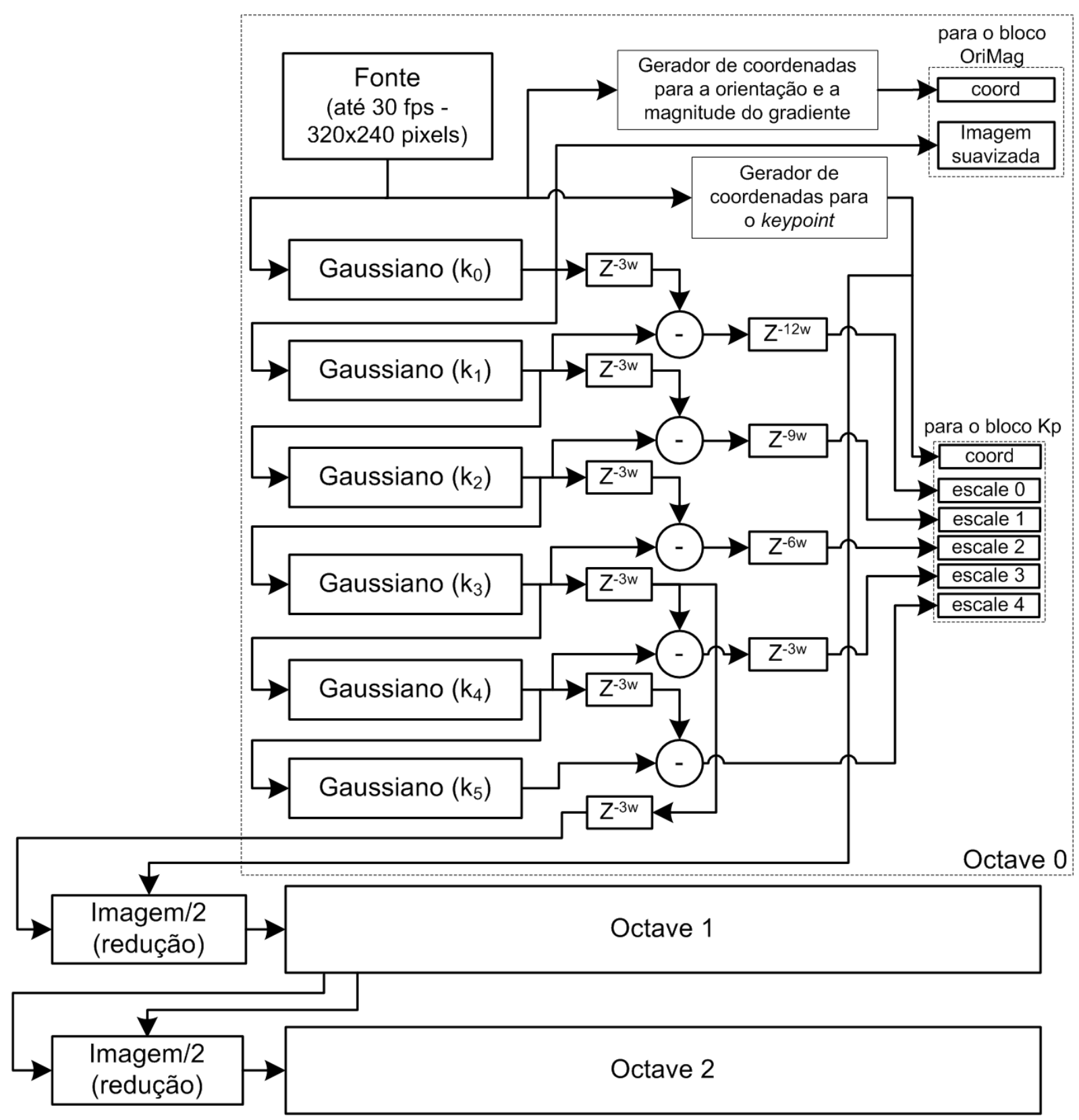

Figura 6.7: Uma arquitetura pipeline que implementa a cascata de filtro Gaussiano e a função da diferença Gaussiana. 


$$
\begin{array}{r}
x_{i+1}=x_{i}-s_{i} y_{i} 2^{-i} \\
y_{i+1}=y_{i}+s_{i} x_{i} 2^{-i} \\
\theta_{i+1}=\theta_{i}-s_{i} \operatorname{atan}\left(2^{-i}\right)
\end{array}
$$

onde: $s_{i}=+1$ se $y_{i}<0$, senão $s_{i}=-1$

O atan é dado no espaço de $[0, \pi]$. No entanto, como nesse sistema a orientação é computada para o atan2, o espaço é dado por $[-\pi, \pi]$. Considerando-se que o CORDIC rotaciona até $\pi$ em qualquer direção, a rotação inicial para computar atan2 deve estar numa distância menor ou igual a $\pi$ em relação a rotação final (resultado). Assim, a rotação inicial proposta não considera somente $x_{0}$ na operação atan, mas também o valor de $y_{0}$ com o objetivo de incluir na operação a informação de qual dos quatro quadrantes do arcotangente o pixel se encontra.

$$
\begin{gathered}
x_{0}=s_{0} x_{0} \\
y_{0}=s_{0} y_{0} \\
\theta_{0}=\alpha
\end{gathered}
$$

onde:

$$
\begin{aligned}
& s_{0}=-1 \text { se } x_{0}<0 \\
& s_{0}=+1 \text { caso contrário } \\
& \alpha=17 \text { se } s_{0}=-1 \\
& \alpha=0 \text { se } s_{0}=1 \text { e } y_{0} \geq 0 \\
& \alpha=35 \text { se } s_{0}=1 \text { e } y_{0} \leq 0
\end{aligned}
$$

No sistema proposto, o intervalo $[-\pi, \pi]$ é representado na faixa $[0,35]$, o qual corresponde aos 36 elementos usados para gerar os descritores das features. Quando $s_{0}$ for negativo, atan2 estará nos quadrantes 2 ou 3 (faixa $[9,23]$ ) e quando for positivo, estará 
nos quadrantes $1[0,8]$ ou $4[24,35]$, os quais são definidos pelos valores $\left\langle x_{0}, y_{0}\right\rangle$.

\subsubsection{Arquitetura para Computação da Orientação e da Magnitude do Gradiente}

A arquitetura proposta, apresentada na Figura 6.8, implementa o algoritmo CORDIC para calcular a orientação e a magnitude do gradiente dos pixels para as três octaves em paralelo. Essa arquitetura contém dois blocos de hardware idênticos do algoritmo CORDIC, em que o primeiro é dedicado para processar os dados da octave 0 e o segundo é compartilhado entre as octaves 1 e 2 . Os dados de entrada para os blocos do CORDIC são as diferenças dos pixels nas direções $x$ e $y$ computados diretamente da sequência de pixels recebida do bloco de hardware DoG. Como visto nessa Figura, a diferença dos pixels é realizada por circuitos simples compostos por buffers de sincronização e redutores.

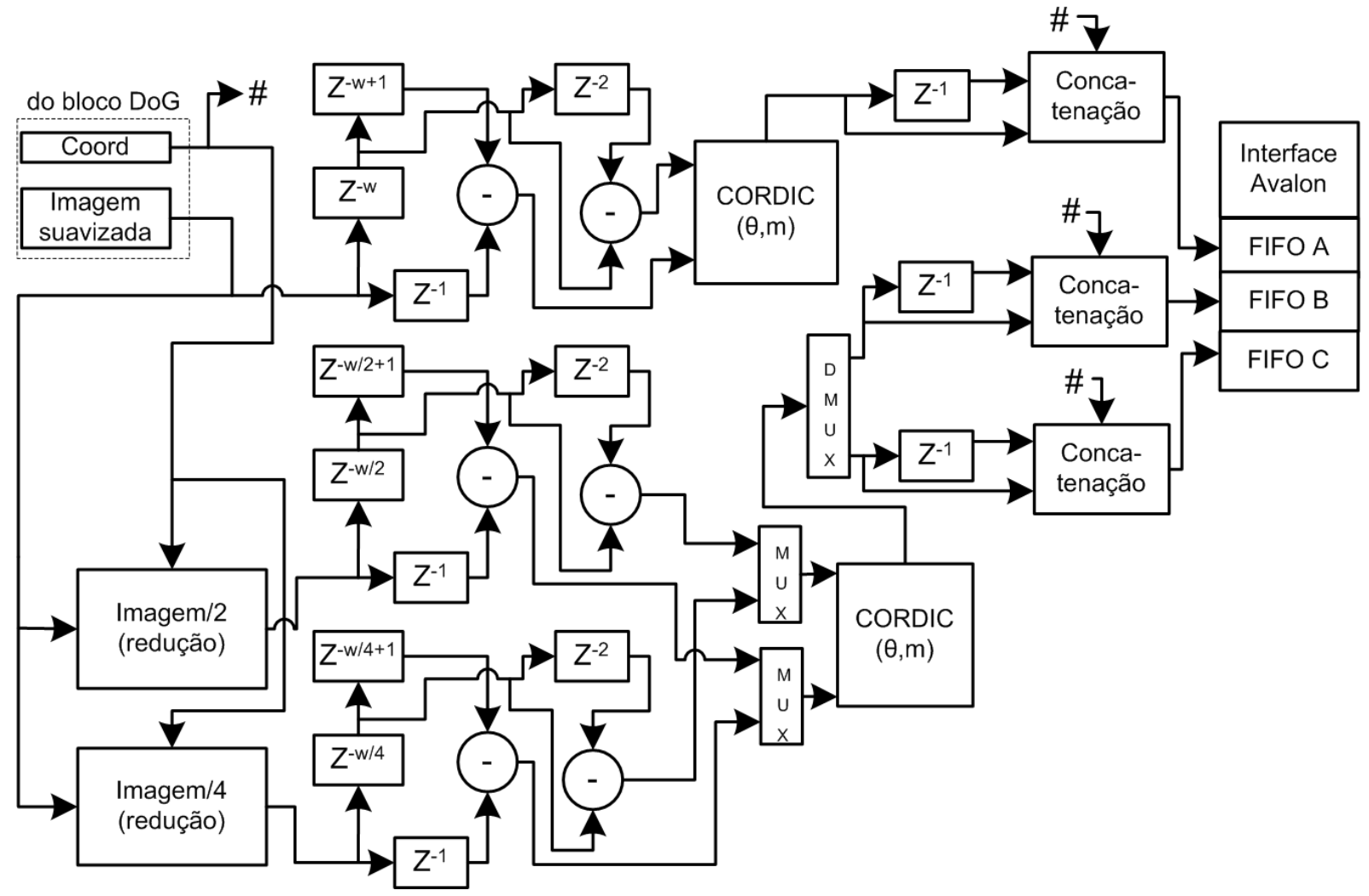

Figura 6.8: Arquitetura para computação da orientação e da magnitude do gradiente baseada no algoritmo CORDIC.

Internamente, o CORDIC representa os dados no formato de ponto fixo [11.8] com 11 bits para a parte inteira, pois a mesma tem o valor máximo de 594, dado pelo valor máximo esperado da Equação 6.9 multiplicado pelo ganho do CORDIC 1,647. Entretanto, 
o número de bits (8) da parte fracionária foi escolhido empiricamente, pois essa resolução é considerada satisfatória para a aplicação. Porém, o resultado final é dado usando-se o formato de números inteiros onde a magnitude do gradiente é representada por 10 bits e a orientação por 6. Nessa arquitetura, cada iteração do CORDIC precisa de 3 ciclos de clock, e como a arquitetura está projetada para executar cinco iterações para a computação de um pixel, o resultado final é gerado em 15 ciclos de clock. O resultado é enviado para a memória do processador NIOS II através de um barramento Avalon usando um canal de DMA (Direct Memory Access). Para otimizar o uso do barramento de dados, cada palavra enviada ao canal de DMA possui 32 bits, permitindo-se a concatenação da magnitude e da orientação de dois pixels por palavra. O resultado na Seção 6.3 demonstra o desempenho e os recursos de FPGA necessários para implementar essa arquitetura.

\subsubsection{Detecção de Keypoints com Verificação da Estabilidade}

Esta seção apresenta uma arquitetura de detecção de keypoint para três octaves, juntamente com a verificação de estabilidade em relação à sua localização, contraste e borda. O hardware proposto, demonstrado na Figura 6.9, recebe como entrada do bloco DoG quinze correntes (streams) de pixels em paralelo e produz como resultado a localização dada pelas coordenadas $\langle x, y\rangle$ e pelos números da octave e da escala.

Cada stream de pixel é temporariamente armazenada nos bancos de memória interna para manter as últimas cinco linhas da imagem recebida do bloco DoG, que são utilizadas para formar uma região da imagem de $5 \times 5$ (vizinhança) necessária para processar keypoints. Tendo as regiões de imagens na memória, o primeiro passo analisa se o pixel DoG localizado no centro da janela é um candidato a keypoint. Essa arquitetura está projetada para identificar candidatos a keypoints para uma octave completa em paralelo, sendo essa operação implementada pelos blocos Extremo vistos na Figura 6.9. Cada candidato a keypoint pré-classificado, passa por um refinamento da localização para as coordenadas $<x, y>$ e escala $s$ em um espaço 3D delimitado pelas regiões de vizinhança localizadas na escala atual do keypoint e nas escalas adjacentes acima e abaixo. Esse refinamento é implementado pelo bloco Localização conforme apresentado na Equação 6.4. Se a loca- 
lização final continua entre as escalas um e três e dentro da região de vizinhança $5 \times 5$, então as funções de verificação do contraste e da borda são aplicadas, conforme apresentado nas Equações 6.5 e 6.6. Finalmente, se o candidato a feature foi aprovado em todas essas fases, a sua localização é enviada para o processador NIOS II através do barramento Avalon para que um descritor baseado na informação de orientação e de magnitude do gradiente, anteriormente computados, seja gerado e associado à feature.

As funções de localização, contraste e qualidade de borda são implementadas utilizandose ponto fixo representado por [20.8]. A parte inteira de 20 bits é necessária para armazenar os valores intermediários da operação de inversão da matriz da Equação 6.4, e a resolução de 8 bits para a parte fracionária foi adotada porque a mesma resulta numa boa relação para a aplicação entre os recursos de hardware necessários e a precisão dos resultados desejados. O formato de ponto fixo permite que mais operações sejam processadas em paralelo do que seriam possíveis com o uso do formato de ponto flutuante com precisão simples, pois os recursos de FPGA necessários para a implementação do hardware de uma unidade de ponto fixo é consideravelmente inferior ao de ponto flutuante. Essa informação é baseada na biblioteca de ponto fixo e de ponto flutuante fornecida pelo ambiente de desenvolvimento DK da Celoxica (Celoxica, 2005a). Embora tenha sido adotada a opção de ponto fixo, o alto nível de paralelismo necessário para alcançar grande desempenho, resultou numa implementação de alto custo de hardware utilizando-se aproximadamente $50 \%$ de todo o hardware do sistema completo. Com o objetivo de obter uma solução completamente embarcada no FPGA (system on-a-chip), esse bloco de hardware Kp é compartilhado entre as três octaves.

\subsubsection{Obtenção de Descritores para as Features}

No último estágio do sistema as features, detectadas no bloco $K p$, recebem um descritor baseado na orientação e na magnitude do gradiente computadas no bloco OriMag. Essa operação foi implementada em software, baseada na biblioteca OpenCV, e otimizada utilizando-se o processador softcore NIOS II (Peron et. al., 2007). O processador é suportado por dois canais de DMA. O primeiro é dedicado para transferir dados das FIFOs A, 


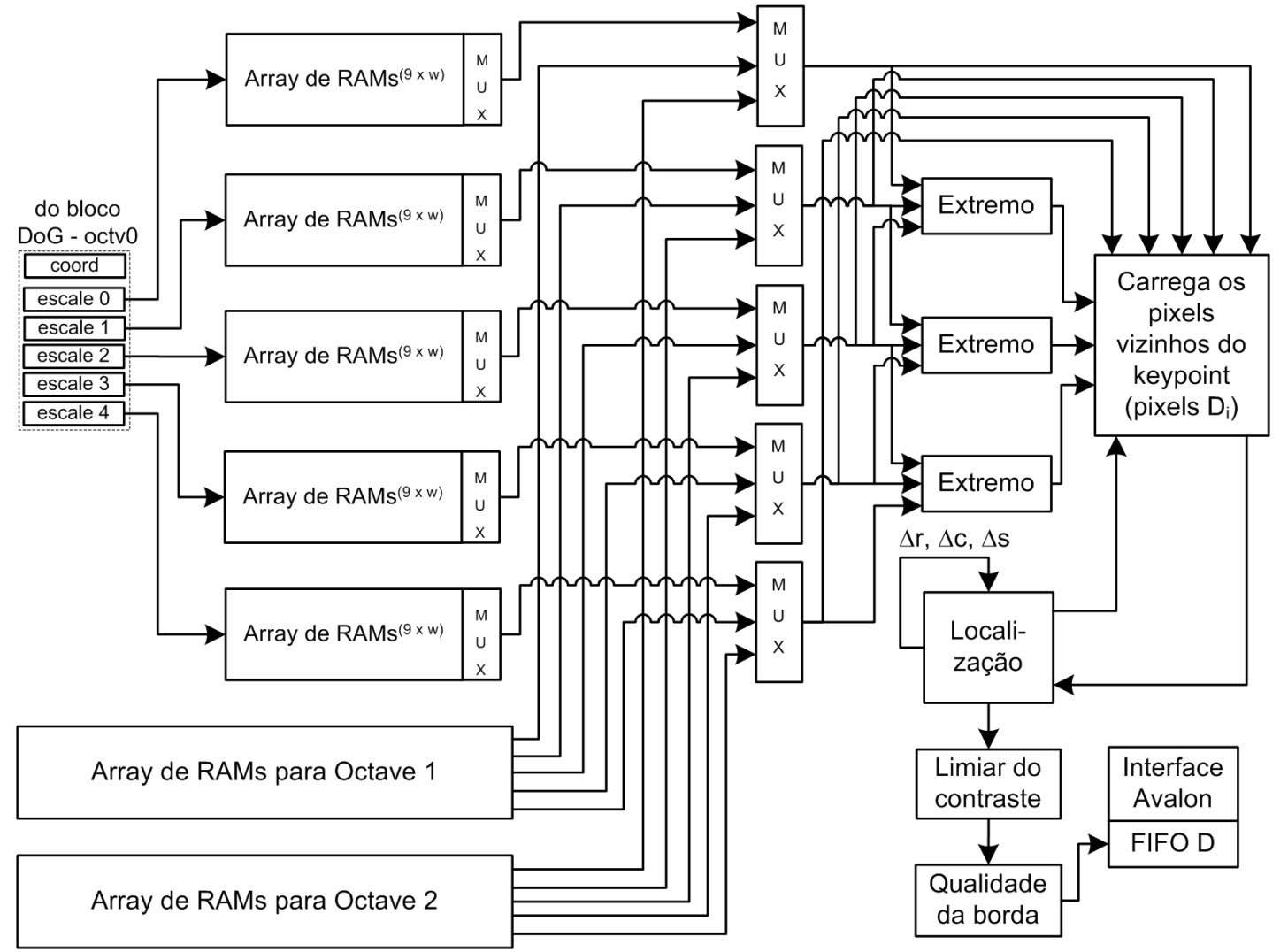

Figura 6.9: Arquitetura para detecção de keypoints com verificação de estabilidade.

B e C (bloco Orimag) para a memória principal do processador onde para cada frame de $320 \times 240$ são transferidas $46 \mathrm{k}$ palavras de $32 \mathrm{bits}$. O segundo é compartilhado entre as FIFO D (bloco $K p$ ) e as FIFOs C0 a C3, as quais são usadas para ler dados diretamente de quatro câmeras CMOS. No caso do DMA ser usado para ler dados das câmeras, existe outro componente controlado via software capaz de ler diretamente os dados da FIFO D. Essa FIFO D pode armazenar até 1024 features, que para a maioria dos casos é suficiente para armazenar todas as features detectadas numa imagem completa. O diagrama de blocos dessa parte do sistema é apresentado na Figura 6.10.

A organização das palavras usadas na FIFO D (a) e nas FIFOs A, B e C (b) é apresentada Figura 6.11. Como a FIFO D é usada para enviar dados para todas as octaves, e o número de features por frame é desconhecido, foi necessário o uso de códigos para auxiliar a comunicação entre o bloco $K p$ e o processador NIOS II. Os códigos de 0x0 a 0x6 apresentados na Tabela 6.1, informam quando frames e octaves estão começando e terminando; e o código 0x7 indica que a palavra possui dado válido. Para as FIFOs A, B 


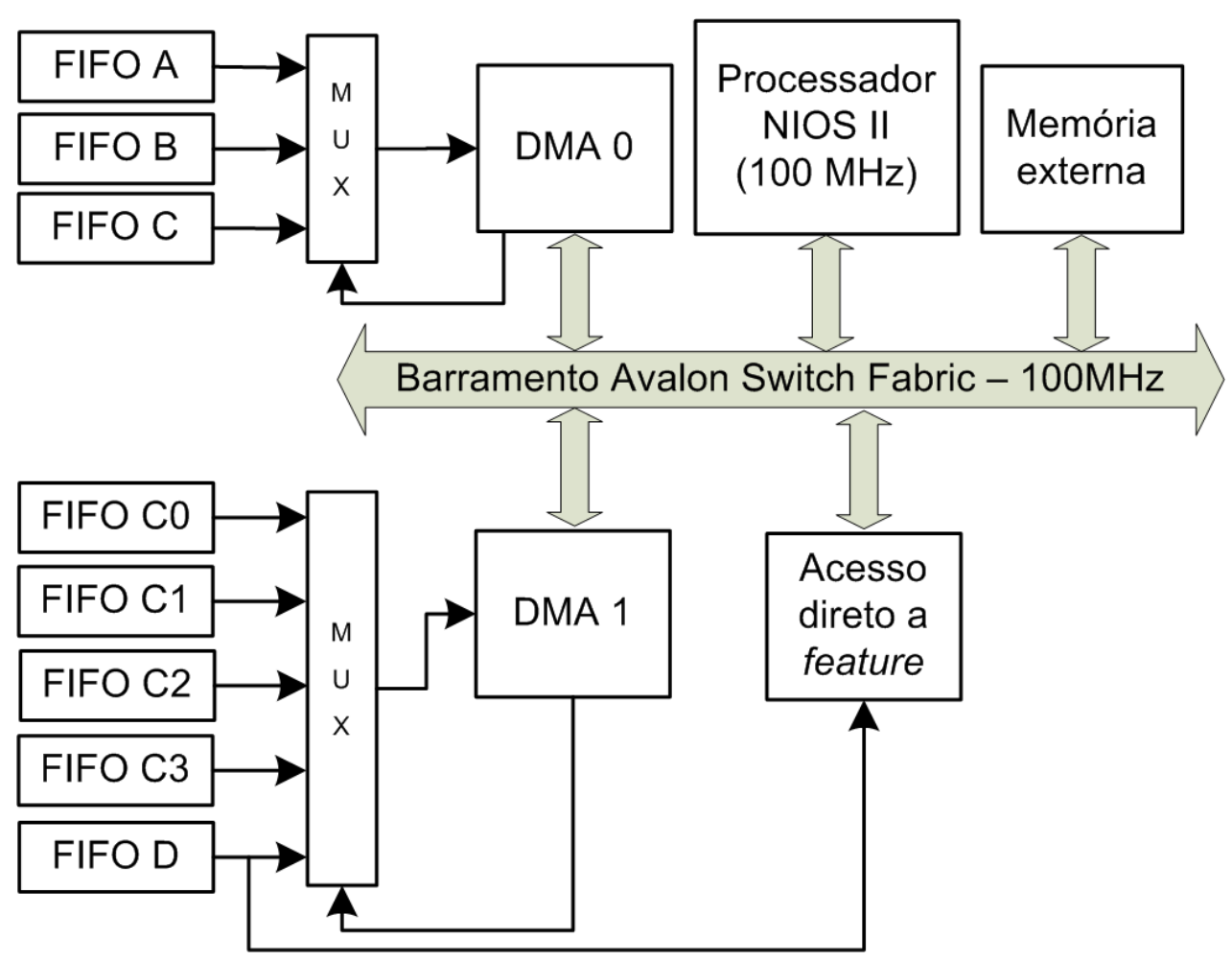

Figura 6.10: Uma arquitetura baseada no NIOS II para associar descritores às features usando a informação da orientação e da magnitude do gradiente recebidos do bloco OriMag.

e C não existem códigos, pois como cada FIFO está associada à uma octave específica, o número de palavras produzidas por frame é sempre constante.

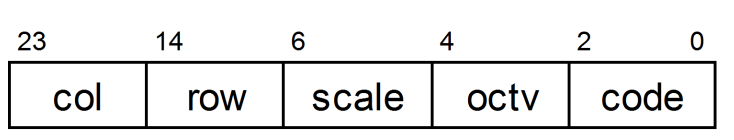

(a)

\begin{tabular}{|l|l|l|l|}
31 & \multicolumn{1}{c}{21} & 15 & 5 \\
mag $_{i+1}$ & ori $_{i+1}$ & mag $_{i}$ & ori $_{i}$ \\
\hline
\end{tabular}

(b)

Figura 6.11: Organização das palavras nas FIFOs. (a) é a palavra na FIFO D e (b) nas FIFOs A, B e C.

Finalmente, uma feature é representada por um vetor de 128 bytes que é invariante a transformações de rotação e escala. Como o sistema proposto também implementa em software o protocolo TCP/IP, as features podem ser usadas numa aplicação local executada diretamente no processador NIOS II, ou ainda serem acessadas remotamente via Ethernet. 
Tabela 6.1: Códigos da FIFO D para comunicar o hardware e o software.

\begin{tabular}{l||c}
\hline Comando & Código \\
\hline \hline new frame & $0 \times 0$ \\
start octv0 & $0 \times 1$ \\
start octv1 & $0 \times 2$ \\
start octv2 & $0 \times 3$ \\
end octv0 & $0 \times 4$ \\
end octv1 & $0 \times 5$ \\
end octv2/end of packet & $0 \times 6$ \\
valid data & $0 \times 7$ \\
\hline \hline
\end{tabular}

\subsection{Resultados}

Os resultados são analisados em três aspectos. Inicialmente, um conjunto de experimentos foi conduzido para identificar a confiabilidade do sistema de detecção de features. Em seguida, o desempenho do sistema foi analisado com o objetivo de verificar o número máximo de features por frame e frames por segundo que o sistema suporta. Finalmente, os recursos de hardware necessários para implementar todo o sistema em um FPGA foram obtidos, apontando-se quais partes do código tem alto custo de implementação na arquitetura de hardware.

\subsubsection{Confiabilidade}

Neste projeto foi dada atenção especial para a confiabilidade dos resultados, pois para a aplicação SLAM, que é baseada no EKF (Smith et. al., 1990), é importante ter baixa ocorrência de positivo falso para evitar divergência do algoritmo. Outro aspecto é que, de acordo com Davison et. al. (2007), 12 features por frame são consideradas suficientes para manter um mapa baseado em features.

Para verificar a confiabilidade do sistema, 30 pares de imagens, lidas diretamente da câmera, foram consideradas a fim de identificar a taxa de associação (matching) de features incorretas. Essa operação foi realizada no processador NIOS II por meio do algoritmo de Beis e Lowe (1997), como sugerido no artigo original do SIFT (Lowe, 2004). Esse matching foi conduzido através da comparação de features obtidas de pares de imagens 
com transformações entre si causadas por rotação e escala produzidas com a mudança da posição da câmera. Para esse conjunto de imagens foram detectadas 870 features das quais 4, $84 \%$ foram associadas incorretamente. Apesar do uso do formato de ponto fixo e da otimização do número de bits para armazenar os pixels produzidos pelo bloco de hardware DoG, a taxa de associação incorreta apresentou resultados similares aos obtidos com a implementação em PC (puramente em software) usando ponto flutuante, como apresentado na Seção 6.2.1. A diferença mais importante entre a implementação realizada em FPGA e a original, puramente em software, implementada no PC é que o número de features da original é maior, conforme já mencionado na subseção 6.2.2, pois na implementação em FPGA os pixels negativos produzidos na imagem DoG são rejeitados. Porém, para a aplicação no SLAM isso não é considerado um ponto negativo, desde de que a proporção de associação entre falso positivo e verdadeiro seja mantida próximo da mesma taxa.

A Figura 6.12 apresenta uma imagem típica usada nos experimentos (a) juntamente com três imagens produzidas no bloco de hardware DoG da octave 0 nas escalas 0 (b), 1 (c) e 2 (d). Para melhorar a visibilidade da imagem DoG os pixels pretos foram transformados em brancos. É possível notar que os detalhes nas imagens vão desaparecendo conforme a escala aumenta, mostrando desse modo que a cascata Gaussiana está produzindo o resultado desejado. Nessa demonstração, os kernels Gaussianos foram gerados com $\sigma=$ $1,25, \sigma=0,96$ e $\sigma=1,21$ para as imagens (b), (c) e (d), respectivamente.

Para ilustrar a operação de associação/matching, a Figura 6.13 exibe dois exemplos de associações para transformações em escala (a) e rotação (b), onde as linhas brancas entre os pares de imagens correspondem à associação encontrada pelo algoritmo BBF. Em (c) é também apresentado um caso de associação incorreta (a linha que está mais inclinada), e como pode ser visualmente notado, apesar da associação global estar incorreta, localmente as regiões associadas são muito parecidas. Isto, consequentemente, resultou em descritores semelhantes, pois as informações da orientação e da magnitude do gradiente das duas regiões são muito parecidas para ambas as features (veja a similaridade das setas nas imagens). Uma solução para esse problema poderia ser expandir a região usada para 


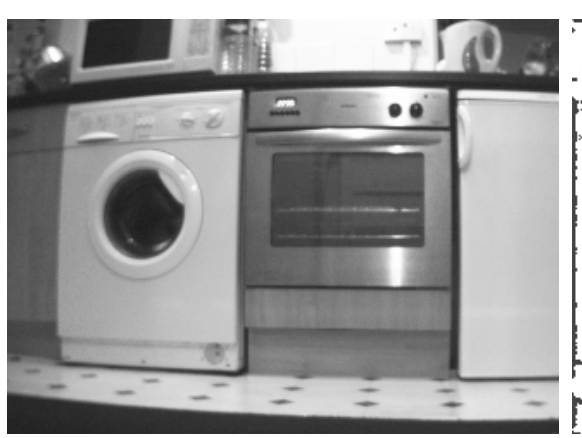

(a)

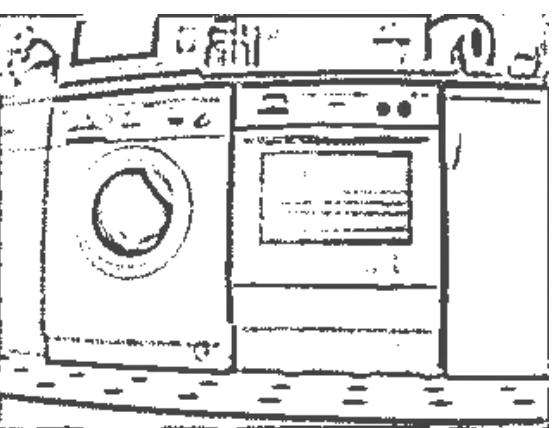

(b)

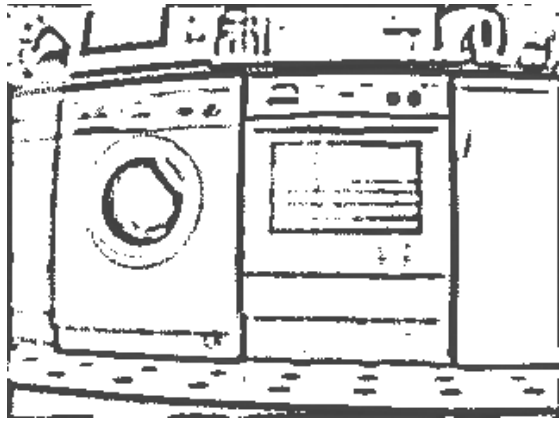

(c)

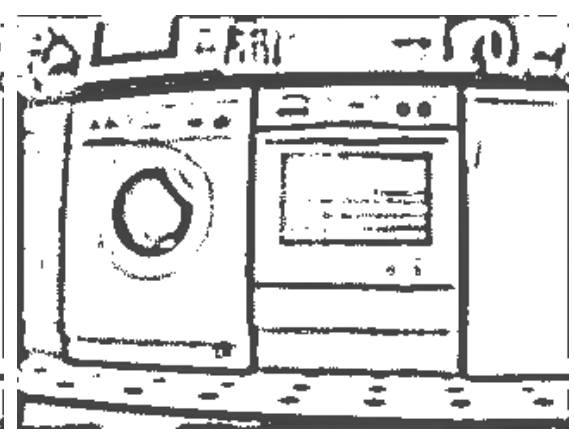

(d)

Figura 6.12: Exemplos de imagens reais obtidas diretamente do bloco de hardware DoG da octave 0 nas escalas 0 (b), 1 (c) e 2 (d).

produzir os descritores, que atualmente é de $16 \times 16$ pixels (como proposto no algoritmo original do SIFT).

Os blocos de hardware foram desenvolvidos para processarem até 2,3M pixels por segundo, o que corresponde a 30 fps de $320 \times 240$ pixels cada. A Tabela 6.2 exibe para cada bloco de hardware a frequência operacional e a quantidade de ciclos de clock necessários para produzir os resultados. O bloco DoG é o único que trabalha no modo pipeline, produzindo um resultado por ciclo de clock e com frequência dada pela taxa de pixels gerada pela câmera. Por outro lado, o bloco OriMag gera um resultado a cada 21 ciclos de clock e isso se deve ao controle interno e principalmente às iterações do algoritmo CORDIC. Assim, o clock precisa ser pelo menos 21 vezes mais rápido do que a taxa de pixels produzidos pela câmera. Nesse experimentos é usado 100MHz. Para o bloco Kp, a quantidade de ciclos necessários para produzir um resultado não é constante; ele depende do número de features existentes na imagem. O caso mais rápido é um resultado para cada 4 ciclos de clock, que ocorre quando o dado a ser processado (pixel DoG) está localizado na região de borda da imagem. Um ponto intermediário é quando o pixel DoG está na 


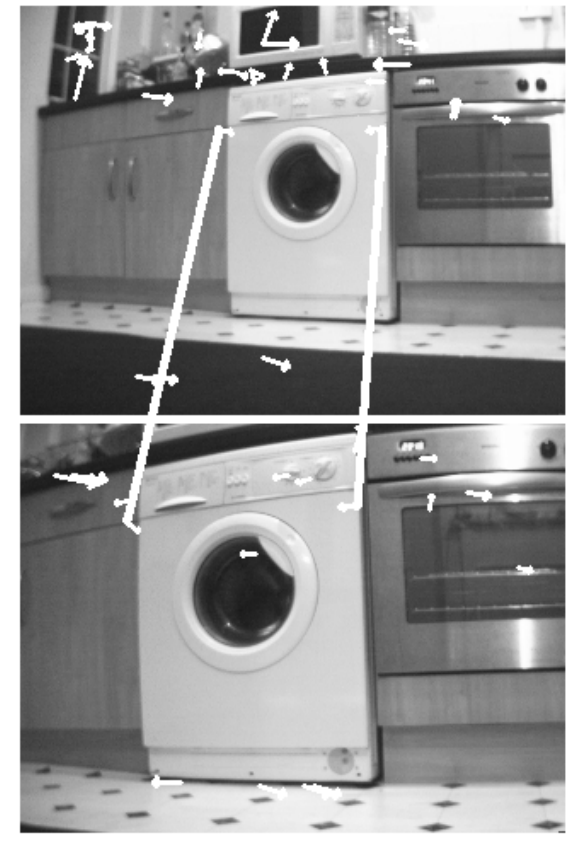

(a)

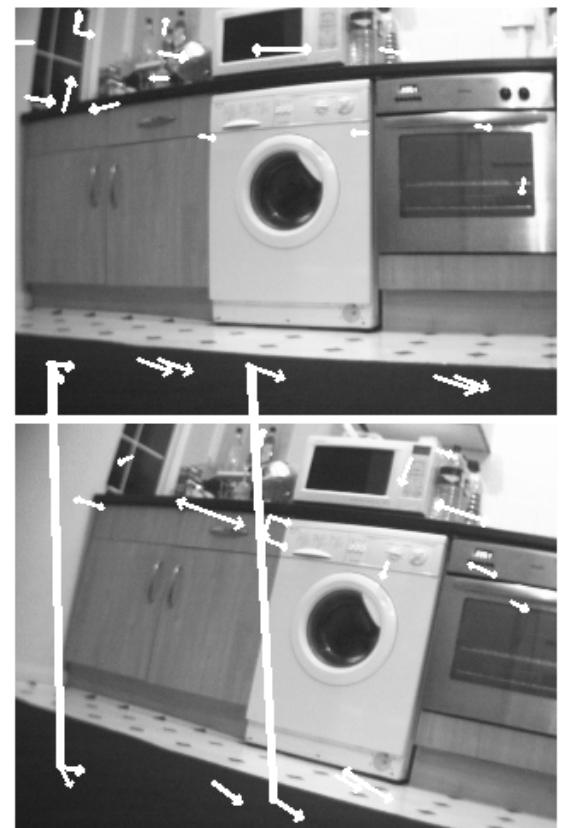

(b)

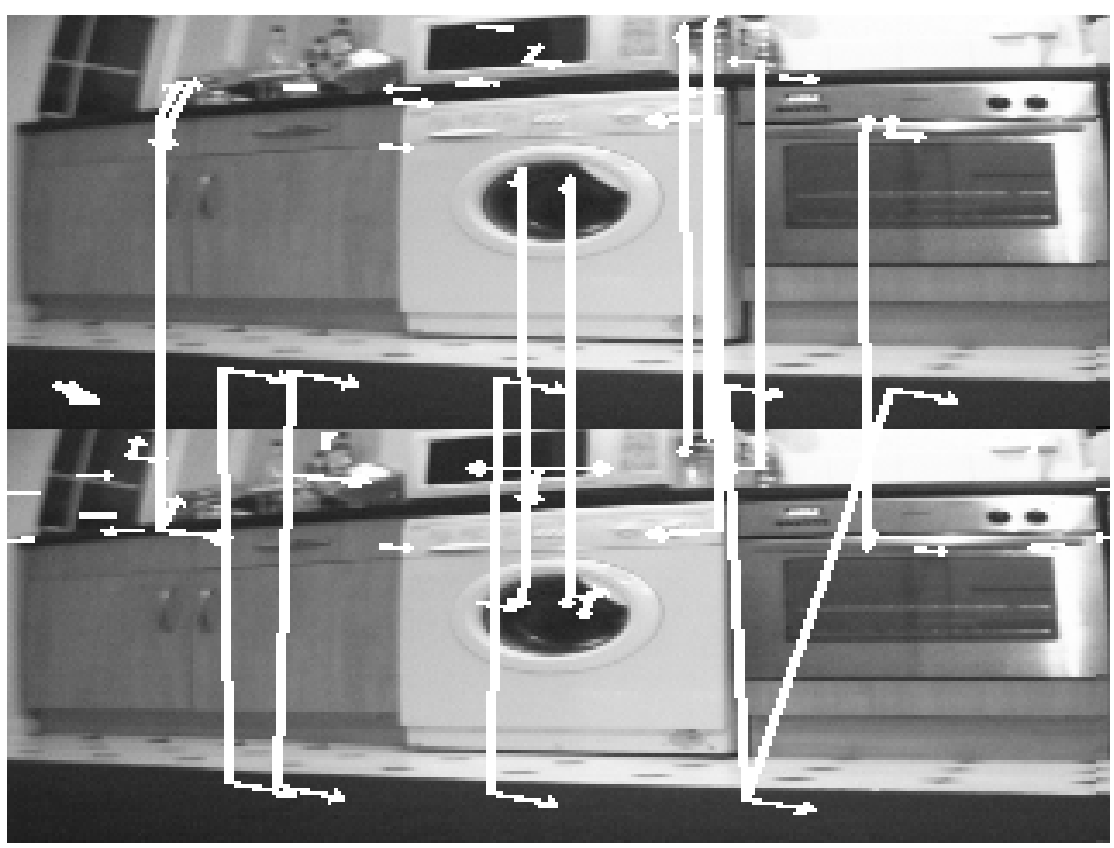

(c)

Figura 6.13: As linhas brancas correspondem às associações de pares de imagens lidas diretamente de uma câmera CMOS e processadas pelo sistema proposto. Os pares (a) e (b) demonstram associações de pares transformados entre si por escala e rotação, respectivamente; e o par (c) apresenta um exemplo de associação incorreta, a qual é representada pela linha mais inclinada. 
região ativa da imagem e não é classificado como um candidato à keypoint. Outro nível é quando o pixel DoG é um candidato à keypoint e testes de estabilidade são aplicados. Nesse caso, o número de clocks varia de 44 até 132 ciclos, dependendo da rejeição do keypoint durante a verificação e do número de vezes que o refinamento da localização é realizado. No pior caso, toda a operação pode demorar até 141 ciclos de clock.

Tabela 6.2: Frequência operacional e resultados produzidos por ciclo de clock para cada bloco de hardware.

\begin{tabular}{c||c|c|c}
\hline $\begin{array}{l}\text { Bloco de } \\
\text { hardware }\end{array}$ & Função & $\begin{array}{l}\text { Resultado por } \\
\text { ciclo de } \text { clock }\end{array}$ & Freq (MHz) \\
\hline \hline DoG & todas & 1 & taxa de pixels \\
\hline OriMag & todas & 21 & 100 \\
\hline \multirow{2}{*}{$\mathrm{kp}$} & detecção de keypoint & 4 até 9 & \multirow{2}{*}{50} \\
\cline { 2 - 3 } & verificação de estabilidade & 44 até 132 & \multirow{2}{*}{} \\
\cline { 2 - 3 } & total & 4 to 141 & \\
\hline
\end{tabular}

Se o sistema tivesse sido projetado somente para o pior caso, a frequência mínima para o bloco Kp deveria ser de 2,3M vezes 141, ou seja, 327MHz. Para a tecnologia FPGA tal frequência para o bloco Kp é difícil de ser alcançada. Para resolver esse problema, o sistema implementa buffers internos para reter dados enquanto o hardware Kp realiza as operações de verificação de estabilidade. A frequência atual do bloco Kp é de $50 \mathrm{MHz}$, que é 21,7 vezes mais rápida que a taxa de pixel DoG. Como um pixel DoG é rejeitado ou classificado como um candidato a keypoint em 9 ciclos de clock, o tempo restante pode ser usado para computar os dados previamente armazenadas no buffer. Em média, menos de $2 \%$ dos pixels de uma imagem são classificados como keypoints. Assim, essa solução foi implementada usando buffers internos para armazenar 1023 pixels DoG para octv0, 511 para octv1 e 127 para octv0 (ver Figura 6.2) e, com esses parâmetros, não houve overflow nos experimentos.

O software é executado numa versão padrão do NIOS II operando a 100MHz, em que 11,7ms é necessário para gerar um descritor para uma feature. Considerando-se que o EKF, apresentado no Capítulo 5, é atualizado a $14 \mathrm{~Hz}$ e que, conforme mencionado no início dessa seção, o ideal seria associar 12 features por frame, o tempo ideal para associar uma feature deveria ser de 6ms; ou seja, praticamente a metade do tempo alcançado. Entretanto, conforme informado em Altera (2007a), a versão padrão do NIOS II processa 128 
DMIPS (Dhrystone Million Instructions Per Second), enquanto que uma versão rápida do NIOS II processa 220 DMIPS. Assim, essa diferença de 11,7ms para 6ms é, praticamente, eliminada trocando-se a versão padrão do NIOS II por uma versão rápida. Isso não foi realizado neste projeto devido a limitação de espaço do FPGA Stratix II 2S60 utilizado na validação do sistema, onde, conforme a tabela 6.3, praticamente não há elementos lógicos disponíveis. Uma outra maneira de aumentar o desempenho sem necessidade de mudanças no projeto proposto, é a troca da família de FPGA Stratix II para Stratix III, pois de acordo com a Altera, isso também aumentaria o desempenho em 35\% na média, além de uma maior capacidade de elementos lógicos, o que permitiria também a inclusão do NIOS II versão rápida.

\subsubsection{Plataforma de Desenvolvimento}

A plataforma de desenvolvimento utilizada para coletar e processar as imagens nos experimentos possui uma placa com FPGA conectado a quatro câmeras CMOS e à uma base robótica móvel, a qual é apresentada na Figura 4.2 do Capítulo 4 (Bonato et. al., 2006b). O fluxo de desenvolvimento deste projeto seguiu o demonstrado na Figura 6.14 (Silva et. al., 2006). Uma vez que o sistema possui quatro câmeras apontando para quatro direções fixas, praticamente, toda a área no entorno do robô é coberta, permitindo um aumento na qualidade das features detectadas através do aumento da rejeição no bloco Kp. O sistema de detecção de features proposto, que é compartilhado entre as quatro câmeras, é capaz de processar pixels obtidos diretamente dos sensores de imagem.

Os blocos de hardware estão implementados em Handel-C (Celoxica, 2005a) e os componentes do barramento Avalon (canais de DMA, controles da FIFO e a interface $I^{2} C$ da câmera) e a interface da câmera estão em VHDL (Brown e Vranesic, 2005). A Tabela 6.3 apresenta os recursos de hardware usados para implementar o sistema em um FPGA Stratix II 2S60 da Altera (Altera, 2007b). Cabe ressaltar, que a linha sistema completo na tabela adiciona também o processador NIOS II, a interface das câmeras e os componentes do barramento Avalon. Como pode ser notado, o sistema completo usa aproximadamente todos os recursos do FPGA. Isso ocorre devido ao fato de que o bloco DoG implementa 


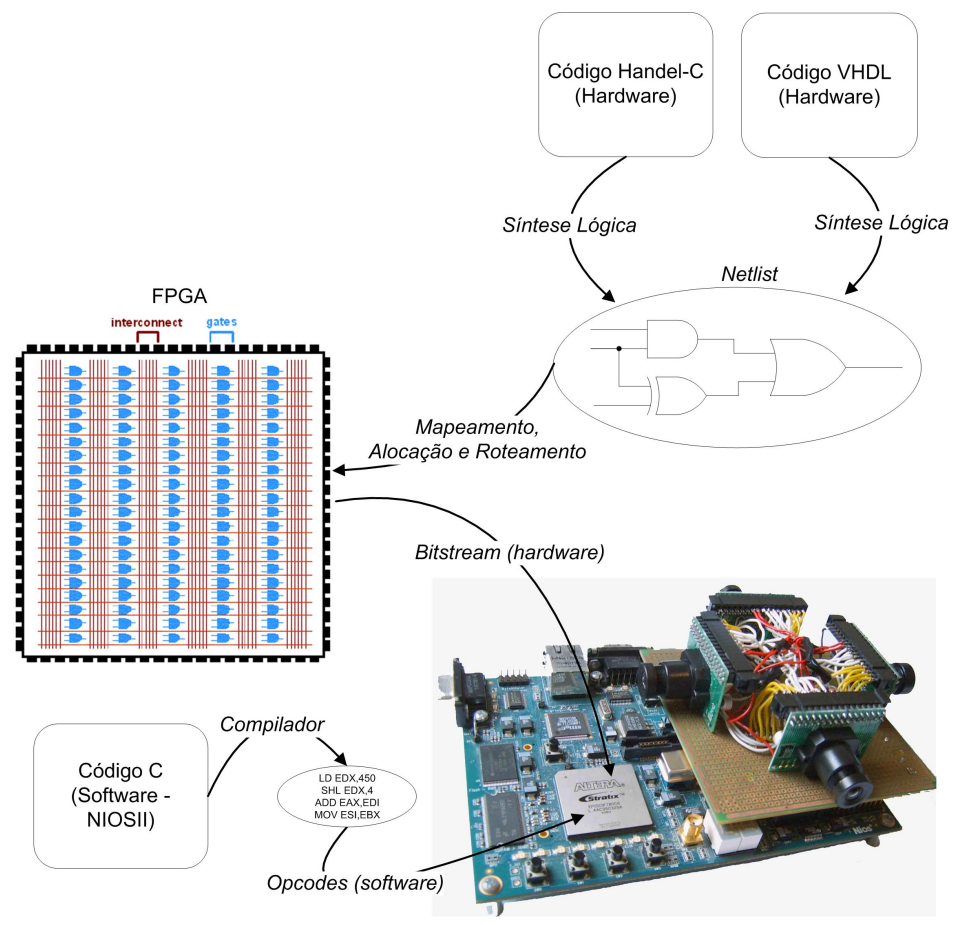

Figura 6.14: Fluxo de desenvolvimento do projeto em FPGA.

18 filtros Gaussianos com kernels de $7 \times 7$ e também porque o bloco Kp implementa em ponto fixo uma quantidade considerável de operações para a verificação da estabilidade, tal como a inversão da matriz de $3 \times 3$ elementos. Para o FPGA adotado, praticamente, não há elementos lógicos livres para outras aplicações. No entanto, é necessário considerar que, atualmente, já existem no mercado FPGAs da Altera com até 3 vezes mais elementos lógicos do que esse utilizado.

Tabela 6.3: Recursos de FPGA (Altera Stratix II EP2S60F672C3) necessários para cada bloco de hardware e para o sistema completo.

\begin{tabular}{l||l|l|c|c|c}
\hline EP2S60 & $\begin{array}{l}\text { Bloco } \\
\text { DSP (9 } \\
\text { bits) }\end{array}$ & $\begin{array}{l}\text { RAM } \\
\text { (Blocos } \\
\text { Mbits })\end{array}$ & Reg. & LUT & $\begin{array}{l}\text { Freq. max. } \\
(\mathrm{MHz})\end{array}$ \\
\hline \hline DoG & 0 & 0,91 & 7256 & 15137 & 149 \\
\hline OriMag & 0 & 0,03 & 670 & 1863 & 184 \\
\hline Kp & 48 & 0,20 & 2094 & 14357 & 52 \\
\hline $\begin{array}{l}\text { Sistema } \\
\text { completo }\end{array}$ & 64 & $\begin{array}{l}1,32 \mathrm{M} \\
(22 \%)\end{array}$ & $\begin{array}{l}19100 \\
(52 \%)\end{array}$ & 43366 & - \\
\hline
\end{tabular}

Como o bloco DoG implementa filtros Gaussianos altamente adaptados e produz um resultado por ciclo de clock, o bloco DoG pode processar até 1940 fps de $320 \times 240$ pixels. 
Porém, quando todo o sistema é conectado o desempenho é limitado pelo bloco mais lento e pelo overflow dos buffers internos. Assim, esses gargalos foram considerados para que o sistema suporte 30 fps, mantendo uma boa relação entre o desempenho desejado e os recursos de hardware necessários.

\subsection{Considerações Finais}

As otimizações propostas para os blocos de hardware foram fundamentais para embarcar o sistema completo num único FPGA, sem comprometer a confiabilidade dos resultados quando comparados com uma implementação original do algoritmo num PC. Outras decisões, tais como o uso do algoritmo CORDIC e do formato de ponto fixo também tiveram uma significante contribuição na otimização dos recursos de hardware.

Como resultado, os blocos de hardware do sistema, totalmente embarcados num FPGA, detectam features em até 30 frames por segundo $(320 \times 240$ pixels $)$, independentemente do número de features por frame. Porém, o desempenho do software, o qual tem a função de associar descritores às features e que é executado numa versão padrão do processador NIOS II, é capaz de associar apenas um número limitado de features por frame, pois cada feature consome 11.7ms. A solução mais simples para reduzir esse tempo seria trocar a versão do processador softcore NIOS II padrão (standard version) para uma versão de alta velocidade (fast version) e também trocar o FPGA por um modelo maior, pois o FPGA atual já está completo.

Como o sistema proposto é independente e embarcado e, além disso, é capaz de ler dados diretamente de um sensor de imagem CMOS, ele poderia ser usado para criar um novo tipo de câmera no mercado que fornecesse não somente imagens, mas também um conjunto de features, juntamente com descritores invariante à escala e rotação. Este novo produto poderia ser usado em diversas aplicações de segurança, como por exemplo, no tracking de pessoas. 


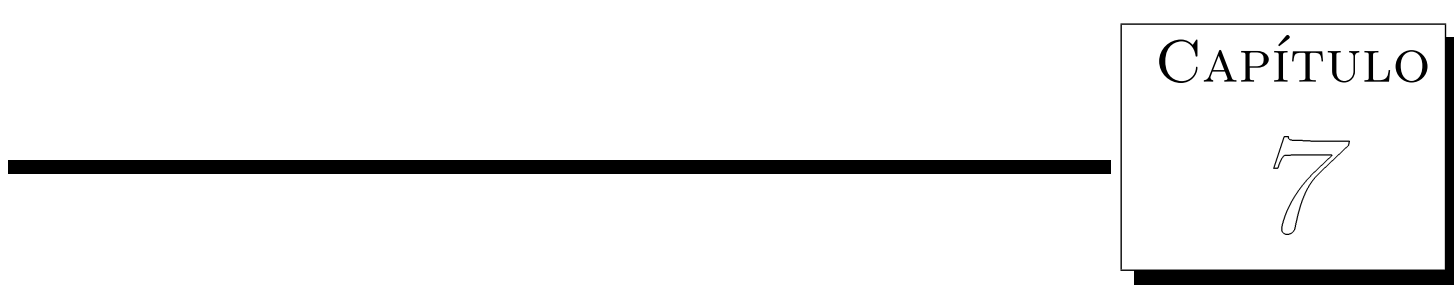

\section{Conclusão}

\subsection{Aspectos Gerais}

Construir robôs móveis com hardware totalmente dedicado e embarcado é uma das tendências atuais da área de robótica. Cada vez mais os robôs móveis estão sendo empregados para tarefas especificas de monitoramento, inspeção, e para auxílio humano complementar em tarefas que exigem precisão ou que são difíceis de serem executadas devido ao seu ambiente de atuação inóspito. Adicionalmente, cada vez mais se faz necessário o uso de câmeras em tais robôs. Assim, este projeto vem ao encontro com uma necessidade emergente de mercado, onde robôs móveis, autônomos e com câmeras (para uso em diversas tarefas), estão sendo cada vez mais solicitados por muitas empresas. Dentro deste contexto, o projeto desenvolvido procurou atender esta demanda, incorporando inovações tecnológicas no desenvolvimento do hardware e do software de um robô que, simultaneamente, mapeia e se localiza num ambiente desestruturado, utilizando-se de câmeras CMOS (SLAM com visão). A plataforma de controle do robô foi totalmente desenvolvida com o emprego da computação reconfigurável (FPGA), a qual se demonstrou bastante adequada, tanto em termos de desempenho, quanto de flexibilidade de implementação, 
superando-se as expectativas iniciais.

O SLAM com visão computacional possibilita a substituição do tradicional sensor laser range finder por câmeras, que são mais compactas e têm menor consumo de energia e custo. Porém, essa flexibilidade tem um custo computacional alto, uma vez que a informação a partir de imagens precisa ser muito mais processada do que a informação obtida de um sensor laser range finder. Essa relação com a imagem também é válida para o caso do sensor sonar. Como as propostas para o SLAM com visão, conforme constatado na revisão bibliográfica, são praticamente todas desenvolvidas para serem executadas em computadores pessoais, o custo computacional para o processamento das imagens e do algoritmo de localização e mapeamento acabam comprometendo o desempenho de todo o sistema. Isso afeta, consequentemente, o tamanho máximo do ambiente que pode ser mapeado e também a qualidade do mapa, uma vez que para aumentar a velocidade de processamento muitas soluções preferem usar algoritmos menos robustos em troca de um menor custo computacional.

A proposta de uma arquitetura para o SLAM composta por blocos de hardware altamente especializados proporciona um aumento significativo do desempenho do sistema. Assim, é importante a escolha de algoritmos eficientes para a implementação em hardware. Neste trabalho, os algoritmos EKF (para geração do mapa) e SIFT (para detectar as features usadas no mapa) foram escolhidos por serem considerados os mais robustos para a função implementada, embora não sejam computacionalmente os mais eficientes.

O uso de quatro câmeras, ao invés de uma ou duas normalmente encontradas nos projetos, mostrou-se ter um impacto significante na precisão e na velocidade de convergência do processo de geração de mapa, conforme apresentado no Capítulo 4.

\subsection{Contribuições}

As principais contribuições deste trabalho de pesquisa estão na implementação das arquiteturas de alto desempenho para o processamento dos algoritmos EKF e SIFT. É conhecido que ambos têm um custo computacional elevado, o que exige otimizações e uma forte exploração do paralelismo em hardware. Também cabe ressaltar, que de acordo com a 
revisão bibliográfica realizada, este trabalho apresenta uma das primeiras implementações desses algoritmos totalmente desenvolvidos em hardware e aplicados ao problema SLAM.

Os resultados experimentais apontaram que o hardware do EKF desenvolvido é capaz de processar 3 vezes mais features do que um processador Pentium $\mathrm{M}$ de $1.6 \mathrm{GHz}$ consegue em tempo real (14 atualizações por segundo) e 13 vezes mais do que um processador ARM920T 200MHz, enquanto consome somente 1,3\% da potência por feature do Pentium M e 12,3\% do ARM920T. É importante notar que a complexidade computacional do EKF é $\Theta\left(n^{2}\right)$, onde $n$ representa o número de features, e que desse modo, para que o Pentium M atinja o mesmo desempenho do hardware proposto em FPGA ele precisaria aumentar seu poder de processamento em 9,9 vezes e o ARM920T em 189 vezes.

Uma outra contribuição importante está relacionada à arquitetura do sistema de detecção de features implementada com o SIFT. Nela foram identificadas e implementadas otimizações e modificações do algoritmo que foram fundamentais para permitir a implementação de todo o sistema num FPGA. Essas otimizações e a exploração do paralelismo, junto com o processamento em pipeline, resultaram num hardware capaz de detectar features em pelo menos uma ordem de magnitude mais rápido do que as soluções implementadas em computadores pessoais. Como resultado, o hardware, que pode ser conectado diretamente a um sensor de imagem CMOS, é capaz de detectar features a uma taxa de 30 frames por segundo de imagens com resolução de $320 \times 240$ pixels.

O sistema de aquisição e pré-processamento de imagens em tempo real para quatro câmeras CMOS, totalmente desenvolvido em FPGA, teve um impacto significativo no desempenho total do sistema. Essas imagens podem ser utilizadas, tanto diretamente nos blocos de hardware, como no processador softcore NIOS II da Altera, com a mesma velocidade para diversos tipos de aplicações. Também pode-se destacar a integração desse sistema com um computador PC via Ethernet, utilizando-se sockets. Isso é muito útil para depuração e validação das imagens capturadas pela placa de FPGA no PC. Este tipo de implementação possibilitou o envio via wireless das imagens capturadas pelas quatro câmeras do robô, servindo também de canal de comunicação para enviar os comandos de controle de movimento do robô. 
Uma outra contribuição foi a adaptação do software da biblioteca de processamento de imagens OpenCV, originalmente desenvolvida para computadores PC, para o processador NIOS II. Isso disponibiliza, para qualquer usuário do NIOS II, mais de trezentas funções de processamento de imagens prontas para serem usadas em soluções embarcadas. No sistema proposto, a biblioteca OpenCV foi utilizada na implementação do software para associação de descritores de features.

Finalmente, foi portado o software do cliente do sistema Player (utilizado para leitura de sensores e controle de velocidade do robô) para o processador NIOS II. Este trabalho possibilitou que o robô fosse controlado totalmente por um hardware embarcado em FPGA, utilizando-se uma das ferramentas de suporte para aplicações robóticas mais populares no meio acadêmico. Consequentemente, o sistema de FPGA desenvolvido pode ser conectado com qualquer ambiente suportado pelo Player.

\subsection{Trabalhos Futuros}

Este trabalho tem um bom potencial para ser reutilizado como base no desenvolvimento de outras pesquisas na área da robótica móvel embarcada, pois ele implementa o detector de features SIFT, considerado o mais eficiente da atualidade, e o algoritmo EKF de localização e mapeamento, que apesar de não ser considerada uma solução computacionalmente eficiente, é também reconhecido pela comunidade científica como uma das soluções mais adequadas para a geração de mapas precisos baseado em features.

Partindo dessa estrutura já criada, onde ocorre a integração dos módulos de hardware com o sistema de aquisição de imagens e de processamento em software embarcado dos modelos matemáticos, do montador de descritores para as features e dos protocolos de comunicação via Ethernet, várias oportunidades para a realização de trabalhos futuros podem ser sugeridas:

- Explorar a nova abordagem do inverso da disparidade proposta por Eade e Drummond (2006) e Montiel et. al. (2006) para estimar a posição das features com a visão monocular. Esse novo método pode ser adicionado ao EKF por meio dos modelos 
matemáticos processados em software. Desse modo, todo o núcleo do EKF, que foi desenvolvido em hardware, poderia ser reutilizado. As principais vantagens desse novo método está na possibilidade de representação de features no infinito e na linearidade do cálculo da distância da feature em relação à câmera;

- Migrar o software de associação dos descritores de features para hardware. É importante notar que isso não aumentaria a velocidade de detecção de features, que atualmente é de 30 frames por segundo, mas sim o número de features com descritores associados em tempo real. Isso possibilitaria, quando necessário, a criação de mapas mais detalhados;

- Explorar com maior profundidade o uso de multi-câmeras, pois, conforme demonstrado no Capítulo 4, o mapa gerado pelo EKF com o uso de quatro câmeras é mais preciso e converge mais rapidamente do que com uma única câmera. Porém, ainda existe a necessidade de um estudo mais detalhado para verificar se esta característica não acaba prejudicando o sistema, em caso de uma convergência incorreta.

- Propor um módulo de odometria visual, semelhante ao apresentado em Nistér et. al. (2004), para a aplicação do sistema proposto em robô não equipado com odômetro mecânico, ou ainda, para trabalhar em conjunto com o odômetro mecânico a fim de melhorar, como um todo, a precisão do sistema.

- Desenvolver um sistema robusto para controlar as influências das variações de luminosidade do ambiente na imagem, pois essa variação pode gerar ruídos na imagem capturada, dificultando o processamento da mesma. 



\section{Referências Bibliográficas}

ActivMedia Robotics Educational price list, 2005.

Disponível em: <http://www.activrobots.com/>. Acesso em: 11/2005.

ActivMedia Robotics Technical specifications, 2006.

Disponível em: <http://www.activrobots.com/ROBOTS/p3dx.html>. Acesso em: $04 / 2006$.

Altera Nios II embedded processor backgrounder, 2007a.

Disponível em: <http://www.altera.com/literature/pr/nios2_backgrounder. pdf $>$. Acesso em: 11/2007.

AlterA Stratix II device handbook, User guide, 2007b.

Disponível em: <http://www.altera.com/literature/hb/stx2/stratix2_ handbook.pdf $>$. Acesso em: 10/2007.

AndrakA, R. A survey of CORDIC algorithms for FPGA based computers. In: Proceedings of the ACM/SIGDA Sixth International Symposium on Field Programmable Gate Arrays, Monterey (USA), 1998, p. 191-200.

BEIS, J. S.; LowE, D. G. Shape indexing using approximate nearest-neighbour search in high-dimensional spaces. In: Proceedings of the IEEE Computer Society Conference on Computer Vision and Pattern Recognition (CVPR), Washington (USA): IEEE Computer Society, 1997, p. 1000-1006.

Bonato, V. Projeto de um módulo de aquisição e pré-processamento de imagem colorida baseado em computação reconfigurável e aplicado a robôs móveis. 2004. Dissertação (Mestrado), Instituto de Ciências Matemáticas e de Computação, Universidade de São Paulo, São Carlos, 2004.

Bonato, V.; Fernandes, M. M.; Marques, E. A smart camera with gesture recognition and SLAM capabilities for mobile robots. International Journal of Electronics, London (UK), v. 93, n. 6, p. 385-401, Junea, 2006a.

Bonato, V.; Holanda, J. A. D.; Marques, E. An embedded multi-camera system for simultaneous localization and mapping. In: Proceedings of Applied Reconfigurable Computing, Lecture Notes on Computer Science - LNCS 3985, Delft (Netherlands): Springer-Verlag, 2006b, p. 109-114. 
Bonato, V.; Marques, E. Um sistema em desenvolvimento de mapeamento e localização simultâneos usando multi-câmeras para robôs móveis. In: Anais da II Jornadas Sobre Sistemas Reconfiguráveis (REC), Porto (Portugal), 2006, p. $129-130$.

Bonato, V.; Marques, E.; Constantinides, G. A. A floating-point Extended Kalman Filter implementation for autonomous mobile robots. In: Proceedings of the IEEE International Conference on Field Programmable Logic and Applications (FPL), Amsterdam (Netherlands), 2007a.

Bonato, V.; Marques, E.; Constantinides, G. A. A floating-point extended Kalman filter implementation for autonomous mobile robots. Journal of Signal Processing Systems for Signal, Image, and Video Technology, -, v. -, n. -, p. -, (Submetido em Novembro de 2007), -a, 2008a.

Bonato, V.; Marques, E.; Constantinides, G. A. A parallel hardware architecture for image feature detection. In: Proceedings of Applied Reconfigurable Computing, Lecture Notes on Computer Science, London (UK), (Aceito para publicação em Março de 2008), 2008b, p. 12p.

Bonato, V.; Marques, E.; Constantinides, G. A. A parallel hardware architecture for scale and rotation invariant feature detection. IEEE Transactions on Circuits and Systems for Video Technology, -, v. -, n. -, p. -, (Submetido em Novembro de 2007), -c, 2008c.

Bonato, V.; Peron, R.; Wolf, D.; Holanda, J. A. D.; Marques, E.; Cardoso, J. M. An FPGA implementation for a kalman filter with application to mobile robotics. In: IEEE International Symposium on Industrial Embedded Systems (SIES), Lisbon (Portugal), 2007b.

Borenstein, J.; Everett, C. H. R.; Feng, L. Where am I? Sensors and methods for mobile robot positioning, 1996.

Disponível em: <http://www \penalty\@M \hskip\z@skip \discretionary $\{-\}\{\}\{\} \backslash$

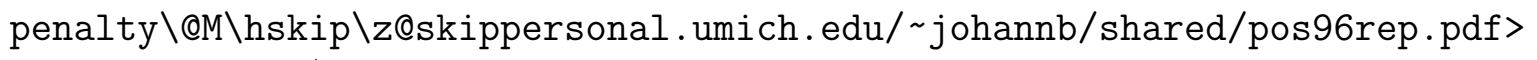
. Acesso em: 05/2005.

Borenstein, J.; Koren, Y. The vector field histogram - fast obstacle avoidance for mobile robots. IEEE Transactions on Robotics and Automation, New York (USA), v. 7, n. 3, p. 278-288, June, 1991.

Brown, M.; Lowe, D. G. Invariant features from interest point groups. In: Proceedings of British Machine Vision Conference (BMVC), Cardiff (Wales), 2002, p. 656-665.

Brown, S.; Vranesic, Z. Fundamentals of digital logic with vhdl design. 2 ed.. Toronto: Mc Graw Hill, 2005.

CEloxicA Handel-C language reference manual, User guide, 2005a. Disponível em: <http://www.celoxica.com>. Acesso em: 10/2007.

CeloxicA RC250 - High Performance System Development \& Evaluation Board, datasheet, 2005b.

Disponível em: <http://www.celoxica.com/products/>. Acesso em: 11/2007. 
Chati, H. D.; Muhlbauer, F.; Braun, T.; Bobda, C.; Berns, K. Hardware/software co-design of a key point detector on FPGA. In: Proceedings of IEEE Symposium on Field-Programmable Custom Computing Machines (FCCM), Napa Valley (USA), 2007, p. 355-356.

Chatila, R.; Laumond, J. Position referencing and consistent world modeling for mobile robots. In: Proceedings of the IEEE Conference on Robotics and Automation (ICRA), 1985, p. 138-145.

Cheeseman, P. C.; Bandari, E.; Jalobeanu, A.; Kuehnel, F.; Stutz, J. C.; TAL, D. Simultaneous 3-d camera and feature pose estimation, NASA Project, Intelligent Systems Division, 2005.

Disponível em: <http://ic.arc.nasa.gov/tech/project/index.php?ta=1\&gid= \&pid=150>. Acesso em: 10/2005.

Chen, W.; Korde, U.; SkaAr, S. Position-control experiments using vision. International Journal of Robotics Research, London (UK), v. 13, p. 199-208, June, 1994.

Civera, J.; Davison, A.; Montiel, J. Inverse depth to depth conversion for monocular SLAM. In: Proceedings of the IEEE Conference on Robotics and Automation (ICRA), 2007, p. 2778-2783.

Company, E. K. Charge-coupled device CCD image sensors, 2003.

Disponível em: <http://www.kodak. com>. Acesso em: 05/2003.

Davison, A.; Reid, I.; Molton, N.; Stasse, O. MonoSlAM: Real-time single camera SLAM. IEEE Transactions on Pattern Analysis and Machine Intelligence, New York (USA), v. 29, n. 6, p. 1052-1067, June, 2007.

DAVISOn, A. J. Real-time simultaneous localisation and mapping with a single camera. In: Proceedings of the International Conference on Computer Vision (ICCV), Nice (France), 2003, p. 1403-1410.

Davison, A. J.; Murray, D. W. Simultaneous localization and map-building using active vision. IEEE Transactions on Pattern Analysis and Machine Intelligence, New York (USA), v. 24, n. 7, p. 865-880, July, 2002.

Deccó, C. C. G. Construção de mapas de ambiente para navegação de robôs móveis com visão omnidirecional estéreo. 2004. Tese (Doutorado), Escola Politécnica, Universidade de São Paulo, São Paulo, 2004.

Dellaert, F.; Fox, D.; Burgard, W.; Sebastian, T. Monte carlo localization for mobile robots. In: Proceedings of the IEEE Conference on Robotics and Automation (ICRA), Detroit (USA): IEEE Robotics and Automation Society, 1999, p. $1322-1328$.

Dempster, A. P.; Laird, A. N.; ; Rubin, D. B. Maximum likelihood from incomplete data via the EM algorithm. Journal of the Royal Statistical Society, London (UK), v. 39, n. 1, p. 1-38, January, 1977. 
DeSouzA, G. N.; KAK, A. C. Vision for mobile robot navigation: A survey. IEEE Transactions on Pattern Analysis and Machine Intelligence, New York (USA), v. 24, n. 2, p. 237-267, February, 2002.

Diebel, J.; Reuterswärd, K.; Thrun, S.; Davis, J.; Gupta, R. Simultaneous localization and mapping with active stereo vision. In: Proceedings of the IEEE/RSJ International Conference on Intelligent Robots and Systems (IROS), Sendai (Japan), 2004, p. 3436-3443.

Doucet, A.; Freitas, N. D.; Murphy, K.; Russell, S. Rao-blackwellised particle filtering for dynamic bayesian networks. In: Conference on Uncertainty in Artificial Intelligence (UAI), Stanford (Canada), 2000.

Eade, E.; Drummond, T. Scalable monocular SLAM. In: Proceedings of the IEEE Computer Society Conference on Computer Vision and Pattern Recognition (CVPR), Los Alamitos (USA): IEEE Computer Society, 2006, p. 469-476.

Electronics, Q. 2007.

Disponível em: <http://www.quasarelectronics.com>. Acesso em: 08/2007.

EleCtronics123 InC. 1/3 color camera mod c3188a, 2005.

Disponível em: <http://www.electronics123.com/s.nl/sc.8/category.45/it.A/ id.42/.f>. Acesso em: 11/2005.

Elfes, A. Occupancy grids: A probabilistic framework for robot perception and navigation. 1989. Tese (Doutorado), Carnegie Mellon University, Pittsburgh, 1989.

Estrada, C.; Neira, J.; TARdós, J. D. Hierarchical SLAM: Real-time accurate mapping of large environments. IEEE Transactions on Robotics, New York (USA), v. 21, n. 4, p. 588- 596, August, 2005.

Fernandes, L. C. Análise e implementação de algoritmos para localização de robôs móveis. 2003. Dissertação (Mestrado), Instituto de Ciências Matemáticas e de Computação, Universidade de São Paulo, 2003.

Folkesson, J.; Jensfelt, P.; Christensen, H. I. Vision SLAM in the measurement subspace. In: Proceedings of the IEEE Conference on Robotics and Automation (ICRA), Barcelona (Spain), 2005.

Fox, D.; Burgard, W.; Thrun, S. Markov localization for reliable robot navigation and people detection. In: Dagstuhl Seminar on Modeling and Planning for Sensor-Based Intelligent Robot Systems, Berlin: Springer-Verlag, 1999.

Fox, D.; Hightower, J.; Liao, L.; Schultz, D.; Borriello, G. Bayesian filters for location estimation. IEEE Pervasive Computing, New York (USA), v. 2, n. 3, p. 24-33, July-September, 2003.

Garcia, M. A.; Solanas, A. 3D simultaneous localization and modeling from stereo vision. In: Proceedings of the IEEE Conference on Robotics and Automation (ICRA), New Orleans (USA), 2004, p. 847-853. 
Gerkey, B. P.; Vaughan, R. T.; Støy, K.; Howard, A.; Sukhtame, G. S.; Matarić, M. J. Most valuable player: A robot device server for distributed control. In: Proceedings of the IEEE/RSJ International Conference on Intelligent Robots and Systems (IROS), Maui (USA), 2001, p. 1226-1231.

Gnedenko, B. V. The theory of probability. Moscow: MIR, 392 p, 1982.

Grabner, M.; Grabner, H.; Bischof, H. Fast approximated SIFT. In: Asian Conference on Computer Vision (ACCV), Hyderabad: Springer-Verlag, 2006, p. 918-927.

Guivant, J.; Nebot, E. Solving computational and memory requirements of featurebased simultaneous localization and mapping algorithms. IEEE Transactions on Robotics and Automation, New York (UK), v. 19, n. 4, p. 749-755, August, 2003.

Guivant, J.; Nieto, J.; Masson, F.; Nebot, E. Navigation and mapping in large unstructured environments. The International Journal of Robotics Research, London (UK), v. 23, p. 449-472, April-May, 2004.

Harris, C; Stephens, M. J. A combined corner and edge detector. In: Proceedings of the Avley Vision Conference, Manchester (UK), 1988, p. 147-152.

Hartley, R. I.; Zisserman, A. Multiple view geometry in computer vision. 2 ed.. Cambridge: Cambridge University Press, 2004.

Häehnel, D.; Burgard, W.; Wegbreit, B.; Thrun, S. Towards lazy data association in SLAM. In: Proceedings of the 11th International Symposium of Robotics Research (ISRR), Sienna (Italy): Springer-Verlag, 2003.

Hähnel, D.; Burgard, W.; Fox, D.; Thrun, S. An efficient FastSLAM algorithm for generating maps of large-scale cyclic environments from raw laser range measurements. In: Proceedings of the IEEE/RSJ International Conference on Intelligent Robots and Systems (IROS), Nevada (USA), 2003, p. 206-211.

Holanda, J. A. D.; Almeida, L. O. D.; Bonato, V.; Cardoso, J. M.; Marques, E. Determinação do perfil de consumo de potência em nível de instrução para processadores soft-core. In: Anais da III Jornadas sobre Sistemas Reconfiguráveis (REC), Lisboa (Portugal), 2007, p. 60-65.

JunG, I.-K.; LACROIX, S. High resolution terrain mapping using low altitude aerial stereo imagery. In: Proceedings of the Ninth IEEE International Conference on Computer Vision (ICCV), Nice (France): IEEE Computer Press Society, 2003.

Kabuka, M. R.; Arenas, A. E. Position verification of a mobile robot using standard pattern. IEEE Journal of Robotics and Automation, New York (UK), v. 3, n. 6, p. 505-516, December, 1987.

Kalman, R. E. A new approach to linear filtering and prediction problems. Transaction of the ASME - Journal of Basic Engineering, -, v. 82, p. 35-45, March, 1960 . 
Karlsson, N.; Bernardo, E. D.; Ostrowski, J.; Goncalves, L.; Pirjanian, P.; Munich, M. E. The vSLAM algorithm for robust localization and mapping. In: Proceedings of the IEEE Conference on Robotics and Automation (ICRA), Barcelona (Spain), 2005, p. 24-29.

Ke, Y.; Sukthankar, R. PCA-SIFT: A more distinctive representation for local image descriptors. In: Proceedings of the IEEE Computer Society Conference on Computer Vision and Pattern Recognition (CVPR), Washington (USA), 2004, p. 506-513.

KIM, G.-H.; KIM, J.-S.; Hong, K.-S. Vision-based simultaneous localization and mapping with two cameras. In: Proceedings of the IEEE/RSJ International Conference on Intelligent Robots and Systems (IROS), Edmonton (Canada), 2005, p. 3401-3406.

Koren, Y.; Borenstein, J. Potential field methods and their inherent limitations for mobile robot navigation. In: Proceedings of the IEEE Conference on Robotics and Automation (ICRA), (USA), 1991, p. 1398-1404.

Kosaka, A.; KAK, A. C. Fast vision-guided mobile robot navigation using modelbased reasoning and prediction of uncertainties. In: Proceedings of the IEEE/RSJ International Conference on Intelligent Robots and Systems (IROS), 1992, p. 2177-2186.

LeE, C.; SAlcic, Z. A fully-hardware-type maximum-parallel architecture for kalman tracking filter in FPGAs. In: Proceedings of the IEEE International Conference on Information, Communications and Signal Processing, Singapore, 1997, p. 1243-1247.

Liu, Y.; Bouganis, C.; Cheung, P. Efficient mapping of a Kalman filter into an FPGA using taylor expansion. In: Proceedings of the IEEE International Conference on Field Programmable Logic and Applications (FPL), Amsterdam (Netherlands), 2007, p. 345-350.

Logic, C. Engineering development kit for ep9315 processor, 2005.

Disponível em: <http://www.cirrus.com/en/pubs/proBulletin/EDB9315-pb.pdf> . Acesso em: 11/2005.

Lowe, D. Distinctive image features from scale-invariant keypoints. International Journal of Computer Vision, Heidelberg (Germany), v. 60, n. 2, p. 91-110, January, 2004.

Lu, F.; MiLios, E. Globally consistent range scan alignment for environment mapping. Autonomous Robots, Heidelberg (Germany), v. 4, p. 333-349, October, 1997.

Lui, Y.; Emery, R.; Charabarti, D.; Burgard, W.; Thrun, S. Using EM to learn 3D models of indoor environments with mobile robots. In: International Conference on Machine Learning (ICML), Williamstown (USA): Morgan Kaufmann, 2001, p. 329-336.

Mataric, M. J. A distributed model for mobile robot environment-learning and navigation. Relatório técnico, Cambridge, MA, USA, 1990. 
MAYBeck, P. S. Stochastic models, estimation, and control, v. 1. London: Academic Press, 1979.

Meltzer, J.; Gupta, R.; Yang, M.-H.; Sontto, S. Simultaneous localization and mapping using multiple view feature descriptors. In: Proceedings of the IEEE/RSJ International Conference on Intelligent Robots and Systems (IROS), Sendai (Japan), 2004, p. 1550-1555.

MikolajczyK, K.; Schmid, C. Scale and affine invariant interest point detectors. International Journal of Computer Vision, Heidelberg (Germany), v. 60, n. 1, p. 63-86, January, 2004.

Montemerlo, M.; Thrun, S.; Koller, D.; Wegbreit, B. FastSlAM: A factored solution to the simultaneous localization and mapping problem. In: Proceedings of the AAAI National Conference on Artificial Intelligence, Edmonton (Canada): AAAI, 2002.

Montiel, J.; Civera, J.; Davison, A. J. Unified inverse depth parametrization for monocular SLAM. In: Proceedings of Robotics: Science and Systems, Philadelphia (USA), 2006.

Moravec, H. P. Obstacle avoidance and navigation in the real world by a seeing robot rover. 1980. Tese (Doutorado), Stanford University, Stanford, 1980.

Moravec, H. P.; Elfes, A. High resolution maps from wide angle sonar. In: Proceedings of the IEEE International Conference on Robotics and Automation, IEEE, 1985, p. 116-121.

Murray, D.; Jennings, C. Stereo vision based mapping and navigation for mobile robots. In: Proceedings of the IEEE Conference on Robotics and Automation (ICRA), Alburquerque (USA), 1997, p. 1694-1699.

NeirA, J.; Ribeiro, I. M.; TARdós, J. D. Mobile robot localization and map building using monocular vision. In: Proceedings of the 5th International Symposium on Intelligent Robotic Systems (SIRS), Stockolm (Sweden), 1997, p. 275-284.

NeIRA, J.; TARdos, J. D. Data association in stochastic mapping using the jointcompatibility test. IEEE Transactions on Robotics and Automation, New York (USA), v. 17, n. 6, p. 890-897, December, 2001.

Newman, P. M. C4b - mobile robotics, 2005.

Disponível em: <http://www.robots.ox.ac.uk/ pnewman/Teaching/ C4CourseResources/C4BMobileRobotics2005.pdf>. Acesso em: 11/2005.

Nistér, D.; Naroditsky, O.; Bergen, J. R. Visual odometry. In: Proceedings of the IEEE Computer Society Conference on Computer Vision and Pattern Recognition (CVPR), Washingtom (USA), 2004, p. 652-659.

Olson, C. F.; Matthies, L. H.; Schoppers, M.; Maimoneb, M. W. Rover navigation using stereo ego-motion. Robotics and Autonomous Systems, Toronto (Canada), v. 43, p. 215-229, June, 2003. 
Paz, L. M.; NeIRA, J. Optimal local map size for EKF-based SLAM. In: Proceedings of the IEEE/RSJ International Conference on Intelligent Robots and Systems (IROS), Beijing (China), 2006, p. 5019-5025.

Peron, R.; Bonato, V.; Wolf, D.; Holanda, J. A. D.; Marques, E. Otimizando algoritmos robóticos em linguagem $\mathrm{C}$ para o processador NIOS II. In: Anais da III Jornadas sobre Sistemas Reconfiguráveis (REC), Lisboa (Portugal), 2007, p. $66-73$.

Pettersson, N.; Petersson, L. Online stereo calibration using FPGAs. In: Proceedings of the IEEE Intelligent Vehicles Symposium (IV), Las Vegas (USA), 2005, p. 55-60.

PiRJanian, P. Current status and future perspective of intelligent service robotics in usa, evolution Robotics, Inc., 2004.

Disponível em: <http://teamster.usc.edu/ iera05/roadmap04/USA.pdf>. Acesso em: $07 / 2005$.

Pirjanian, P.; Karlsson, N.; Goncalves, L.; Bernardo, E. D. Low-cost visual localization and mapping for consumer robotics. Industrial Robot: an international journal, v. 30, n. 2, p. 139-144, January-February, 2003.

SAlCIC, Z.; LEE, C. FPGA-based adaptive tracking estimation computer. IEEE Transactions on Aerospace and Electronic systems, New York (USA), v. 37, n. 2, p. 699-706, April, 2001.

SE, S.; Lowe, D.; LiTtle, J. Mobile robot localization and mapping with uncertainty using scale-invariant visual landmarks. The International Journal of Robotics Research, London (UK), v. 21, n. 8, p. 735-758, August, 2002.

Se, S.; NG, H.-K.; Jasiobedzki, P.; Moyung, T.-J. Vision based modeling and localization for planetary exploration rovers. In: Proceedings of International Astronautical Congress (IAC), Vancouver (Canada), 2004, p. 11.

SÁEz, J. M.; Escolano, F. A global 3d map-building approach using stereo vision. In: Proceedings of the IEEE Conference on Robotics and Automation (ICRA), New Orleans, 2004, p. 1197-1202.

ShI, J.; Tomasi, C. Good features to track. In: IEEE Conference on Computer Vision and Pattern Recognition (CVPR), Seatle (USA), 1994, p. 593-600.

Shokoufandeh, A.; Marsic, I.; Dickinson, S. J. View-based object recognition using saliency maps. Image and Vision Computing, New York (UK), v. 17, n. 5-6, p. 445-460, April, 1999.

Silva, J.; Fernandes, M. M.; Bonato, V.; Menotti, R.; Cardoso, J. M.; MarQUES, E. Using mobile robotics to teach reconfigurable computing. In: IEEE Computer Society Workshop on Reconfigurable Computing Education (WRCE - RC Education 2006), Karlsruhe (Germany), 2006, p. 6p.

Sim, R.; Elinas, P.; Griffin, M.; Little, J. J. Vision-based SlAM using the Rao-Blackwellised particle filter. In: Workshop on Reasoning with Uncertainty in Robotics (IJCAI), Edinburg (Scotland), 2005. 
Smith, R.; Self, M.; Cheeseman, P. A stochastic map for uncertain spatial relationships. In: Fourth International Symposium of Robotics Research, Santa Clara (USA): MIT Press, 1988, p. 467-474.

Smith, R.; Self, M.; Cheeseman, P. Estimating uncertain spatial relationships in robotics. Autonomous robot vehicles, New York (USA): Springer-Verlag, p. 167193, -, 1990.

Sola, J.; Monin, A.; Devy, M. BiCamSlAM: Two times mono is more than stereo. In: Proceedings of the IEEE International Conference on Robotics and Automation (ICRA), Roma (Italy), 2007, p. 4795-4800.

Strobl, K.; Sepp, W.; Fuchsm, S.; Paredes, C.; Arbter, K. Camera calibration toolbox for Matlab, 2006.

Disponível em: <http://www.vision.caltech.edu/bouguetj/calib_doc/>. Acesso em: 09/2007.

Thrun, S.; ; Thayer, S.; Whittaker, W.; Baker, C.; Burgard, W.; Ferguson, D.; Hähnel, D.; Montemerlo, M.; Morris, A.; Omohundro, Z.; Reverte, C.; Whittaker, W. Autonomous exploration and mapping of abandoned mines. IEEE Robotics and Automation Magazine, New York (USA), , n. 4, p. 79-91, Decembera, 2004a.

Thrun, S. Robotic mapping: A survey. Relatório técnico CMU-CS-02-111, School of Computer Science - Carnegie Mellon University, 2002.

Thrun, S.; Burgard, W.; Fox, D. A probabilistic approach to concurrent mapping and localization for mobile robotics. Machine Learning, Hingham, v. 31, n. 1-3, p. 29-53, April, 1998.

Thrun, S.; Burgard, W.; Fox, D. Probabilistic robotics. Cambridge, USA: MIT Press, 2005.

Thrun, S.; Liu, Y.; Koller, D.; NG, A. Y.; Ghahramani, Z.; Durrant-Whyte, H. Simultaneous localization and mapping with sparse extended information filters. The International Journal of Robotics Research, London (UK), v. 23, n. 7/8, p. 693-716, July-Augustb, 2004b.

UNECE World robotics, press Release, 2004.

Disponível em: <http://www. unece.org/press/pr2004/04stat_p01e.pdf>. Acesso em: $07 / 2005$.

WANG, C.-C. Simultaneous localization, mapping and moving object tracking. 2004. Tese (Doutorado), Carnegie Mellon University, Pittsburgh, 2004.

Wang, C.-C.; Thorpe, C. Simultaneous localization and mapping with detection and tracking of moving objects. In: Proceedings of the IEEE International Conference on Robotics and Automation (ICRA), Washington (USA), 2002, p. 2918-2924.

Wang, C.-C.; Thorpe, C.; Thrun, S. Online simultaneous localization and mapping with detection and tracking of moving objects: Theory and results from a ground vehicle 
in crowded urban areas. In: Proceedings of the IEEE International Conference on Robotics and Automation (ICRA), 2003, p. 842-849.

Wolf, D.; Holanda, J.; Bonato, V.; Peron, R.; Marques, E. A FPGA-based mobile robot controller. In: Southern Conference on Programmable Logic, Mar Del Plata (Argentina), 2006.

Wolf, D.; Holanda, J. A. D.; Bonato, V.; Peron, R.; Marques, E. Towards FPGA-based mobile robots. In: Anais da III Jornadas sobre Sistemas Reconfiguráveis (REC), Lisboa (Portugal), 2007, p. 56-59.

Wolf, J.; Burgard, W.; Burkhardt, H. Robust vision-based localization by combining an image-retrieval system with Monte Carlo localization. IEEE Transactions on Robotics, New York (USA), v. 21, n. 2, p. 208-216, April, 2005.

ZhangXing, Z.; XinhuA, Z. Design of FPGA-based kalman filter with CORDIC algorithm. In: International Workshop on Systems, Signal and Image Processing, Manchester (UK), 2002, p. 191-199. 